MOYSÉS DE ARAUJO

\title{
EDUCAÇÃO A DISTÂNCIA E A WEB SEMÂNTICA: MODELAGEM ONTOLÓGICA DE MATERIAIS E OBJETOS DE APRENDIZAGEM PARA A \\ PLATAFORMA COL
}

Tese apresentada à Escola Politécnica da Universidade de São Paulo para obtenção do título de Doutor em Engenharia

\section{SÃO PAULO}


MOYSÉS DE ARAUJO

\title{
EDUCAÇÃO A DISTÂNCIA E A WEB SEMÂNTICA: MODELAGEM ONTOLÓGICA DE MATERIAIS E OBJETOS DE APRENDIZAGEM PARA A PLATAFORMA COL
}

\author{
Tese apresentada à Escola Politécnica da \\ Universidade de São Paulo para obtenção do \\ título de Doutor em Engenharia \\ Área de Concentração: \\ Sistemas Digitais \\ Orientadora: \\ Profa. Dra. Maria Alice Grigas Varella Ferreira
}

\section{São Paulo}




\section{FICHA CATALOGRÁFICA}

\section{Araujo, Moysés de}

Educação à distância e a WEB Semântica: modelagem ontológica de materiais e objetos de aprendizagem para a plataforma COL / M. Araújo. -- São Paulo, 2003. $178 p$.

Tese (Doutorado) - Escola Politécnica da Universidade de São Paulo. Departamento de Engenharia de Computação e Sistemas Digitais.

1.Educação à distância 2.Ontologia I.Universidade de São Paulo. Escola Politécnica. Departamento de Engenharia de Computação e Sistemas Digitais II.t. 
Dona Néia, este trabalho é dedicado à senhora.

É a maneira que encontrei para retribuir todos os esforços feitos realizados pelo meus estudos.

A senhora é minha inspiração!!!

Valeu!!!! Muito obrigado, minha mãe!!!!! 


\section{AgradeCimentos}

À Profa. Dra. Maria Alice Grigas Varella Ferreira pela orientação, críticas construtivas durante todo este trabalho e sua eterna paciência e simplicidade.

À Profa. Dra. Maria das Graças Marietto, pelo incentivo, críticas, idéias, sugestões e apoio nas horas de desespero. Você foi aquela luz no fim do túnel.

À Ana Lucia pela calma e compreensão.

Ao Prof. Dr. Wilson Ruggiero pela liberação da Plataforma CoL.

À Profa. Dra. Regina M. Silveira, Luciana M. Zaina e Gustavo B. Cinelli pela assessoria e suporte à Plataforma CoL.

À Miriam Segre Rosenfeld por apagar um incêndio de ultima hora.

A Marisa Leonne pela sua eterna simpatia e alegria.

As gaúchas Regina e Diana pelas correções do texto e apoio moral.

A todos colegas e amigos que direta ou indiretamente contribuíram para este trabalho. 


\title{
SUMÁRIO
}

\author{
LISTA DE TABELAS \\ LISTA DE FIGURAS \\ LISTA DE ABREVIATURAS E SIGLAS \\ RESUMO
}

ABSTRACT

1. INTRODUÇÃ̃O

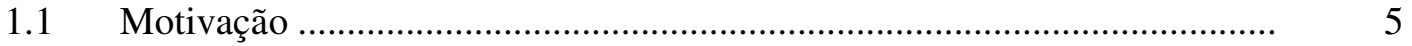

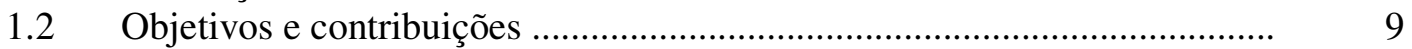

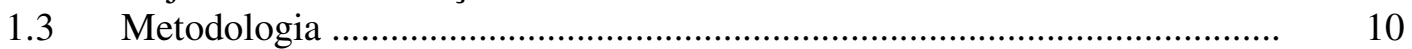

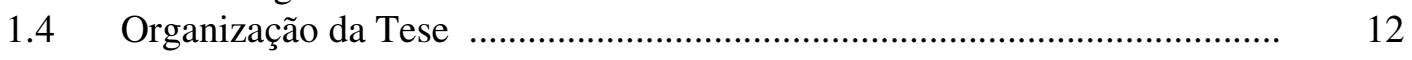

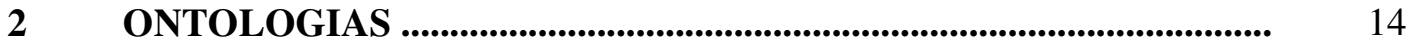

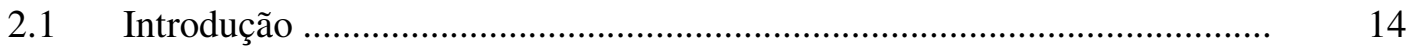

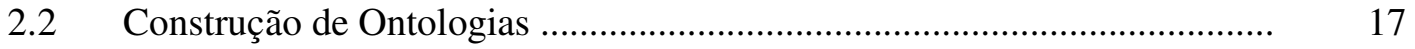

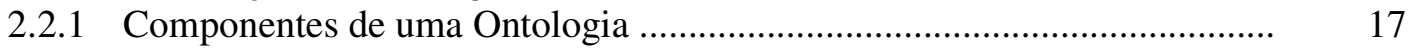

2.2.2 Critérios para construção de Ontologias ..................................................... 18

2.2.3 Tipos de Ontologias ............................................................................. $\quad 20$

2.2.4 Metodologia para construção de Ontologias .............................................. 21

2.2.5 A Metodologia METHONTOLOGY …................................................. 25

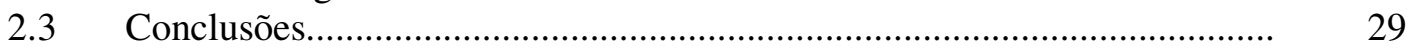

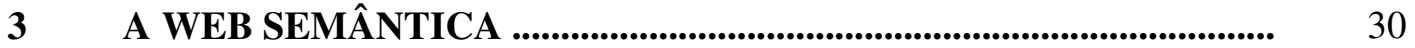

3.1 Definição ................................................................................ $\quad 30$

$3.2 \quad$ XML - Extensible Markup Language ................................ 33

3.2.1 HTML e SGML .............................................................................. 33

3.2.2 XML Schema .................................................. 43

3.3 RDF - Resource Description Framework ........................... 46

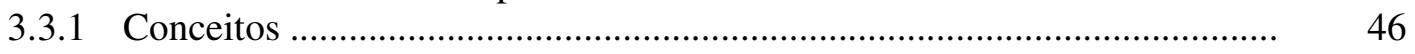

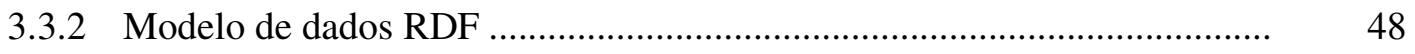

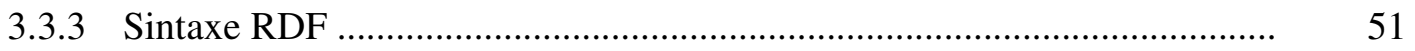

3.3.4 Dublin Core e RDF ............................................................................ 53

3.3.5 Contêiner RDF .................................................................................. 54

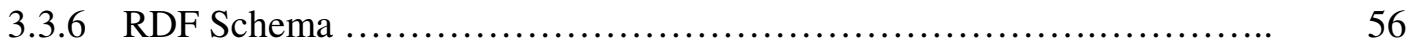

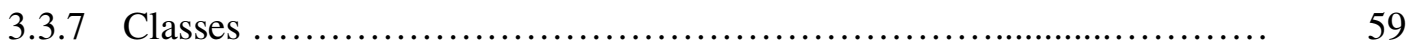

3.3.8 Desvantagens do RDF Schema ............................................................. 64

3.4 Ontologias na Web Semântica ................................................................. 64

3.4.1 OIL - Ontology Inference Layer ................................ 65 


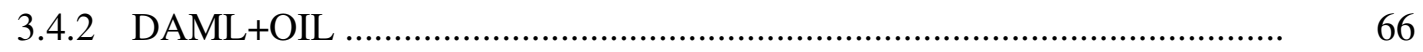

3.5 Ferramentas para Web Semântica ………………………………………... 74

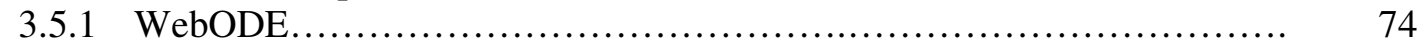

3.5.2 Protégé-2000 ...................................................................................

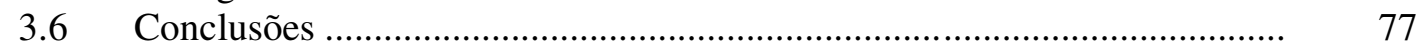

4 A EDUCAÇÃO BASEADA NA WEB (EBW) ....................................... 79

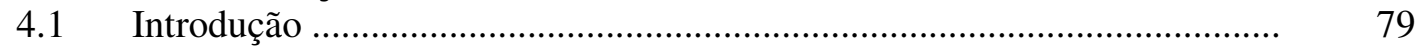

4.2 Limitações da Educação Baseada na Web (EBW) .................................... 82

4.2.1 Limitações Conceituais .......................................................................... 82

4.2.2 Limitações Tecnológicas ..........................................................................

4.2.3 Limitações das Ferramentas de Autoria para EBW ...................................... 83

4.3 Interação e a Educação baseada na Web ...................................................... 84

4.4 Educação Baseada na Web e a Web Semântica .............................................. 86

4.4.1 Metadados e Ontologias .......................................................................... 88

4.4.2 Metadados e descrição do conteúdo do material de aprendizagem ........... 91

4.4.3 Metadados e descrição do contexto dos materiais de aprendizagem .......... 91

4.4.4 Metadados e descrição da estrutura dos materiais de aprendizagem ............ 91

4.5 Trabalhos Correlatos ............................................................................... 92

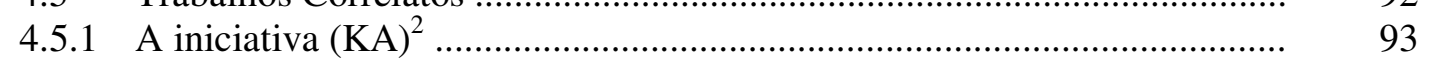

4.5.2 Reuso de conteúdos educacionais no Aulanet ............................................. 95

4.5.3 Ontologias para o Domínio da Educação Mediada pela Web ..................... 95

4.6 Conclusões ............................................................................................. 96

5 UMA ONTOLOGIA PARA MATERIAIS E OBJETOS DE APRENDIZAGEM....................................................................................... 97

5.1 A Ferramenta COL - Cursos on Larc ………………………………….... 97

5.2 Materiais de Aprendizagem e Objetos de Aprendizagem .............................. 101

5.3 Construindo uma Ontologia para Materiais de Aprendizagem ..................... 105

5.3.1 Especificação............................................................................................ 107

5.3.2 Conceitualização .................................................................................. 108

5.4 Proposta de um Modelo Baseado em Ontologias para Pesquisa de Materiais de Aprendizagem..................................................................... 115

5.4.1 Base Ontológica de Conhecimento .......................................................... 115

5.4.2 Anotação …………………………………………………………. 115

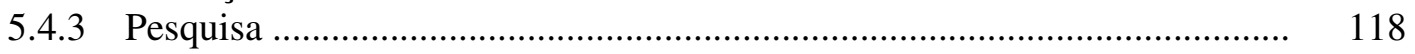

5.5 Conclusões....................................................................................... 121

6 CONSIDERAÇÕES FINAIS ................................................................ 122

$6.1 \quad$ Síntese do trabalho........................................................................... 122

6.2 Trabalhos Futuros ................................................................................ 125 
Anexo A - Relação dos documentos gerados pela ferramenta WebODE da Metodologia METHONTOLOGY …........................................... 128

Anexo B - Testes da proposta do Modelo Ontológico ....................................... 143

Lista de Referências 166

Apêndice A - Descrição das Ferramentas SHOE e ONTOBROKER................. A.1 


\section{LISTAS DE FIGURAS}

Figura 1.1 - Número de computadores na Internet ........................................... 1

Figura 1.2 - Número de páginas indexadas por programas de pesquisa (Sulivan, 2001) ......................................................................... 3

Figura 2.1 - Ontologia de um ambiente educacional...................................... 19

Figura $\quad 2.2$ - Tipos de Ontologia e duas relações (Guarino, 1998) ....................... 21

Figura 2.3 - Arquitetura de Abstração da Metodologia Proposta ....................... 24

Figura 2.4 - Arquitetura Funcional da Metodologia Proposta ............................ 25

Figura 3.1 - Arquitetura proposta para a Web Semântica ................................. $\quad 32$

Figura 3.2 - Modelo de classes para estudante e disciplinas .............................. 36

Figura 3.3 - Codificação de um documento em HTML ................................... 37

Figura 3.4 - Codificação de um documento em XML ...................................... 38

Figura 3.5 - Codificação DTD do documento mostrado na Figura 3.4 .............. $\quad 40$

Figura 3.6 - Verificação da estrutura de um documento XML (McGrath,

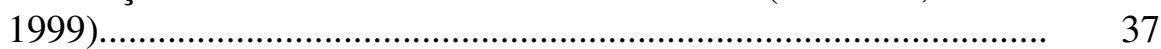

Figura 3.7 - Parte de um documento XML..........................................................

Figura 3.8 - Parte da codificação do XML Schema da Figura 3.4.................... 45

Figura 3.9 - Modelo RDF - Iannella (1999) ................................................... 49

Figura 3.10 - Grafo da declaração ................................................................. $\quad 50$

Figura 3.11 - Codificação RDF serializada em XML ......................................... 51

Figura 3.12 - RDF e namespace ................................................................. $\quad 52$

Figura 3.13 - Codificação RDF com Dublin Core............................................. 54

Figura 3.14 - Grafo RDF - Contêiner Barg........................................................... 55

Figura 3.15 - Codificação RDF - Contêiner e RDF............................................. 56

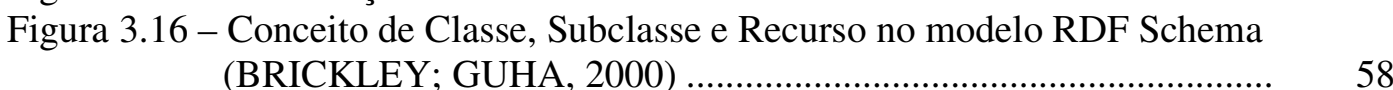

Figura 3.17 - Hieraquia de classes do modelo RDF Schema (BRICKLEY; GUHA, 2000) ................................................................ 58

Figura 3.18 - Modelo de classes .............................................................. 61

Figura 3.19 - Codifição RDF Schema ….......................................................... 61

Figura 3.20 - As raízes do OIL (HORROCKS et al., 2000) .................................. 65

Figura 3.21 - DAML+OIL como extensão do RDF Schema (FENSEL et al.,

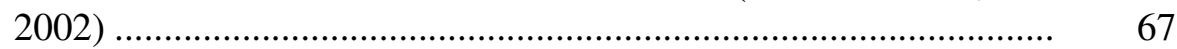

Figura 3.22 - Interface Gráfica da ferramenta WebODE...................................... 76

Figura 3.23 - Arquitetura do Protégé-2000 (GENNARI et al., 2002) .................... 77

Figura 4.1- Modos de interação em Educação a Distância (ANDERSON, 2002).

Figura 4.2 - Ontolologia de Pessoal do KA) ${ }^{2}$

87

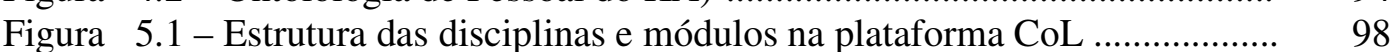

Figura 5.2 - Estrutura da disciplina XML - Conceitos Básicos........................... 100

Figura 5.3 - Representação da granularidade (QIN, 2001) ................................ 104 
Figura 5.4 - Diagrama UML parcial da plataforma CoL ................................... 106

Figura 5.5 - Relacionamento entre os conceitos de disciplina, módulo e

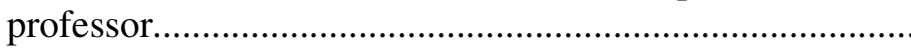

Figura 5.6 - Relacionamneto entre os conceitos módulo e material de Aprendizagem............................................................................ 110

Figura 5.7 - Relacionamento entre material de aprendizagem ........................... 111

Figura 5.8 - Relacionamneto entre material de aprendizagem, tipos de Componentes e formato

Figura 5.9 -Ontologia dos materiais de aprendizagem ..................................... 114

Figura 5.10- Proposta de modelo para pesquisa de materiais de aprendizagem...... 116

Figura 5.11 - Codificação em DAML+OIL do conceito Material_Aprendizagem.. 117

Figura 5.12 - Anotação do conceito Material_Aprendizagem .............................. 119

Figura 5.13 - Interface gráfica do sistema AQ-Search ............................................ 120

Figura 5.14 - Interface gráfica com os resultados da pesquisa ............................. 120 


\section{LISTA DE TABELAS}

Tabela 3.1 - Modelo de uma declaração RDF ...................................................... $\quad 50$

Tabela 3.2 - Comparação entre as linguagens XML Schema, RDF Schema e DAML+OIL (GIL et al., 2000) ............................. 73

Tabela 4.1 - Novos paradigmas educacionais (Reinhard, 1995.) ……................. 80

Tabela 4.2 - Evolução dos Modelos de Educação a Distância (TAYOR,2001) ......................................................................... 81

Tabela 4.3 - Exemplo de metadados ................................................................ 88

Tabela 5.1 - Parte do Glossário de Termos ............................................................. 113 


\section{LISTA DE ABREVIATURAS E SIGLAS}

ACC - Árvore de Classificação de Conceitos

API - Application Programmers Interface

ARIADNE - Alliance of Remote Instructional Authoring and Distribution Networks for Europe

ASP - Active Server Pages

CGI - Common Gateway Interface

CSS - Cascading Style Sheets

COL - Cursos on Larc

DAML - Darpa Agent Markup Language

DAML + OIL - Darpa Agent Markup Language + Ontology Inference Layer

DARPA - Defense Advanced Research Project Agency

DRB - Diagrama de Relações Binárias

DTD - Document Type Definitions - Definição de Tipos de Documentos

EBW - Educação Baseada na Web

FTP - File Transfer Protocol

GT - Glossário de Termos

HTML - Hyper Text Markup Language

HTTP - Hyper Text Transfer Protocol

IMS - Instructional Management Systems

LOM - Learning Object Model

MathML - Mathematical Markup Language - Linguagem de Marcação Matemática

OIL - Ontology Inference Layer

OML - Ontology Markup Language

OWL - Ontology Web Language

PHP - PHP: Hypertext Language

RDF - Resource Description Framework - Estrutura de Descrição de Recursos

RDF Schema - Resource Description Framework Schema

SGML - Standard Generalized Markup Language

SHOE - Simple HTML Ontology Extension

SMIL - Synchronized Multimedia Integration Language - Linguagem de Integração de multimídia Sincronizada

SMTP - Simple Mail Transfer Protocol

TCP/IP - Transmission Control Protocol/Internet Protocol

UML - Unified Modeling Language

URI - Universal Resource Indicators

URL - Universal Resource Locator

Web - World Wide Web

W3C - World Wide Web Consortium

XML- Extensible Markup Language

XML Schema - Extensible Markup Language

XOL - Ontology Exchange Language

XSL - Extensible Style Language

ZOPE - Z Object Publishing Environment 


\section{RESUMO}

A World Wide Web está se tornando uma grande biblioteca virtual, onde a informação sobre qualquer assunto está disponível a qualquer hora e em qualquer lugar, com ou sem custo, criando oportunidades em várias áreas do conhecimento humano, dentre as quais a Educação não é exceção. Embora muitas aplicações educacionais baseadas na Web tenham sido desenvolvidas nos últimos anos, alguns problemas nesta área não foram resolvidos, entre as quais está a pesquisa de materiais e objetos de aprendizagem mais inteligentes e eficientes, pois como as informações na World Wide Web não são estruturadas e organizadas, as máquinas não podem "compreender" e nem "interpretar" o significado das informações semânticas. Para dar uma nova infra-estrutura para a World Wide Web está surgindo uma nova tecnologia conhecida com Web Semântica, cuja finalidade é estruturar e organizar as informações para buscas mais inteligentes e eficientes, utilizando-se principalmente do conceito de ontologia. Este trabalho apresenta uma proposta de modelagem ontológica de materiais e objetos de aprendizagem baseada nas tecnologias da Web Semântica para a plataforma de ensino a distância CoL - Cursos on LARC. Esta proposta estende esta plataforma adicionandolhe a capacidade de organizar e estruturar seus materiais de aprendizagem, de forma a que pesquisas mais "inteligentes" e estruturadas possam ser realizadas, nestes materiais e propiciando a possibilidade de reutilização do conteúdo desses materiais. 


\begin{abstract}
The World Wide Web is turning itself into a huge virtual library, where a piece of information about any subject is available at any time in any place, with or without fees, creating opportunities in several areas of human knowledge. Education is no exception among this areas. Although many Web based educational applications have been recently developed, some problems in the area have not been solved yet. Among these is the search for more intelligent and effective object learning and materials, since the World Wide Web information is not structured, nor organized. The machines do not "understand" neither "interpret" the meaning of semantic information. In order to restructure the World Wide Web there is a new technology, known as Web Semantics, being developed. It aims to structure and organize information for more intelligent and effective search, making use of the ontology concept. This work presents an ontological modeling for learning subjects and materials, based on the Web Semantics Technology for the long distance education platform $\mathrm{CoL}$ - Courses on LARC. This proposal extends such platform, adding to it the possibility of organizing and structuring its learning materials, making possible more "intelligent" and structured searches on the materials as well as making possible the re-use of the materials contents.
\end{abstract}




\section{INTRODUÇÃO}

Graças à Internet e à invenção da $W^{1}$ em 1989 por Tim Berners-Lee, os computadores estão se transformando, de simples máquinas isoladas, em pontos de entrada de uma grande rede mundial,possibilitando a comunicação de forma multidirecional com qualquer parte do planeta, viabilizando a troca de dados e o acesso a informações de forma interativa.

Segundo Castells (1999, p. 369), em meados da década de 90, a Internet conectava 44 mil redes de computadores com cerca de 3,2 milhões de computadores em todo o mundo, com mais ou menos 25 milhões de usuários. A figura 1.1 mostra o crescimento de computadores conectados à Internet até janeiro de 2003. Em julho de 2000 havia, aproximadamente, 2,1 bilhões de páginas na Internet, com uma taxa de crescimento de 7,3 milhões de páginas por dia (MURRAY; MOORE, 2000). Para 2002, a previsão da IDC (LAKE, 2000) era de que existiriam aproximadamente 8,0 bilhões de páginas distribuídas ao redor do mundo.

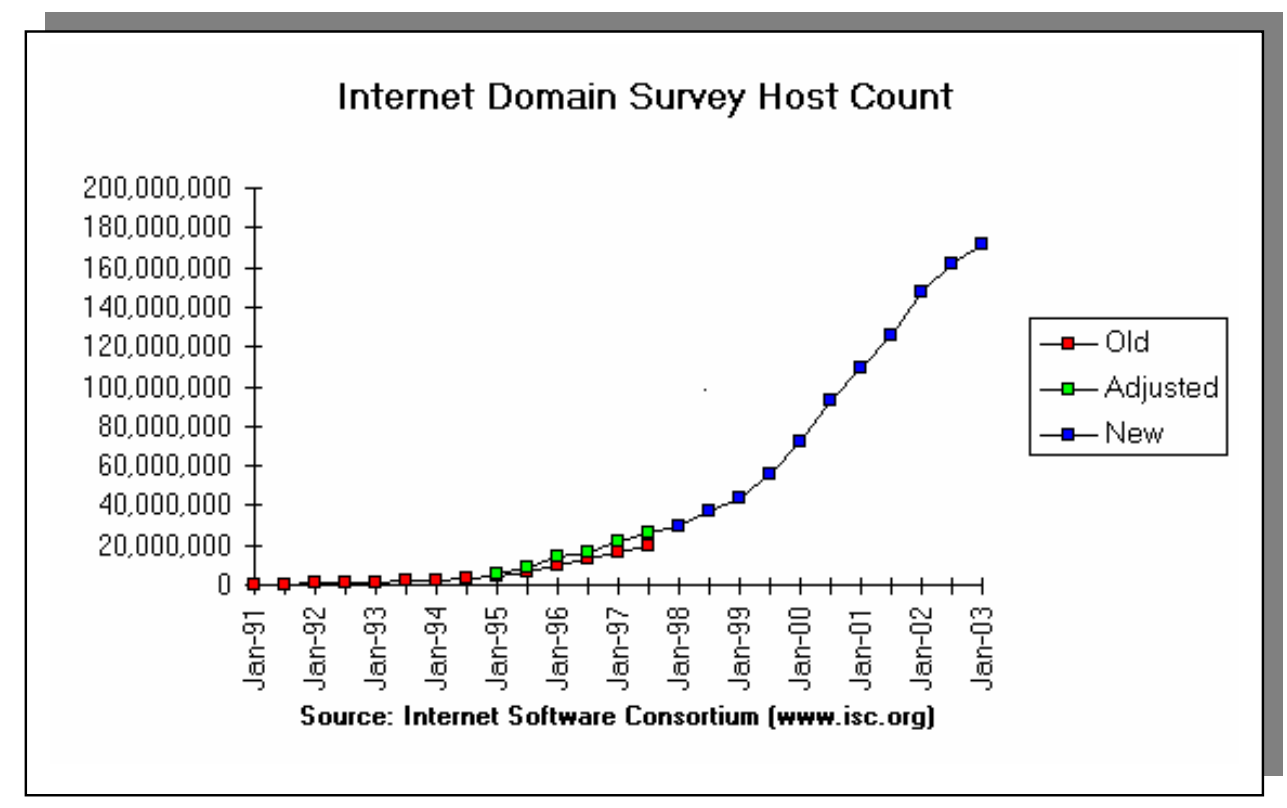

Fig. 1.1 - Número de computadores na Internet

\footnotetext{
${ }^{1}$ Neste texto, o termo Web refere-se a World Wide Web.
} 
Estes dados fornecem uma idéia da grande quantidade de informações potencialmente úteis, hoje disponíveis na Web. Entretanto, este crescimento exponencial traz grandes dificuldades para pesquisar, acessar, apresentar e manter as informações requisitadas por uma grande variedade de usuários. Isto ocorre porque o conteúdo destas páginas é apresentado em linguagem natural, elas são de natureza heterogênea, encontram-se distribuídas e não estão estruturadas. Utiliza-se, geralmente, o protocolo HTTP e a linguagem HTML para criar a infraestrutura de acesso às informações, mas esta tecnologia é limitada para acessá-las e processá-las, deixando a maior parte do trabalho - extrair e interpretar as informações - para o usuário.

Por exemplo, para localizar as informações, muitas empresas criaram programas de busca. O Yahoo! classifica os sites em categorias, da mesma forma que uma biblioteca faz com livros. Este método de classificação em categorias torna muito difícil manter-se o índice atualizado com o crescimento da Web e, muitas vezes, é difícil determinar em qual categoria deve-se classificar um determinado site.

Outros programas de busca, como o Google, Lycos ou AltaVista operam segundo um princípio diferente: eles pesquisam cada página da Web e tentam indexar as informações. Tipicamente, os índices armazenam a frequiência de palavras. Quando os usuários digitam algumas palavras-chave, o sistema de busca apresenta todas as páginas que incluem essas palavras. Este método chama-se PageRank e está descrito em Haveliwala (1999). A figura 1.2 apresenta o número de páginas indexadas por alguns programas de pesquisa até dezembro de 2001.

Verificando-se a quantidade de páginas previstas e a quantidade de páginas indexadas, percebe-se que uma pequena parte do material disponível é acessado pelos programas de busca, o que não impede que os usuários recebam um grande número de páginas como resultado de sua pesquisa. Neste ponto, o usuário pesquisa de página em página até encontrar a informação desejada. Isto ocorre porque uma palavra pode ter significados diferentes em contextos diferentes e quando as palavras são indexadas, os índices não preservam a noção de relação entre elas. 
Os programas de busca também não são capazes de processar consultas estruturadas tais como:

- "Listar as universidades que mantêm repositórios de objetos de aprendizagem";

- "Procurar um gráfico que reproduza uma animação da função seno";

- "Listar as disciplinas do curso de Pós-graduação em Redes de Computadores".

Os programas de busca simplesmente produzem uma lista de documentos contendo os termos fornecidos pelo internauta, pois os documentos existentes na Web, no formato de textos HTML, não estão estruturados para responder estas questões. Processar corretamente estas consultas requer tecnologias que representem, explicitamente, fatos sobre os temas consultados, ou seja, para melhorar o resultado das pesquisas é necessário que os programas de busca "compreendam" o significado exato das palavras e as relações conceituais entre elas. Esta é uma das metas da Web Semântica (BERNERS-LEE, 2001).

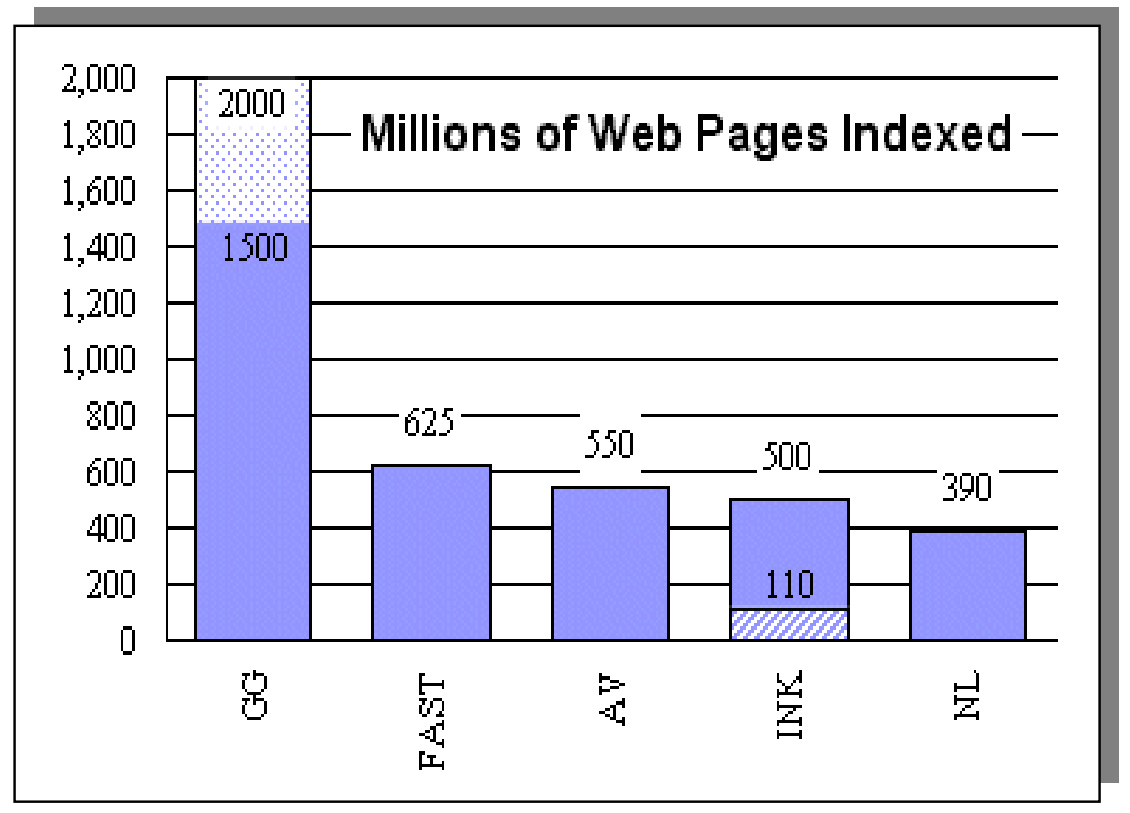

Fig. 1.2 - Número de páginas indexadas por programas de pesquisa (SULIVAN, 2001) $(\mathrm{GG}=$ Google, $\mathrm{AV}=$ AltaVista, $\mathrm{INK}=$ Inktomi $, \mathrm{FAST}=\mathrm{FAST}, \mathrm{NL}=$ Northern Light $)$ 
A Web Semântica permite melhorar a organização das informações através da estruturação dos dados com a utilização de linguagens como XML (BRAY, 1998), XML Schema (THOMPSON et al., 2001), RDF (LASSILA; SWICK, 1999), RDF Schema (BRICKLEY; GUHA, 2000) e DAML+OIL (CONNOLLY et al., 2001a). A principal característica destas linguagens é possibilitar exprimir algumas representações de conhecimento e também estruturar os dados na Web.

A Web Semântica também está baseada no uso de ontologias, que fornecem os vocabulários necessários para permitir a definição das relações entre os conceitos dos sistemas. Aurélio Buarque de Holanda Ferreira (2003), define ontologia como:

\footnotetext{
ontologia. [De ont(o)- + -logia.] S. f. Filos. 1. Parte da filosofia que trata do ser enquanto ser, $i$. e., do ser concebido como tendo uma natureza comum que é inerente a todos e a cada um dos seres: "Com Kant (v. kantiano), o universo é uma dúvida: com Locke, é dúvida o nosso espírito: e num destes abismos vêm precipitar-se todas as ontologias." (Alexandre Herculano, Lendas e Narrativas, II, p. 107.) [Cf. metafísica.]
}

Esta é claramente uma definição filosófica, entretanto, a Inteligência Artificial (IA) tomou este termo "emprestado" e deu-lhe um outro significado. A definição mais utilizada deve-se a Gruber (1993) que diz que:

"Uma ontologia é uma especificação formal, explícita e compartilhada de uma conceituação".

O significado exato desta definição está discutido no capítulo 2 , onde se discute especificamente o papel das ontologias dentro da computação. Para o entendimento dos objetivos deste trabalho, pode-se colocar aqui, resumidamente, que uma ontologia é um conjunto de conceitos e termos que podem ser usados para descrever alguma área do conhecimento ou construir a sua representação. Através destes termos, pode-se descrever fatos sobre um determinado domínio, que podem ser utilizados pelas máquinas para responder questões de mais alto nível, como as listadas na página anterior.

Com isto, é possível expressar as informações de uma forma precisa, para que estas possam ser compreendidas e interpretadas pelos computadores, para facilitar a 
reutilização e pesquisa de informações. Segundo Dertouzos (2002, p. 101), a Web Semântica "não é uma entidade independente da World Wide Web, mas na verdade, o acréscimo (a ela) de uma capacidade que permite relacionar significado (a "semântica") com a informação existente nas páginas, figuras e links".

\subsection{Motivação}

A Web está se tornando uma grande biblioteca virtual, onde a informação sobre qualquer assunto está disponível a qualquer hora e em qualquer lugar, com ou sem custo, criando oportunidades em várias áreas do conhecimento humano, dentre as quais a Educação não é exceção.

Os avanços na tecnologia da informação e nas telecomunicações estão permitindo que empresas e universidades desenvolvam ferramentas para a educação através da Web, que simulam as características da instrução presencial, através do uso de áudio, vídeo, chats, e-mail, videoconferência etc. Particularmente, no Brasil, nos últimos anos tem-se falado muito em Educação a Distância. Entretanto, muito pouco de novo tem-se feito, efetivamente, a respeito. Um conjunto de dificuldades contribui para esta "aparente" imobilidade: custos computacionais, falta de teorias consistentes a respeito e problemas tecnológicos. No entanto, esta imobilidade é de fato "aparente". Dentro dos institutos de pesquisa e universidades o tema está em grande efervescência. Os últimos cinco anos se caracterizaram por uma pesquisa intensa em torno do tema, visando atualizar uma série de conceitos, que vão desde a preocupação com a pesquisa tecnológica sobre as redes de computadores (e os problemas relativos a largura de banda de transmissão) até os mais abstratos, como a estruturação dos dados - que devem levar junto consigo os atributos que os especificam. Dentro do cerne da questão, está sutilmente infiltrado o conceito de Educação Baseada na Web $(\mathrm{EBW})^{2}$.

Não é objetivo deste trabalho, entretanto, discutir os problemas educacionais relativos a este tópico. Ao contrário, o que se pretende é focar apenas uma parcela "muito pequena" dos modelos conceituais envolvidos neste termo.

Como recurso educacional, a Web está, segundo Lima (2000):

\footnotetext{
${ }^{2}$ Será discutido no capítulo 4.
} 
- Permitindo que dados disponibilizados se transformem em conhecimento;

- Democratizando o acesso à educação e desenvolvendo o conceito de autodesenvolvimento;

- Tornando-se um importante meio de distribuição de cursos e seminários, via educação a distância;

- Permitindo desenvolver formas de suporte ao processo educativo a distância;

- Permitindo um processo de aprendizagem cooperativa;

- Permitindo um processo de interação e suporte ao aprendizado via aconselhamento, avaliação de desempenho, suporte etc.

Nos trabalhos de McCormack e Jones (1997), Simonson et al. (2000), Aggarwal (2000) e Abbey (2000), encontram-se descrições detalhadas sobre Análise, Planejamento, Projeto, Implementação, Testes, Avaliação, Manutenção e aspectos instrucionais e cognitivos de sistemas educacionais baseados na Web.

Entretanto, com a revolução que a Web tem possibilitado no acesso à informação, novas abordagens podem ser feitas para melhorar a qualidade e incrementar a eficiência da educação baseada na Web. Entre elas podem-se citar (DEVEDZIC, 2002):

- Compartilhamento e reutilização de materiais de aprendizagem entre aplicações;

- Estruturação dos materiais de aprendizagem através de pontos comuns de referência;

- Capacitação dos computadores para que possam compreender e interpretar os materiais de aprendizagem.

Atualmente, não existe nenhuma forma automática de compartilhar e reutilizar material de aprendizagem entre as aplicações. A maioria dos sistemas utiliza formatos, linguagens e vocabulários diferentes para representar e armazenar estes materiais. Assim sendo, os professores se vêm com um grande dilema a resolver: 
- Como encontrar informações sobre materiais de aprendizagem para ilustrar as suas aulas, destinados a uma platéia cada vez mais exigente e acostumada aos padrões de qualidade da televisão e da Internet?

- Como reutilizar o material encontrado de forma fácil, sem ter de, a cada vez, produzir um novo material?

Inúmeros sistemas destinados à Educação a Distância têm sido descritos, porém, a maioria deles se encontra muito aquém do que um professor necessita. Na sua maioria, são sistemas com finalidades administrativas, destinados às tarefas mais burocráticas do ensino, como administrar turmas de alunos, divulgar materiais didáticos, supervisionar salas de chats, promover videoconferências, aplicar testes através da rede etc. Na verdade, automatizam as tarefas mais comuns, e assim, mais bem definidas, relativas ao problema educacional. O professor pode utilizá-las para aprimorar a sua metodologia educacional, porém elas não oferecem a este professor recursos facilitadores da tarefa maior: a divulgação de conhecimento. Mesmo a metodologia didática muitas vezes não é priorizada; sobre isso, alguns trabalhos, como o de Romani (2000) e de Tessarollo (2000) mostram a problemática envolvida com estas ferramentas.

Entretanto, as tarefas típicas dos professores, como preparar os roteiros de aulas e adquirir material didático adequado para fornecimento a seus alunos, continuam ainda delegadas a plano secundário. Ao professor cabe a tarefa de, em meio ao grande arsenal de conhecimento, continuar "redescobrindo a roda" e preparando o seu material didático a partir do zero, a cada aula que necessita ministrar.

A solução deste problema não é simples, porém, em torno dele têm sido desenvolvidas importantes pesquisas, visando busca, recuperação e adaptação de materiais didáticos. Uma das soluções possíveis é desenvolver aplicações educacionais nas quais os materiais de aprendizagem sejam baseados em ontologias.

Para estruturar os materiais de aprendizagem com pontos comuns de referência é necessário que os conceitos e relações estejam baseados em um vocabulário padrão. Com este vocabulário, e usando as ontologias, pode-se manter todas as partes que compõem os materiais de aprendizagem interligadas entre si. 
Para que os computadores possam compreender e interpretar os materiais de aprendizagem, as páginas que compõem as aplicações necessitam estar anotadas, ou seja, devem conter uma marcação semântica, baseada nos termos definidos por uma ou mais ontologias. Estas anotações possibilitam que pesquisas mais estruturadas possam ser realizadas nos materiais de aprendizagem.

Também estão sendo realizadas pesquisas para a utilização de objetos de aprendizagem nas aplicações educacionais (QUINTON, 2002); (LONGMIRE, 2001); (DOWNES, 2000). Segundo Wiley (2001) “objeto de aprendizagem é qualquer recurso digital que possa ser reutilizado para suporte ao ensino. A principal idéia dos objetos de aprendizagem é quebrar os materiais de aprendizagem em pequenos pedaços, que possam ser reutilizados em diferentes ambientes de aprendizagem, no espírito da programação orientada a objetos."

Esta idéia possibilita que os materiais de aprendizagem tornem-se mais estruturados, organizados e que possam ser disponibilizados na Web em vários formatos diferentes, como hipertexto, vídeo, animações etc. só para citar os mais comuns, nos dias de hoje.

Portanto, os sistemas educacionais baseados na Web podem adotar uma nova abordagem em seu desenvolvimento, a utilização das tecnologias que formam a base da Web Semântica (XML, RDF e ontologias) ${ }^{3}$, com a utilização dos objetos de aprendizagem ${ }^{4}$. A Web Semântica possibilitará novas dimensões para a educação baseada na Web, facilitando a pesquisa, o compartilhamento e o reuso dos materiais de aprendizagem.

A plataforma CoL - Cursos on Larc - (SILVEIRA et al., 2002) é um sistema de gerenciamento de cursos a distância, ou assistidos, desenvolvido pelo Laboratório de Arquitetura e Redes de Computadores da Escola Politécnica da Universidade de São Paulo (Larc). É um sistema que se propõe a hospedar cursos baseados em páginas HTML e recursos multimídia, oferecendo o suporte necessário para a organização dos alunos em turmas, supervisão de matrículas, realização de avaliações online, gerenciamento de chat, viabilização de listas de discussão, entre outros.

\footnotetext{
${ }^{3}$ Serão detalhados nos capítulos 2 e 3 .,

${ }^{4}$ Objetos de aprendizagem serão estudados, em detalhes, no capítulo 5.
} 
A integração da Web Semântica em plataformas de ensino a distância abre novas possibilidades para o desenvolvimento de materiais e objetos de aprendizagem, para a educação baseada na Web.

Este vem a ser o tema central deste trabalho, a integração da Web Semântica na plataforma CoL, e suas implicações no desenvolvimento dos materiais de aprendizagem desta plataforma.

\subsection{Objetivos e contribuições}

O principal objetivo deste trabalho é propor uma modelagem ontológica de materiais e objetos de aprendizagem baseada nas tecnologias da Web Semântica para a plataforma CoL, de modo a dar a esta plataforma a capacidade de organizar e estruturar seus materiais de aprendizagem, possibilitando que pesquisas mais estruturadas possam ser realizadas, bem como permitir o compartilhamento de materiais de aprendizagem.

As etapas necessárias para atingir este objetivo são:

- Apresentar um estudo teórico sobre a Web Semântica e suas tecnologias, propiciando ao leitor uma visão abrangente das principais tecnologias nesta área, e também permitindo um melhor entendimento do projeto realizado;

- Analisar a utilização de ferramentas disponíveis até o momento, para alavancar os trabalhos na Web Semântica, com vistas a Educação Baseada na Web;

- Possibilitar um entendimento da linguagem de ontologia DAML+OIL, bem como seu emprego nas plataformas para Educação Baseada na Web.

- Apresentar uma metodologia para utilização de ontologias, para a recuperação da informação contida em ferramentas educacionais baseadas na Web, para que possa ser pesquisada e reutilizada;

- Verificar a viabilidade de utilização dos padrões de metadados existentes para os materiais e objetos de aprendizagem;

- Propor a integração destas técnicas na plataforma CoL. 
Desta forma, espera-se contribuir significativamente para a melhoria das ferramentas educacionais, propiciando o embasamento teórico e de projeto para o desenvolvimento de ferramentas de autoria mais amigáveis para auxiliarem as atividades do professor, que desta forma ficará liberado de exaustivas pesquisas manuais para obter e compor seu material didático. Finalmente, o Col é uma ferramenta que se encontra disponibilizada na Intranet da Poli, ou seja, é acessível a todos os professores e alunos da escola.

Não é, entretanto, objetivo deste trabalho, realizar a implantação deste projeto na ferramenta, e sim levantar a metodologia que possibilitaria esta implantação, promovendo desta forma, a extensão das funcionalidades do CoL.

As metodologias aqui descritas, apesar de terem como foco as atividades educacionais, podem ser empregadas em outras áreas, pois o principal mecanismo envolvido são as máquinas de busca de informação.

\subsection{Metodologia}

Este trabalho iniciou-se com pesquisas realizadas com a finalidade de responder algumas perguntas colocadas, freqüentemente, por professores no seu dia a dia, como as listadas na página 3. Outras perguntas deste tipo poderiam ser:

- Onde encontro tópicos que me permitem preparar uma aula sobre a linguagem XML?

- Que outro professor de meu grupo de pesquisas poderia me emprestar material didático para o curso para o qual fui designado em substituição ao meu colega que teve que se afastar?

- Como posso reaproveitar material didático de uso comum em nosso laboratório, ou que foi tornado público na rede?

Estas perguntas não são apenas de professores, mas podem ser também colocadas pelos alunos, em seus estudos a distância (ou não). Frequientemente, estudantes ou profissionais estão "navegando" na rede em busca de informações, muitas vezes, sem que estejam inseridos em um curso regular. 
Assim, os objetivos iniciais deste trabalho levaram a investigar os problemas principais relacionados com a reutilização de conteúdo, no caso, de cunho educacional. Estes estudos conduziram, naturalmente, à Web Semântica e aos conceitos a ela relacionados. Isto levou a seguinte seqüência de pesquisas:

- Estudo das tecnologias que compõem os fundamentos básicos da Web Semântica, tais como as linguagens XML, XML Schema, RDF, RDF Schema e DAML+OIL;

- Estudo sobre ontologias e sobre as metodologias para desenvolvimento de sistemas baseados em ontologias;

- Estudo e análise dos padrões de metadados existentes para a área educacional, para selecionar um vocabulário a ser utilizado na ontologia. Metadados são informações sobre dados. Os metadados são empregados para possibilitar a atribuição de semântica (significado) ao conteúdo dos recursos (documentos) da Web, para que possam ser entendidos pelas máquinas. Ser "entendido pelas máquinas”, significa simplesmente fornecer dados explícitos para elas, de modo que possam identificar relações entre os recursos da Web e criar ligações entre eles, que não estavam presentes originalmente. Metadados serão discutidos no capítulo 3;

- Seleção de ferramentas para construção e edição de ontologias, anotação de páginas Web e mecanismos de pesquisa para extrair informações de uma Base Ontológica de conhecimento;

- Estudo da arquitetura da plataforma CoL e elaboração de uma ontologia para esta ferramenta.

As pesquisas foram realizadas em livros, revistas e anais de congressos. Parte considerável da pesquisa foi efetuada através da própria Web. A abertura das bibliotecas digitais do IEEE, da ACM e de outras importantes editoras internacionais à pesquisa, através dos convênios firmados pela CAPES e USP com estas instituições foi de importância ímpar para o desenvolvimento destas pesquisas. O contacto com os pesquisadores Lora Aroyo, da Universidade de Twente e Vladan Devedzic, da 
Universidade de Belgrado, através de email foi muito importante para esclarecimento de duvidas e troca de informações. Também foi muito valiosa a participação, como aluno, no curso a distância de JavaScript, oferecido pelo Núcleo de Ensino a Distância da UNICAMP. A participação no IX Congresso Internacional de Ensino a Distância, da Associação Brasileira de Ensino a Distância, e no Workshop de Ontologias para a construção de metodologias de busca na web por conteúdos educacionais, no XIII Simpósio Brasileiro de Informática na Educação, ajudaram na realização deste trabalho.

Finalmente, o sistema $\mathrm{CoL}$ foi estudado quanto à sua estrutura interna. Este sistema não foi desenvolvido através de uma metodologia orientada de objetos, e assim, foi necessária uma reengenharia que permitisse determinar a sua estrutura, caso fosse baseado em classes, a fim de integrá-lo com o projeto ontológico que se baseia nesta metodologia. A notação gráfica utilizada para as ontologias é, via de regra, muito próxima da UML. Porém é necessário destacar que o nível de abstração utilizado com as ontologias é conceitual, enquanto que o nível da UML é sistêmico, ou seja, atualmente em UML não se pode representar a semântica formal e os mecanismos de inferência utilizados em ontologias.

Finalmente, foi desenvolvido o projeto proposto, segundo uma metodologia que foi considerada adequada. Algumas ferramentas encontradas na rede ou obtidas junto a pesquisadores da área permitiram implementar parte considerável da ontologia, e testá-la, através da formulação de questões sobre os assuntos colocados nas perguntas típicas, que se desejava responder no início da pesquisa (como as da página 3). Isso permitiu demonstrar a viabilidade do projeto.

\subsection{Organização da Tese}

Este trabalho, além desta introdução, contém mais seis capítulos, cujos conteúdos estão descritos a seguir.

O capítulo dois é dedicado ao estudo de ontologias. São discutidos os tipos de ontologias, metodologia e construção de ontologias para uso em ambientes 
dinâmicos e distribuídos, como é a Web. Procura-se identificar os elementos diretamente relacionados com ontologias, educação e reutilização da informação.

O capítulo três introduz os conceitos da Web Semântica e sua tecnologia, enfocando tópicos como XML, XML Schema, RDF, RDF Schema e os aspectos técnicos do uso de ontologias e suas relações com XML Schema e RDF Schema. Também são discutidas as linguagens OIL e DAML + OIL, além de algumas ferramentas para a Web Semântica.

O capítulo quatro comenta alguns aspectos da educação baseada na Web e sua utilização com a Web Semântica. São comentadas as limitações da Educação Baseada na Web, tais como as limitações conceituais, tecnológicas e das ferramentas de autoria. São discutidos aspectos sobre a interação entre professores, alunos e matérias educacionais e como a Web Semântica pode contribuir para a melhoria dos sistemas educacionais baseados na Web.

O capítulo cinco apresenta a metodologia e a arquitetura proposta para a pesquisa dos materiais e objetos de aprendizagem, com a utilização das tecnologias da Web Semântica. Faz-se uma rápida descrição da ferramenta COL, e a ferramenta de pesquisa para testar a modelagem proposta.

O capítulo seis comenta as possíveis utilizações da ontologia gerada, contém as conclusões deste trabalho comentando suas contribuições e perspectivas futuras.

O anexo A apresenta uma relação de documentos gerados pela ferramenta WebODE, utilizada na construção do modelo ontológicos proposto.

$\mathrm{O}$ anexo B apresenta alguns pesquisas realizados no modelo proposto para confirmar a sua viabilidade.

O apêndice A apresenta a estrutura das ferramentas SHOE e OntoBroker. 


\section{ONTOLOGIAS}

Desde o inicio dos anos noventa, as ontologias se tornaram um tópico comum de investigação na área de Inteligência Artificial, incluindo a engenharia e representação do conhecimento e o processamento de linguagem natural. Mas, recentemente, a noção de ontologia tem-se expandido para as áreas de recuperação de informações na Internet, gestão de conhecimento e elaboração de sistemas educacionais inteligentes. A razão da sua popularidade está sustentada, basicamente, na promessa de que um determinado domínio de conhecimento pode ser representado computacionalmente, de modo que a comunicação entre pessoas e computadores se realize automaticamente.

\subsection{Introdução}

As próximas gerações de sistemas educacionais baseados na Web (EBW), deverão ser desenvolvidas com embasamento em ontologias e o desenvolvimento da Web Semântica também estará fortemente embasado em ontologias.

Mas o que é uma ontologia?

Segundo o dicionário Aurélio, "ontologia é a parte da filosofia que trata do ser enquanto ser, i.e., do ser concebido como tendo uma natureza comum, que é inerente a todos, e a cada um, dos seres".

A área de Inteligência Artificial (IA) tomou este termo emprestado da filosofia e deulhe um outro significado. A definição mais freqüentemente encontrada é a dada por Gruber (1993):

"Uma ontologia é uma especificação formal, explícita e compartilhada de uma conceitualização".

Studer et al.(1998) analisa os termos desta definição. "Conceitualização" refere-se a um modelo abstrato de algum fenômeno no mundo, pela identificação dos conceitos relevantes desse fenômeno. "Explícita" significa que o tipo de conceito usado e suas restrições, estão explicitamente definidos. "Formal" refere-se ao fato de que a 
ontologia pode ser compreendida pelas máquinas. "Compartilhada" refere-se à noção de que uma ontologia captura um conhecimento consensual, isto é, não é originada de alguns indivíduos, mas aceita por um grupo.

Várias definições surgiram na literatura que enriquecem esta definição ou sugerem outras. Para Swartout (1999) uma ontologia refere-se a um conjunto de conceitos ou termos que podem ser usados para descrever alguma área de conhecimento ou construir sua representação. Uma ontologia pode ser de alto nível, consistindo de conceitos que organizam a parte superior de um conhecimento base, ou de um domínio específico, tal como uma ontologia de veículos.

Chandrasekaram (1999) coloca que o termo é usado com dois tipos de significado:

- Ontologia é a representação de um vocabulário, freqüentemente especializado em algum domínio ou assunto importante. Mais precisamente, não é o vocabulário que qualifica uma ontologia, mas os conceitos que os termos do vocabulário transmitem. Então, transferindo os termos de uma ontologia de uma linguagem para outra, por exemplo do Inglês para o Francês, não muda o conceito ontológico;

- O termo ontologia é usado algumas vezes para referir-se a um conjunto de conhecimentos que descreve algum domínio, usando um vocabulário representativo.

Em outras palavras, a representação do vocabulário é composta de termos que descrevem os fatos em algum domínio, enquanto que o conjunto de conhecimento usa o vocabulário como uma coleção de fatos a respeito do domínio.

Destas definições e observações pode-se concluir que a importância de uma ontologia é esclarecer a estrutura de um conhecimento. Dado um domínio, sua ontologia forma o centro de qualquer sistema de representação do conhecimento daquele domínio. Sem ontologia, ou sem a conceituação do conhecimento, não pode haver um vocabulário que represente o conhecimento. Então, o primeiro passo para projetar um sistema de representação de conhecimento eficiente, e seu vocabulário, é realizar uma análise ontológica eficiente do domínio. 
Portanto, como afirma Daum (2002) uma ontologia é uma descrição formal dos conceitos e relacionamentos que existem dentro de um domínio. Isso significa que uma ontologia se relaciona com um vocabulário específico e com uma linguagem específica.

Deve-se observar que uma ontologia é um acordo. Esse acordo, não necessariamente precisa abranger toda a conceitualização de determinado domínio, mas pode abranger apenas uma parte dele, ou seja, ele pode oferecer uma visão para o domínio. Uma ontologia, assim, atua como um contrato entre parceiros, permitindo que se comuniquem com segurança dentro do contexto do domínio de informação. Por exemplo, um agente de software que esteja comprometido com uma ontologia será capaz de interpretar semanticamente os itens de informações abrangidos por essa ontologia e se comunicar com outros agentes comprometidos com essa ontologia. Este comprometimento, de acordo com Gruber (1993a), chama-se comprometimento ontológico, ou seja, a partir de um conjunto bem definido de termos é possível formar sentenças coerentes, que auxiliam na resolução de tarefas, bem como ajudam no raciocínio do problema considerado.

Portanto, as ontologias permitem entender e explicar o domínio que está sendo analisado. Marietto (2002) aponta os principais benefícios no desenvolvimento de ontologias:

- Propicia ao desenvolvedor uma compreensão mais apurada do domínio abordado;

- Possibilita o compartilhamento de conhecimento, levando em consideração o compartilhamento de termos de um dado domínio;

- Possibilita a troca de informações;

- Oferece suporte à interoperabilidade entre sistemas computacionais, considerando o relacionamento de diferentes paradigmas, linguagens, métodos etc.;

- Auxilia no reuso de conhecimento; 
- Auxilia em processos de especificação de requisitos;

- Auxilia no processo de verificação de um sistema computacional, porque ontologias explicitam a especificação de tais sistemas, servindo como base de comparação entre o modelo conceitual e o modelo computacional;

- Auxilia na manutenção e documentação de sistemas computacionais.

\subsection{Construção de Ontologias}

A construção de ontologias é uma tarefa complexa e requer alguns critérios e metodologias para que possam ser bem desenvolvidas. Para isto é necessário compreender os componentes básicos de uma ontologia.

\subsubsection{Componentes de uma Ontologia}

Segundo Peréz (2002) uma ontologia tem cinco componentes: conceitos, relações, funções, axiomas e instâncias.

Conceitos podem ser abstratos ou concretos, simples ou compostos, reais ou fictícios. Em resumo, um conceito pode ser "qualquer coisa" a respeito de "algo" que estamos explicando, e por esse motivo pode ser a descrição de uma tarefa, função, ação, estratégia ou um processo de raciocínio. Em algumas linguagens de ontologia, os conceitos são conhecidos como classes. Os conceitos são, normalmente, organizados em taxonomias, a partir das quais são aplicados os mecanismos de herança. Uma taxonomia é o estabelecimento de relacionamentos entre objetos e classes, subclasses e classes-pai. Estes relacionamentos são chamados relacionamentos hierárquicos ou do tipo is-a (é-um).

Relações são um tipo de interação entre os conceitos de um domínio e seus atributos. Além dos relacionamentos hierárquicos, incluem-se outros tipos de relacionamentos, como por exemplo, é-composto-por, é-dirigido-por, é-instânciade, é-parte-de etc. 
Funções são um tipo especial de relação. Como exemplo podemos ter Exponencial (x), Mediafinal (P1, P2).

Os axiomas são usados para modelar sentenças que são sempre verdadeiras e podem ser usados com vários propósitos, tais como: impor restrições, verificar a correção e realizar dedução de novas informações. Por exemplo, a afirmação: "uma bicicleta tem pelo menos uma roda" é um tipo de restrição e, por isto, um axioma.

As instâncias representam elementos do domínio associados a um conceito específico.

Por exemplo, a figura 2.1 é uma ontologia simples de uma unidade educacional e ilustra algumas relações. Pode-se afirmar que Moysés é uma instância de Professor e que Sistemas Operacionais é uma instância de Disciplina. Há os relacionamentos hierárquicos (é-um) entre os conceitos Pessoa, Estudante e Professor e os relacionamentos não hierárquicos (ensinada-por), indicando um relacionamento entre os conceitos Professor e Disciplina. Pode-se afirmar que Moyses ensina Sistemas Operacionais. Este tipo de representação permite que os mecanismos de pesquisa tenham informações sobre o significado dos termos. Em vez do termo "ensinada" ser tratado como uma cadeia de caracteres e verificar quantas vezes esta cadeia de caracteres ocorre em um documento, o mecanismo de pesquisa pode explorar diretamente os conceitos que este termo relaciona. Deste modo, o usuário obtém acesso às informações disponíveis sobre aquele conceito.

\subsubsection{Critérios para construção de ontologias}

Para atingir os benefícios proporcionados pelas ontologias, alguns critérios devem ser observados em seu desenvolvimento. Gruber (1995) apud Uschold (1996) cita resumidamente os seguintes:

Clareza: Uma ontologia deve, efetivamente, comunicar o significado pretendido na definição dos termos. Suas definições devem ser objetivas e independentes do contexto social ou computacional. Quando uma definição puder ser declarada em axiomas lógicos, ela deve ser usada. Quando for possível, uma definição completa é 
preferida em relação a uma definição parcial e todas as definições devem ser documentadas com linguagem natural, de modo a reforçar a clareza.

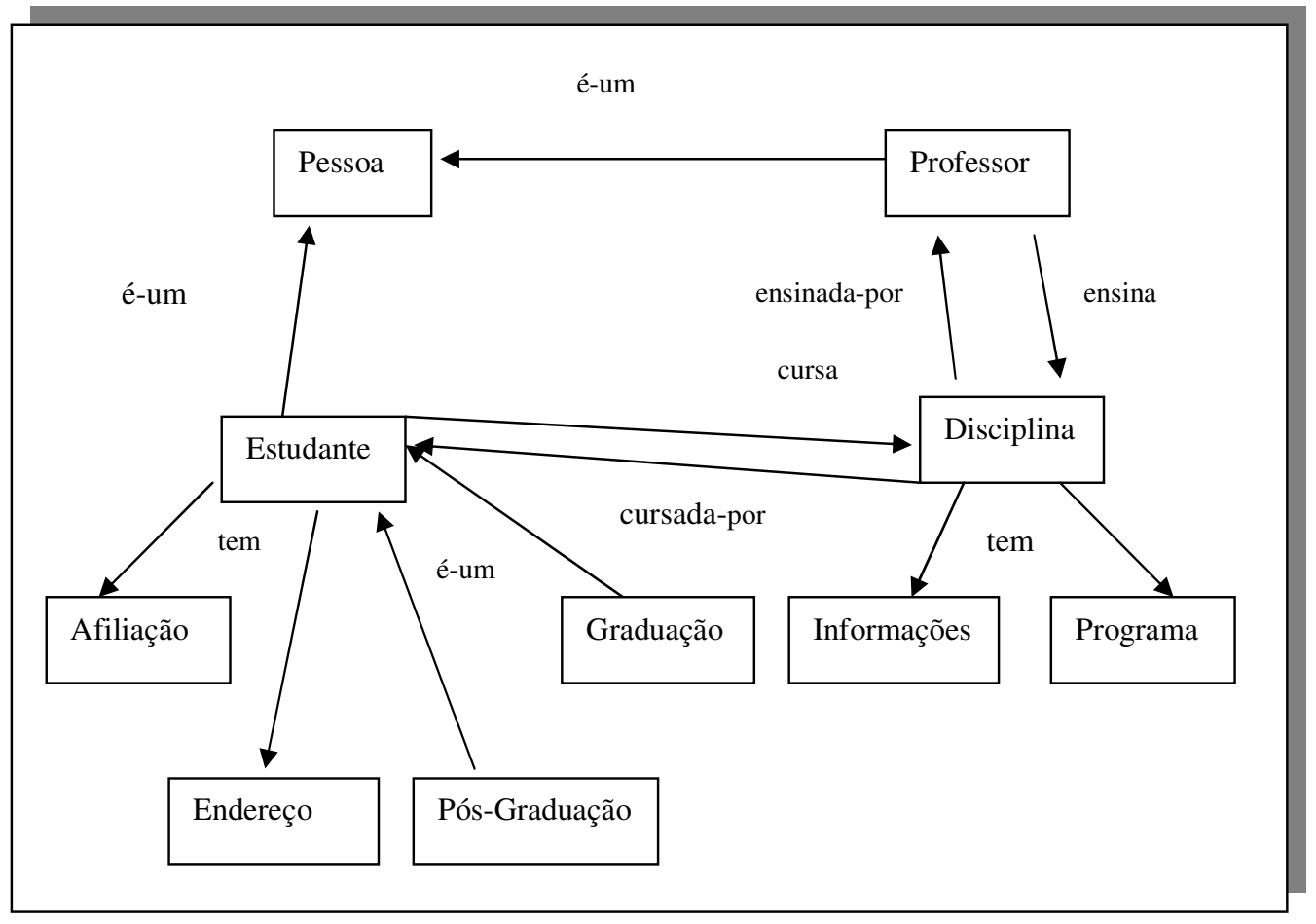

Fig. 2.1 - Ontologia de um ambiente educacional

Coerência: Uma ontologia deve ser coerente, isto é, as inferências devem ser consistentes com as definições axiomáticas. Coerência deve ser aplicada para os conceitos que são definidos formal e informalmente. Se uma sentença é passível de ser inferida a partir dos axiomas da ontologia contradiz uma definição, ou exemplo dado informalmente, então a ontologia é incoerente.

Extensibilidade: Uma ontologia deve ser projetada para antecipar usos de um vocabulário compartilhado, ou seja, uma ontologia deve ser capaz de definir novos termos para usos especiais, baseados em um vocabulário existente, sem haver necessidade de rever definições existentes.

Compromissos de codificação mínimos: A conceituação deve ser especificada no nível de conhecimento, sem depender de uma tecnologia particular de representação de conhecimento. 
Compromissos ontológicos mínimos: O conjunto de compromissos ontológicos de uma ontologia deve ser suficiente para suportar as atividades de compartilhamento de conhecimento. Uma ontologia deve fazer poucas imposições a respeito do domínio que está sendo modelado, permitindo que as partes comprometidas com a ontologia fiquem livres para especializar e instanciar a ontologia, na medida do necessário.

Em relação aos termos, os seguintes critérios devem ser considerados (USCHOLD, 1996a):

- Definição dos termos em linguagem natural, da forma mais precisa possível;

- Garantia de consistência dos termos, através do uso de dicionários e glossários técnicos, e evitando-se sempre a possível introdução de novos termos;

- Relacionamento do termo que está sendo definido com os outros termos existentes;

- Definição de cada termo, de forma a ser necessária e suficiente para especificar seu significado;

- Suspensão do uso do termo, se for ambíguo;

- Colocação clara das idéias através da definição cuidadosa de cada conceito, usando-se a menor quantidade possível de termos técnicos, ou somente daqueles cujas definições já são aceitas;

- Apresentação de exemplos, onde for necessário.

\subsubsection{Tipos de Ontologias}

Guarino (1998) identifica quatro tipos de ontologias:

Ontologias de nível superior ou genéricas: são compartilhadas por uma grande comunidade e definem apenas termos muito gerais, tais como, espaço, tempo, matéria, objeto, evento, ação etc., e são independentes de um problema ou domínio particular. 
Ontologias de domínio: expressam conceituações de domínios particulares, descrevendo o vocabulário relacionado a um domínio genérico, tal como medicina, indústria farmacêutica ou de computadores.

Ontologias de tarefas: expressam conceituações sobre a resolução de problemas, independentemente do domínio em que ocorram, isto é, descrevem o vocabulário relacionado a uma atividade ou tarefa genérica, tal como diagnose ou vendas.

Ontologias de aplicação: descrevem conceitos dependentes do domínio e de tarefas particulares. Estes conceitos, freqüentemente, correspondem a papéis desempenhados por entidades do domínio, quando da realização de uma certa atividade.

A figura 2.2 mostra a relação entre estas ontologias. Os conceitos de uma ontologia de domínio ou de tarefa devem ser especializações dos termos introduzidos por uma ontologia genérica. Os conceitos de uma ontologia de aplicação, por sua vez, devem ser especialização dos termos das ontologias de domínio e de tarefa correspondentes. Perez (1999), acrescenta nessa classificação as ontologias de método, que oferecem definições de conceitos e relações, usados para especificar um processo de raciocínio, para resolver uma tarefa em particular.

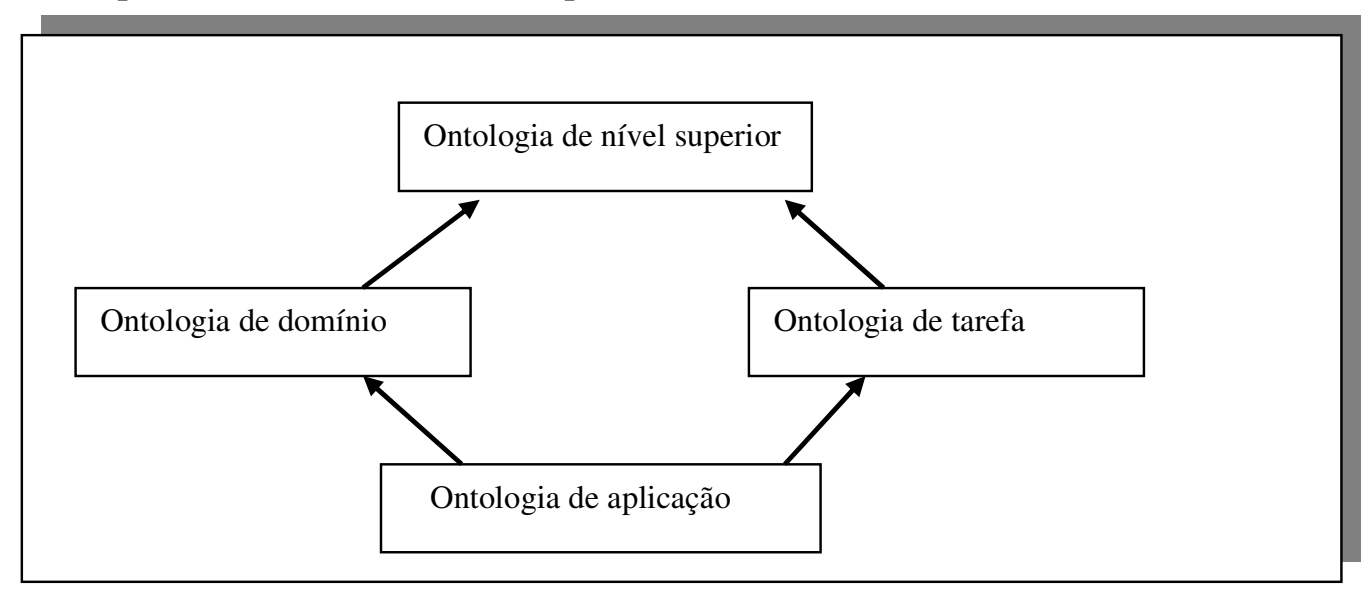

Fig 2.2 - Tipos de ontologia e suas relações (Guarino, 1998)

\subsubsection{Metodologia para construção de Ontologias}

Embora não existam padrões para a construção de ontologias, várias propostas são encontradas na literatura. Entre elas destaca-se o projeto Enterprise Ontology 
(USCHOLD, 1996), o projeto TOVE (Toronto Virtual Enterprise) (GRUNINGER, 1995) e a metodologia denominada METHONTOLOGY (FERNÁNDEZ, 1997). Uschold (1995) propôs cinco passos que uma metodologia deve ter: identificação do propósito e do escopo, construção da ontologia, avaliação e documentação. A construção da ontologia é dividida em três passos: captura da ontologia, codificação e integração com outras ontologias. Estes passos foram usados na construção do projeto Enterprise, mas este não chegou a empregar um procedimento de avaliação formal. Este foi o foco principal do projeto TOVE; através de uma metodologia formal, que suportava avaliação da ontologia, usou a noção de questões de competência. A idéia central foi definir um conjunto de questões que a ontologia deveria responder. Estas questões ajudam a estimar e medir a qualidade da ontologia e, também, avaliar a sua expressividade, que é necessária para representar estas questões e caracterizar as suas soluções. Por exemplo, no ambiente educacional da figura 2.1 podemos ter o seguinte conjunto de questões de competência:

- Quais as características de uma determinada disciplina?

- Quais estudantes cursam uma determinada disciplina?

- Uma disciplina é ensinada por qual professor?

- Quem são os estudantes de pós-graduação?

- Qual o endereço de um determinado estudante de graduação?

Em Araújo et al. (2002), há uma metodologia proposta para a construção de ontologias, que procura responder as seguintes questões:

- Quais e como as ontologias devem ser construídas?

- Quais relações devem existir entre elas?

A metodologia apresentada pode ser inserida na estruturação de sistemas baseados em conhecimento, tais como sistemas educacionais, de comércio eletrônico, jogos interativos, dentre outros. Tal metodologia baseia-se em dois passos principais: (i) construção de uma biblioteca de ontologias, procurando captar a base teórica do 
sistema modelado, (ii) definição funcional do sistema modelado pela biblioteca de ontologias, capturando a dinâmica do mesmo.

O primeiro passo da metodologia está relacionado à visão estática do sistema baseado em conhecimento modelado. Propõe-se que esta visão estática seja capturada em duas etapas:

- Definição da principal função do sistema, considerando-o como uma entidade com estruturas internas que levam ao alcance desta função;

- Definição de tarefas que dão suporte ao alcance do objetivo principal, explicitando-se o conhecimento necessário à operacionalização das mesmas.

A primeira etapa identifica o problema a ser abordado, separando-o de seus efeitos e de suas causas, e das ações a serem realizadas para resolvê-lo. Esta identificação é fundamental, pois um dos objetivos do processo de construção de ontologias é estabelecer um vocabulário para a definição de um modelo de processo de resolução do problema em questão.

Na segunda etapa é feita uma análise para determinar os conhecimentos necessários para que a função principal do sistema seja realizada. Neste momento, uma biblioteca de ontologias deve ser modelada e construída, objetivando especificar e explicitar a sintaxe da estrutura teórica do sistema.

Nesta metodologia, tem-se uma biblioteca composta por três tipos de ontologias: ontologia de domínio, ontologia de métodos e ontologia de aplicação. Estas ontologias estão estruturadas em dois níveis de abstração, iniciando com o mais geral/abstrato (Nível 1) e alcançando o mais específico/detalhado (Nível 2), conforme ilustrado na figura 2.3. Tal arquitetura objetiva auxiliar no reuso e compartilhamento de conhecimento, uma vez que as informações inseridas no Nível 1 poderão ser herdadas pelos componentes alocados no Nível 2. 


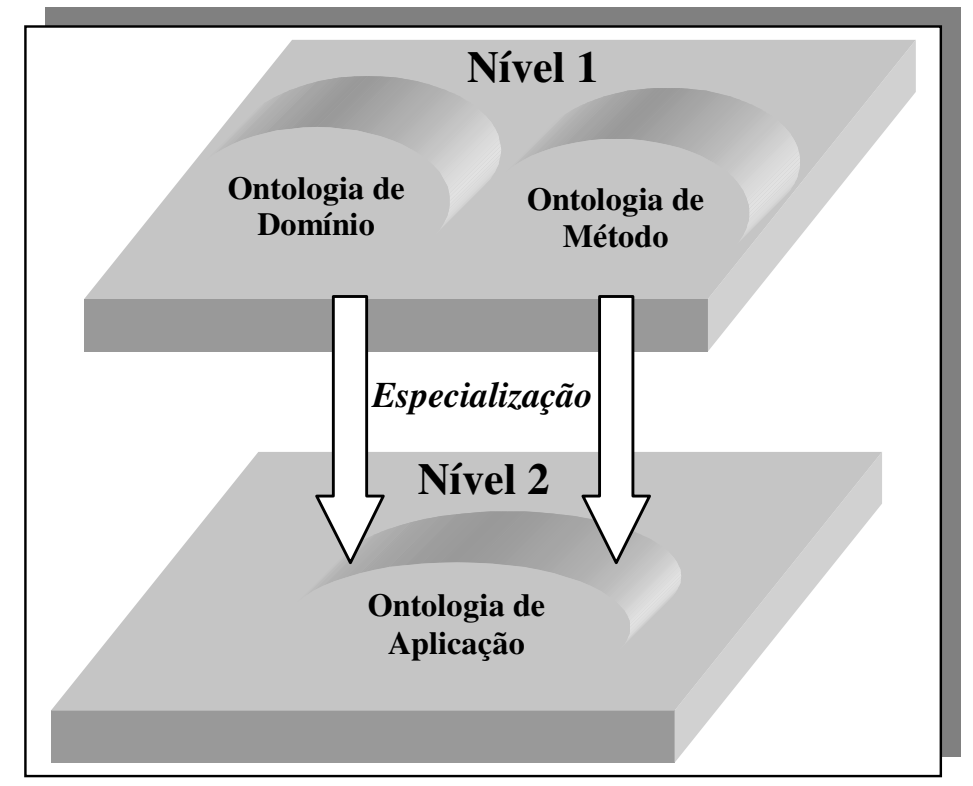

Fig. 2.3 - Arquitetura de abstração da metodologia proposta

A arquitetura de abstração, ilustrada na figura 2.3, apresenta uma visão estática da biblioteca de ontologias, pois não retrata como estas se relacionam para dar suporte à execução da função principal do sistema modelado. A especificação destes relacionamentos é de fundamental importância, pois retrata a semântica da estrutura teórica do sistema modelado através da explicitação de seu funcionamento. Assim, o segundo passo da metodologia refere-se à visão dinâmica do sistema, considerandose a definição do relacionamento funcional entre as ontologias. Esta descrição pode ser feita utilizando linguagem natural, ou com mecanismos mais formais, como a linguagem UML. A descrição deve apresentar um cenário geral do uso integrado das ontologias, indicando valores de entrada e saída que estabeleçam dependências funcionais entre as mesmas. A figura 2.4. ilustra esta abordagem dinâmica, considerando-se a biblioteca de ontologias apresentada anteriormente.

O cenário geral que ilustra uma interação com a biblioteca de ontologias começa com o acesso de um usuário ao sistema baseado em conhecimento modelado. Este acesso é intermediado pela ontologia de métodos, que por sua vez acessa a ontologia de domínio para obter informações relacionadas à execução das tarefas do sistema. Como as ontologias de aplicação são especializações das ontologias de domínio e de método, estas têm acesso às suas ontologias-mãe através do relacionamento de 
especialização. Haverá casos aonde o usuário se comunicará diretamente com uma ontologia de aplicação. Tais casos ocorrem quando a ontologia de aplicação englobar métodos que não estejam inseridos na ontologia de métodos.

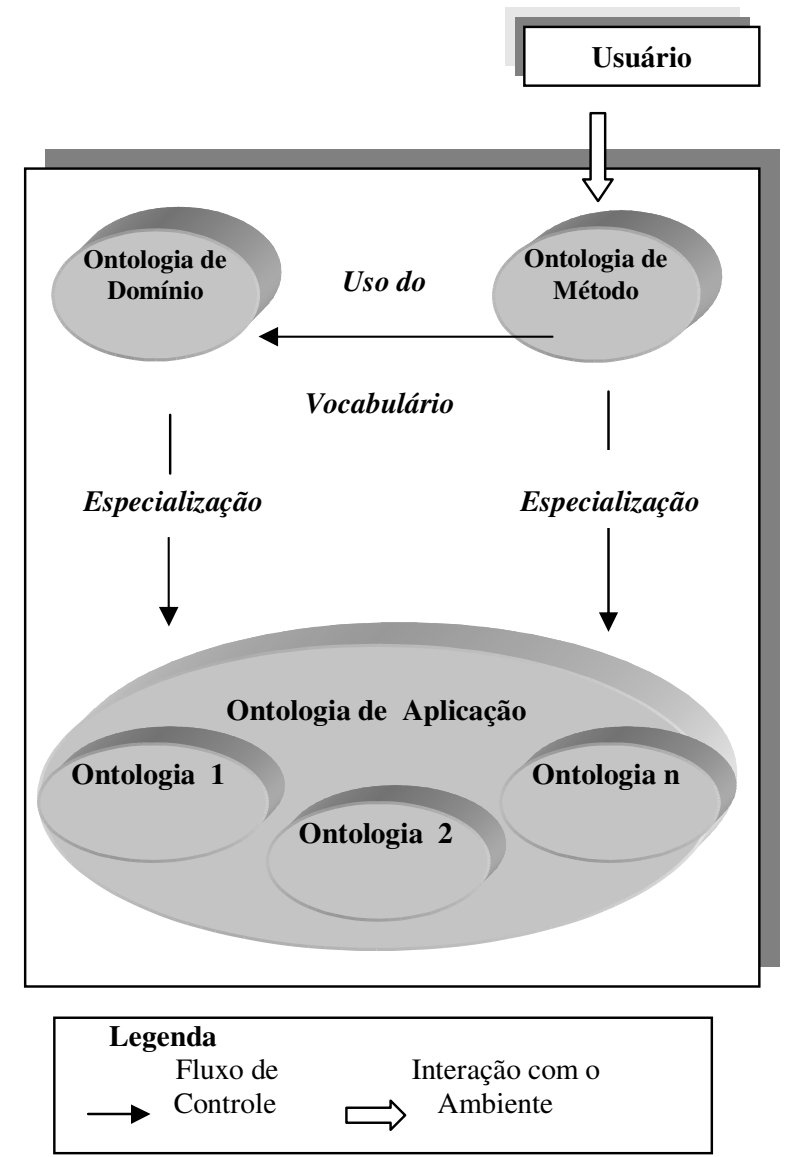

Fig.2.4 - Arquitetura funcional da metodologia proposta

\subsubsection{A Metodologia METHONTOLOGY}

Nesta seção analisaremos em mais detalhes a metodologia METHONTOLOGY, que será utilizada na modelagem dos materiais de aprendizagem da plataforma CoL Cursos-on Larc. A escolha desta metodologia se deve ao fato dela indicar as atividades a serem realizadas para a construção de ontologias, bem como indicar a sequiência/ordem e o nível de detalhamento em que tais atividades devem ser executadas. Acompanha esta metodologia a ferramenta WebODE (VEGA, 2000), que é um repositório central de ontologias e que auxilia a execução dos seus estágios. 
A METHONTOLOGY é um método estruturado para a construção de ontologias, composto dos estágios descritos a seguir. Esta análise está, parcialmente, baseada em Fernández (1997) e Marietto (2002).

\subsubsection{Especificação}

O objetivo é produzir um documento escrito em linguagem natural, usando um conjunto de representações intermediárias ou usando questões de competência. A especificação contém o objetivo principal da ontologia, considerando seus usuários alvo, cenários de uso etc., o nível de formalismo da ontologia implementada e o escopo, que inclui o conjunto de termos a ser representado, suas características e granularidade. O resultado desta fase é a geração de um documento de especificação de requisitos.

\subsubsection{Aquisição de conhecimento}

As atividades desta fase são executadas no transcorrer de todos estágios da ontologia. Possíveis fontes de conhecimento são: especialistas, livros, outras ontologias etc. Técnicas utilizadas para a aquisição do conhecimento são: brain storming, entrevistas, análises de textos, dentre outras.

\subsubsection{Conceitualização}

É a fase principal da metodologia. Nesta fase, o domínio do conhecimento será estruturado em um modelo conceitual, descrevendo o problema e suas possíveis soluções, tendo como base o vocabulário definido nas fases de especificação e aquisição do conhecimento. Envolve a elaboração de várias representações intermediárias, que agem como uma ponte entre o que as pessoas pensam sobre o domínio e as linguagens nas quais as ontologias são formalizadas. A partir da especificação das representações intermediárias, é possível separar o desenvolvimento da ontologia em diferentes equipes.

A primeira atividade a ser realizada é construir um Glossário de Termos (GT). Aqui, termos incluem conceitos, instâncias, verbos, propriedades etc. O GT contém o nome do termo e sua descrição. Após a construção do GT, os termos devem ser 
organizados em árvores de classificação de conceitos (ACC), utilizando relações tais como é-um, subclasse-de, composto-por etc. Estas árvores organizam os conceitos em taxonomias, sendo usadas não somente para saber como os conceitos estão relacionados entre si, mas para modularizar o conhecimento do domínio em ontologias independentes. Assim, a partir das ACC são identificadas as taxonomias do domínio e, conforme proposto na metodologia, cada taxonomia produz uma ontologia.

Logo após, são construídos diagramas de relações binárias ad-hoc (DRB) entre as ACC. Tais diagramas estabelecem relações entre conceitos da mesma ontologia, ou de ontologias diferentes. Assim, auxilia a definição de linhas gerais para integrar ontologias. Agora, para cada árvore de classificação de conceitos são construídas as seguintes representações intermediárias: Dicionário de dados/conceitos, Tabelas de relações binárias ad-hoc, Tabelas de atributos de instâncias, Tabela de atributos de classes, Tabela de constantes, Árvores de classificação de atributos, Tabelas de fórmulas, Árvores de classificação de atributos e Tabelas de instâncias.

Ao final desta fase, deve-se ter uma especificação do domínio sem redundâncias, omissões ou inconsistências. O documento do modelo conceitual gerado nesta fase deve permitir determinar se uma ontologia é útil para uma determinada aplicação, sem analisar seu código fonte. Também, deve permitir comparar o escopo e completude de várias ontologias, sua reusabilidade e compartilhamento.

\subsubsection{Formalização}

Nesta fase trabalha-se com as tabelas de axiomas lógicos, objetivando definir os conceitos através de expressões lógicas, que são sempre verdadeiras no domínio considerado. Por exemplo, pode-se querer representar formalmente o axioma: "Para trabalhar com o requisito Falha Lógica, uma plataforma precisa trabalhar com o requisito Falha Operacional." 


\subsubsection{Integração}

Quando da tentativa de integrar a ontologia que está sendo construída com outras já existentes, apresentam-se algumas indicações para auxiliar este processo. Em primeiro lugar, é necessário analisar meta-ontologias, objetivando encontrar a que melhor se adeque às características da conceitualização considerada. Em segundo lugar, reusando ou não meta-ontologias, deve-se buscar bibliotecas de ontologias que ofereçam definições de termos com semântica e implementação coerentes com os termos identificados na conceitualização considerada.

\subsubsection{Implementação}

Nesta fase, tem-se a implementação do modelo conceitual através de uma linguagem formal. Um ambiente para o desenvolvimento de ontologias deve oferecer um analisador léxico e sintático, tradutores para garantir a portabilidade das definições, um editor para adicionar, remover e alterar definições, um navegador para pesquisar o conteúdo da biblioteca de ontologias e avaliadores para detectar incompletudes, inconsistências e redundâncias.

\subsubsection{Avaliação}

A avaliação deve levar em consideração os processos de verificação e validação.

\subsubsection{Documentação}

A documentação da metodologia é composta dos seguintes elementos:

- Documentos de especificação de requisitos, obtido após a fase de especificação;

- Documentos de aquisição de conhecimento, obtido após a fase de aquisição de conhecimento;

- Documento do modelo conceitual, obtido após a conceitualização;

- Documento de formalização, obtido após a fase de formalização; 
- Documento de integração.

\subsection{Conclusões}

Neste capítulo foram discutidos alguns conceitos básicos sobre ontologias, tipos de ontologias, critérios e metodologias para construção de ontologias. A modelagem de aplicações baseadas em ontologias é recente e por isto propõe-se a utilização da ferramenta WebODE para auxiliar esta modelagem. Segundo Uschold (1966) o termo ontologia é usado para referir-se ao compartilhamento de conhecimento de algum domínio de interesse, que pode ser usado como uma estrutura unificada para resolver os problemas de:

- Comunicação entre pessoas com diferentes necessidades e pontos de vista;

- Interoperabilidade entre sistemas através da tradução de diferentes métodos de modelagem, paradigmas, linguagens e ferramentas de software;

- Melhoria da reusabilidade, confiabilidade e especificações dos sistemas.

As ontologias começam a ser aplicadas nas áreas de Processamento de Linguagem Natural (DAHLGREEN, 1995), Gerenciamento de Conhecimento (STAAB, 2001) e Comércio Eletrônico (FENSEL, 2001a). Também é a base para a compreensão e desenvolvimento de aplicações para a Web Semântica, tema do próximo capítulo. 


\section{A WEB SEMÂNTICA}

A Internet existe desde meados de 1969 e a Web desde 1989, inventada por Tim Berners-Lee (BERNERS-LEE et al., 2001). Este percebeu que o conceito de hipertexto poderia ser aplicado à Internet com a utilização de três tecnologias conhecidas por seus acrônimos: URL (Universal Resource Locator), que determina que cada página da Web tenha um endereço único, HTTP (Hyper Text Transfer Protocol), que é um protocolo para transferência de textos, gráficos, som, vídeo etc. pela Internet e HTML (Hyper Text Markup Language) que descreve como textos e gráficos devem ser exibidos.

Com a utilização do protocolo TCP/IP e a invenção dos navegadores, a Web tornouse um grande repositório de informações textuais e visuais, assim como um grande veículo para distribuí-las. Através de ferramentas adequadas, estas informações podem ser processadas diretamente pelo homem, pois este reconhece facilmente seu significado. Porém, o que aconteceria se estas mesmas informações pudessem ser entendidas, interpretadas e processadas pelos computadores?

Desta interrogação surgiu o termo Web Semântica, uma próxima geração da Web que pode ser entendida pelos homens e também pelas máquinas.

\subsection{Definição}

O termo Web Semântica foi proposto por Tim Berners-Lee, cuja definição é:

“A Web Semântica ${ }^{5}$ não é uma Web separada, mas uma extensão da atual, na qual a informação é utilizada com significado bem definido, aumentando a capacidade dos computadores para trabalharem em cooperação com as pessoas" (BERNERS-LEE et al., 2001).

Por enquanto, é uma possibilidade ter dados na Web conectados e com significados definidos, de modo que possam ser usados pelos computadores, ou seja, se em determinada página da Web existir a palavra "banco" será possível distinguir se ela significa um "assento" ou um "estabelecimento comercial”. A Web atual é uma

${ }^{5}$ Segundo o dicionário eletrônico Houaiss (2002) da língua portuguesa, a palavra semântica designa um ramo da lingüística que estuda o significado das palavras e de outros símbolos que servem à comunicação humana. 
enorme fonte de informações passivas e desorganizadas e a Web Semântica destinase a colocar ordem neste caos.

Hendler (2001) apresenta um exemplo de como a Web Semântica poderia ajudar os tripulantes de um barco de pesca a evitar uma tempestade em alto mar. Uma consulta a um sítio de previsão de tempo da Marinha retornaria informação insuficiente para que os tripulantes decidissem ficar ou deixar uma determinada área. Com a Web Semântica, a tripulação poderia receber, como informação adicional, imagens de satélites da área em que está o barco, produzidas em tempo real, ou ainda receber informações de um serviço de resgate. A diferença é que a consulta processada pela Web Semântica não está "limitada por palavras". O agente que processa a consulta considera outros conceitos como localização geográfica, navegação náutica e preferências dos pescadores em permanecer em determinada localização, evitando as áreas de tempestades.

Para que estas consultas e pesquisas possam ser executadas, muitas áreas de conhecimentos, distintas, são envolvidas no processo: a Inteligência Artificial, que dá lógica e impõe as regras, os banco de dados, que integram as informações, e a plataforma computacional, que é a própria Internet. As páginas que compõem a Web devem estar estruturadas, para facilitar a explicação de seu significado. Para construir aplicações que envolvam a Web Semântica, Berners-Lee et al. (2001) propuseram uma arquitetura em camadas, que está representada na figura $3.1^{6}$.

Esta arquitetura, em suas camadas, define as tecnologias necessárias para que os conteúdos das páginas Web possam ser compreendidos pelos computadores.

Na primeira camada, o UNICODE (via HTTP) permite que textos e imagens possam ser lidos pelos computadores em qualquer lugar e o URI (Universal Resource Indicators) fornece um endereço global único dos recursos disponibilizados na Web. Um recurso da Web pode ser uma página Web, uma aplicação completa, um documento pessoal, etc.

Na camada seguinte, as tecnologias XML, Namespaces e XML Schema permitem que os documentos da Web sejam estruturados em uma hierarquia de árvore, baseada em marcas (tags), criadas pelo usuário.

\footnotetext{
${ }^{6}$ http://www.w3.org/2000/Talks/1206-xml2k-tbl/slide10-0.html
} 
Na camada RDF (Resource Description Framework - Estrutura de Descrição de Recursos) os dados já têm significado e o RDF Schema propicia representação do conhecimento através de expressões lógicas. É um padrão aberto, recomendado pelo W3C (World Wide Web Consortium), para descrição de recursos Web. É um tipo de descrição de dados sobre dados, chamado metadados.

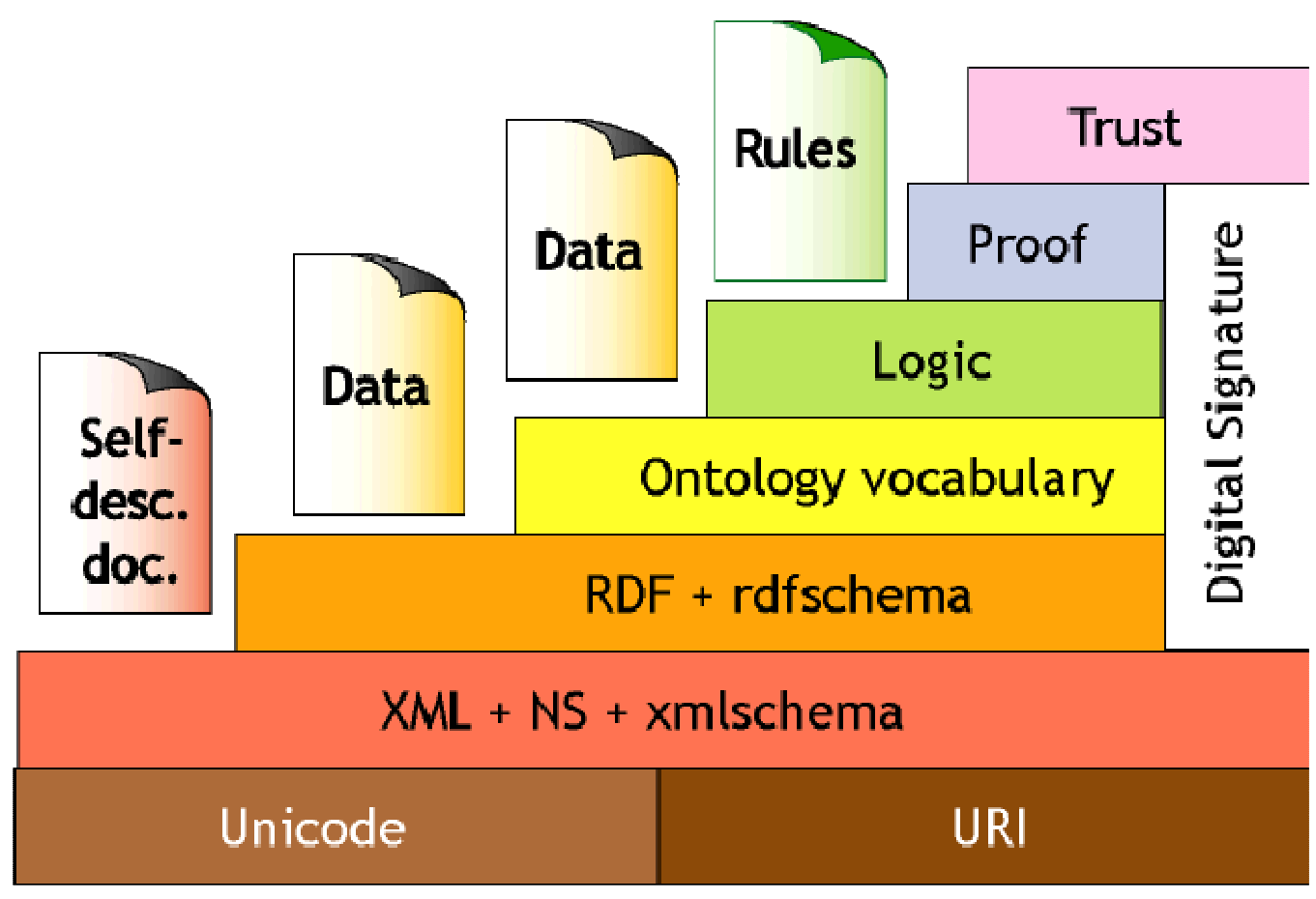

Fig. 3.1 - Arquitetura proposta para a Web Semântica

Na camada ontologias, tem-se um vocabulário compartilhado, que pode ser usado para modelar um determinado domínio, isto é, o tipo de objetos e/ou conceitos que existem neste domínio, suas propriedades e relações. Isto permite que as máquinas "raciocinem" a respeito do significado dos dados e possam inferir novos fatos. Estas camadas estão descritas com mais detalhes nas próximas seções.

As demais camadas ainda estão em estudo pelo consórcioW $3 C^{7}$ e não são objeto de estudo, neste trabalho. Resumidamente, pode-se comentar que a camada de Lógica (Logic) tem como objetivo especificar linguagens de lógica mais poderosas que as atuais, para facilitar a construção de inferências. A camada de Prova (Proof) seria a especificação de uma linguagem para provar que as informações trocadas entre

\footnotetext{
${ }^{7}$ http://www.w3.org/
} 
agentes e máquinas são verdadeiras. A troca pode ser verdadeira mas a informação pode ser falsa. A camada Confiança (Trust) é para verificar, através de assinatura digital, se a pessoa que realiza as transações previstas pelas aplicações é, de fato, "ela mesma”.

\subsection{XML - Extensible Markup Language}

O desenvolvimento da tecnologia de sistemas de informação tem resultado no desenvolvimento crescente de muitas aplicações nas áreas educacionais, comerciais, científicas e militares. Para estas organizações, integrar, acessar e compartilhar seus dados eficientemente, extrair informações destes dados e fazer uso destas informações tornou-se uma tarefa urgente e de extrema importância. Com o advento da Web, estas tarefas tornaram-se complexas: agora os dados estão espalhados em diversos tipos de sítios e em diferentes tipos de banco de dados. Novas ferramentas e tecnologias são necessárias para manipular estes dados, extrair informações e conhecimentos destes dados e permitir interoperabilidade entre as aplicações. Uma destas ferramentas é o XML que é um acrônimo de Extensible Markup Language e será o objeto de estudo das próximas seções.

\subsubsection{HTML e SGML}

Segundo Daum e Udo (2002), o desenvolvimento da Internet e da Web se tornou possível através da definição dos padrões abertos. Entre aqueles que modelaram a Internet estão:

- TCP/IP (Transmission Control Protocol/Internet Protocol)

- HTTP (Hypertext Transfer Protocol)

- $\quad$ SMTP (Simple Mail Transfer Protocol)

- FTP (File Transfer Protocol)

\section{- HTML (Hypertext Markup Language)}

Todos estes padrões servem a uma tarefa específica: eles definem a semântica de forma clara. A especificação HTML, por exemplo, descreve não somente a sintaxe das páginas Web, mas também define como um navegador precisa processar os elementos de uma página Web em HTML. Mas, a semântica rígida destes padrões - 
especialmente do HTML - levou a um problema: é difícil adaptar essa tecnologia a novos domínios de aplicação. Hoje, as páginas Web consistem de uma mistura de HTML, JavaScript, Java e assim por diante, aumentada pela tecnologia de servidor para gerar páginas Web dinâmicas, como ASP, Java ServLets, CGI, PHP, ZOPE, Cold Fusion etc.

O HTML tem suas origens no SGML (Standard Generalized Markup Language), que é um padrão internacional, definido em 1986, para descrever documentos eletrônicos. SGML é uma meta linguagem, usada para escrever outras linguagens, e ajuda a descrever textos dos documentos, de forma lógica e estruturada. Segundo Moultis e Kirk (2000), a SGML vem sendo utilizada na área de publicação técnica, em que a necessidade de lidar com documentos grandes e complexos, em diversas plataformas, é comum. Também é utilizada na indústria automotiva, no campo de assistência médica, em muitas áreas da industria de telecomunicações e em qualquer área em que grandes volumes de texto necessitam ser estruturados em formatos de fácil acesso. A linguagem SGML é uma muito complexa, sua especificação contém mais de 500 páginas, o que torna difícil sua implementação nos navegadores Web. Portanto, para facilitar a publicação de textos na Web de forma acessível a todos, criou-se uma linguagem de marcação de fácil utilização, a HTML.

A linguagem HTML pode ser considerada uma aplicação derivada da SGML, que define um conjunto fixo de elementos e atributos. Alguns exemplos destes elementos, chamados de marcas, são H1, FORM e TABLE. As aplicações HTML, tais como os navegadores, compreendem este conjunto de elementos e atributos (Wood, 1999).

A linguagem HTML popularizou-se rapidamente. As principais razões são:

- Ser extremamente simples;

- Possuir estilo próprio para a formatação de documentos;

- Possibilitar que as ligações de hipertexto criadas facilmente;

- Apresentar suporte ao uso de formulários;

- Permitir a interação homem-máquina; 
- Possibilitar programação simples, através do CGI (Common Gateway Interface).

Com a aceitação da linguagem HTML e o crescimento da Web, o mercado passou a necessitar de características que o HTML não possuía. Furgeri (2001) aponta as seguintes limitações:

- Qualidade de apresentação dos documentos: as principais versões da linguagem HTML eram muito restritas com relação ao tamanho e tipo de letras utilizadas (fontes de código), posicionamento dos objetos na tela e outros fatores que faziam com que a qualidade final, no sentido da apresentação visual, fosse prejudicada. Surgiu então, o HTML dinâmico e a folha de estilo CSS (Cascading Style Sheets), que tornou possível definir exatamente a posição de uma imagem na tela, a sobreposição de imagens, a aplicação de textos sobre imagens, possibilitando com isso melhorar a qualidade de apresentação dos documentos.

- Conjunto de marcas fixo: quem produz um documento HTML fica restrito a utilizar apenas as marcas que fazem parte da linguagem. Esse fator restringe o significado das informações armazenadas no documento.

- Informações do documento não possuem significado: esta é a maior restrição da linguagem HTML - ela não consegue dar significado ao conteúdo do texto. Esta limitação faz com que as ferramentas de busca encontrem um grande número de itens que não é de interesse do usuário; além de dificultar o trabalho humano, praticamente não permite que computadores troquem informações entre si de maneira "inteligente", impossibilitando que programas de computador se comuniquem. Bosak (1997) chama esta limitação de falta de extensibilidade.

- Diferenças físicas de hardware: devido à grande variedade de sistemas de computadores, com diferentes recursos de hardware, cada um reproduz o documento HTML de maneira diferente.

- Os documentos HTML não são reutilizáveis: O conteúdo de um documento HTML não pode ser utilizado, nem total, nem parcialmente, em um outro documento HTML, a não ser que seja feita uma cópia para ser depois inserida. Não existem formas de ligação para que seja possível exibir, na mesma tela do navegador, o conteúdo de dois ou mais documentos HTML, formando um único documento. 
Além da falta de extensibilidade, Bosak (1997) aponta outras duas limitações: a falta de estrutura, isto é, não suportar a especificação das estruturas necessárias para representar esquemas de banco de dados ou hierarquias da orientação a objetos e a falta de validação, isto é, não suportar a especificação de uma linguagem que possa verificar a validade das estruturas de dados.

Estas limitações levaram o grupo de trabalho W3C a desenvolver o XML como um padrão para criar linguagens de marcação, baseado no SGML. Light (1999) afirma que XML é um subgrupo de SGML e descreve em detalhes as diferenças entre SGML e XML. De acordo com Rabarijoana (2000), a linguagem XML permite aos usuários:

- Definir seus próprios elementos e atributos;

- Extrair dados de um documento;

- Definir a estrutura dos dados e estrutura dos documentos em qualquer nível de complexidade;

- Fazer aplicações que validem a estrutura dos documentos. Qualquer documento XML pode conter uma descrição opcional da sua gramática para uso em aplicações que façam a verificação da estrutura.

Para entender e comparar os temas a serem estudados nas próximas seções será utilizado o diagrama representado na figura 3.2. A figura 3.3 representa um documento HTML e a figura 3.4 representa um documento XML, baseados no mesmo diagrama.

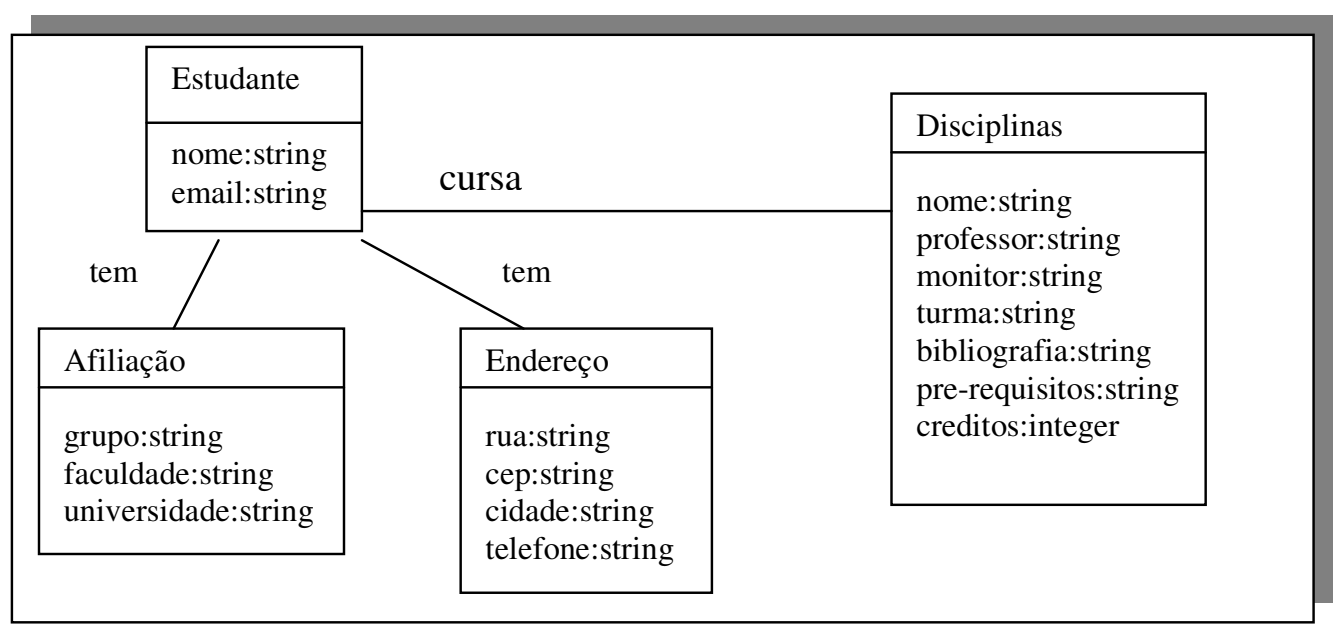

Fig. 3.2 - Modelo de classes para estudante e disciplinas 


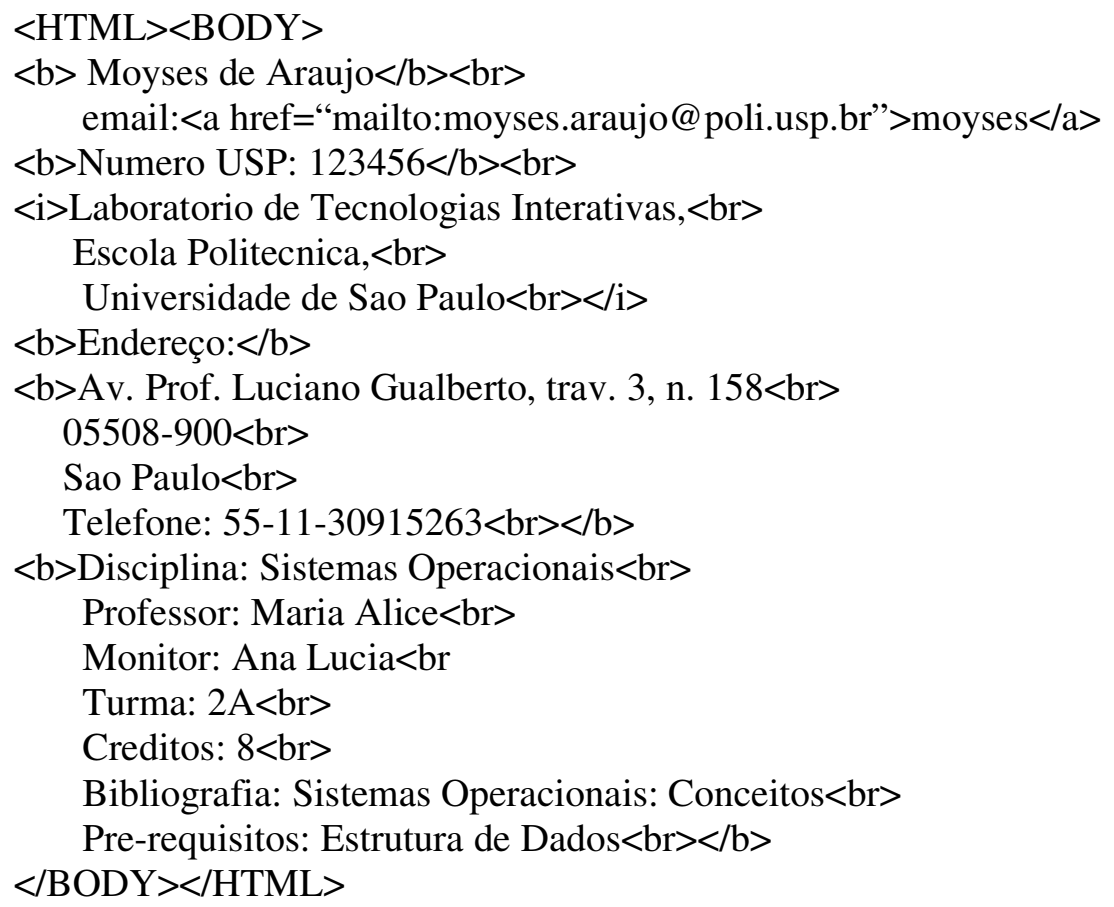

Fig. 3.3 - Codificação de um documento em HTML

Segundo Daum e Udo (2002), XML é uma linguagem de marcação, ou seja, um documento pode ser estruturado com a ajuda de elementos de marcação sintática, semelhantes aos que são usados na HTML. Moultis e Kirk (2000) ressaltam que em XML, um elemento é algo que descreve um dado. Um elemento é diferente de uma marca usada em HTML, pois esta linguagem realmente descreve a marca e não o conteúdo. Por exemplo, a marca $<b>$ em HTML descreve que o texto deve ser marcado como negrito. Em XML, entretanto, os elementos são identificáveis por marcas de início e fim, que são apenas contêineres de armazenamento de dados.

O elemento, delimitado por <estudante > e </estudante>, guarda todo o conteúdo do documento da classe "estudante". Todos os demais elementos são subelementos aninhados sob o elemento <estudante>. Os elementos são criados conforme as necessidades do desenvolvedor do documento, eliminando a restrição imposta pelo HTML, onde apenas as marcas definidas pela linguagem podem ser usadas. 


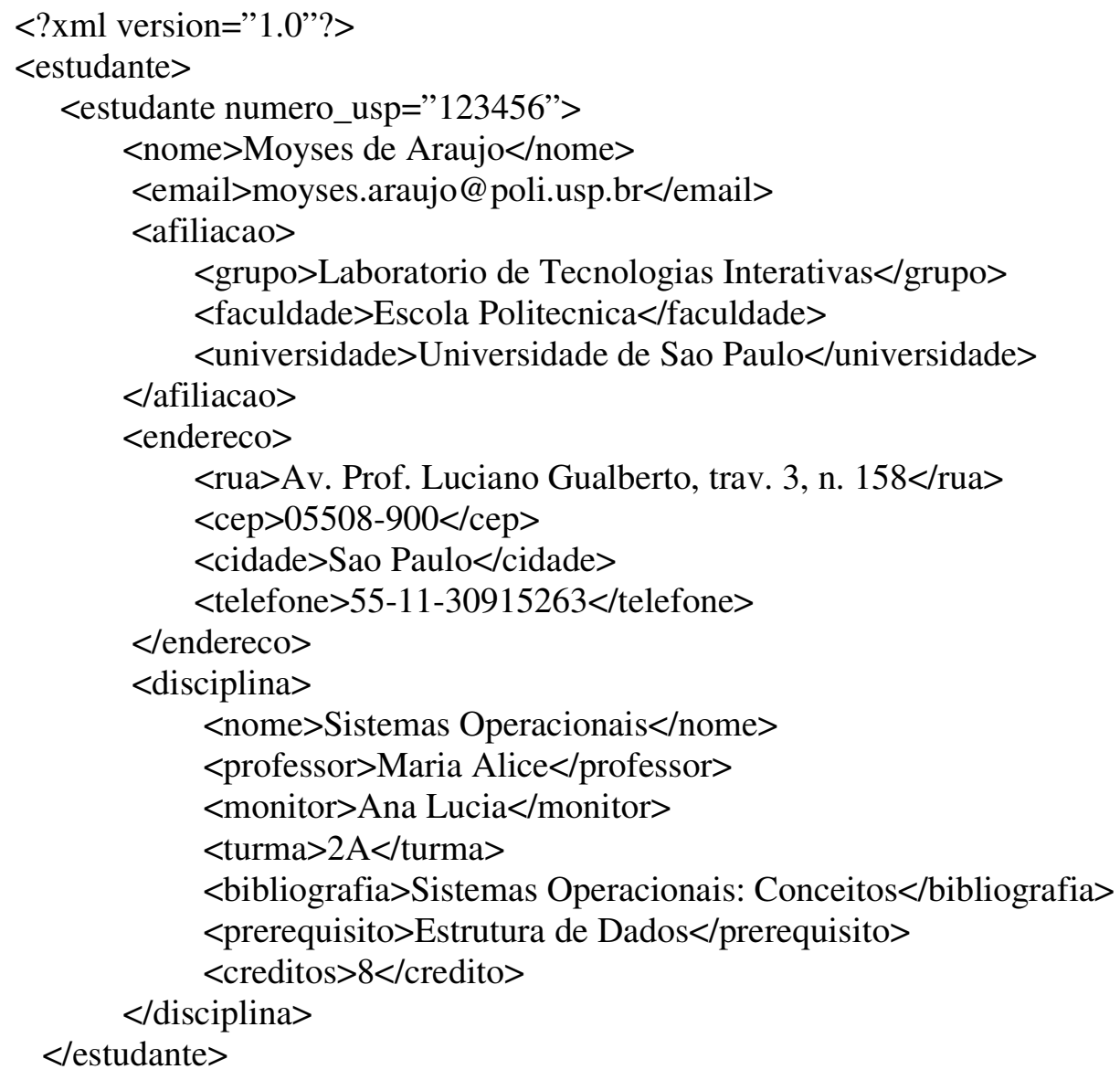

Fig. 3.4 - Codificação de um documento em XML

Os atributos são fontes de informações adicionais sobre um elemento e sempre precisam ter um valor, e o valor sempre precisa estar cercado por apóstrofos ou aspas. Esta facilidade de criar nomes de elementos livremente, gera alguns problemas, pois um mesmo nome de elemento pode ser usado por diferentes pessoas, para diferentes finalidades.

No exemplo da figura 3.4 o elemento <disciplina> representa a matéria que o estudante está cursando. Em outro documento, este mesmo elemento pode ter outro significado. Se estes documentos forem compartilhados, pode ocorrer colisão de nomes de elementos. Para evitar este tipo de confusão, criou-se o conceito de namespace em XML, que é uma coleção de nomes, usados em um documento XML como elementos e atributos, identificados por um URI (Universal Resource 
Identifier). A especificação completa sobre namespace em XML encontra-se em Bray et al. (1999).

Estes elementos permitem extrair dados dos documentos. Podemos realizar pesquisas do tipo "Encontrar todos os estudantes do Laboratório de Tecnologias Interativas" ou "Quais estudantes cursam a disciplina Sistemas Operacionais".

A linguagem XML preserva as informações úteis e torna o documento mais “inteligente", criando uma estrutura que mostra claramente qual é o significado das informações.

Segundo McGrath (1999), os documentos são compostos de três componentes distintos:

- Conteúdo de dados: as palavras propriamente ditas;

- Estrutura: o tipo de documento e a organização de seus elementos;

- Apresentação: a forma como as informações são apresentadas ao leitor.

A idéia central defendida pelos criadores da XML é que benefícios significativos são adicionados ao documento, quando estes três aspectos podem ser mantidos e manipulados separadamente. No exemplo, podemos verificar facilmente a estrutura e o conteúdo do documento XML, enquanto que em HTML observa-se apenas o conteúdo.

Quanto à apresentação, XML utiliza um mecanismo de folhas de estilo chamado XSL (Extensible Style Language), que associa regras de formatação a elementos diferentes em um documento e instrui o navegador sobre como formatar o elemento e seu conteúdo para visualização pelo usuário. Fornece mais recursos que a CSS (da HTML), além de ser compatível com ela. Encontram-se informações detalhadas sobre o XSL em (MOULTIS; KIRK, 2000) e (McGRATH, 1999). Para validar as estruturas de um documento XML existe um mecanismo para definição de regras que controlam como os documentos estão estruturados. É chamado de DTD (Document Type Definitions - Definição de Tipos de Documentos). A figura 3.5 representa a codificação DTD do documento da figura 3.4. Podem-se observar os seguintes recursos dentro da DTD (MOULTIS; KIRK, 2000): 
- Os tipos de elementos que serão permitidos dentro do documento XML;

- As diversas características de cada tipo de elemento juntamente com os atributos usados com cada elemento e o conteúdo que cada elemento é capaz de ter;

- Quaisquer notações que possam ser encontradas dentro de um documento;

- As entidades que podem ser usadas dentro do documento.

$<$ !ELEMENT estudante (nome, afiliacao,endereco, disciplina)>

$<$ !ATTLIST estudante numero_usp ID \#REQUIRED>

$<$ !ELEMENT nome (\#PCDATA)>

$<$ !ELEMENT email (\#PCDATA) $>$

$<$ !ELEMENT afiliacao (grupo,faculdade, universidade) $>$

$<$ !ELEMENT grupo (\#PCDATA) $>$

$<$ !ELEMENT faculdade (\#PCDATA) $>$

$<$ !ELEMENT universidade (\#PCDATA) >

$<$ !ELEMENT endereco (rua,cep,cidade,telefone) $>$

$<$ !ELEMENT rua (\#PCDATA) $>$

$<$ !ELEMENT cep (\#PCDATA) $>$

$<$ !ELEMENT cidade (\#PCDATA) $>$

$<$ !ELEMENT telefone (\#PCDATA) $>$

$<$ !ELEMENT disciplina (professor, monitor,turma,creditos, bibliografia,prerequisitos)>

$<$ !ELEMENT Professor (\#PCDATA) $>$

$<$ !ELEMENT Monitor (\#PCDATA) >

$<$ !ELEMENT Turma (\#PCDATA) $>$

$<$ !ELEMENT Creditos (\#PCDATA) $>$

$<$ !ELEMENT Bibliografia (\#PCDATA) $>$

$<$ !ELEMENT Pre-requisitos (\#PCDATA) >

Fig. 3.5 - Codificação DTD do documento mostrado na Fig. 3.4 
Um DTD é formado por um arquivo externo, separado do documento XML principal. A estrutura do documento XML é verificada por um programa utilitário denominado XML Parser, que testa se o documento corresponde, ou não, às regras prescritas, conforme pode ser visto na figura 3.6.

Segundo Moultis e Kirk (1999), a flexibilidade do XML permite que os desenvolvedores criem seus próprios conjuntos de elementos, atributos e entidades. Com isto, vários tipos de vocabulários (ou conjunto de componentes XML) podem ser criados como padrões para várias indústrias ou tipos de funções da Web. Um vocabulário XML é um conjunto de elementos e regras para criação de uma determinada estrutura e sintaxe, para atender a uma determinada necessidade.

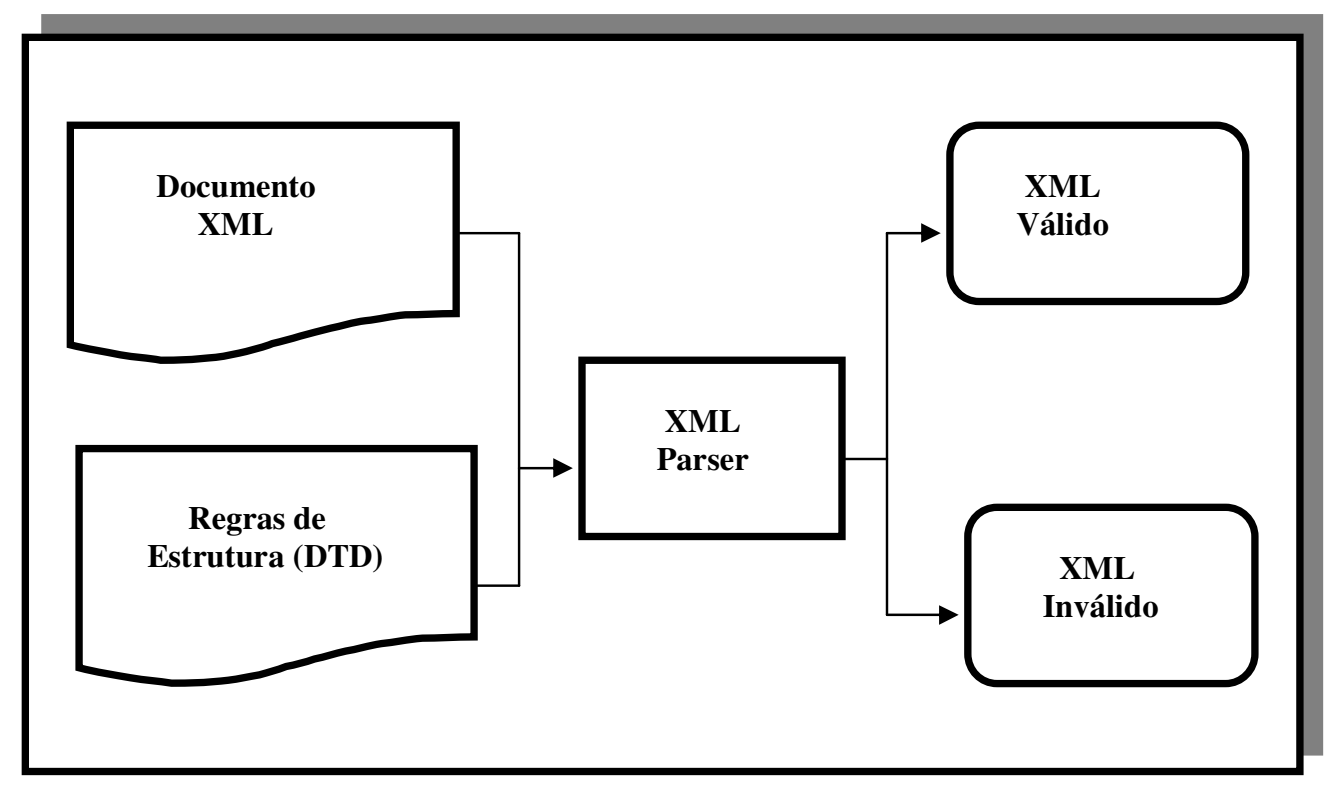

Fig. 3.6 - Verificação da estrutura de um documento XML (McGrath, 1999)

Por exemplo, a MathML (Mathematical Markup Language - Linguagem de Marcação Matemática) é um vocabulário XML, que é uma DTD da XML, que permite ao desenvolvedor XML criar equações matemáticas dentro de uma página Web. A SMIL (Synchronized Multimedia Integration Language - Linguagem de Integração de Multimídia Sincronizada) é um vocabuário que auxilia os desenvolvedores na integração de recursos multimídia em seus sítios. SMIL fornece uma maneira padronizada de descrever multimídia e os vários componentes 
necessários para usar, exibir e manipular recursos multimídia na Internet. Uma descrição detalhada sobre o MathML e SMIL encontra-se em Phillips (2000).

Como ressaltam Daum e Udo (2002) a principal finalidade da XML parece ser a de criar outras linguagens. Ao final do ano 2000, existiam cerca de 500 linguagens de uso especiais baseadas em XML. Algumas delas são orientadas a domínio (verticais) e definem formatos de troca de informações dentro de um setor ou comunidade. Outras, são orientadas a tarefa (horizontais) e atuam como linguagens globais para tarefas técnicas especiais ou orientadas à aplicação, como descrição de serviço, aquisição, gerenciamento do ciclo de vida dos produtos e assim por diante.

O DTD foi o modo padrão para se definir um esquema para um tipo de documento XML. No entanto, surgiram várias linguagens alternativas ao DTD. O motivo está em algumas deficiências do DTD. Daum e Udo (2002) enumeram as seguintes:

- As DTDs não são um documento XML por si só. Isso é um problema, porque as ferramentas XML mais comuns não podem ser usadas para editar, validar e transformar DTDs;

- As DTDs não aceitam tipos de dados no sentido clássico. Não podemos definir, por exemplo, elementos e atributos que precisam ser numéricos ou inteiros. $\mathrm{O}$ conteúdo dos elementos e o valor dos atributos sempre são considerados como sendo cadeias de caracteres. Também não é possível criar tipos de dados definidos pelo usuário, como acontece nas linguagens de programação usuais;

- As DTDs não podem especificar seqüências não-ordenadas de elementos;

- Nas DTDs, todos os elementos são definidos em nível de documento. Isso torna impossível definir elementos sensíveis ao contexto - elementos com o mesmo nome, mas com uma estrutura diferente nos diferentes contextos;

- O suporte para referências cruzadas nas DTDs é fraco. Somente os valores de atributo podem ser usados como chaves, e não é possível gerar uma chave que seja combinação de vários atributos. As chaves sempre são definidas em nível de documento, de modo que não é possível definir o escopo de chaves;

- As DTDs não aceitam namespaces. 
Estas limitações foram suficientes para o W3C iniciar a definição de uma nova linguagem de esquema. Esta linguagem foi chamada de XML Schema.

\subsubsection{XML Schema}

O principal objetivo da linguagem XML Schema é descrever a estrutura, o conteúdo, restrições e os tipos de dados dos vários elementos e atributos de um documento XML. XML Schema pode ser considerado um conjunto de DTDs, namespaces e tipos de dados (DAUM; UDO, 2002). Seja o exemplo da figura 3.7, onde se apresenta um trecho de um documentoXML.

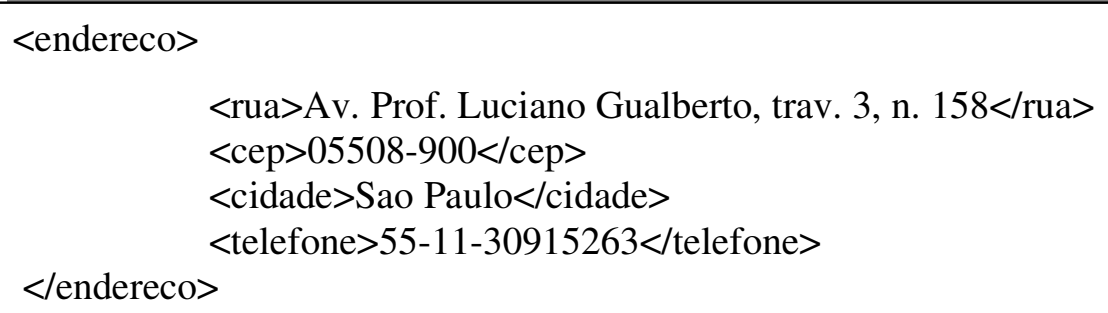

Fig. 3.7 - Parte de um documento XML

Estes dados, para serem válidos, devem seguir as seguintes restrições:

- O elemento endereço deve ser composto dos elementos rua, seguido por cep, cidade e telefone;

- O elemento rua é formado por caracteres alfanuméricos;

- O elemento cep é formado por cinco dígitos seguidos por um traço e mais três dígitos;

- O elemento cidade é formado por caracteres alfanuméricos;

- O elemento telefone é formato por até 13 dígitos, podendo conter traços entre eles.

Todas estas restrições podem ser expressas usando XML Schema, pois sua especificação define vários tipos de dados tais como cadeias (strings), inteiros, lógicos ou booleanos, datas, tempos (time) entre outros. XML Schema também permite a criação de novos tipos de dados. 
Outro ponto importante é que a especificação XML Schema assume que, pelo menos dois documentos XML são utilizados: um documento instância e, pelo menos um, documento esquema. O documento instância contém a informação propriamente dita e o documento esquema descreve a estrutura e o tipo dos elementos do documento instância. A distinção entre instância e esquema é semelhante à distinção entre objeto e classe em linguagens de programação orientadas a objetos. Uma classe descreve um objeto, assim como um esquema descreve um documento instância. (Box et al.,(2000) apud Braganholo (2001)).

A figura 3.8 mostra uma parte da codificação do XML Schema da figura 3.4. Comparando-se a codificação DTD com a XML Schema verifica-se, por exemplo, que o DTD especifica o valor de telefone apenas como caracteres. Usando XML Schema, definiu-se um novo tipo de dado, chamado telType para representar o elemento telefone e suas restrições. Esta característica permite que os documentos XML possam ser validados de maneira mais precisa, e é o grande diferencial sobre as funcionalidades do DTD.

Outra característica importante de XML Schema é o suporte à herança. Podem-se criar novos esquemas, derivados de esquemas existentes, possibilitando melhorias no processo de desenvolvimento de aplicações XML, na manutenção de código e na produtividade dos programadores (ROY; RAMANUJAN, 2001).

XML Schema é integrada com os namespaces do XML, tornando fácil criar elementos e atributos em um namespace. No exemplo, o comando:

<xsd:schema mlns:xsd="http://www/w3.org/2001/XMLSchema">

define um namespace chamado http://www/w3.org/2001/XMLSchema, que é representado pelo nome xsd. Todos elementos e atributos prefixados com xsd pertencem a este namespace. Isto simplifica a criação e validação de documentos XML que usam namespaces múltiplos, definidos por vários XML Schema. (ROY;RAMANUJAN, 2001). 


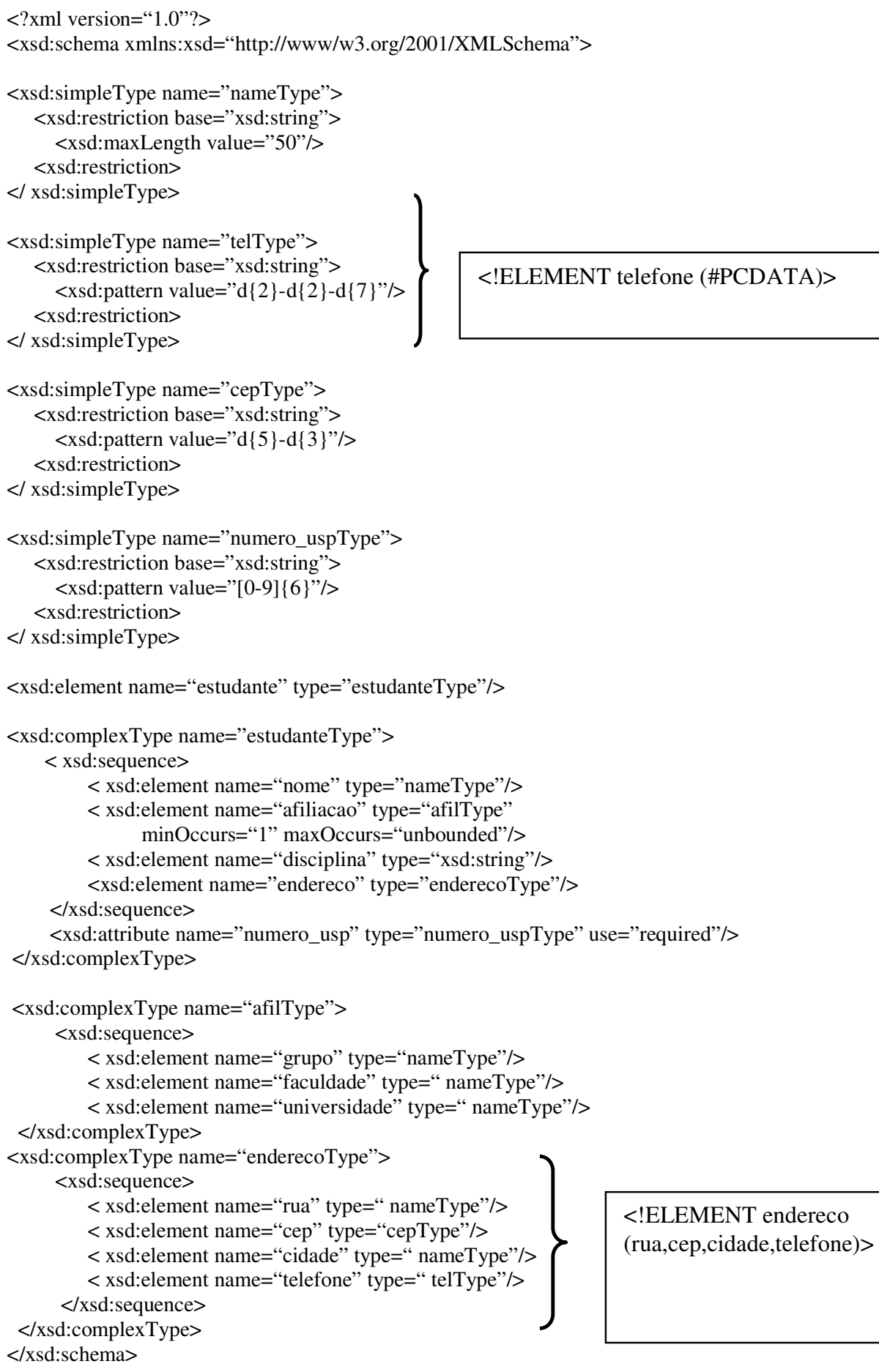

$<$ !ELEMENT endereco (rua,cep,cidade,telefone) $>$

Fig. 3.8 - Parte da codificação em XML Schema da Fig. 3.4 
Outra diferença importante em relação à DTD é que a codificação em XML Schema utiliza a sintaxe XML, simplificando o desenvolvimento das aplicações porque tanto o documento que descreve a estrutura dos documentos, quanto seus respectivos XML Schema, têm a mesma sintaxe (KLEIN, 2001).

Todas estas características tornaram o XML Schema um padrão muito complexo. Fallside (2001) descreve as facilidades deste padrão e procura orientar a criação de esquemas, usando o XML Schema. Thompson et al. (2001) especificam a definição da linguagem e Biron e Malhota (2001) descrevem como criar tipos de dados. Gulbransen (2002) apresenta dois exemplos de aplicação de XML Schema: um para geração de nota fiscais e outro para gerenciamento de recursos humanos.

\subsection{RDF - Resource Description Framework}

Umas das maiores críticas ao XML é que sua especificação não define semântica para as marcas. Segundo Erdmann e Studer (2000), XML permite aos usuários adicionar estruturas arbitrárias em seus documentos, mas não diz nada a respeito do significado destas estruturas. Embora o significado das marcas em um documento XML seja claro para leitores humanos, se estiverem no escopo do conhecimento do leitor, para os computadores elas não significam nada, pois tratam da sintaxe e não da semântica. As DTDs só permitem a descrição do vocabulário e da estrutura de um documento, não permitindo descrever a semântica de um documento XML. Em resumo, falta para o XML um modelo semântico e não é solução para propagar semântica através da Web Semântica. A solução é utilizar o RDF (Resource Description Framework - Estrutura de Descrição de Recursos), que oferece um mecanismo para adicionar semântica em um documento da Web. RDF foi também desenvolvido pelos membros da W3C.

\subsubsection{Conceitos}

Porque é necessário adicionar semântica em um documento da Web?

Como já foi comentado anteriormente, o volume de informações na Web é muito grande, o que torna cada vez mais difícil encontrar a informação desejada através dos atuais mecanismos de pesquisa. Uma solução para este problema é tornar estes mecanismos, e as máquinas, mais "inteligentes”, ou seja, possibilitar que a semântica 
(significado) do conteúdo dos "recursos" (documentos) da Web possa ser entendida pelas máquinas (chamadas de machine-understandable). Neste contexto, "entendida pelas máquinas", significa simplesmente fornecer dados explícitos para as máquinas, de modo que estas possam identificar relações entre os recursos da Web e criar ligações entre eles, que não estavam presentes originalmente.

Para isto é necessário descrever de maneira estruturada a semântica (significado) do conteúdo dos recursos Web para as máquinas. Isto é feito através de metadados. Portanto, RDF é uma forma de descrever os recursos da Web de maneira estruturada utilizando metadados, de modo que as máquinas ajudem os usuários a descobrir recursos na Web, de maneira mais eficaz e eficiente que os mecanismos de busca atuais. Segundo Swick (1999), o RDF fornece uma forma simples de fazer declarações sobre recursos disponíveis na Web.

Moultis e Kirk (1999) destacam que o RDF foi concebido para funcionar com todos os tipos de dados eletrônicos, possibilitando uma variedade de aplicações, entre as quais podemos destacar as seguintes:

- Identificação consistente de direitos autorais, marcas registradas e outras informações de propriedade intelectual em recursos da Web;

- Catalogação avançada de recursos e seus relacionamentos dentro de um único sistema ou entre vários sistemas;

- Pesquisa mais acurada de arquivos de dados, pois os dados em si estão bem identificados;

- Filtragem mais precisa de dados para sistemas de avaliação de conteúdo;

- Capacidade de representar conjuntos inteiros de documentos como um único e grande documento, quando apropriado;

- Estabelecimento de relacionamentos seguros entre documentos e computadores para facilitar o intercâmbio de idéias e de recursos, bem como de comércio eletrônico. 


\subsubsection{Modelo de dados RDF}

Para que os dados possam ser entendidos pelas máquinas, Lassila e Swick (1999) propuseram um modelo de dados para o RDF, consistindo de três tipos de objetos:

- Recursos (Resources): é considerado um recurso, qualquer objeto que possa ser descrito por uma expressão RDF e que tenha um URI como endereço na Web. Por exemplo, pode ser uma página Web como o documento HTML "http://www.w3.org/Overview.html", pode ser parte de uma página, como um elemento específico dentro de um documento HTML ou XML. Um recurso pode ser um sítio completo da Web, ou até um objeto, que não é diretamente acessível pela rede, como um livro impresso;

- Propriedades (Properties): uma propriedade é um aspecto específico, uma característica, um atributo ou uma relação, usado para descrever um recurso. Cada propriedade tem um significado específico que define os valores permitidos, os tipos de recursos que pode descrever e sua relação com outras propriedades;

- Declarações (Statements): um recurso específico, junto com uma propriedade nomeada, mais o valor dessa propriedade para o recurso é uma declaração de RDF. Estas três partes individuais de uma declaração são chamadas respectivamente de sujeito, predicado e objeto. O objeto de uma declaração (o valor da propriedade) pode ser outro recurso, uma cadeia de caracteres, um endereço da Web ou outro tipo de dado definido pela XML.

Resumindo estes conceitos, Iannella (1999) afirma que um recurso é descrito através de uma coleção de propriedades chamada Descrição RDF. Cada uma destas propriedades tem um tipo e um valor. A figura 3.9 ilustra estes conceitos. Complementando estes conceitos, Miller (1998) afirma também que o tipo de propriedade expressa relações de valores associados com recursos. Em RDF, valores podem ser de natureza atômica (números, cadeia de caracteres etc.) ou outros recursos que podem ter suas próprias propriedades.

Para demonstrar a aplicação do modelo de dados do RDF, consideremos as seguintes declarações:

1. O estudante da disciplina Sistemas Operacionais é Moysés de Araujo. 
2. Moysés de Araujo é estudante da disciplina Sistemas Operacionais.

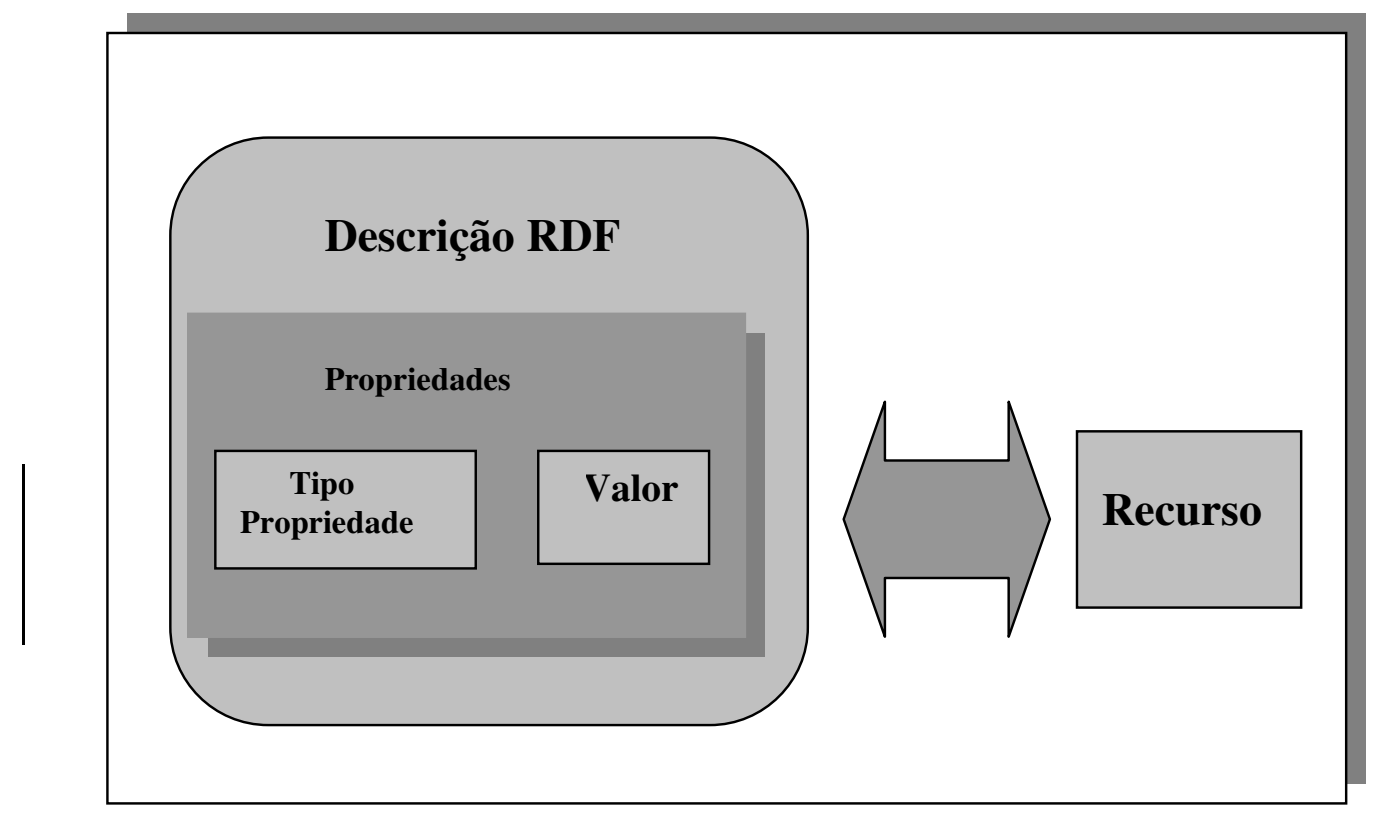

Fig. 3.9 - Modelo RDF - Iannella (1999)

Para os humanos, estas declarações têm o mesmo significado. Para uma máquina estas declarações são completamente diferentes, pois estas não conseguem extrair significado de construções diferentes. Usando o modelo de recursos, os tipos das propriedades e os valores correspondentes podem expressar a semântica de uma declaração para que possa ser codificada e entendida pela máquina.

Na declaração "Moysés de Araujo é estudante de Sistemas Operacionais", o sujeito é "Moysés de Araujo", pois estamos falando/descrevendo alguma coisa sobre ele, "é estudante de" é o predicado, e o objeto é "Sistemas Operacionais". Supondo que Moysés de Araujo tenha na Web uma página http://www.moyses.com.br, tem-se na tabela 3.1, o modelo de uma declaração RDF.

Uma declaração RDF pode ser representada na forma de uma tripla composta de predicado, sujeito e objeto através da notação (predicado, [sujeito], [objeto]) ou por grafos, também chamados de diagramas de nós e arcos. Os recursos aparecem como elípses, as propriedades aparecem nos arcos e os valores das propriedades em retângulos. 
Seja a declaração:

"Moysés de Araujo é estudante de Sistemas Operacionais, cujo livro é Sistemas Operacionais: Conceitos, e o autor é Silberchatz".

Tabela. 3.1 - Modelo de uma declaração RDF

\begin{tabular}{|l|l|}
\hline Recurso (Sujeito) & $\begin{array}{l}\text { Moysés de Araujo - } \\
\text { http }: / / \text { www } \cdot \text { moysesaraujo } \cdot c o m \cdot b r\end{array}$ \\
\hline Propriedade (Predicado) & Estudante \\
\hline Valor (Objeto) & Sistemas Operacionais \\
\hline
\end{tabular}

Neste caso queremos descrever o objeto Sistemas Operacionais, que neste contexto é o recurso a ser descrito, que tem como tipo de propriedade livro e autor. A figura 3.10 representa o grafo desta declaração.

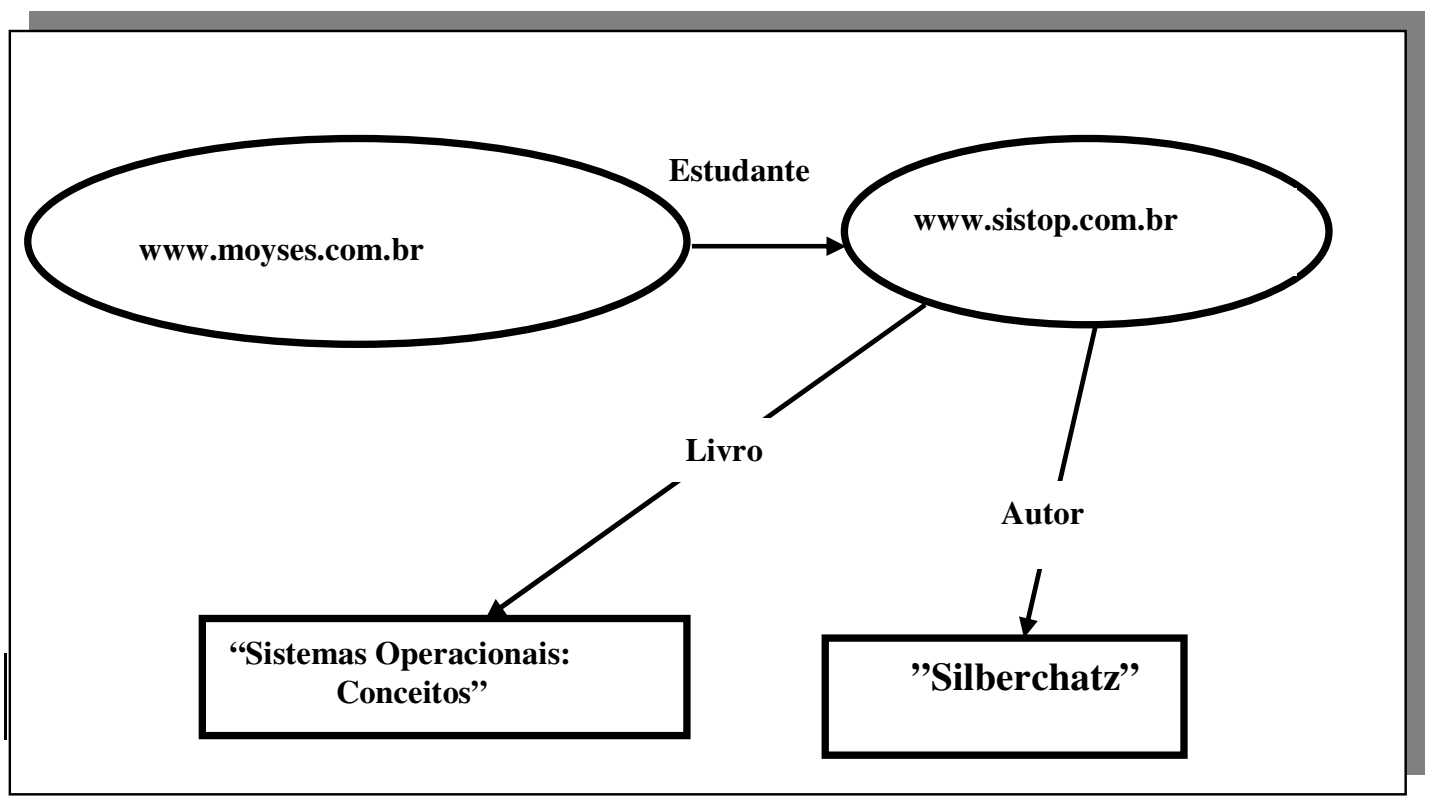

Fig. 3.10 - Grafo da declaração

Portanto, um recurso é um objeto do qual queremos fazer uma descrição e nem sempre é o sujeito de uma declaração. Aqui, estamos supondo que a disciplina 
Sistemas Operacionais tem um sítio http://www.sistop.com.br. A figura 3.10 tem as seguintes triplas associadas:

(estudante,[http://www.moyses.com.br], "http://www.sistop.com.br")

(livro,[http://www.sistop.com.br], "Sistemas Operacionais: Conceitos”)

(autor,[http://www.sistop.com.br], "Silberchatz")

\subsubsection{Sintaxe RDF}

A sintaxe RDF é definida em (LASSILA, 1999) e é baseada em XML. Esta escolha permite que as declarações RDF sejam representadas como um elemento XML e possam ser incluídas diretamente dentro de um documento Web, bem como ser transferida para outros meios. Duas sintaxes em XML são propostas para expressar os modelos RDF:

- Serializada: que expressa toda a potencialidade do modelo RDF;

- Abreviada: que inclui construtores adicionais para expressar, de forma mais compacta, o modelo RDF.

A codificação RDF do exemplo da figura anterior está representada na figura 3.11.

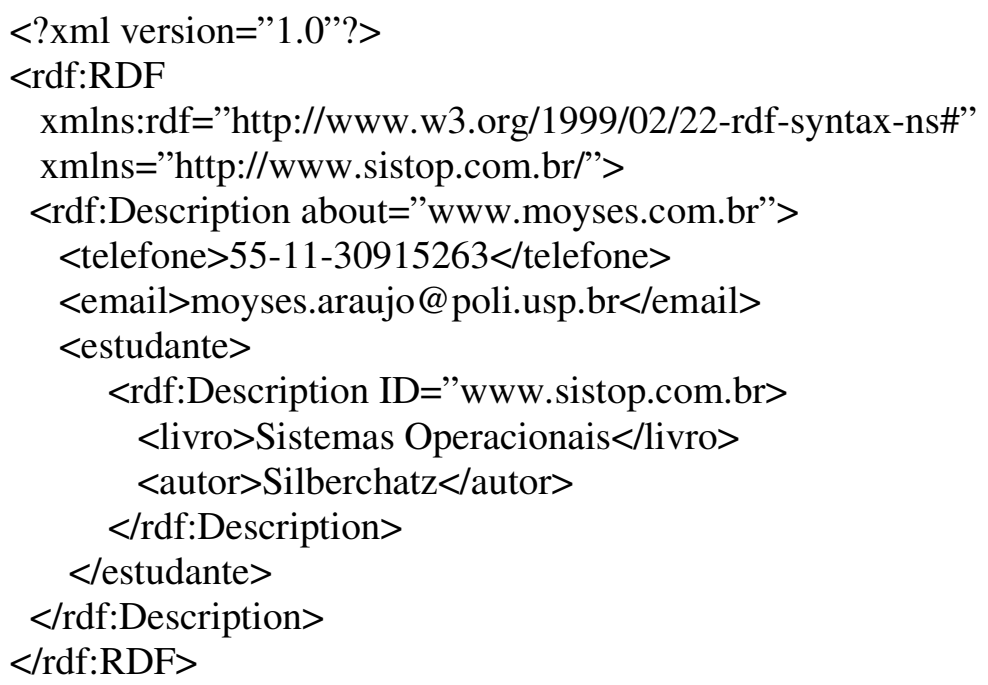

Fig. 3.11 - Codificação RDF serializada em XML 
As marcas definidas para RDF são iniciadas com o identificador $r d f$ :, que foi atribuído no URI do namespace RDF. O elemento Description contém a identificação do recurso a ser descrito e uma lista de propriedades que se aplicam a esse recurso. A identificação do atributo é feita através dos atributos about e ID. O atributo about indica que o sujeito é um recurso externo que já existe. Se o recurso não existir, utiliza-se o atributo $I D$. As propriedades do recurso que está sendo descrito são telefone e email. O elemento estudante indica a relação entre os recursos. O próximo elemento Description descreve o recurso Sistemas Operacionais e suas propriedades.

Uma maneira de evitar conflitos quando necessitamos mesclar descrições RDF, é utilizar as facilidades do namespace disponíveis no XML. A figura 3.12 representa a utilização de namespaces. Os prefixos a: e so: identificam a localização dos vocabulários que definem os elementos utilizados e indicam que a declaração do namespace é um identificador global, único, para um esquema particular de metadados, que é usado para definir o uso das propriedades telefone, email, livroe autor.

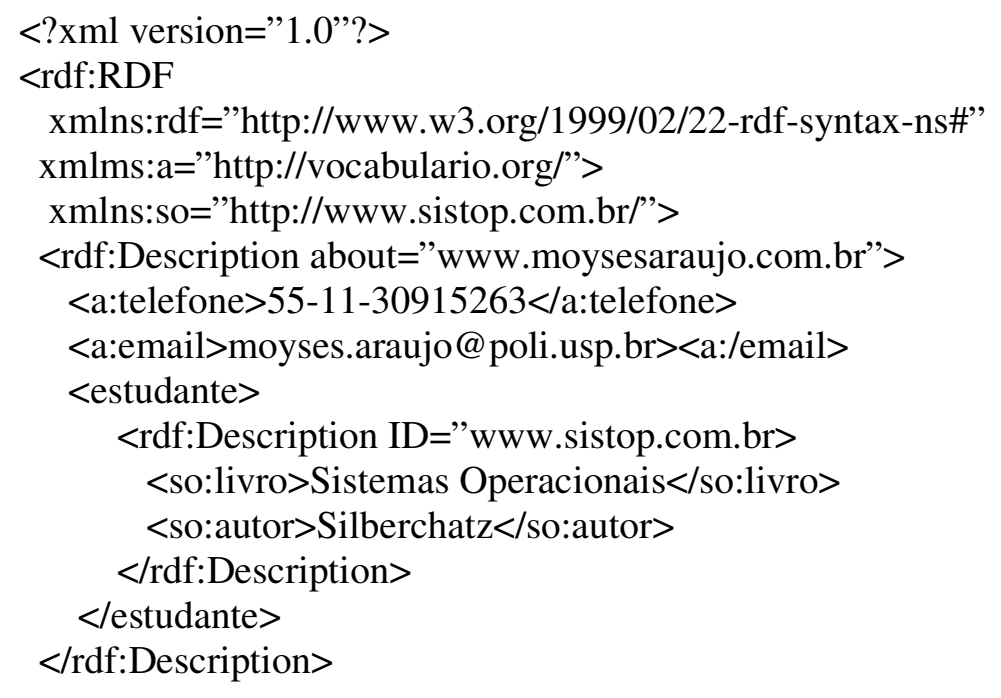

Fig. 3.12 - RDF e namespace 


\subsubsection{Dublin Core e RDF}

RDF é a base para processamento de metadados. Metadados são dados sobre dados. Quando aplicados especificamente no contexto do RDF, os metadados são dados sobre recursos da Web. Descrever metadados de forma consistente é o grande objetivo do RDF (MOULTIS; KIRK, 2000).

O Dublin Core (Dublin Core Metadata Initiative, 1999) é uma lista de quinze elementos de metadados, que foram desenvolvidos, originalmente, para aperfeiçoar a descoberta de recursos na Web e desenvolver mecanismos para descrever as relações entre tais recursos. O Dublin Core não possui uma sintaxe específica e não é um componente direto do RDF, porém é um dos principais esquemas testados com o RDF. Alguns elementos e sua descrição estão em (MOULTIS; KIRK, 2000):

- Title: o título que um autor ou editor atribui a um trabalho;

- Subject: - sobre o que trata o trabalho; definido como palavras-chave ou informações;

- Creator: a pessoa ou a organização responsável pelo conteúdo intelectual de um recurso;

- Publisher: - um agente ou agência responsável pela disponibilização do trabalho em sua forma atual; normalmente, uma editora ou instituição educacional;

- Date: data associada com a criação ou disponibilidade do recurso.

Normalmente, o Dublin Core é usado no RDF através de namespace. Como exemplo, consideremos a seguinte declaração:

“A página http://www.moysesaraujo.com.br foi criada por Moysés de Araujo".

A figura 3.13 apresenta a codificação RDF com Dublin Core.

Neste exemplo, embora não descrito na declaração usou-se os tipos de propriedade Creator, Title e Date do namespace Dublin Core, explicitados pelo prefixo DC. 


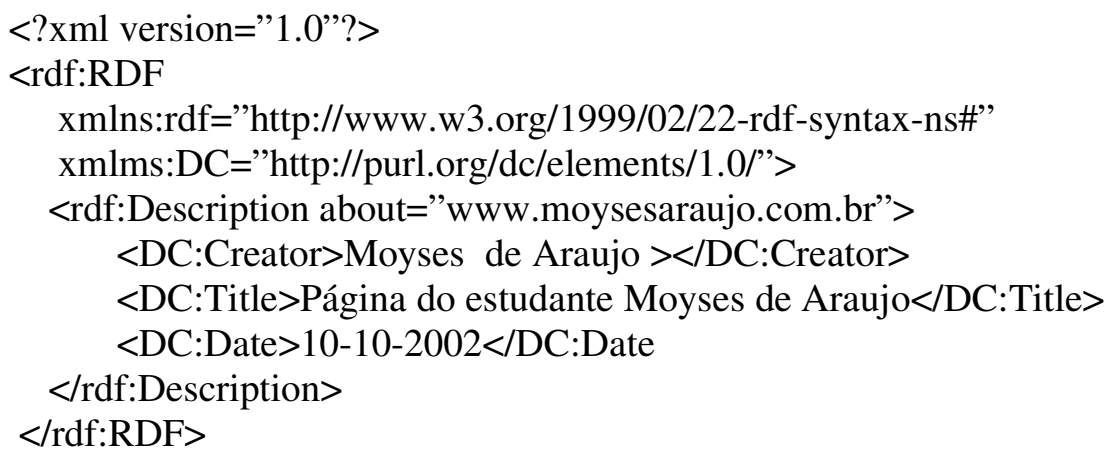

Fig. 3.13 - Codificação RDF com Dublin Core

\subsubsection{Contêiner RDF}

Freqüentemente, é necessário fazer declarações a respeito de uma coleção de recursos, por exemplo, listar os estudantes de um curso ou participantes de um projeto. Para esta tarefa podemos fazer uma declaração para cada elemento da coleção; entretanto, se desejarmos fazer uma declaração a respeito de todos os participantes do curso ou projeto, deve-se usar um contêiner. RDF define três tipos de contêiners que podem representar uma coleção de recursos ou literais. Decker et al. (2000) e Lassila e Swick (1999) descrevem estes três recursos:

- Bag (Bolsa): são listas não ordenadas de recursos ou literais. São usadas para declarar que uma propriedade tem vários valores e que a ordem em que estes valores aparecem não tem nenhum significado, podendo aparecer, inclusive, duplicados;

- Sequence (Sequiência): são listas ordenadas de recursos ou literais. São usadas para declarar que uma propriedade tem vários valores, e que a ordem em que estes valores aparecem, tem significado. Podem ser usadas, por exemplo, para preservar uma ordem alfabética de valores, que podem aparecer duplicados;

- Alternative (Alternativa): é uma lista de recursos ou literais de possíveis valores de uma propriedade, da qual uma é selecionada. Poderia ser usada, por exemplo, para escolher a melhor alternativa de vôo entre São Paulo e Rio de Janeiro. 
Para representar uma coleção de recursos, o RDF usa um recurso adicional que identifica uma coleção específica (uma instância de uma coleção, na terminologia da modelagem de objetos). Este recurso deve ser declarado como sendo uma instância de um dos tipos de contêiner definidos. Esta declaração é feita com a propriedade type.

Por exemplo, consideremos a seguinte declaração:

“Os estudantes de Sistemas Operacionais são Vera, Graça, Ana Lucia e Moysés"

A figura 3.14 representa o grafo de uma coleção RDF do tipo $r d f: B a g$ e a figura 3.15, a sua codificação RDF.

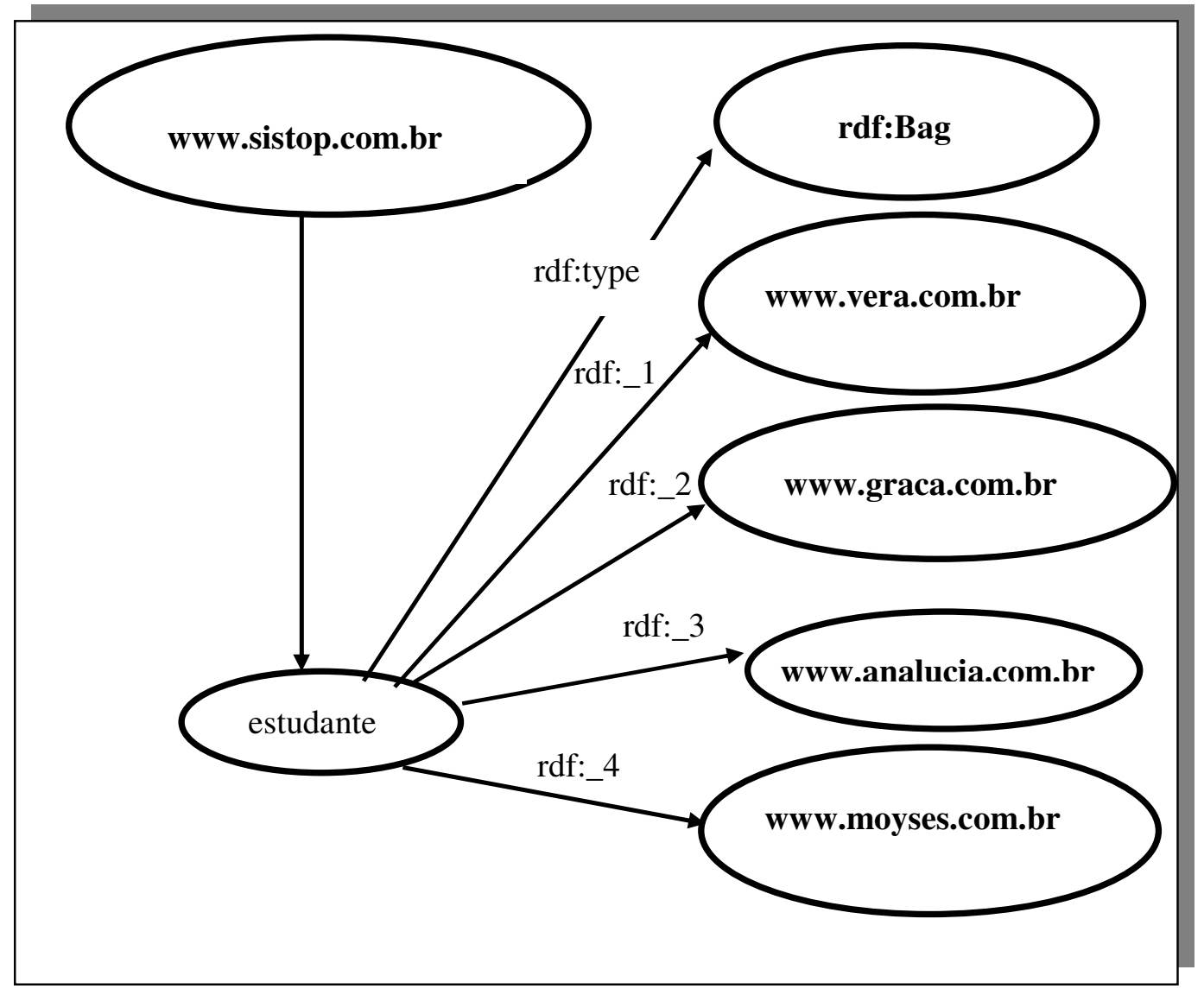

Fig. 3.14 - Grafo RDF - Contêiner Bag

Neste exemplo, temos o conjunto de alunos que estudam Sistemas Operacionais. A declaração rdf:type especifica o tipo de coleção, no exemplo, uma instância de 
rdf:Bag. Cada membro da coleção é simplesmente rotulado por rdf:_1, rdf:_2, rdf:_3, rdf:_4,..., rdf:_n.

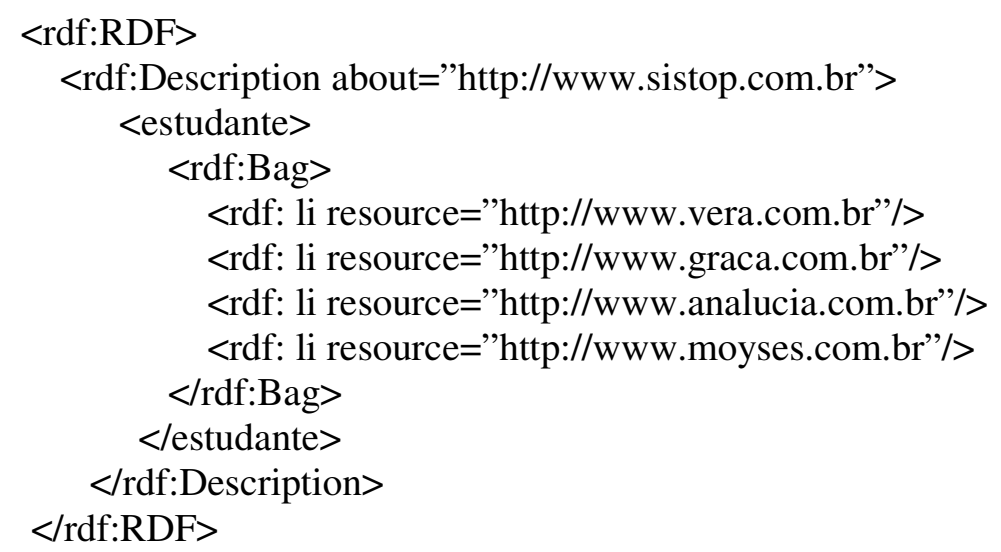

Fig. 3.15 - Codificação RDF - Contêiner Bag

Estes são os conceitos básicos de RDF para a compreensão deste trabalho. Descrições detalhadas sobre a serialização da sintaxe, reificação em RDF, a gramática, modelo formal e outros recursos do RDF encontra-se em (DAUM; UDO, 2002), (CHAMPIN, 2001), (LASSILA; SWICK, 1999), (MOULTIS; KIRK, 2000), (PHILLIPS, 2000).

\subsubsection{RDF Schema}

O RDF Schema é o mecanismo que veio complementar o modelo RDF básico na tarefa de perseguir interoperabilidade semântica no contexto Web. Segundo Brickley e Guha (2000), o RDF define um modelo simples para descrever relacionamentos entre recursos em termos de propriedade e valores. Propriedades RDF podem ser vistas como atributos de recursos. Assim sendo, correspondem a pares (atributo, valor) tradicionais. As propriedades RDF também representam relacionamentos entre recursos. Deste modo, o modelo de dados RDF pode representar um diagrama Entidade-Relacionamento. Entretanto, o modelo de dados RDF não fornece um mecanismo para declarar essas propriedades, nem fornece mecanismos para definir os relacionamentos entre essas propriedades e outros recursos. Este papel é representado pelo RDF Schema. 
O RDF Schema fornece um sistema de tipos básicos para uso em modelos RDF, que aliado aos mecanismos de reificação e namespaces, permite que comunidades de descrição de recursos possam criar e compartilhar seus próprios vocabulários, que estão definidos em um namespace RDF chamado rdfs. (rdfs=http://www.w3.org/2000/01/rdf-schema\#). Um RDF Schema representa a definição de um conjunto de propriedades com a semântica correspondente de um recurso, como por exemplo título, autor, assunto, tamanho e cor. Além disso, provê meios para definir o tipo do recurso, como por exemplo páginas Web, pessoas, bancos de dados ou conceitos abstratos. Em uma abordagem orientada a objetos, os tipos de recursos e as propriedades de um RDF Schema podem ser interpretados como as classes e seus atributos, respectivamente.

Segundo Brickley e Guha (2000), o sistema de tipos do RDF Schema é similar ao tipo de dados de linguagens de programação orientada a objetos, como Java. Entretanto, RDF difere de tais sistemas, pois, ao invés de definir uma classe em termos de propriedades e suas instâncias, um RDF Schema define as propriedades em termos das classes de recursos aos quais elas se aplicam. Esta abordagem, centrada na propriedade, facilita a descrição de recursos existentes na Web, principal objetivo da arquitetura RDF.

Como tudo em RDF é considerado um recurso e o RDF Schema estabelece que eles podem ser organizados em classes, os recursos foram agrupados em classes, propriedades e restrições, para facilitar a descrição. A figura 3.16 representa os conceitos de classe, subclasse e recurso. Uma classe é representada por um retângulo arredondado, um recurso é representado por um ponto grande. As setas são desenhadas de um recurso para a classe que os define. Uma subclasse é representada por um retângulo arrendondado dentro de outro (a superclasse). Na figura 3.16 a classe Property tem uma subclasse Constraint Property.

A figura 3.17 mostra a hierarquia entre classes, através de um grafo. A seta com o indicativo " $\mathrm{S}$ ", parte do nó que representa a subclasse e vai ao nó que representa a sua respectiva classe, indicando que há entre elas uma propriedade $r d f$ s:subClass $O f$; por exemplo, na figura 3.17, uma seta rotulada "s" sai de Class e atinge 
Resource. A seta com o indicativo " $t$ ", sai do nó que representa o recurso, indo ao nó da sua instância, indicando que há entre eles uma propriedade rdf:type .

Por exemplo, há uma instância da classe Class, denominada Property, e label, comment, isDefinedBy, seeAlso, subclassof e subPropertyof são instâncias de Property .

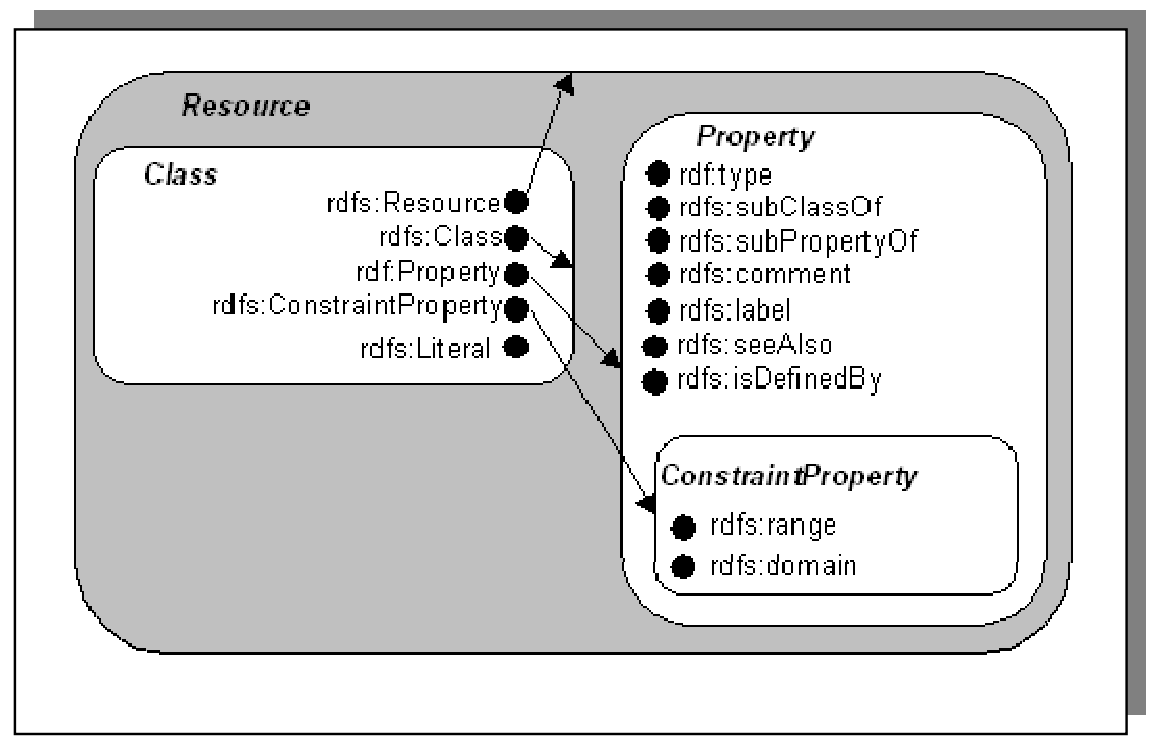

Fig. 3.16 - Conceito de classe, subclasse e recurso no modelo RDF Schema (BRICKLEY; GUHA, 2000)

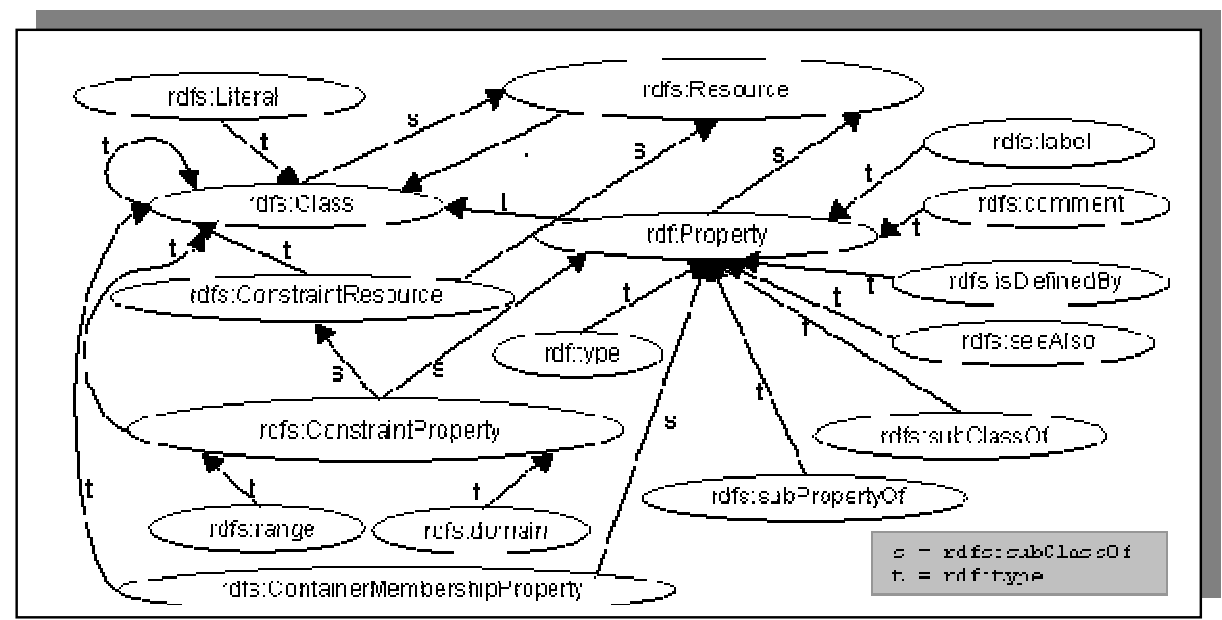

Fig. 3.17 - Hierarquia de classes do modelo RDF Schema (BRICKLEY; GUHA, 2000) 


\subsubsection{Classes}

Um dos objetivos do RDF Schema é permitir a definição de subclasses que herdam as definições de uma ou mais classes ascendentes, permitindo a implementação de herança múltipla. Esta propriedade incorpora uma grande extensibilidade ao modelo RDF, pois se pode herdar definições de esquemas já existentes, especializando os metadados de uma determinada comunidade, promovendo assim o reuso e o compartilhamento destes esquemas. Os recursos são classes definidas como parte do vocabulário de RDF Schema:

- rdfs:Resource: representa a classe genérica no modelo RDF Schema. Todo objeto descrito por expressões RDF é um recurso;

- rdfs:Class: é subclasse de $r d f s:$ Resource e representa o conceito genérico de tipo ou categoria, similar à noção de classe em orientação a objetos;

- rdf:Property: é subclasse de rdfs:Resource e representa um aspecto do recurso sendo descrito, similar à noção de atributo em orientação a objetos.

\subsubsection{Propriedades}

As propriedades são instâncias da classe $r d f$ :Property e fornecem mecanismos para expressar relacionamentos entre classes e suas instâncias ou superclasses. As principais propriedades são:

- rdf:type: denota que um recurso é instância de uma classe, possuindo todas as suas características. Um recurso pode ser instância de mais de uma classe.

- rdfs:subClass Of: - denota a relação de subclasse/superclasse entre duas classes. Esta propriedade é a principal responsável pela herança múltipla, em virtude de sua característica de transitividade. Somente instâncias de $r d f s$ :Class podem ter a propriedade $r d f s: s u b C l a s s O f$. O valor dessa propriedade é sempre do tipo rdf:type rdfs:class. Uma classe pode ser subclasse de mais de uma classe. Porém existe uma restrição, que evita grafos de herança cíclicos. Uma classe não pode ser subclasse de si mesma, e nem de uma de suas subclasses;

- rdfs:subPropertyOf: denota a relação de especialização entre duas propriedades, possibilitando a definição de uma hierarquia de propriedades; 
- rdfs:seeAlso e rdf:isDefinedBy: a propriedade seeAlso pode ser usada para apontar descrições alternativas de um recurso, pois um dado recurso pode estar descrito em mais de um local na Web. A subpropriedade isDefinedBy aponta para a descrição original ou autoria do recurso;

- rdfs:label e rdfs:comment: - são utilizadas para fins de documentação, ou seja, para descrever os recursos de uma forma mais compreensível. A propriedade rdfs:label é usada para dar um nome compreensível para um recurso e rdsf:comment é usado para dar uma descrição mais detalhada de um recurso.

\subsubsection{Restrições}

O RDF Schema permite associar restrições junto às propriedades de um recurso. As restrições são as seguintes:

- rdfs:ConstraintResource e rdfs:ConstraintProperty: são superclasses de $r d f s$ :domain e de $r d f s:$ range. São utilizadas para informar que existem restrições a respeito de algum recurso;

- rdfs:range: é uma instância da classe rdfs:ConstraintProperty e restringe os valores que uma propriedade pode assumir. Por exemplo, a propriedade livro deve ter como rdfs:range, a classe String. Uma propriedade admite somente um rdfs:range;

- rdfs:domain: é uma instância da classe $r d f s$ :ConstraintProperty e especifica a qual classe uma propriedade se aplica. Por exemplo, a propriedade livro pode ter como rdfs:domain a classe Sistemas Operacionais. Uma propriedade pode ser aplicada a mais de uma classe.

Para exemplificar os conceitos do RDF Schema, utiliza-se o modelo de classes a figura 3.18. A figura 3.19 mostra a codificação RDF Schema. 


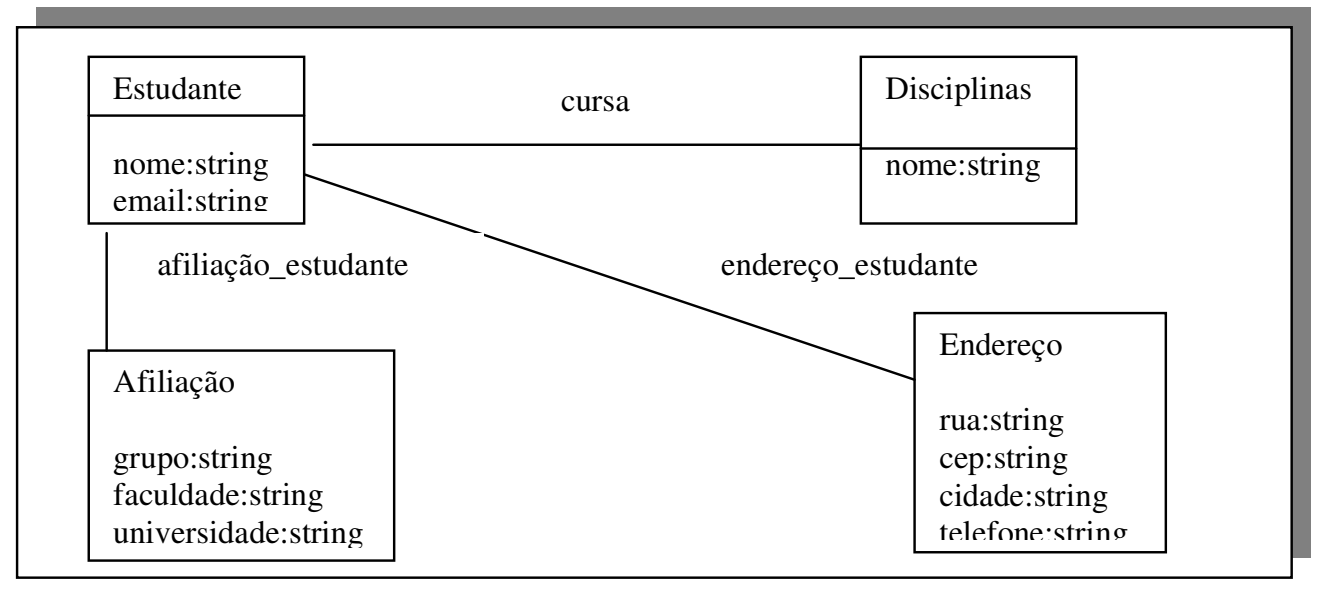

Fig. 3.18 - Modelo de classes

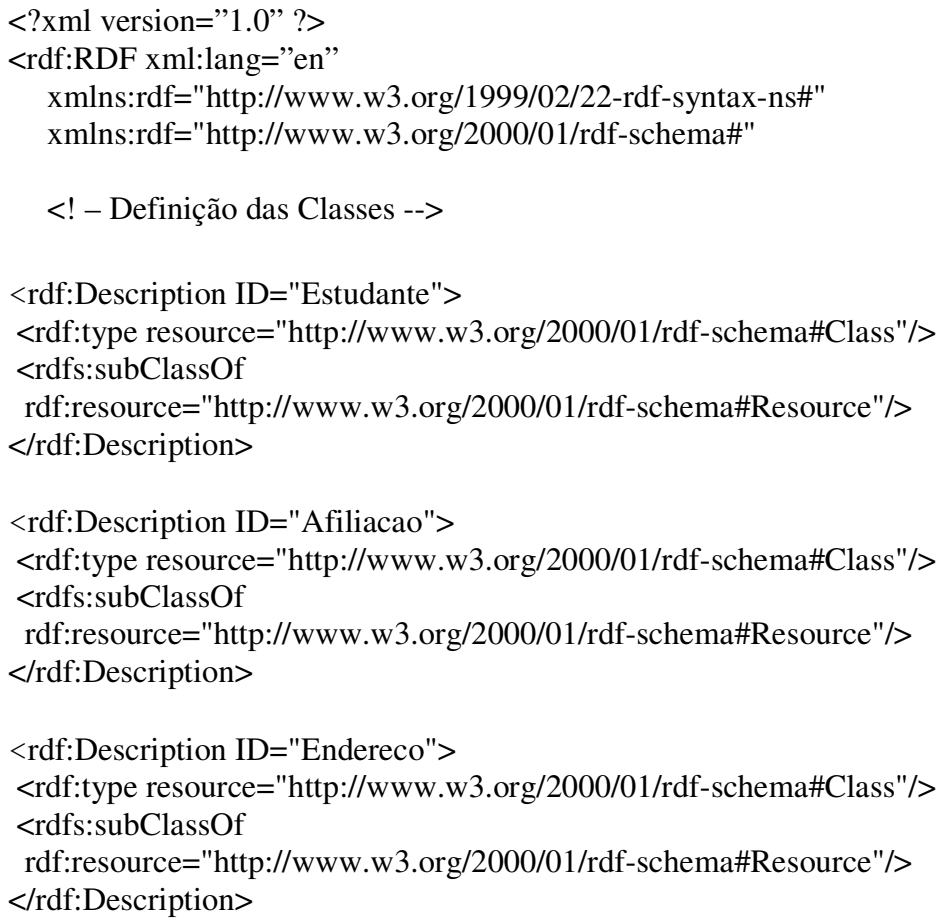

Fig. 3.19 - Codificação RDF Schema 
$<$ rdf:Description ID="Disciplina" $>$

<rdf:type resource="http://www.w3.org/2000/01/rdf-schema\#Class"/> $<$ rdfs:subClassOf

rdf:resource="http://www.w3.org/2000/01/rdf-schema\#Resource"/> $</$ rdf:Description $>$

$<--$ Propriedades da classe Estudante -- >

$<$ rdf:Description ID="nome" $>$

<rdf:type resource="http://www.w3.org/2000/01/rdf-schema\#Property"/> $<$ rdfs:domain rdf:resource="\#Estudante" $/>$

$<$ rdfs:range rdf="http://www.w3.org/TR/xmlschema-2\#string"/>

$<$ rdf:Description $>$

$<$ rdf:Description ID="email">

$<$ rdf:type resource="http://www.w3.org/2000/01/rdf-schema\#Property"/> $<$ rdfs:domain rdf:resource="\#Estudante"/>

<rdfs:range rdf="http://www.w3.org/TR/xmlschema-2\#string"/>

$</$ rdf:Description $>$

<rdf:Description ID="afiliação_estudante" >

$<$ rdf:type resource="http://www.w3.org/2000/01/rdf-schema\#Property"/> $<$ rdfs:domain rdf:resource="\#Estudante"/>

$<$ rdfs:range rdf:resource="\#Afiliação"/>

$</$ rdf:Description $>$

$<$ rdf:Description ID="endereço_estudante" $>$

$<$ rdf:type resource="http://www.w3.org/2000/01/rdf-schema\#Property"/> $<$ rdfs:domain rdf:resource="\#Estudante"/>

$<$ rdfs:range rdf:resource="\#Endereço"/>

$</$ rdf:Description $>$

$<$ rdf:Description ID="cursa" $>$

$<$ rdf:type resource="http://www.w3.org/2000/01/rdf-schema\#Property"/> $<$ rdfs:domain rdf:resource="\#Estudante"/>

$<$ rdfs:range rdf:resource="\#Disciplina"/>

$</$ rdf:Description $>$

$<--$ Propriedades da classe Disciplina -- >

$<$ rdf:Description ID="nome" $>$

$<$ rdf:type resource="http://www.w3.org/2000/01/rdf-schema\#Property"/>

$<$ rdfs:domain rdf:resource="\#Disciplina"/>

<rdfs:range rdf="http://www.w3.org/TR/xmlschema-2\#string"/>

$</$ rdf:Description $>$

Fig. 3.19 - Codificação RDF Schema (cont) 


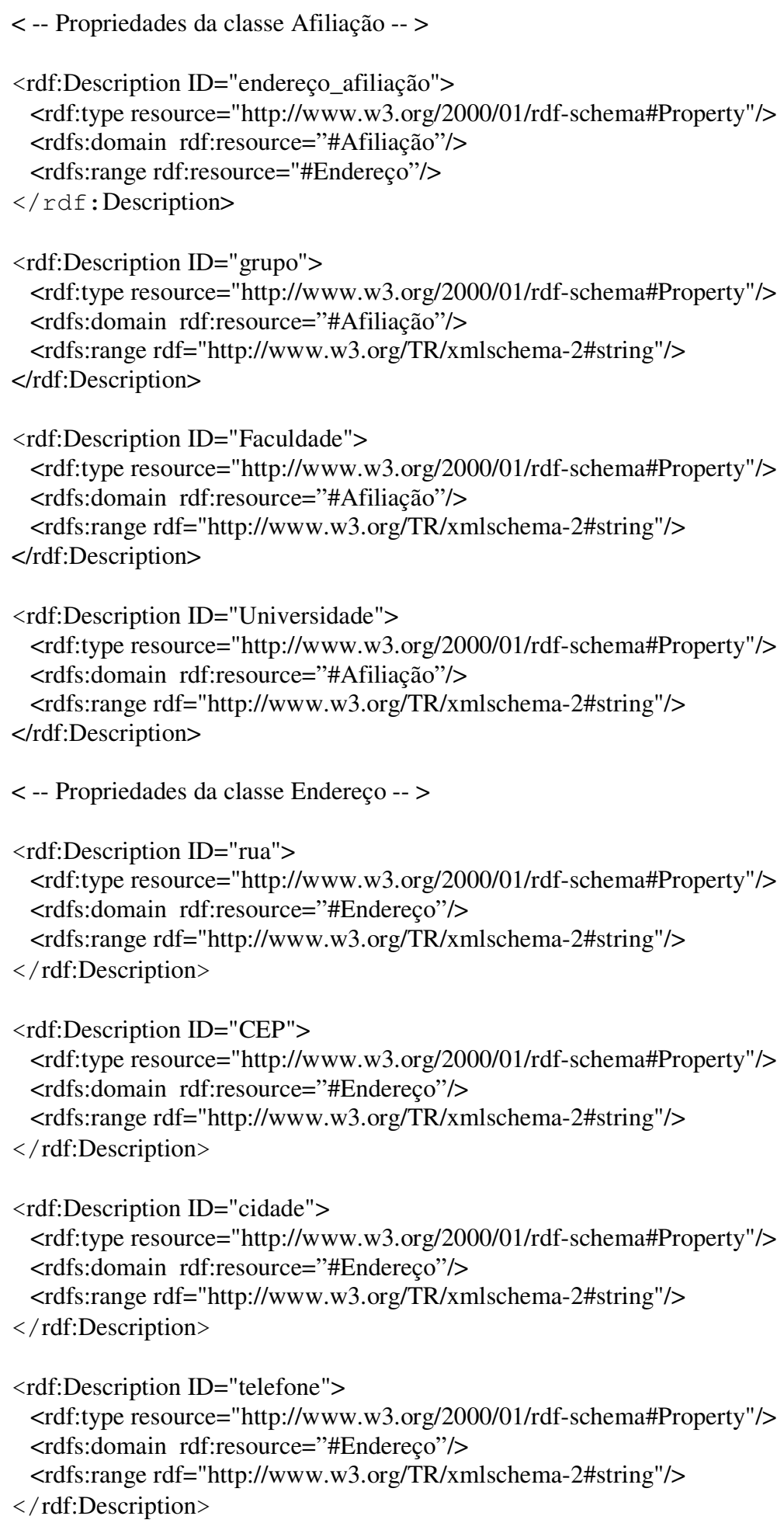

Fig. 3.19 - Codifição RDF Schema (cont) 


\subsubsection{Desvantagens do RDF Schema}

O RDF Schema provê um meio de definir um vocabulário para expressar a estrutura e as restrições dos metadados que descrevem os recursos da Web. Entretanto, é bastante simples, se comparado com as linguagens de representação de conhecimento. Segundo Broesksta et al. (2001), não há uma semântica formal definida para as primitivas do RDF Schema e a expressividade destas primitivas não é suficiente para desenvolver modelos ontológicos e de raciocínio. Heflin (2001a) afirma que falta ao RDF Schema um mecanismo para uma definição geral de axiomas, por meio dos quais seria possível usar lógica para restringir o significado dos termos e com isto prover uma semântica mais robusta. Os axiomas podem ser usados para inferir informações adicionais que não estavam explícitas. A solução é fazer o uso de ontologias e das linguagens de representação de ontologias.

\subsection{Ontologias na Web Semântica}

Ontologia é uma tecnologia essencial para a Web Semântica, porque fornece o vocabulário necessário que permite definir a estrutura e a semântica de documentos, de modo que possam ser compreendidos pelas máquinas, possibilitando pesquisas inteligentes na Web. Permite também o compartilhamento do conhecimento de um domínio que pode ser partilhado entre pessoas e aplicações.

Entretanto, para atender estas necessidades são necessárias linguagens que representem a semântica das informações na Web, possibilitando a troca de dados entre ambientes heterogêneos. Segundo Perez e Corcho (2002), várias linguagens para ontologias foram desenvolvidas no contexto da Web Semântica, algumas baseadas na sintaxe do XML tais como a Ontology Exchange Language (XOL) e a Ontology Markup Language (OML) e outras baseadas no RDF Schema, tais como a Ontology Inference Layer (OIL) e a DAML (Darpa Agent Markup Language). Descrição sobre XOL encontra-se em (KARP et al., 1999) e sobre OML encontra-se em (KENT, 1998).

Embora diferentes em alguns aspectos, as linguagens OIL e DAML deram origem à linguagem DAML+OIL, uma nova proposta do consórcio W3C, para servir como ponto de partida para as atividades da Web Semântica quanto à definição da Ontology Web Language (OWL), para a representação de ontologias e metadados e 
que inclui inúmeras construções novas (primitivas para a Web Semântica), que aumentaram bastante o poder da linguagem. Este trabalho utilizará a linguagem DAML+OIL, mas para melhor compreensão desta linguagem, é feita uma introdução sobre a OIL.

\subsubsection{OIL - Ontology Inference Layer}

Esta seção faz uma breve descrição da OIL. A especificação completa desta linguagem encontra-se em (HORROCKS et al., 2000). Para expressar e representar ontologias, são necessárias linguagens com ferramentas de suporte avançadas. Esta linguagem é baseada em três tecnologias diferentes, como mostra a figura 3.20. São elas:

- Lógica Descritiva: para dar um suporte eficiente para raciocínio e semântica formal;

- Sistemas Baseados em Frames: para modelagem epistemológica de primitivas;

- Linguagens da Web: para relacionar dados semi-estruturados e os padrões do modelo RDF para integração e troca de informações.

Lógica Descritiva:

Semântica Formal \&

Suporte ao Raciocínio
Sistemas Baseados em Frames: Modelagem epistemológica de Primitivas
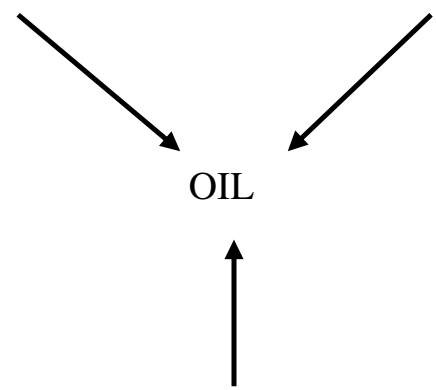

Linguagens Web:

Sintaxe baseada em XML e RDF

Fig. 3.20 - As raízes do OIL (HORROCKS et al., 2000) 
Segundo Bechhofer et al. (2001), sistemas baseados em frames e em orientação a objetos modelam primitivas baseadas em classes (ou frames) com certas propriedades conhecidas como atributos. Estes atributos têm escopo local e são aplicáveis nas classes em que são definidos. A OIL utiliza estas características e permite a definição de classes em termos de uma coleção de superclasses e de uma coleção de atributos. A lógica descritiva descreve conhecimento em termos de conceitos de regras de restrição, que podem, automaticamente, derivar em classificações hierárquicas. Permitem a definição de classes em termos de descrições que especificam as propriedades satisfeitas pelos objetos pertencentes ao conceito. As descrições são feitas através dos operadores de conjunção, disjunção, negação e de várias formas de regras de quantificação. As inferências são feitas através da lógica de primeira ordem.

\subsubsection{DAML+OIL}

DAML+OIL é uma linguagem de ontologia desenvolvida pelo USAmerican/European Committee no contexto da DAML, um projeto da DARPA (Defense Advanced Research Project Agency) ${ }^{8}$. Substitui a OIL e acrescenta algumas características:

- Introduz os tipos de dados do XML Schema tais como inteiros, cadeias (strings) e reais. Propriedades são diferenciadas em duas classes disjuntas: propriedades do objeto (object properties) cujo valor é uma instância de uma classe e propriedades de tipo de dados (data-type properties), cujo valor é uma instância dos tipos de dados do XML Schema;

- A possibilidade de importar explicitamente outra ontologia DAML+OIL, contendo definições que se aplicam à ontologia DAML+OIL atual;

- Definir enumerações.

DAML+OIL usa a sintaxe da RDF e como mostra a figura 3.21, é considerada como uma extensão de RDF Schema, devido ao acréscimo de propriedades de OIL. A figura 3.21 mostra as primitivas herdadas de RDF Schema e as acrescentadas a partir de OIL. A seguir, são descritas as principais primitivas da DAML+OIL baseadas em (CONNOLLI et al., 2001a) e (McGUINNESS et al., 2002).

\footnotetext{
${ }^{8}$ Home page em http://www.arpa.mil
} 


\subsubsection{Introdução}

$\mathrm{O}$ primeiro passo para se definir um documento nesta linguagem é afirmar que o documento RDF Schema é uma ontologia, através da declaração:

$<$ daml: Ontology rdf:about="”>

O atributo $a b o u t=$ "' indica que o assunto desta afirmação é este documento.

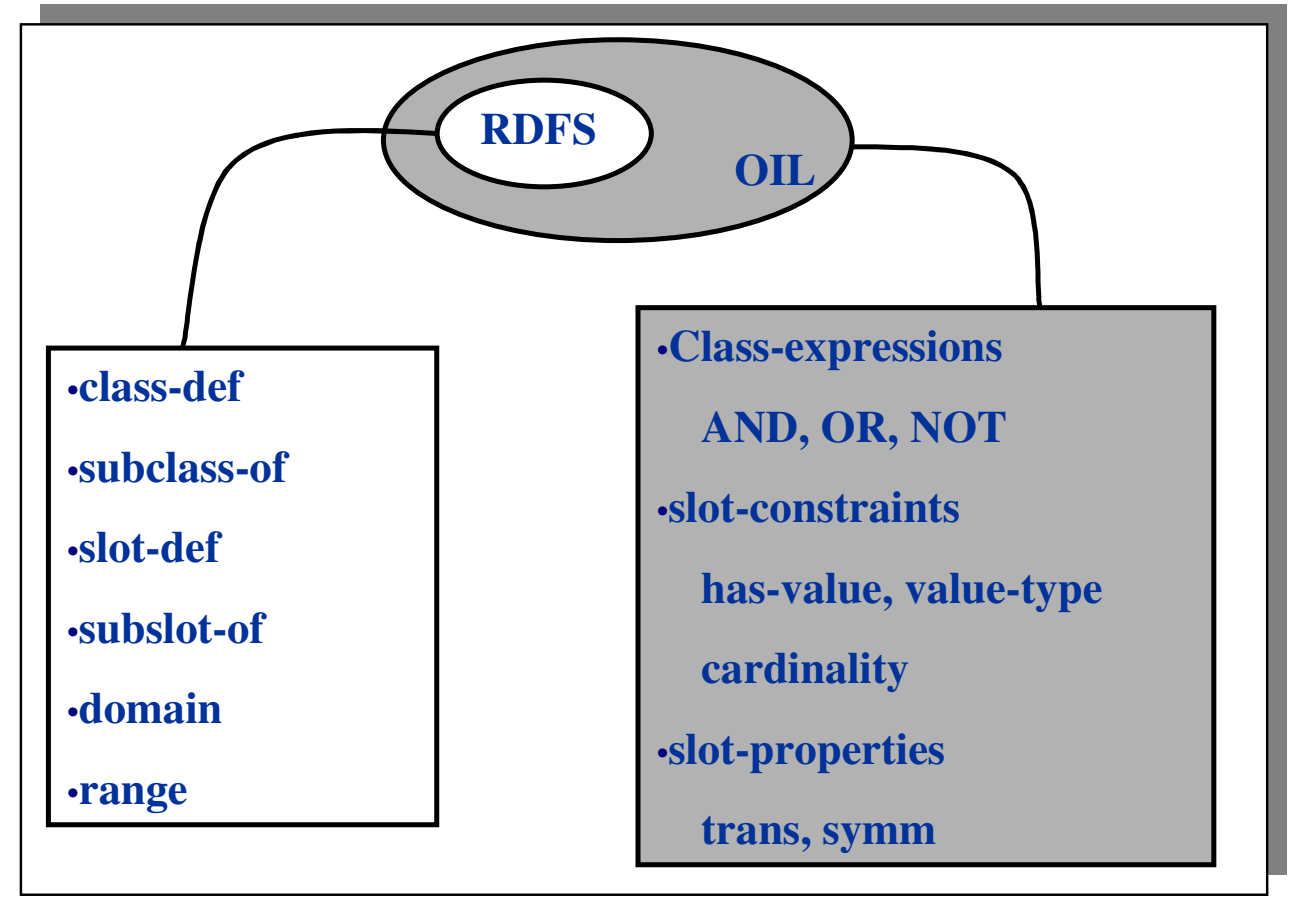

Fig. 3.21 - DAML+OIL como extensão do RDF Schema (FENSEL et al., 2001)

\subsubsection{Descrição de classes}

Uma ontologia consiste da descrição de objetos. Para isto é necessário descrever-se o tipo de objeto. Se o domínio de interesse forem as pessoas de um Departamento de Computação, pode-se ter uma classe geral chamada Pessoas, que se descreve através da marca (tag) Class:

<daml:Class rdf:ID="Pessoas"> 
Esta declaração apenas informa que há uma classe chamada Pessoas e não diz mais nada a seu respeito. Para identificar e fazer comentários sobre esta classe, utilizam-se as marcas label e comment.

$<$ rdfs:label $>$ Pessoas $</$ rdfs:label $>$

$<$ rdfs:comment $>$

Esta classe descreve as pessoas de um Departamento de Computação. $</$ rdfs:comment $>$

Para encerrar a descrição usa-se:

$</$ daml:Class $>$

Para se descrever tipos de Pessoas, tais como estudante e professor, usa-se:

$$
\begin{aligned}
& \text { <daml:Class rdf:ID="Professor"> } \\
& \quad<\text { rdfs:subClassOf rdf:resource="\#Pessoas"/> } \\
& \text { </daml:Class }> \\
& \text { <daml:Class rdf:ID="Estudante"> } \\
& \text { <rdfs: } \text { :ubClassOf rdf: } \text { resource="\#Pessoas"/> } \\
& \text { </daml:Class }>
\end{aligned}
$$

A marca subClassOf afirma que o sujeito Professor e o sujeito Estudante são subclasses de seu objeto, o recurso identificado por \#Pessoas. Se for possível afirmar que Pessoas não podem ser Estudante e Professor simultaneamente, usam-se as marcas about e disjointWith:

$<$ daml:Class rdf:about="\#Professor"> $<$ daml:disjointWith rdf:resource="\#Estudante" $>>$ $</$ daml:Class $>$ 


\subsubsection{Descrição de propriedades}

Uma propriedade, ou uma relação binária, conecta dois itens. Em DAML+OIL as propriedades relacionam objetos com outros objetos, ou objetos com valores de tipo de dados. No exemplo seguinte, usa-se a marca ObjectProperty para definir a propriedade temNome para Pessoas.

$$
\begin{aligned}
& \text { <daml:ObjectProperty rdf:ID="temNome"> } \\
& <\text { rdfs:domain rdf:resource="\#Pessoas"/> } \\
& <\text { rdfs:range rdf:resource="\#Pessoas"/> } \\
& \text { </daml:ObjectProperty > }
\end{aligned}
$$

As marcas domain e range têm a mesma função que em RDF Schema. Neste caso a propriedade temNome é aplicada somente a Pessoas. Para relacionar-se propriedades de objetos com valores de tipo de dados, usa-se a marca DatatypeProperty. No exemplo seguinte, a propriedade email é uma cadeia, e é única (UniqueProperty).

$$
\begin{aligned}
& \text { <daml:DatatypeProperty rdf:ID="email"> } \\
& <\text { <df:type } \\
& \text { rdf:resource="http://www.daml.org/2001/03/daml+oil\#UniqueProperty"/> } \\
& \text { <rdfs:range rdf="http://www.w3.org/2000/10/XMLSchema\#string"/> } \\
& \text { <daml:DatatypeProperty> }
\end{aligned}
$$

\subsubsection{Restrição de propriedades}

As primitivas domain e range oferecem informações globais a respeito das propriedades. O exemplo seguinte mostra como fazer restrições a uma classe de objetos, através da marca Restriction.

A classe Pessoas agora é uma subclasse com duas restrições: uma que restringe o tipo de propriedade e uma que restringe o número de nomes que as Pessoas podem ter. Cada restrição é definida por uma classe anônima - a classe de todas as coisas que satisfazem a restrição. O nome do recurso no elemento onProperty é o nome da 
propriedade a ser restrita e o nome do recurso no elemento toClass é o nome da classe na qual a propriedade é restrita. Outros tipos de restrições estão exemplificadas em (CONNOLLY, 2001b).

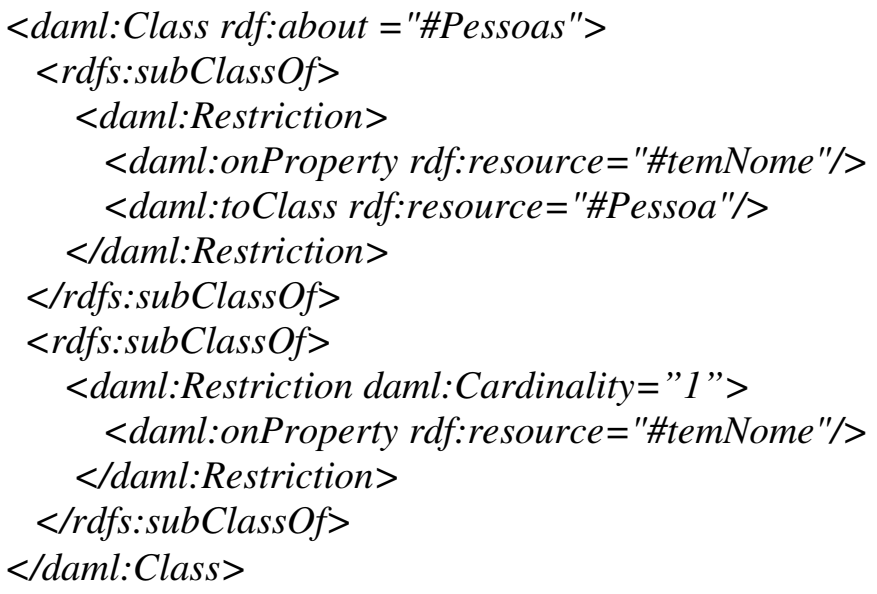

\subsubsection{Notação de classes}

Classes podem ser escritas de várias maneiras através das propriedades daml:complementOf, daml:intersectionOf e daml:unionOf que, respectivamente, significam negação, conjunção e disjunção de classes. Estas propriedades, aplicadas a classes, são conhecidas como expressões de classe. Por exemplo, se um trem nunca é uma pessoa, poder-se-ia escrever:

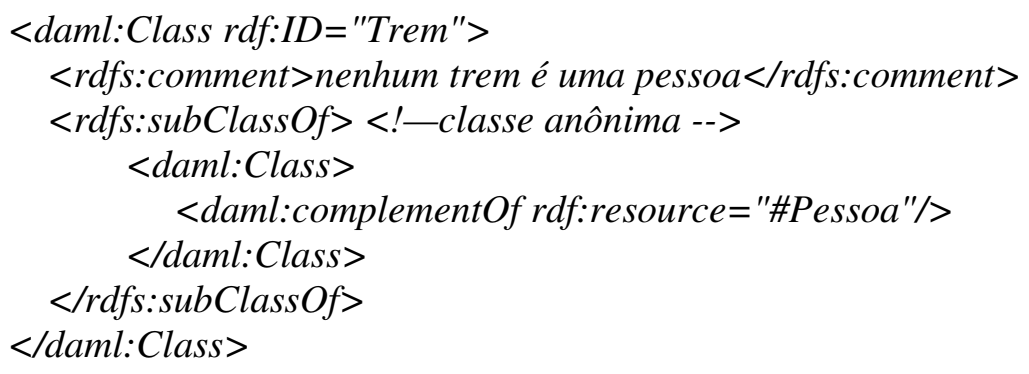


Nesse caso, Trem é uma classe, que é uma especialização de uma outra classe anônima, que consiste de todas as coisas, exceto Pessoas. Pode-se construir uma nova classe, como uma intersecção de outras classes, através do elemento daml:intersectionOf:

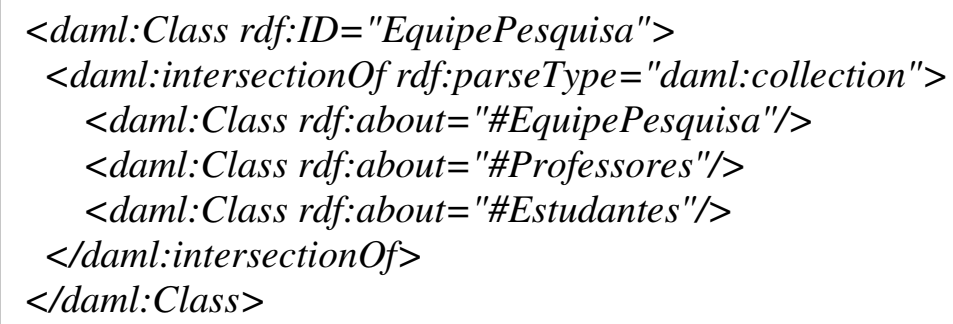

Neste caso a Equipe de Pesquisa é formada pelas classes Equipepesquisa, Professores e Estudantes. O elemento daml:intersectionOf contém múltiplos subelementos. A marca parseType ="daml:collection" indica que estes subelementos são tratados como uma unidade.

\subsubsection{Conclusões}

O DAML+OIL permite que o usuário defina seus próprios tipos de dados. Também é possível definir objetos individuais em uma classe. A especificação completa do DAML+OIL contém quarenta e um elementos, e está descrita em (CONNOLLY et al., 2001b) e (OGBUJI; OUELLET, 2002).

Existem poucas aplicações práticas com o uso do DAM+OIL, relatadas. Cost et al. (2002) apresentam um sistema chamado ITtalks, que é um portal Web que oferece acesso a informações a respeito de palestras, seminários e colóquios sobre tecnologia da informação. Os usuários podem visualizar as informações sobre localização, palestrantes, patrocinadores e assuntos. Agentes recuperam e manipulam informações armazenadas na base de conhecimento do ITtalks. O DAML+OIL, através da ontologia definida para o ITtalks, é usado para a representação da base de conhecimento, para prover capacidade de dedução e para todas as comunicações, incluindo mensagens simples e consultas. Segundo o autor, o maior benefício do DAML+OIL foi possibilitar ao ITtalks a habilidade de interagir com qualquer agente 
DAML+OIL sem supervisão humana, tornando mais eficiente a interação entre sistemas e usuários.

Taboada et al. (2002) descrevem como representar uma base de conhecimento para aplicações heurísticas usando DAML+OIL. Esta base contém conhecimentos sobre históricos oftalmológicos, exames e patologias dos olhos, relatos de procedimentos clínicos e as relações entre todos estes conhecimentos. Esta base foi desenvolvida em duas fases: primeiro foi modelada uma ontologia para representar graficamente os objetos, classes e relações do domínio de conhecimento e depois a base foi representada em DAML+OIL. Segundo o autor, o DAML+OIL possibilitou:

- Maior poder de expressividade: relações comuns em orientação a objetos podem ser expressas em DAML+OIL;

- Interoperabilidade sintática: as estruturas de domínio e de dados podem ser lidas facilmente;

- Interoperabilidade semântica: as relações básicas são representadas em DAML+OIL, existindo uma conexão direta do modelo de domínio e sua representação em DAML+OIL.

A ontologia adotada usa agregações simples, que podem ser descritas pelas primitivas de modelagem incluindo label, classes, um conjunto de partes de uma classe e cardinalidade. Esta agregação pode ser mapeada para o DAML+OIL diretamente, da seguinte maneira:

- Definir uma propriedade nova designando um label da agregação;

- Especificar o domínio da propriedade como a classe na agregação;

- Especificar o limite (range) da propriedade como uma união de classes, tornando-a parte de uma agregação;

- Adicionar novas restrições para a classe na agregação e especificar a cardinalidade requerida.

A tabela 3.2, adaptada de Gil e Ratnakar (2000) apresenta uma comparação das linguagens XML Schema, RDF Schema e DAML+OIL. 
Tabela 3. 2 - Comparação entre as linguagens XML Schema, RDF Schema e DAML+OIL (GIL e Ratnakar, 2000)

\begin{tabular}{|c|c|c|c|c|}
\hline Dimensão & Detalhes & XML Schema & RDF Schema & DAML+OIL \\
\hline Contexto & Contexto & Sim & Sim & Sim \\
\hline \multirow[b]{2}{*}{ Classes } & $\begin{array}{l}\text { Objetos, Classes } \\
\text { \& Propriedades }\end{array}$ & Não & $\begin{array}{l}\text { Sim } \\
(r d f s: \text { Class } \quad \& \\
\text { rdfs:Property }\end{array}$ & $\begin{array}{l}\text { Sim } \\
\text { (daml:Class, } \\
\text { daml:ObjectProperty, } \\
\text { daml:DatatypeProperty) }\end{array}$ \\
\hline & Herança & $\begin{array}{l}\text { Não (embora possa ser } \\
\text { estendida para o } \\
\text { elemento Type) }\end{array}$ & $\begin{array}{l}\text { Sim (Propriedades e } \\
\text { Classes) } \\
\text { rdfs:subClassOf, } \\
\text { rdfs:subPropertyOf }\end{array}$ & $\begin{array}{l}\text { Sim } \\
\text { (Propriedades e Classes) } \\
\text { Usa sintaxe RDF }\end{array}$ \\
\hline \multirow[t]{3}{*}{$\begin{array}{l}\text { Propriedades/ } \\
\text { Elementos } \\
\text { Restrições }\end{array}$} & Range & $\begin{array}{l}\text { Sim } \\
\text { (Global e Local) }\end{array}$ & $\begin{array}{l}\text { Sim } \\
\text { (somente Global - } \\
\text { rdfs:domain) }\end{array}$ & $\begin{array}{l}\text { Sim } \\
\text { (Global - rdfs:range \& } \\
\text { local - daml:Restriction, } \\
\text { onProperty, toClass }\end{array}$ \\
\hline & Domain & Sim & $\begin{array}{l}\text { Sim } \\
\text { (Global somente) - } \\
\text { rdfs:domain }\end{array}$ & $\begin{array}{l}\text { Sim } \\
(\text { Global })-r d f s: \text { domain }\end{array}$ \\
\hline & Cardinalidade & \begin{tabular}{|l} 
Sim \\
(somente Local - \\
minOccurs, \\
maxOccurs)
\end{tabular} & Não & $\begin{array}{l}\text { Sim } \\
\text { (Local - minCardinality, } \\
\text { maxCardinality \& Global } \\
\text { - UniqueProperty, or } \\
\text { Restriction a subClass of } \\
\text { "\#Resource") }\end{array}$ \\
\hline \multirow{3}{*}{$\begin{array}{ll}\text { Tipos } & \text { de } \\
\text { dados } & \& \\
\text { Instâncias } & \end{array}$} & $\begin{array}{l}\text { Tipos de dados } \\
\text { Básicos }\end{array}$ & $\begin{array}{l}\text { Sim } \\
\text { Variação de tipo de } \\
\text { dados numérico, data } \\
\text { e string }\end{array}$ & $\begin{array}{l}\text { Não } \\
\text { Somente Literais }\end{array}$ & $\begin{array}{l}\text { Sim } \\
\text { Permite o uso de tipo de } \\
\text { dados do XML Schema }\end{array}$ \\
\hline & $\begin{array}{l}\text { Enumeração de } \\
\text { Propriedades/Valo } \\
\text { res }\end{array}$ & $\begin{array}{l}\text { Sim } \\
<\text { <enumeração }>\end{array}$ & Não & $\begin{array}{l}\text { Sim } \\
<\text { daml:oneOf> } \\
\text { Pode usar enumeração do } \\
\text { XML Schema }\end{array}$ \\
\hline & Instâncias & Sim & $\begin{array}{l}\text { Sim } \\
<r d f: I D>\end{array}$ & Usa sintaxe RDF \\
\hline \multirow{2}{*}{$\begin{array}{l}\text { Conjunto de } \\
\text { Dados }\end{array}$} & Listas & Não & Não & Sim <daml:colletion $>$ \\
\hline & $\begin{array}{l}\text { Conjunto de dados } \\
\text { ordenados }\end{array}$ & Sim & $\begin{array}{l}\text { Sim } \\
<r d f: \text { Seq }>\end{array}$ & $\begin{array}{l}\text { Sim } \\
<\text { daml:list }>\end{array}$ \\
\hline \multirow{3}{*}{$\begin{array}{l}\text { Negação, } \\
\text { Disjunção e } \\
\text { Conjunção }\end{array}$} & Negação & Não & Não & $\begin{array}{l}\text { Sim } \\
<\text { daml:ComplementOf }>\end{array}$ \\
\hline & $\begin{array}{l}\text { Classes } \\
\text { Disjuntivas }\end{array}$ & Não & Não & $\begin{array}{l}\text { Sim } \\
<\text { daml:disjointUnionOf }> \\
<\text { daml:unionOf }>\end{array}$ \\
\hline & $\begin{array}{l}\text { Classes } \\
\text { Conjuntivas }\end{array}$ & Não & $\begin{array}{l}\text { Sim } \\
\text { Múltiplo } \\
<r d f: \text { subClassOf> }\end{array}$ & $\begin{array}{l}\text { Sim } \\
<\text { daml:intersectionOf }>\end{array}$ \\
\hline Definição & $\begin{array}{l}\text { Nec.\& Suff, } \\
\text { Cond.' For } \\
\text { Membership }\end{array}$ & Não & Não & $\begin{array}{l}\text { Sim } \\
<\text { daml:sameClassAs }> \\
<\text { daml:UnambigousPrope } \\
\text { rty> }\end{array}$ \\
\hline \multirow[t]{2}{*}{$\begin{array}{l}\text { Tipos de } \\
\text { propriedades }\end{array}$} & Inversa & Não & Não & $\begin{array}{l}\text { Sim } \\
<\text { daml:inverseOf> }\end{array}$ \\
\hline & Transitiva & Não & Não & $\begin{array}{l}\text { Sim } \\
<\text { daml:TransitiveProperty } \\
>\end{array}$ \\
\hline
\end{tabular}


Uma diferença importante entre estas linguagens é em relação à semântica; enquanto o RDF Schema e o DAML+OIL podem trabalhar com semântica o XML Schema, não. Sem semântica, não é possível interpretar as construções da linguagem e desenvolver as regras de inferências que possibilitam o raciocínio. Observa-se também que, somente a linguagem DAML+OIL possui as operações de negação, disjunção, conjunção, inversão e transitividade. Pode-se concluir que o DAML+OIL traz melhoras significativas sobre o RDF Schema e XML Schema, principalmente por ser baseada em lógica descritiva e em frames tornando-se uma ferramenta muito útil para descrever conteúdos da Web.

\subsection{Ferramentas para Web Semântica}

Apesar de recente, já se encontram disponibilizadas algumas ferramentas para a Web Semântica. Algumas são editores de ontologia, que permitem aos usuários se concentrarem no desenvolvimento das ontologias e, automaticamente, gerarem códigos no formato RDF Schema, RDF ou DAML+OIL. Outras são mais completas: além dos editores trazem ferramentas para pesquisa, anotação de páginas e banco de dados. Neste trabalho foram utilizadas parcialmente as ferramentas WebODE e Protege 2000, descritas a seguir. Em Ding (2001) encontra-se um resumo das

principais ferramentas disponíveis para a Web Semântica e no Apêndice A encontram-se as descrições das ferramentas SHOE e OntoBroker.

\subsubsection{WebODE}

Segundo Arpírez (2001) a ferramenta WebODE foi desenvolvida para dar suporte a fase de conceitualização da metodologia METHONTOLOGY e nas atividades do ciclo de vida de uma ontologia. As ontologias são armazenadas em um repositório central usando um banco de dados relacional e é necessário obter uma senha para sua plena utilização. Os principais componentes são:

- Conceitos: conhecido como classes, são identificados pelo nome e pela classe de atributos, cujos valores devem ser os mesmos para todas as instâncias do conceito. No anexo A.3 está apresentado um dos conceitos e suas classes de atributos e no anexo A.5 está apresentado um exemplo da tabela de classe de atributos. 
- Relações Binárias ad-hoc: são as relações entre os conceitos, identificadas pelo nome da relação, nome do conceito de origem, nome do conceito de destino e pela cardinalidade, que estabelece o número de fatos (instâncias da relação) entre a origem e o destino. No anexo A.4 está apresentado um exemplo da tabela de relações binárias.

- Relações pré-definidas: são as relações de taxonomias entre os conceitos. Incluem as relações de subclass-of, not-subclass-of, disjointsubclass-partition, exhaustive-subclass-partition, transitive-part-of e intransitive-part-of. No anexo A.2 está apresentado um exemplo destas relações.

- Glossário de Termos: são representados todos os termos utilizados para a criação da Ontologia e é criado automaticamente pela ferramenta. No anexo A.1 está apresentado um exemplo do glossário de termos.

- OntoDesigner: é uma interface gráfica para o usuário visualizar a construção das relações $a d-h o c$ e das relações pré-definidas entre os conceitos da ontologia.

Estes são os principais componentes da ferramenta que foram utilizadas neste trabalho. A figura 3.22 representa a interface da ferramenta com alguns dos componentes discutidos.

\subsubsection{Protégé-2000}

Segundo Noy et al. (2001), o Protégé-2000 é uma ferramenta gráfica para edição de ontologias e aquisição de conhecimento, que pode ser aplicada às linguagens da Web Semântica, dentre as quais a RDF, RDF Schema e DAML+OIL. Com o Protégé2000 o usuário preocupa-se somente com os conceitos e as relações do domínio e com os fatos que precisam ser expressos, pois a sintaxe da linguagem é gerada automaticamente. Suas principais características são:

- Um modelo de conhecimento extenso: o Protégé-2000 tem classes, instâncias destas classes, slots (propriedades) que descrevem os atributos das classes e instâncias e restrições (facets), que expressam informações adicionais sobre as propriedades; 
- Formato customizado do arquivo de saída: é possível implementar componentes que traduzem a representação interna do Protégé-2000 para representação em qualquer linguagem;

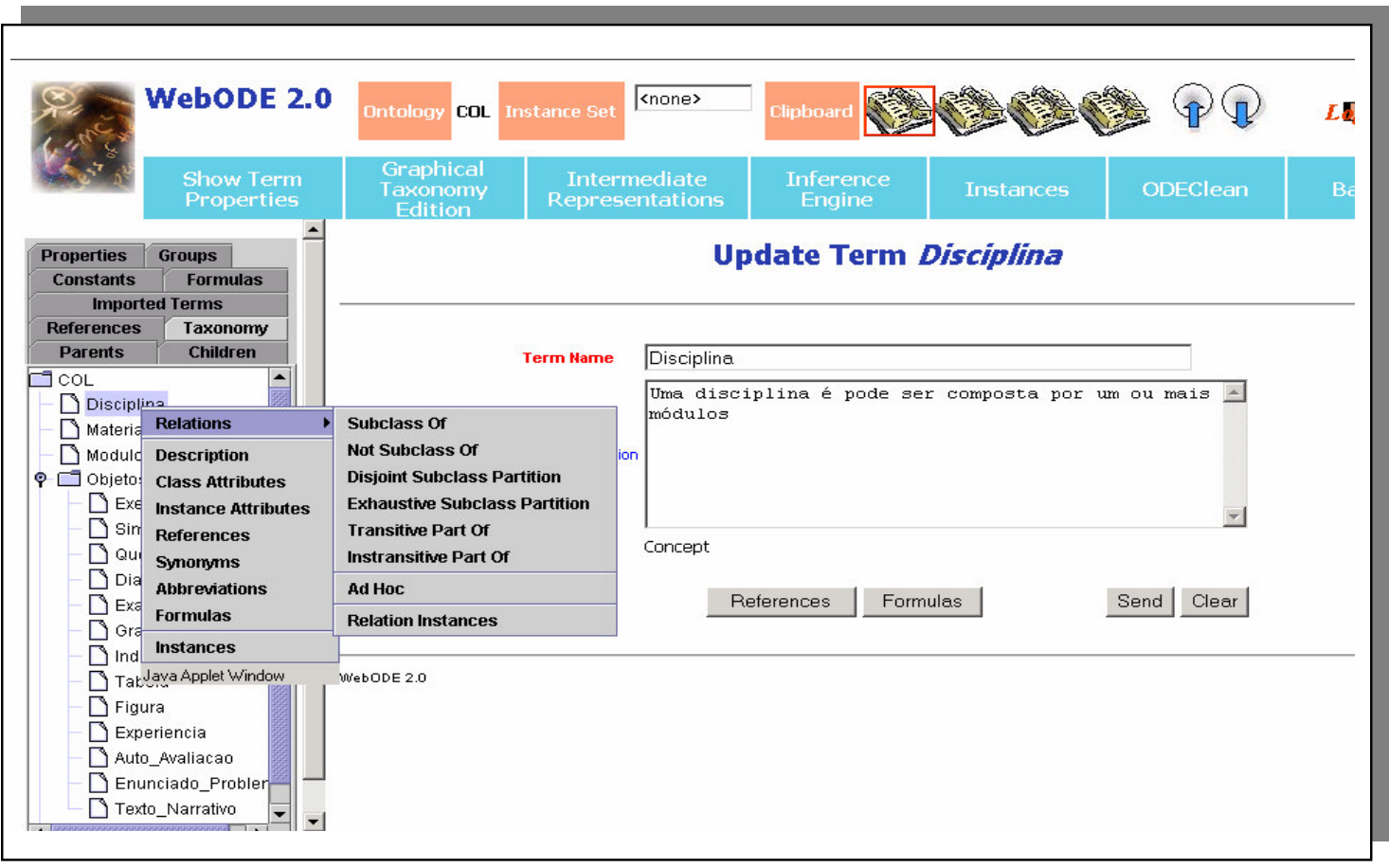

Fig. 3.22 - Interface gráfica da ferramenta WebODE

- Interface de usuário customizada: a interface do usuário pode ser adaptada com novos componentes, que representem melhor uma nova linguagem; consiste de várias tabelas para edição de diferentes elementos de uma base de conhecimento;

\section{- Uma arquitetura que possibilita integração com outras aplicações.}

A figura 3.23 representa a arquitetura plug-in do Protégé-2000 (GENNARI et al., 2002). O núcleo é o modelo de conhecimento. A interação com os objetos que residem na base de conhecimento (classes, instâncias, etc.) deve ser feita via Protégé API (Application Programmers Interface). O desenvolvimento e publicações destas APIs é que permite aos desenvolvedores construir componentes que adicionam ou modificam as funcionalidades do Protégé-2000. 


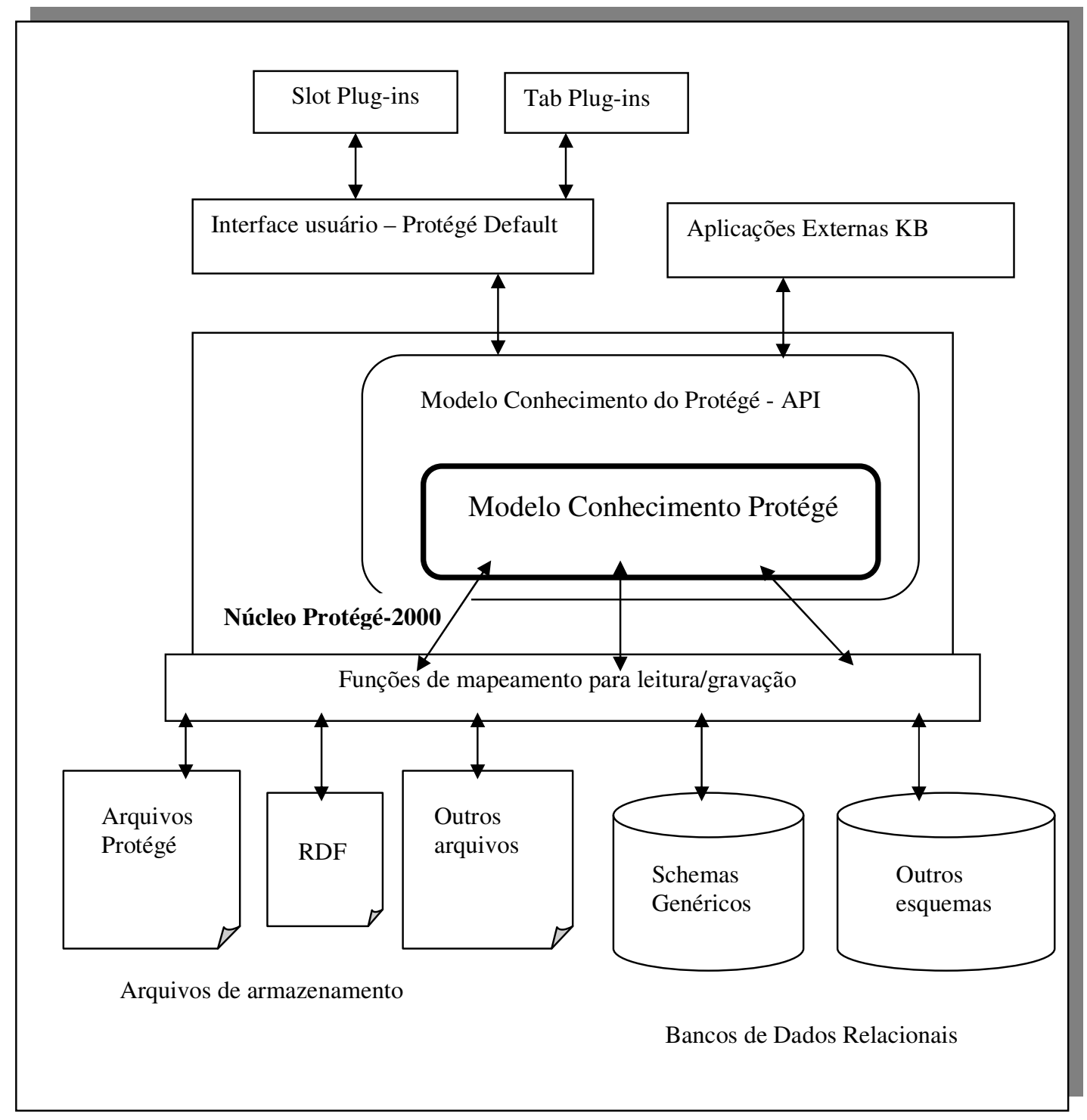

Fig. 3.23 - Arquitetura do protegé-2000 (GENNARI et al., 2002)

\subsection{Conclusões}

Este capítulo teve a finalidade de apresentar as tecnologias envolvidas na Web Semântica. Suas principais características são:

- Elas já começam a ter grande aceitação e sua sintaxe, baseada em marcas e namespaces, já estão sendo padronizadas.

- Oferecem possibilidades da representação semântica do conhecimento e dados na Web, principalmente com a utilização de RDF e RDF Schema; 
- Elas podem oferecer alto grau de interoperabilidade entre as aplicações na troca de documentos, possibilitando o compartilhamento e reuso de informações.

- São aceitas como padrão, de fato, e gradualmente estão se tornando padrões oficiais.

O principal objetivo da Web Semântica é facilitar a aquisição e representação do conhecimento, o que poderá transformar a Web atual em uma Web voltada ao conhecimento e trará grandes benefícios nas aplicações educacionais que adotarem esta tecnologia. É o que será visto no próximo capítulo. 


\section{A EDUCAÇÃ̃ BASEADA NA WEB (EBW) E A WEB SEMÂNTICA}

Com as tecnologias atuais, as máquinas não podem compreender e interpretar o significado das informações disponíveis na Web, pois uma grande parte desta informação é representada em linguagem natural. A Web Semântica torna possível expressar a informação de maneira que esta possa ser interpretada e compreendida pelas máquinas. A contribuição desta tecnologia para os sistemas educacionais baseados na Web é o que será analisado nas próximas seções.

\subsection{Introdução}

A extraordinária expansão e acessibilidade da Internet e da World Wide Web na última década possibilitou a criação de várias ferramentas que ajudam a educação das pessoas no mundo contemporâneo. O uso de ferramentas especializadas na produção de material educacional ou de ambientes de autoria agregados à Internet podem ajudar a superar os meios convencionais de educação a distância em diversos aspectos: possibilitando troca de informações e recursos de forma mais rápida, acessando especialistas em inúmeras áreas, mantendo-se atualizado o material relativo aos vários domínios de interesse, possibilitando a formação de equipes de trabalho cooperativo, independentemente das distâncias geográficas e acessando várias formas diferentes de arquivos e repositórios de informações.

De acordo com Reinhard (1995), estas novas tecnologias estabelecem uma mudança significativa no paradigma educacional, representada pela tabela 4.1, que compara modelos antigos com novos modelos de aprendizagem.

Segundo Krämer (2002), as possibilidades oferecidas por estas novas tecnologias de informação e comunicação para a reconstrução educacional são:

- Apresentação de materiais de aprendizagem através de todos os tipos de mídias disponíveis, tais como textos, gráficos - em duas e três dimensões -, sons, imagens, vídeos e simulações;

- Sincronização entre estas mídias, para explicar a seqüência de processos complexos, visualizados através de animações e comentários; 
- Construção de aplicações com conceitos hipermídia;

- Movimentação livre, com ajuda de mecanismos de pesquisa e navegação, para que o estudante possa mover-se livremente em busca de informações, seguindo seu estilo pessoal e interesses;

- Disponibilização de ferramentas diversas para que operações sequienciais e os caminhos de aprendizado preferidos possam ser gravados, avaliados e reativados, se necessário. $\mathrm{O}$ estudante pode adicionar suas próprias referências estruturais e notas pessoais nos materiais dos cursos.

Tabela 4. 1 - Novos paradigmas educacionais (REINHARD, 1995)

\begin{tabular}{|l|l|l|}
\hline Modelo Antigo (docente) & Modelo Novo (discente) & Implicações Tecnológicas \\
\hline Aulas expositivas & Processo de facilitação & $\begin{array}{l}\text { Rede de computadores com } \\
\text { acesso à informação }\end{array}$ \\
\hline Estudante espectador & Estudante colaborador & $\begin{array}{l}\text { Requer habilidades de } \\
\text { desenvolvimento e simulação }\end{array}$ \\
\hline Aprendizagem individual & Aprendizado em equipe & $\begin{array}{l}\text { Ferramentas colaborativas e } e \text { - } \\
\text { mail }\end{array}$ \\
\hline Professor como fonte & Professor como guia & Requer acesso a especialistas \\
\hline Conteúdo estável & Conteúdo dinâmico & $\begin{array}{l}\text { Requer redes e ferramentas de } \\
\text { publicação }\end{array}$ \\
\hline Homogeneidade & Diversidade & $\begin{array}{l}\text { Requer uma variedade de } \\
\text { ferramentas de acesso e métodos }\end{array}$ \\
\hline
\end{tabular}

A tabela 4.2, adaptada de Taylor (2001), mostra a evolução dos modelos da educação a distância. Pode-se observar que as possibilidades acima se adaptam às tecnologias citadas na quarta geração, e que a quinta geração é, essencialmente, uma derivação da quarta geração. A característica da quarta geração é a interatividade, que é mediada pelos computadores, e a quinta geração propõe que esta interatividade possa ser feita de modo automático pelos computadores. Como esta automação pode ser realizada, é o que será apresentado nas próximas seções. 
Tabela 4. 2 - Evolução dos modelos de educação a distância (TAYLOR, 2001)

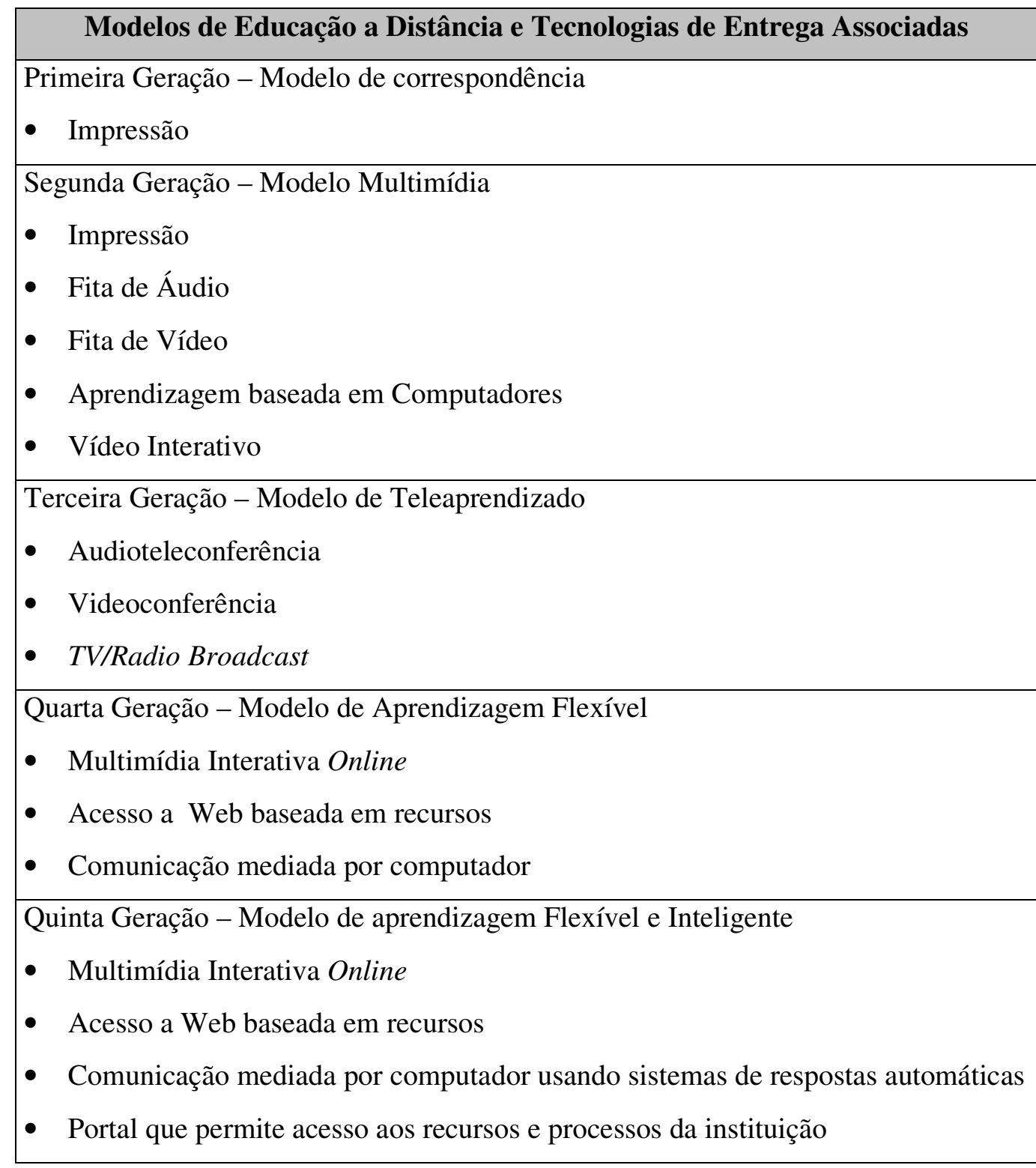

A tabela 4.1 mostra também que este tipo de paradigma, devido à sua característica dinâmica, exige o apoio de ferramentas de publicação eficientes, para permitir ao professor a elaboração do conteúdo instrucional, e de uma infraestrutura computacional robusta, capaz de dar apoio às diversas atividades exigidas do aluno. A tabela 4.2 mostra os principais recursos exigidos pelo novo paradigma 
educacional, onde se destacam materiais educacionais de tipo variado, com destaque para a Web baseada em recursos, extensamente discutida no capítulo anterior.

\subsection{Limitações da educação baseada na Web (EBW)}

A discussão destas limitações está baseada em Devedzic (2002). Os atuais sistemas educacionais baseados na Web apresentam limitações que podem ser divididas em três categorias: conceitual, tecnológica e relacionadas com ferramentas que implementam estes sistemas.

\subsubsection{Limitações conceituais}

Atualmente, os sistemas EBW são construídos sem levar em consideração alguns conceitos importantes. São os seguintes:

- Compartilhamento e reutilização dos materiais de aprendizagem entre aplicações: atualmente, não existem métodos automáticos para compartilhamento e reutilização dos materiais de aprendizagem entre as aplicações. O problema é que estes sistemas usam formatos, linguagens e vocabulários diferentes para representar e armazenar os materiais de aprendizagem. Mesmo que aplicações diferentes façam parte do mesmo domínio, não há interoperabilidade entre elas, bem como são diferentes as estratégias de ensino, procedimentos de avaliação e os modelos dos estudantes. Assim sendo, para atingir os objetivos listados nas duas tabelas apresentadas, é necessário pesquisar-se tecnologias que permitam resolver estes problemas e uma das soluções possíveis, é desenvolver aplicações educacionais, nas quais os materiais de aprendizagem sejam baseados em ontologias.

- Estruturar os materiais de aprendizagem através de pontos comuns de referência: para estruturar os materiais de aprendizagem com pontos comuns de referência é necessário que os conceitos e relações estejam baseados em um vocabulário padrão. Com este vocabulário, e usando ontologias, pode-se manter todas as partes que compõem o material de aprendizagem interligadas entre si.

- Anotar os materiais de aprendizagem para facilitar o acesso: para que os computadores possam compreender e interpretar os materiais de aprendizagem, as páginas que compõem as aplicações necessitam estar anotadas, ou seja, conter uma marcação semântica, baseada nos termos definidos por uma ou mais 
ontologias. O processo de anotação foi discutido no capítulo 3, quando foram apresentadas as características de algumas ferramentas voltadas para a Web Semântica. Como já se expôs anteriormente, as anotações permitem a localização e recuperação destes materiais de forma automática.

- Suporte à interação entre as aplicações e usuários: os serviços oferecidos pelos atuais sistemas EBW são limitados, em termos de suporte, para facilitar a interação entre os sistemas e usuários. Do ponto de vista dos estudantes, alguns dos serviços oferecidos são: pesquisar e percorrer os materiais de aprendizagem, realizar avaliações online, acessar referências, utilizar algumas ferramentas para colaboração, etc. Do ponto de vista do professor, ou autor, os sistemas EBW possibilitam a integração do material de aprendizagem (criar lições, intercalar conteúdos etc.), montar a seqüência do curso e disponibilizar o curso na Internet. Nestes casos, é o usuário que realiza os trabalhos necessários ao uso desses serviços, ou seja, as atuais aplicações EBW requerem dos usuários uma grande carga de trabalho - e cognitiva - para utilizar os serviços. Estes sistemas não são, ainda, projetados com a possibilidade de automatizar e melhorar os serviços oferecidos. A interação nos sistemas EBW é discutida em detalhes no item 4.3.

\subsubsection{Limitações tecnológicas}

Parte das limitações dos sistemas EBW vêm da própria Web. Atualmente, as fontes de informações disponíveis são heterogêneas, distribuídas e não estruturadas, baseadas no protocolo HTTP e na linguagem de marcação HTML. O HTTP e o HTML provêem a estrutura necessária para criar e acessar os conteúdos através das páginas Web, links e navegadores. Estas tecnologias oferecem suporte limitado para acesso e processamento das informações e delegam o trabalho de extrair e interpretar as informações ao usuário. A solução para esta limitação é automatizar o uso da Web e aumentar o nível de interação dos usuários com a Web. Para isto, pode-se utilizar as tecnologias disponibilizadas pela Web Semântica.

\subsubsection{Limitações das ferramentas de autoria para EBW}

Existem várias ferramentas para a construção de sistemas EBW. Dentre elas pode-se citar: Learning Space, CourseInfo, TopClass, WebCT, WBC e AuthorWare, descritas em Gonzáles (2000). Todas elas apresentam as seguintes limitações: 
- Não têm explícito, em sua construção, representações de teorias de projeto instrucional e de aprendizagem e nem ligações para estas representações. $\mathrm{O}$ responsável pelo desenvolvimento, e não a ferramenta, é que deve conhecer estas teorias;

- Há grandes diferenças conceituais entre as ferramentas e os autores;

- São pouco amigáveis e "inteligentes”, ou seja, não são capazes de adaptar-se ao comportamento e às circunstâncias sob a qual o usuário trabalha (MIZOGUSHI, 2000);

- Não existe suporte para compartilhamento e reutilização dos materiais de aprendizagem, ou de seus componentes, desenvolvidos em outros sistemas educacionais.

Levando-se em consideração estas limitações, o processo de elaboração de sistemas EBW nestas ferramentas é difícil para quem não tem experiência em elaborar páginas na Web. As ferramentas não suportam o processo de autoria em termos de prover um guia e as restrições para a construção do sistema EBW. Atualmente, não há ferramentas que suportem o desenvolvimento dos materiais de aprendizagem que possam ser apresentados, modificados e interligados, consistentemente. Isto somente é possível, se os materiais de aprendizagem produzidos puderem ser anotados, com ponteiros para ontologias apropriadas.

Outra limitação, que restringe severamente o uso das ferramentas na criação de sistemas EBW, é a falta de um vocabulário padrão para os domínios educacionais e projetos instrucionais. A falta de um vocabulário padrão é também uma das razões pela qual não há uma ontologia padrão que poderia cobrir as várias áreas e aspectos de ensino e aprendizado (seqüência curricular, modelo de estudante, modelo do professor, modelo pedagógico, etc.). Algumas propostas para um vocabulário padrão já estão sendo discutidas. O item 4.4.1 comenta algumas delas.

\subsection{Interação e a educação baseada na Web}

Muitas vezes, os termos educação a distância e educação baseada na Web são usados como sinônimos. Pela tabela 4.2, pode-se observar que a educação baseada na Web refere-se à quarta e quinta geração dos modelos de educação a distância. Portanto, o 
termo educação baseada na Web refere-se ao uso da plataforma Web para a implementação de ferramentas que possibilitam implementar educação a distância.

Freire (1978, p. 78) diz que: "A educação autêntica, repitamos, não se faz de 'A' para 'B' ou de 'A' sobre 'B', mas de 'A' com 'B', mediatizados pelo mundo'. González (2000, p. 11) define Educação a Distância como: "um sistema didático, de comunicação pedagógica não contínua, unidirecional ou bidirecional, organizada em forma de auto-estudo, onde as ações dos professores são executadas de forma independente das ações dos alunos, onde a comunicação professor-aluno e alunoaluno está diferida no tempo, no espaço, ou em ambos, sem que fique excluído o contato direto entre eles".

Da afirmação de Freire (1978), pode-se concluir que educar trata basicamente de interação, e da definição de González (2000), pode-se concluir que a educação a distância é composta de três fatores básicos: distância, independência e interação. Destes fatores, o que mais gera controvérsias é a questão da interação, que vem a ser um dos principais problemas para a educação baseada na Web. Wagner (1994) apud Anderson (2002), define interação como: "Eventos recíprocos que requerem no mínimo dois objetos e duas ações. A interação ocorre quando estes objetos e eventos mutuamente influenciam um e outro". Moore (1989), levanta algumas questões sobre interação: Qual nível de interação é essencial para um aprendizado efetivo? O que é uma boa interação? Como nós podemos alcançá-la? Em que, a interação em tempo real contribui? Seus custos são compensadores? Sem dar respostas a estas questões, Moore (1989), sugere que as aplicações em educação a distância devem ter, no mínimo, três tipos de interações:

- Interação estudante-conteúdo: a forma mais antiga de interação com o conteúdo, em ensino a distância, é o texto didático. Mais recentemente, os estudantes passaram a interagir com o conteúdo através de programas de rádio, televisão, fitas de áudio, fitas de vídeo, software e videodiscos. Normalmente, o aprendizado é autodirigido e, em algumas situações, existem alguns professores para ajudar o estudante.

- Interação estudante-professor: nesta interação, os professores planejam o conteúdo a ser ensinado e procuram manter os alunos motivados e estimulados, 
através de apresentações, avaliações periódicas para avaliar o progresso e, se necessário, mudanças nas estratégias de aprendizado.

- Interação estudante-estudante: esta forma de interação traz uma nova dimensão para a educação a distância. A interação entre os estudantes de uma classe ou de outros grupos, é um recurso essencial de aprendizado. Esta interação é crítica nas tarefas cooperativas e colaborativas. Neste caso, os professores podem interagir individualmente com os alunos por e-mails e os alunos podem interagir entre si, assincronamente, através de $e$-mails e, sincronamente, através de chats.

Estas são as interações básicas para as aplicações de educação a distância. Anderson (2002) acrescenta outros três tipos de interações: professor-professor, professorconteúdo, conteúdo-conteúdo, representados na figura 4.1. A interação professorprofessor é crítica nos modelos atuais de universidades, pois estas interações contribuem para a produção de pesquisa. Além disso, também são importantes para os sistemas EBW e o que se coloca é como melhorar estas interações. Sistemas EBW, com a utilização das tecnologias da Web Semântica, podem ser a solução para esta questão.

\subsection{Educação baseada na Web e a Web Semântica}

A arquitetura da Web Semântica provê um ambiente no qual o significado do conteúdo disponível na Web pode ser automaticamente interpretado e compreendido pelas máquinas, possibilitando novas formas de navegação e acesso ao conteúdo. Com a Web Semântica, alguns aspectos da educação baseada na Web podem ser melhorados. Dentre eles pode-se citar: (STOJANOVIC et al., 2001):

- Entrega: Itens dos materiais de aprendizagem são distribuídos na Web, mas são conectados através de uma ontologia comum. Isto possibilita consulta semântica nos tópicos de interesse; 


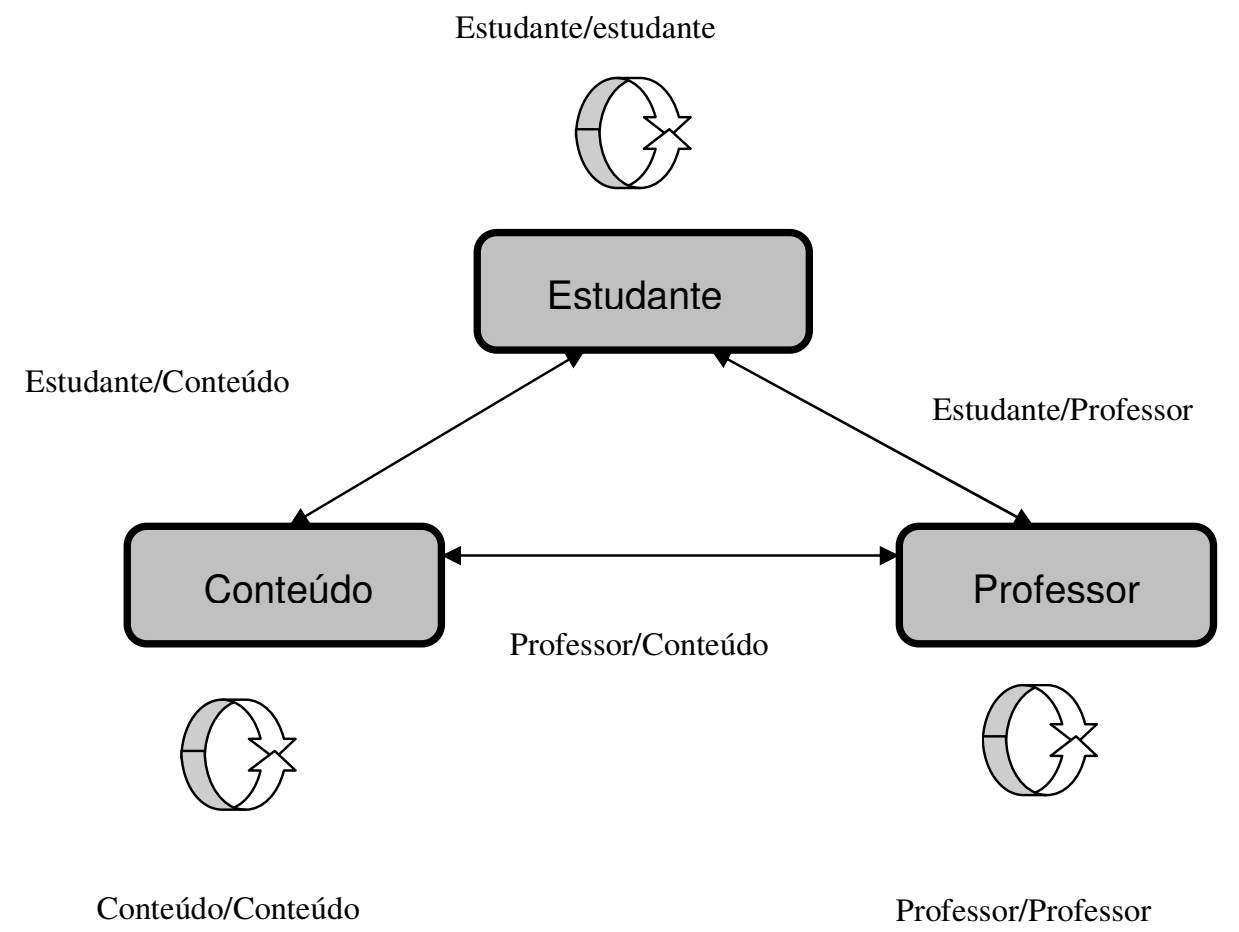

Fig. 4. 1 - Modos de interação em educação a distância (ANDERSON, 2002)

- Acesso: O estudante pode realizar pesquisas semânticas nos materiais de aprendizagem disponíveis. Por exemplo, consultas do tipo "Quais materiais de aprendizagem sobre engenharia de software estão disponíveis na Universidade de São Paulo?", irão "devolver" como resposta não só os materiais educacionais disponibilizados para o curso do aluno, como outros materiais desenvolvidos para outros cursos, que eventualmente, poderiam também ser utilizados por ele para complementação de seus estudos;

- Integração: Potencial para integração entre as diversas plataformas de negócios de uma organização com as atividades de aprendizagem;

- Distribuição: Possibilita maior distribuição dos materiais de aprendizagem, através da anotação semântica; 
Personalização: O material de aprendizagem pode ser personalizado de acordo com as necessidades de cada estudante. A ontologia estabelece a conexão entre estas necessidades e o material de aprendizagem.

Estes aspectos facilitam a busca e a interação dos materiais de aprendizagem. Isto é possível porque a Web Semântica possibilita o uso de ontologias baseadas em metadados no desenvolvimento das aplicações baseadas na Web. Entender o que são metadados e suas relações com ontologias em ambientes educacionais é a chave para o desenvolvimento de aplicações educacionais baseadas na Web e sua integração com as tecnologias da Web Semântica. É o que será apresentado nas próximas seções.

\subsubsection{Metadados e ontologias}

Com o crescimento das informações disponíveis na Web, procurar informações relevantes na Web é cada vez mais difícil. Normalmente, os mecanismos de pesquisa oferecem milhares de resultados, quando esta é realizada através de palavras chave, sem a aplicação de filtros adequados. Um dos problemas é que as páginas HTML e os conteúdos multimídia ainda não são descritos adequadamente. A solução é a utilização de metadados. Metadados são, normalmente, descritos como sendo "dados a respeito de dados". Mais tecnicamente, pode-se dizer que metadados são dados estruturados que descrevem as características de um recurso. Consistem de um número pré-definido de elementos que representam atributos específicos de um recurso e cada elemento pode ter um ou mais valores. A tabela 4.3 exemplifica um metadado.

Tabela 4. 3 - Exemplo de metadado

\begin{tabular}{|l|l|}
\hline \multicolumn{1}{|c|}{ Elemento } & \multicolumn{1}{c|}{ Valor } \\
\hline Título & Página Web de Moysés de Araujo \\
\hline Criador & Moysés de Araujo \\
\hline Publicação & Universidade de São Paulo \\
\hline Identificação & http://www.moysesaraujo.com.br \\
\hline Formato & Texto/html \\
\hline
\end{tabular}


Segundo Steinacker (2001), metadados podem ser úteis para resumir o significado dos dados, permitir aos usuários pesquisar os dados mais facilmente e determinar se os dados encontrados são realmente os solicitados, dar informações a respeito do uso dos dados (tamanho, condições legais, idade, etc.) e indicar relações com outros recursos. $\mathrm{Na}$ área educacional três padrões de metadados estão surgindo para descrever os recursos utilizados na EBW: do Learning Technology Standards Committee of the IEEE (2002), conhecido como LOM (Learning Object Model), do IMS Global Learning Consortium (2001) e ARIADNE (Alliance of Remote Instructional Authoring and Distribution Networks for Europe $)^{9}$.

Estes padrões de metadados definem como os materiais de aprendizagem podem ser descritos para que possam ser pesquisados de modo mais preciso, bem como facilitar a interoperabilidade entre as aplicações. Todos os elementos necessários para descrever um recurso podem ser classificados em várias categorias, cada uma oferecendo uma visão distinta de um recurso. Por exemplo, o padrão LOM contém os seguintes níveis de metadados, segundo Stojanovic et al. (2001):

- Geral: grupos que descrevem as características independentes do contexto, mais a descrição semântica do recurso;

- Ciclo de vida: grupos de características ligadas com o ciclo de vida do recurso;

- Meta-metadados: grupos de elementos de dados que descrevem os metadados que indexam os documentos;

- Técnicos: grupos de elementos de dados que descrevem as características técnicas do documento;

- Educacional: grupos de elementos de dados que descrevem as características educacionais e pedagógicas do recurso;

- Direitos: grupo de elementos de dados que relatam as condições de uso dos recursos;

- Relações: grupos de elementos de dados que descrevem a ligação entre o sujeito e outros recursos;

\footnotetext{
${ }^{9}$ http://ariadne.unil.ch/Metadata/
} 
- Anotações: grupo de elementos de dados que permitem comentários do uso educacional dos recursos;

- Classificação: grupos de elementos de dados que descrevem a posição de um recurso em uma classificação existente no sistema.

O modelo conceitual LOM para definição de metadados é o hierárquico. A hierarquia completa do modelo é chamada de "estrutura de árvore" do documento e a implementação de LOM é baseada em RDF e RDF Schema.

O projeto ARIADNE foi recentemente transformado em uma Fundação e um de seus mais importantes objetivos é organizar o desenvolvimento e exploração do KPS (Knowledge Pool System), um banco de dados distribuído para reutilização de componentes de aprendizagem associados com os metadados que os descrevem. A comunidade ARIADNE recomenda que vinte e três elementos do LOM tornem-se mandatórios. Assim, estão desenvolvendo uma taxonomia de tipos de ciências, disciplinas e subdisciplinas, que deverá ser usada para indicar a semântica dos conteúdos de aprendizagem. A tecnologia básica para o desenvolvimento das ferramentas do ARIADNE é o XML.

Por sua vez, o consórcio IMS liberou a versão 1.1 da sua especificação de metadados em setembro de 2001, baseada na especificação do LOM. Sua especificação inclui a sugestão de um vocabulário controlado de doze elementos. Usa a tecnologia XML na forma de um DTD.

Estas entidades têm desenvolvido seus próprios padrões de vocabulários de metadados para suas necessidades específicas. Entretanto, na maioria destes padrões de metadados falta uma semântica formal. Embora estes padrões possibilitam interoperabilidade dentro de um mesmo domínio, eles introduzem o problema de incompatibilidade, quando padrões de metadados diferentes são usados na descrição dos domínios. Esta falta de entendimento compartilhado entre termos de um vocabulário, bem como entre termos em vários vocabulários de metadados, pode ser evitada usando ontologias como principal suporte para o ambiente de EBW. 
Segundo Stojanovic et al. (2001) no ambiente da EBW, sob o ponto de vista de um estudante, os critérios para pesquisar um material de aprendizado são: sobre o que é o material de aprendizado (conteúdo) e em qual forma os tópicos do material de aprendizagem são apresentados (contexto). O contexto, mais o conteúdo, forma a estrutura do material de aprendizagem. O conteúdo, contexto e estrutura são descritos através dos metadados.

\subsubsection{Metadados e descrição do conteúdo do material de aprendizagem}

Em um ambiente de EBW há o risco de dois autores expressarem o mesmo conteúdo de maneiras diferentes. Semanticamente, são conceitos idênticos, mas podem ser explicados por termos diferentes de um vocabulário. Por exemplo, um autor pode usar qualquer dos termos equivalentes para o conceito de Agente: "agente", "autor", “criador", "contribuinte", "trabalhador" e "ator". O problema pode ser resolvido pela integração de um domínio léxico na ontologia, e então, definir o mapeamento dos termos do vocabulário de um domínio para seu significado definido pelos conceitos da ontologia. No exemplo, "agente”, “autor", “criador", “contribuinte”, "trabalhador" e "ator" são símbolos usados no mundo real e que são mapeados para o mesmo conceito, Agente, na ontologia de domínio.

\subsubsection{Metadados e descrição do contexto dos materiais de aprendizagem}

Os materiais de aprendizagem podem ser apresentados em vários contextos. Pode-se distinguir os contextos como introdução, análise de um tópico ou uma discussão. Um exemplo ou uma figura, normalmente, fazem parte da apresentação do contexto. A descrição do contexto possibilita pesquisas relevantes do material de aprendizagem, de acordo com as preferências do usuário. Por exemplo, se o usuário necessita de explicações mais detalhadas de um tópico, é razoável procurar materiais de aprendizagem que descrevam um exemplo de um determinado tópico. Para compreender o significado do vocabulário do contexto, pode-se construir uma ontologia para o contexto considerado.

\subsubsection{Metadados e descrição da estrutura dos materiais de aprendizagem}

Normalmente o material de aprendizagem é estruturado em pequenas "peças" de informação, que podem ser conectadas para compor um curso completo a ser 
ministrado. A estrutura do curso pode ser configurada conforme o perfil dos alunos para os quais este curso se destina. Dependendo do tipo, do grau de conhecimento e das preferências do usuário, bem como das dependências semânticas que existem entre as partes de informação, inúmeros cursos diferentes poderiam ser "montados". Vários tipos de relações entre as partes do material de aprendizado podem ser identificadas para que estes possam ser relacionados entre si. Algumas delas são: Anterior, Próximo, ÉPartede, Temparte, Referências, ÉReferenciadoPor, ÉBaseadoEm, ÉBasePara, Requer, ÉRequeridoPor. Existem conexões semânticas entre algumas destas relações que podem se definidas por axiomas. Por exemplo, ÉParteDe e TemParte são relações inversas. $\mathrm{O}$ axioma correspondente pode ser explorado ao se pesquisar uma informação. Sem a definição da relação inversa, pesquisar informações dependeria da maneira como o metadado foi descrito pelo autor do conteúdo de aprendizagem. Se um autor define que um material de aprendizagem de nome " $X$ " ÉBaseadoEm algum outro material de aprendizado de nome "Y", não há possibilidade - sem programação ou especificação explícita - de descobrir todo o material de aprendizagem em que o material de aprendizagem "Y" "ÉBa seadoPara".

Pode-se notar que estas três dimensões de metadados também aparecem no modelo convencional de metadados (conteúdo = metadado de classificação, contexto = metadado educacional e pedagógico, estrutura = metadado relacional). Entretanto, estes metadados são metadados baseados em ontologias e têm, por este motivo, uma precisão semântica definida. A base semântica resulta em uma melhor descrição do conteúdo de aprendizagem e em melhores métodos de pesquisa dos conteúdos, de acordo com a preferência do usuário.

\subsection{Trabalhos correlatos}

Ainda não há ferramentas de autoria que possibilitem o desenvolvimento de sistemas EBW que utilizem plenamente os avanços proporcionados pela tecnologia da Web Semântica. Os estudos, nesta área, estão ainda em sua fase inicial e o que existe, ainda está em fase de especificação ou em experimentos em protótipos. As iniciativas encontradas através da literatura estão descritas a seguir. 


\subsubsection{A iniciativa $(\mathrm{KA})^{2}$}

Esta iniciativa está descrita em Benjamin et al. (1999). Para investigar a praticabilidade do Ontobroker - descrito de forma resumida no Apêndice A -, seus pesquisadores desenvolveram um sistema de gerenciamento de conhecimento, com o objetivo de capturar o conhecimento de uma comunidade científica. (KA) ${ }^{2}$ significa Knowledge Annotation Initiative of the Knowledge Acquisition Community (http://ka2portal.aitb.uni-karlsruhe.de/) e descreve uma organização virtual, consistindo de pesquisadores, universidades, projetos e publicações. A informação reside em páginas da WWW, onde os pesquisadores publicam informações a respeito de suas afiliações, projetos, publicações, etc. Para este sistema foi construída uma ontologia com os seguintes critérios: modularidade, para permitir maior flexibilidade em uma variedade de usos, especialização dos conceitos - indo dos mais gerais para os mais específicos -, classificação dos conceitos em grupos com características similares, para garantir a herança de tais características e padronização de nomes. A ontologia desta comunidade consiste de sete ontologias relacionadas que são: Organização, Projeto, Pessoal, Tópicos de Pesquisa, Publicação, Eventos e Produtos de Pesquisa. A título de ilustração, a ontologia de Pessoal está representada na figura 4.2. Esta ontologia define o tipo de pessoas que trabalham em um ambiente acadêmico e suas características. Esta ontologia define dez classes e vinte e três relações. A indentação denota a relação de sub-classe.

Cada pesquisador faz anotações em sua página para que esta possa se tornar visível para outros pesquisadores. Por ser um trabalho tedioso, lento e propenso a erros, foi desenvolvido um software para anotação chamado Ontopad. 
Class hierarchy (10 classes defined):

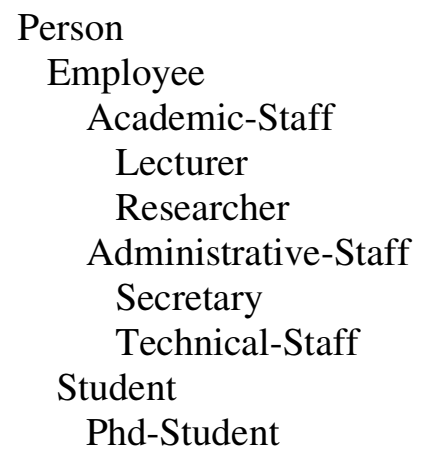

Address, Affiliation, Cooperates-With, Editor-Of, Email, First-Name, Has-Publication, Head-Of-Group, Head-Of-Project, Last-Name, Member-Of-Organization, Member-Of-Program-Committee, Member-Of-Research-Group, Middle-Initial, Organizer-Of-Chair-Of, Person-Name, Photo, Research-Interest, Secretary-Of, Studies-At, Supervises, Supervisor, Works-At-Projects.

Fig. 4. 2 - Ontologia de pessoal do (KA) $)^{2}$

Após esta tarefa, os pesquisadores registram suas páginas no Ontobroker, informando qual a URL da página. Neste instante, estas páginas já estão prontas para serem consultadas e recuperadas pelas interfaces do Ontobroker. Uma consulta possível é perguntar por todos os pesquisadores da comunidade. A resposta, não somente inclui os pesquisadores que têm suas páginas anotadas, mas também os pesquisadores que cooperam com estes pesquisadores. A ontologia que define a cooperação entre os pesquisadores e possibilita esta dedução é: se $X \operatorname{coopera~} \operatorname{com} Y$, então $X$ e $Y$ devem ser pesquisadores. O Ontobroker utiliza este tipo de definição para derivar novos fatos (for exemplo, Y também é pesquisador). Este exemplo ilustra que é possível acessar um conhecimento que não está explicitamente representado, o que é uma grande vantagem, se comparado com a pesquisa feita por 
palavra-chave. $\mathrm{O}(\mathrm{KA})^{2}$ foi o passo inicial para a definição de ambientes mais sofisticados e está sendo adaptado para a Web Semântica ${ }^{10}$.

\subsubsection{Reuso de materiais de aprendizagem no AulaNet}

Este projeto é descrito por Goni et al. (2002). O objetivo desta proposta é mostrar uma aplicação do Protégé 2000 para a geração de ontologias numa arquitetura multiagente, a Web Semantic Search (WebSS). AulaNet é uma ferramenta baseada em agentes para o reuso de materiais de aprendizagem em servidores AulaNet, e é implementada a partir de uma arquitetura de agentes para acesso, descrição, localização e reuso de conteúdo educacional, respeitando a granularidade do ambiente AulaNet, para o menor nível semântico possível. Utiliza o padrão IMS, onde todo conteúdo é relacionado a uma série de características como, por exemplo, o título do conteúdo, sua descrição, seu formato e o usuário pretendido para o mesmo. O modelo de Classes do AulaNet é usado como base para criar a ontologia de uma aplicação. Esta ontologia é editada no Protégé 2000, que gera automaticamente a codificação RDF e RDF Schema. Este projeto está em sua fase inicial, sendo que a ferramenta WebSS ainda não foi implementada.

\subsubsection{Ontologias para o domínio da educação mediada pela Web}

Este é um projeto de pesquisa apresentado por Campos et al. (2002). Desenvolvido em parceria entre a Universidade Federal de Juiz de Fora e a Universidade Estadual do Rio de Janeiro, este projeto é intitulado "Web Semântica: Usando Ontologias para Buscas no Domínio da Educação Mediada pela Web”. O seu objetivo é construir uma biblioteca virtual (BV) para a educação mediada pela Web. Esta biblioteca irá abrigar textos, sistemas e ferramentas neste domínio. A indexação está organizada segundo uma ontologia construída para esse fim, e utiliza a tecnologia de agentes inteligentes na Web. Neste projeto serão usados os agentes de interface e de informação. A ontologia é composta de duas categorias: Educação Baseada na Web e Aprendizagem Cooperativa por Computador. Este é um projeto de 24 meses, que está em sua fase inicial e não há ainda nenhuma ferramenta implementada, no momento.

\footnotetext{
${ }^{10}$ Ver http://ka2portal.aifb.uni-karlsruhe.de
} 


\subsection{Conclusões}

Este capítulo descreve as novas possibilidades educacionais proporcionadas pelas ferramentas educacionais para EBW. Através da Internet podemos ter acesso a grandes volumes de informação e a grandes repositórios de materiais educacionais, que se constituem em um grande potencial para educação e entretenimento. Entretanto, as limitações conceituais e tecnológicas dos sistemas EBW e as limitações das ferramentas que implementam estes sistemas impedem o pleno aproveitamento deste material. Outro fator importante, mas limitado em sistemas EBW é a interação entre professores, alunos e os materiais educacionais. Estas limitações podem ser superadas com a utilização das tecnologias que compõe a Web Semântica, tais como ontologias, metadados, RDF, RDF Schema e DAML+OIL no desenvolvimento de Sistemas EBW. Como aplicar estas tecnologias em um ambiente educacional específico é o será estudado no próximo capítulo. 


\section{UMA ONTOLOGIA PARA MATERIAIS E OBJETOS DE APRENDIZAGEM}

O objetivo principal desta ontologia é descrever como poderiam ser estruturados os materiais de aprendizagem na plataforma CoL para incorporar representação semântica dos conteúdos destes materiais, possibilitando a pesquisa "inteligente" e a reutilização.

\subsection{A ferramenta CoL - Cursos OnLarc}

A descrição a seguir baseou-se em um resumo apresentado por Silveira et al. (2002). O CoL é um sistema de gerenciamento de cursos a distância, presenciais e semipresenciais, desenvolvido pelo Laboratório de Arquitetura e Redes de Computadores da Escola Politécnica da Universidade de São Paulo (LARC). É um sistema que se propõe a hospedar cursos baseados em páginas HTML e recursos multimídia, oferecendo o suporte necessário para a organização de alunos, turmas, matrículas, avaliações, chat, listas de discussão entre outros.

Um curso no CoL é formado por módulos, disciplinas e turmas. Uma turma pode ter várias disciplinas e uma disciplina pode ter vários módulos. A figura 5.1 representa a hierarquia entre as entidades que formam um curso.

O módulo é a unidade básica de um curso no CoL. É considerado uma abstração de um conceito, um capítulo de um livro ou um assunto qualquer. Deve ser formado por uma ou mais páginas HTML ligadas entre si e pode conter qualquer tipo de arquivo associado ao conteúdo, como vídeo, som, imagens, animações, etc., que devem estar disponibilizados no servidor que gerencia o CoL. 


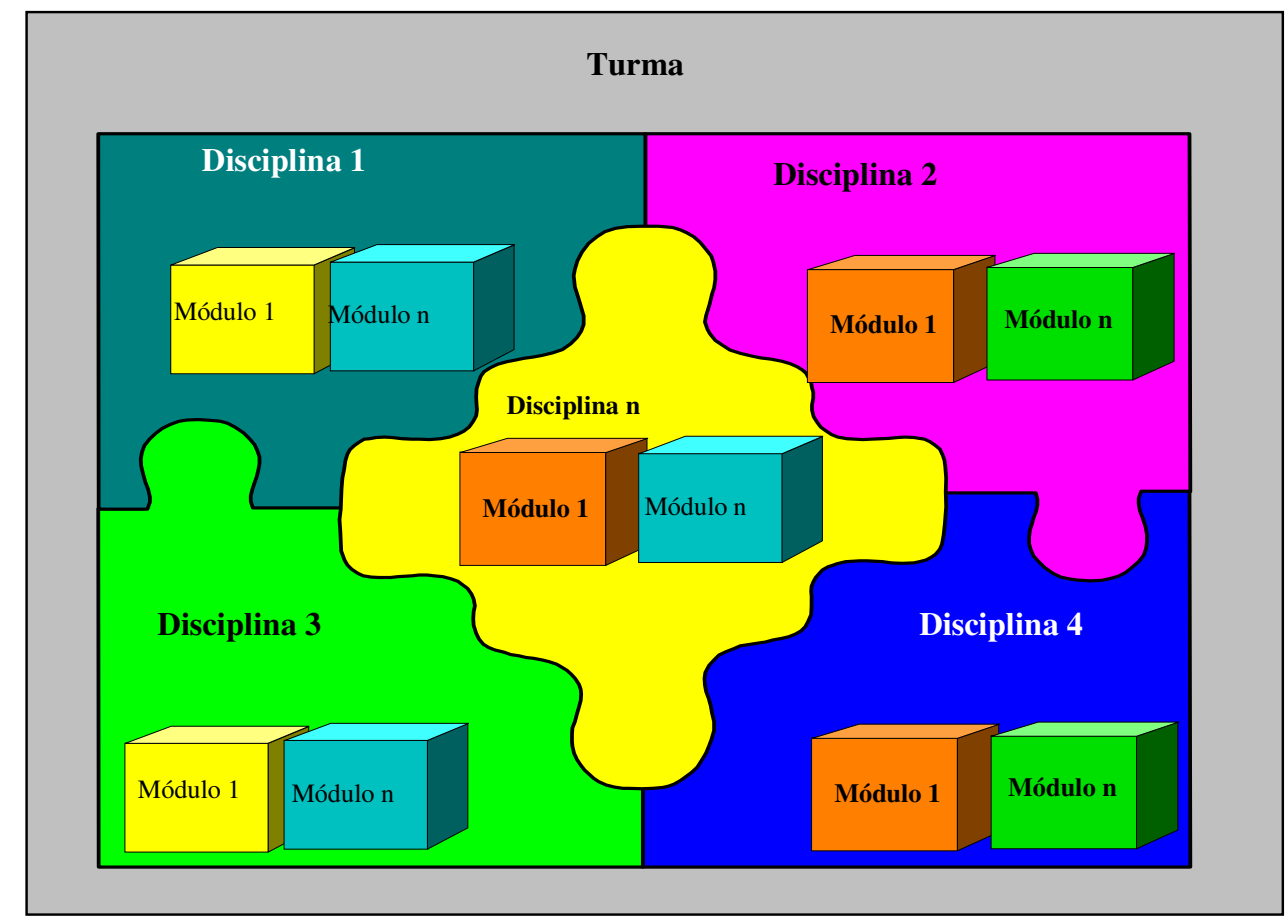

Fig. 5.1 - Estrutura das disciplinas e módulos na plataforma CoL, segundo Silveira et al. (2002)

A um módulo ou disciplina pode estar, ou não, associada uma avaliação, cujo propósito é exclusivamente verificar a aquisição de algum conceito apresentado no conteúdo do módulo. Montadas as disciplinas, o professor pode disponibilizá-las para turmas de alunos selecionadas, que podem estar cursando uma ou mais disciplinas. A turma tem diversos itens configuráveis como o tempo de duração, quantidade de alunos, entre outros.

O CoL possui ferramentas interativas como chat, apresentação e listas de discussão, que podem ser utilizadas pelas turmas, de forma a amenizar os problemas causados pela distância. O professor pode observar a freqüência com que os alunos estão estudando o conteúdo dos módulos, o seu aproveitamento nas avaliações, dividir a gerência da turma com outros professores, aproveitar o material desenvolvido por outro professor, etc.

Para melhorar o entendimento da estrutura do CoL, exemplificam-se estes conceitos. Seja, por exemplo,um curso de Pós-Graduação em Web Semântica e como turma, pode-se considerar, Pos2003A, composta de um número qualquer de alunos. As 
disciplinas a serem cursadas podem ser: XML - Conceitos Básicos, RDF/RDF Schema, Ontologias e Linguagens para a Web Semântica. A disciplina XML Conceitos Básicos pode ter a estrutura mostrada na figura 5.2.

A mesma estrutura pode ser aplicada para as demais disciplinas. O itens numerados representam o conteúdo programático de cada módulo. Cada item é uma página HTML, desenvolvida pelo professor responsável pela disciplina ou pelo módulo. Arquivos de vídeo, som, imagens, animações etc., devem possuir um link na página HTML para serem exibidos.

Assim como outras plataformas de educação a distância, a plataforma CoL trata basicamente do gerenciamento dos cursos e das atividades dos participantes. A ferramenta, entretanto facilita o acesso ao material didático do curso, bem como permite condicionar esse acesso ao bom entendimento do conteúdo anterior, através de vinculação do material de aprendizagem a testes programados pelo professor, nos quais se exige do aluno um número mínimo de acertos. Por outro lado, para a preparação do material didático, o professor pode fazer uso da ferramenta de autoria que julgar mais conveniente.

O CoL não especifica como o professor deve organizar o material de aprendizagem de seu curso. As definições e restrições colocadas na especificação técnica desta plataforma detêm-se ao nível do módulo. Desta forma, este trabalho estende a plataforma CoL, propondo uma forma de organização do material de aprendizagem voltada para a reutilização do material didático, permitindo a recuperação automatizada do conteúdo educacional armazenado nos bancos de dados desta plataforma. 
Módulo 1 - Informações sobre a disciplina

1.1 - Objetivos

1.2 - Organização da Disciplina

1.3 - Convenções da disciplina

1.4 - Como testar os arquivos

1.5 - Pré-requisitos

1.6 - Sistema de Avaliação

Módulo 2- Linguagens de Marcação

2.1 - Definição

2.2 - SGML

2.3 - HTML - Definição

2.4 - HTML - Importância

2.5 - HTML - Formato

2.6 - HTML - Vantagens e Limitações

2.7 - Resumo

2.8 - Exercícios

2.9 - Avaliação

Módulo 3 - Introdução ao XML

3.1 - XML - Definição

3.2 - XML - Documentos válidos e bem formatados

3.3 - XML - Vantagens

3.4 - Aplicações XML

3.5 - Resumo

3.6 - Exercícios

3.7 - Avaliação

Módulo 4 - Elaboração de documentos XML

4.1 - Marcações de inicio e fim

4.2 - Atributos

4.3 - Entidades

4.4 - Comentários

4.5 - Instruções de Processamento

4.6 - Seções CDATA

4.7 - Declaração do tipo de documento

4.8 - Um documento XML completo

4.9 - Resumo

4.10 - Exercícios

4.11 - Avaliação

Fig. 5.2 - Estrutura da disciplina XML - Conceitos Básicos 
Entretanto, a preparação dos materiais de aprendizagem tornou-se um processo fundamental para o sucesso destas plataformas. No trabalho de González (2000), encontram-se estratégias pedagógicas para elaboração de cursos em pequenas unidades de conteúdo chamadas de Unidades de Aprendizagem. Em Toscaro et al. (2003) encontram-se algumas orientações para preparação dos materiais de aprendizagem. As mais importantes são:

- Dividir os materiais dos módulos em textos pequenos e objetivos;

- Utilizar, quando possível, tópicos no lugar de parágrafos;

- Utilizar imagem, animação, vídeo ou som em assuntos dinâmicos;

- Vídeos devem ser de, no máximo, três minutos;

- Colocar leituras complementares ao final de cada tópico abordado;

- Apresentar linguagem simples e direta;

- Colocar referências dos materiais de aprendizagem relacionadas ao assunto;

- Manter a consistência e uniformidade dos botões de navegação.

Uma das soluções possíveis para tratar das limitações conceituais discutidas no capítulo 4, tais como o compartilhamento e reutilização dos materiais de aprendizagem entre aplicações, estruturação dos materiais de aprendizagem através de pontos comuns de referência e anotação dos materiais de aprendizagem para facilitar o acesso e, ainda, atender algumas das recomendações colocadas, é a utilização dos materiais de aprendizagem formados por um ou mais objetos de aprendizagem.

\subsection{Materiais de aprendizagem e objetos de aprendizagem}

Neste trabalho, será considerada a seguinte definição de materiais de aprendizagem:

"Material de aprendizagem equivale a cada item do conteúdo programático de um módulo.” 
Por exemplo, na disciplina XML - Conceitos Básicos, apresentada na figura 5.2, tem-se que "HTML - Importância" e "HTML - Formato" são materiais de aprendizagem do módulo Linguagens de Marcação. Estes materiais de aprendizagem são compostos por um ou mais objetos de aprendizagem. Um objeto de aprendizagem pode ser uma figura, um gráfico, uma simulação, etc.

Atualmente, objetos de aprendizagem estão tornando-se um modelo padronizado de armazenamento e distribuição de informações em sistemas de ensino a distância através da Web, estando estruturados para uma integração direta com as tecnologias da Web Semântica.

Não existe uma definição de consenso entre os autores que pesquisam sobre objetos de aprendizagem. De acordo com a Learning Technology Standards Commitee of the IEEE (2002), um objetos de aprendizagem é:

"Qualquer entidade, digital ou não digital, que possa ser usada para aprendizado, educação e treinamento.”

Esta definição é extremamente vaga e generalista; pode-se concluir a partir dela que qualquer elemento pode ser considerado um objeto de aprendizagem. Wiley (2001) apresenta uma outra definição:

"Qualquer recurso digital que possa ser reutilizado para apoio ao aprendizado. A principal idéia dos objetos de aprendizado é quebrar o conteúdo educacional em pequenos pedaços que possam ser reutilizados em diferentes ambientes de aprendizagem, em um espírito de programação orientada a objetos".

Já Sosteric e Hesemeier (2002) apresentam a seguinte definição:

"Um objeto de aprendizagem é um arquivo digital (imagem, filme, etc.) que pode ser utilizado para fins pedagógicos que incluem, internamente ou através de associação, sugestões sobre o contexto apropriado para a sua utilização". 
Segundo os autores esta definição é incompleta, mas é um ponto de partida para uma definição real dos objetos de aprendizagem. Como não há consenso sobre a definição de objetos de aprendizagem, para fins deste trabalho será adotada a seguinte:

Objeto de aprendizagem é um tipo de componente dos materiais de aprendizagem, que pode ser independente da mídia utilizada, entendidos como entidades digitais que podem ser acessadas simultaneamente através da Web, por vários aprendizes.

Independentemente do tipo de aplicação educacional, os objetos de aprendizagem apresentam as seguintes características (LONGMIRE, 2001; FRIESEN, 2001):

- Reusabilidade: um objeto de aprendizagem pode ser usado em diversos materiais de aprendizagem diferentes;

- Facilidade de pesquisa e atualização: com a utilização dos padrões de metadados existentes (item 4.4.1) é possível obter informações sobre os objetos de aprendizagem, tais como seu conteúdo, utilização, autor, tamanho, formato, e outras, tornando-o compreensível para diversas plataformas computacionais; Normalmente, os metadados estão separados dos objetos de aprendizagem, o que possibilita o seu uso na Web;

- Modularidade: um objeto de aprendizagem pode conter outros objetos de aprendizagem, ou estar contido em um ou mais materiais de aprendizagem. Um objeto de aprendizagem deve ser construído de tal maneira que os usuários não precisem saber sobre seus componentes e sobre sua complexidade interna.

- Interoperabilidade: um objeto de aprendizagem deve ser capaz de utilizado em diversos tipos de hardware, sistemas operacionais, navegadores ou outros ambientes de aprendizagem.

Uma solução para atender estas características é a modelagem dos materiais de aprendizagem baseada em ontologias, utilizando a infraestrutura da Web Semântica, formada por componentes tais como metadados, linguagens de ontologia (DAML+OIL). Segundo Qin (2001), esta abordagem permite que os materiais de 
aprendizagem possam ser representados em diferentes níveis de granularidade, como demonstrado na figura. 5.3.

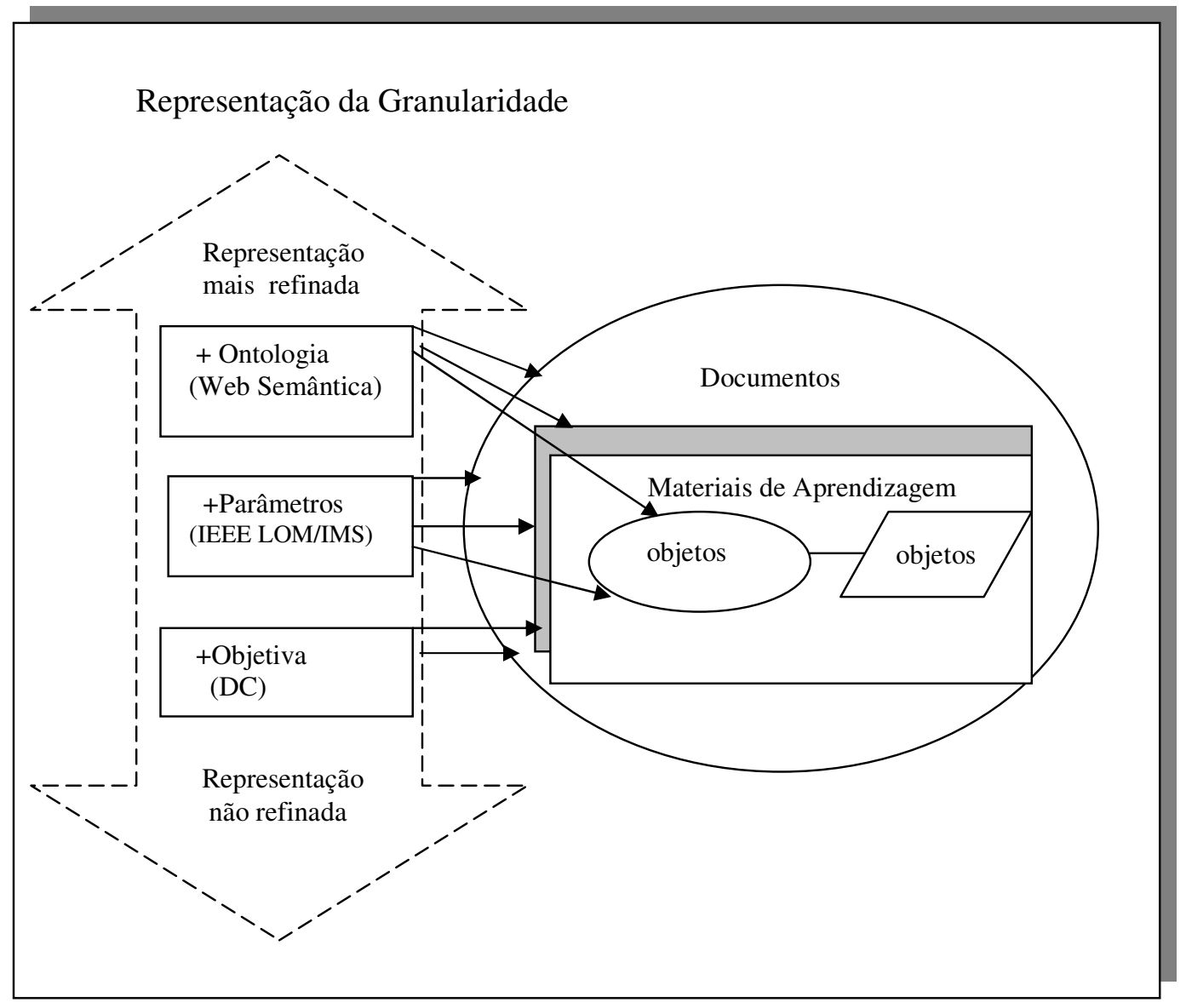

Fig. 5.3 - Representação da granularidade (QIN, 2001)

$\mathrm{Na}$ figura. 5.3, a representação não refinada descreve de forma mais objetiva os documentos e os materiais de aprendizagem que formam os documentos. Isto é feito pelo padrão Dublin Core Metadata (Dublin Core Metadata Initiative, 1999). A representação mais refinada permite descrever uma coleção de documentos, os materiais de aprendizagem que formam os documentos e os objetos de aprendizagem que formam os materiais de aprendizagem. Isto é feito pelos padrões de metadados da Learning Technology Standards Committee of the IEEE (2002) e da IMS Global 
Learning Consortium (2001), que definem parâmetros técnicos e educacionais mais específicos dos materiais de aprendizagem.

Utilizando ontologias, através da Web Semântica na representação mais refinada, pode-se representar e correlacionar os objetos que compõem os materiais de aprendizagem. Armazenando-se as relações entre os objetos é possível, aos usuários realizar pesquisas para recuperar e reutilizar estes objetos. A próxima seção descreve como são construídas estas ontologias e as bases ontológicas do conhecimento.

\subsection{Construindo uma ontologia para materiais de aprendizagem}

Como visto no capítulo 2, uma ontologia refere-se a um conjunto de conceitos ou termos que podem ser usados para descrever algum domínio de interesse, neste caso, os materiais de aprendizagem. Portanto, para um entendimento satisfatório deste domínio é necessário conhecer os conceitos pertencentes a este domínio, as relações existentes entre estes conceitos bem como os termos do vocabulário deste domínio.

A primeira atividade para a construção desta ontologia foi a elaboração parcial de um diagrama UML da plataforma CoL, para a obtenção dos principais conceitos, relações e atributos. O diagrama está representado na figura 5.4 e foi elaborado através de trabalho de reengenharia efetuado sobre um documento interno, que relaciona as principais tabelas do sistema CoL. Cabe destacar que, apesar de ter sido utilizado a notação UML nesta figura, a versão atual da plataforma $\mathrm{CoL}$ não foi desenvolvida através de Orientação a Objetos. A opção de representação das estruturas internas do CoL nessa notação deve-se à conveniência de unificar a notação ao longo deste documento, uma vez que a notação gráfica utilizada nas ontologias é, quase sempre muito próxima a UML.

Pode-se observar que os materiais de aprendizagem não fazem parte do diagrama, pois não é uma preocupação da plataforma representá-lo. O desenvolvimento da ontologia dos materiais de aprendizagem tem como objetivo então produzir um diagrama de classes que representem estes materiais e que possa ser integrado ao diagrama UML da plataforma CoL. 


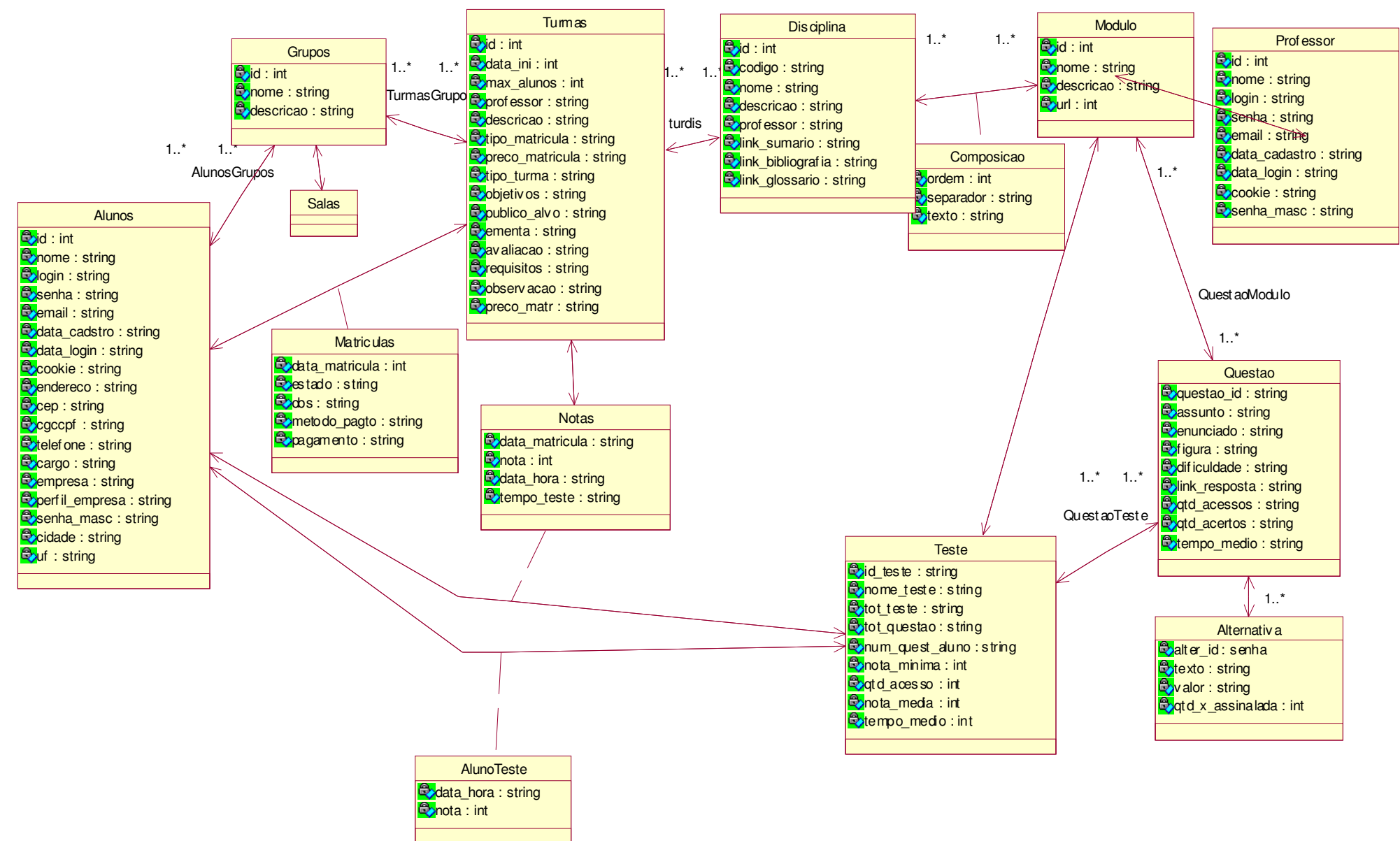

Fig. 5.4 - Diagrama UML parcial da plataforma $\mathrm{CoL}$ 
Para a construção desta ontologia serão utilizados os estágios propostos na metodologia METHONTOLOGY, discutida no item 2.2.5 deste trabalho. Como auxílio é utilizada a ferramenta WebODE, um editor de ontologias que permite a edição colaborativa de ontologias e dá suporte ao estágio de conceitualização da metodologia METHONTOLOGY e na maioria das demais atividades do ciclo de vida de uma ontologia (reengenharia, conceitualização, implementação, etc.).

\subsubsection{Especificação}

O principal objetivo desta ontologia é possibilitar uma representação semântica dos materiais e objetos de aprendizagem da plataforma $\mathrm{CoL}$ para que possam ser reutilizados, compartilhados, estruturados e que os usuários (professores, alunos, administradores) desta plataforma possam realizar pesquisas "inteligentes" nestes materiais e objetos de aprendizagem. Esta ontologia deve prover um vocabulário para que os materiais de aprendizagem possam ser explicitados e anotados bem como um conjunto de relacionamentos entre os termos do vocabulário, para propiciar inferências na base de conhecimento formada. Portanto, esta ontologia deve ser capaz de responder a questões de competência do tipo:

1. Quais são as disciplinas ensinadas pelos professores na plataforma CoL?

2. Quais disciplinas e módulos existem na plataforma CoL?

3. Quem são os responsáveis pela criação de módulos na plataforma CoL?

4. Quais materiais de aprendizagem compõe a plataforma CoL?

5. Quais os pré-requisitos de um determinado material de aprendizagem?

6. Existem materiais de aprendizagem similares entre si na plataforma CoL?

7. Quais os tipos de objetos de aprendizagem que compõem os materiais de aprendizagem da plataforma CoL?

8. Qual o formato dos objetos de aprendizagem que compõem os materiais de aprendizagem? 
9. Quais as características dos objetos de aprendizagem que compõem os materiais de aprendizagem?

\subsubsection{Conceitualização}

Esta é a principal fase da metodologia METHONTOLOGY. Ao final desta atividade obtém-se:

- o Glossário de Termos (GT) - está apresentado no anexo A.1;

- a Árvore de Classificação de Conceitos (ACC) - esta árvore está apresentada no anexo A.2.;

- o Dicionário de Conceitos - está apresentado no anexo A.3;

- as Relações Binárias ad-hoc - estão apresentadas no anexo A.4;

- as Representações Intermediárias, conforme detalhado no item 2.2.5.3. Estas informações são mantidas internamente pela ferramenta de desenvolvimento.

Para esta fase foi usada a ferramenta WebODE, que permite gerar a documentação necessária, e cujas saídas se encontram no anexo A. A opção de se colocar em anexos este material foi decorrência da decisão de não quebrar demasiadamente o fluxo de leitura deste capítulo.

Os Cursos na plataforma CoL são estruturados em disciplinas que, por sua vez são formadas por módulos e os responsáveis pela criação destes módulos são os professores. Para responder as questões de competência 1, 2 e 3, faz-se necessário estabelecer a relação entre os conceitos disciplina, módulo e professores, representada na figura 5.5 . 


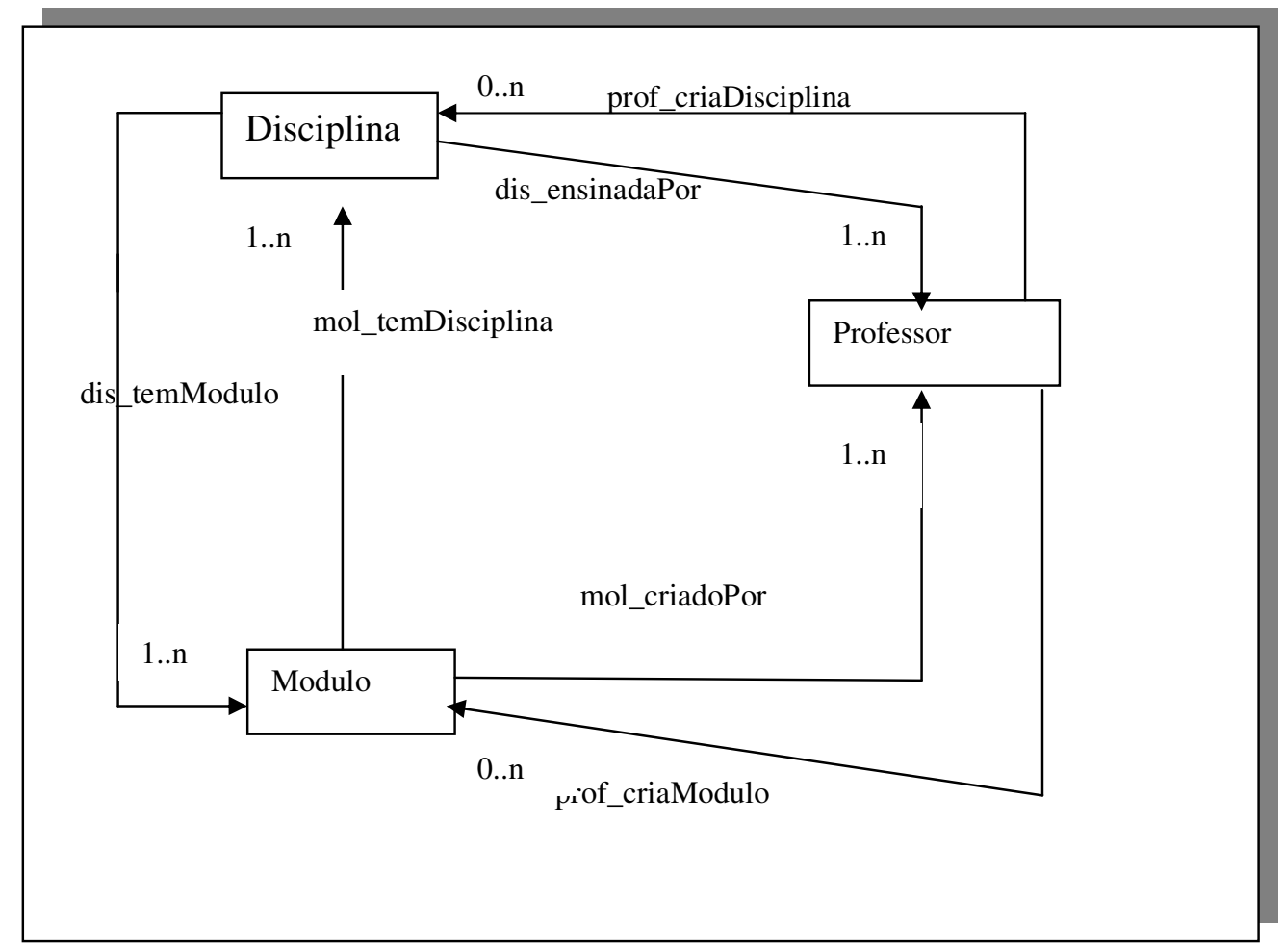

Fig. 5.5 - Relacionamento entre os conceitos de disciplina, módulo e professor.

A seguir tem-se a descrição das relações consideradas na figura 5.5:

- A relação dis_temModulo denota que uma disciplina é formada por um ou mais módulos. Esta relação tem a cardinalidade $(1, n)$, que determina o axioma: “Toda disciplina tem um ou mais módulos”.

- As relações prof_criaDisciplina e prof_criaModulo denota que os professores são responsáveis pela criação de disciplinas e módulos e a cardinalidade $(0, n)$ determina o axioma: "Os professores podem criar zero ou mais disciplinas e módulos".

- A relação mol_temDisciplina indica que módulos podem pertencer a disciplinas, sendo uma relação inversa de dis_temModulo.

- A relação mol_criadoPor indica que módulos são criados por professores. 
- A relação dis_ensinadaPor indica os professores responsáveis para ensinar as disciplinas.

Os módulos são formados por materiais de aprendizagem. Para responder a questão de competência 4 é necessário estabelecer uma relação entre os conceitos de módulo e de material de aprendizagem, e esta relação está representada na figura 5.6.

A seguir tem-se a descrição das relações consideradas na figura 5.6:

- A relação mol_temMaterial_Aprendizagem denota que um módulo é formado por materiais de aprendizagem. Esta relação tem a cardinalidade $(1, n)$ que determina o axioma: "Todo módulo é formado por um, ou mais, materiais de aprendizagem".

- A relação mat_temModulo indica que os materiais de aprendizagem são elementos componentes de módulos.

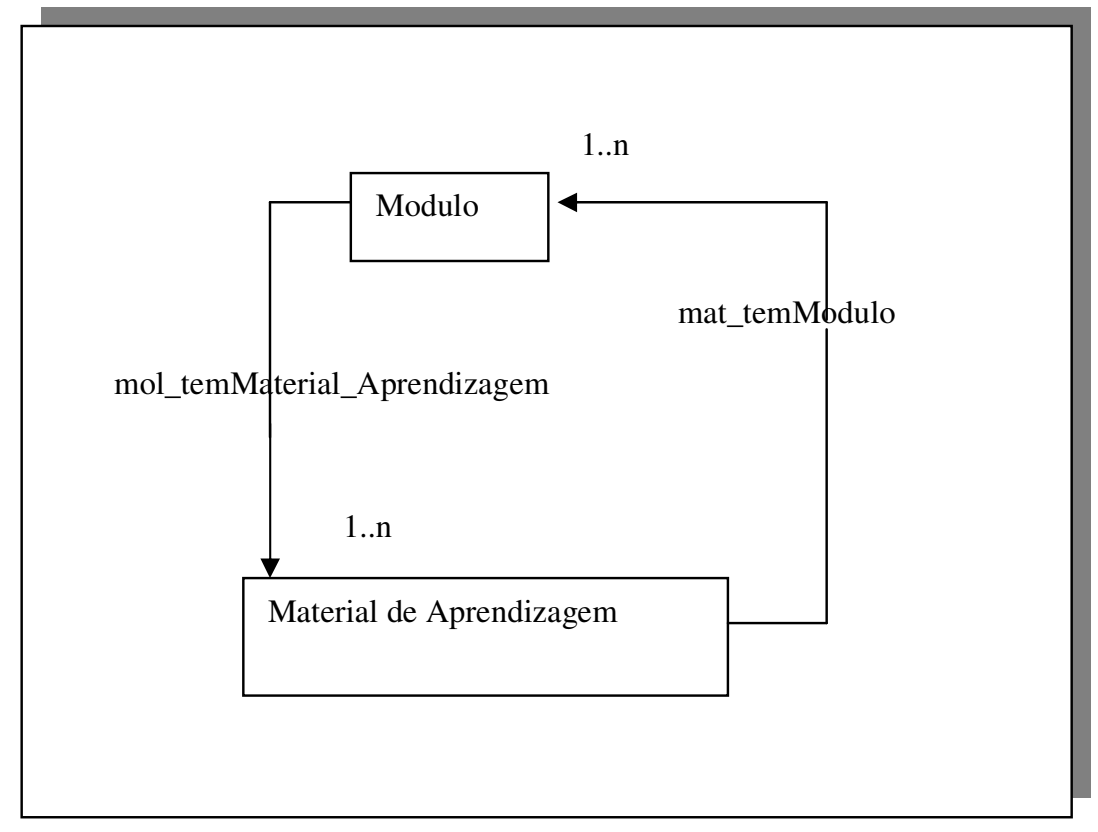

Fig. 5.6 - Relacionamento entre os conceitos módulo e material de aprendizagem

As questões de competências 5 e 6 são respondidas pelas relações entre os materiais de aprendizagem, representadas na figura 5.7. São elas: 
- as relações mat_ePreRequisitoDe e mat_temPreRequisitoDe são relações inversas, ou seja, se um material de aprendizado B tem como prérequisito A, então A é pré-requisito de $\mathrm{B}$. O mesmo raciocínio é aplicado para as relações mat_temSimilaridadeCom e mat_eSimilarA. Um material de aprendizagem é similar a outro, quando um mesmo assunto, por exemplo, equações do segundo grau, pode ser tratado através de um texto, um gráfico ou uma animação.

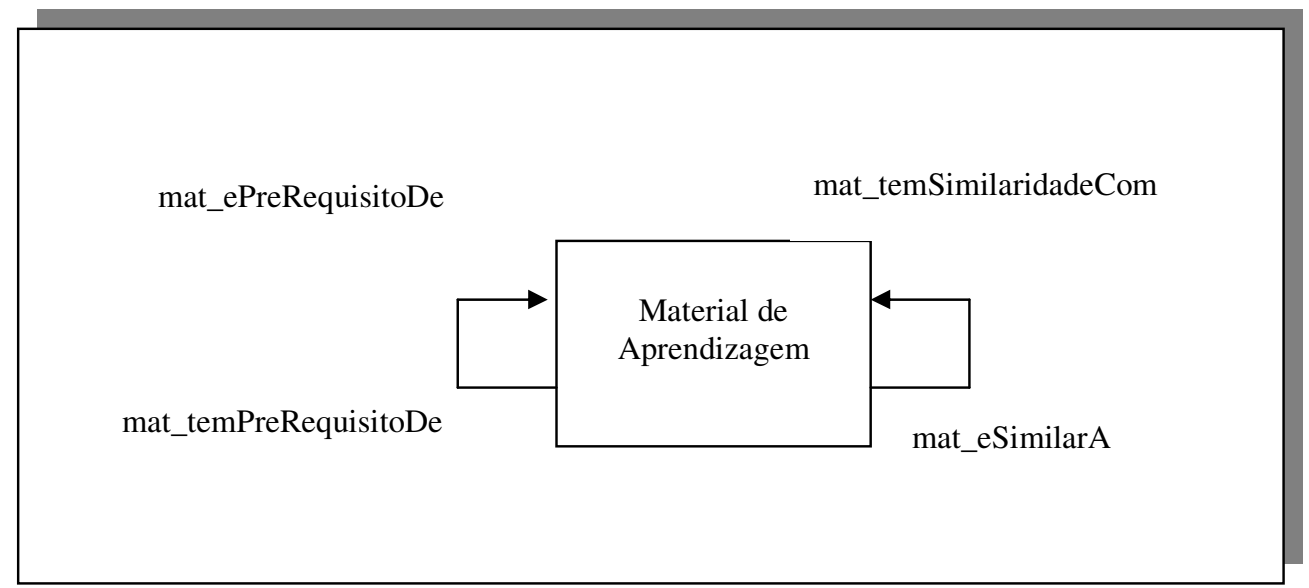

Fig. 5.7 - Relacionamento entre material de aprendizagem

A questão de competência 7 refere-se aos objetos de aprendizagem que compõem os materiais de aprendizagem. Segundo a especificação da Learning Technology Standards Committee of the IEEE (2002, p. 25) e a especificação da IMS Global Learning Consortium (2001, p. 29), os tipos de objetos de aprendizagem são: Exercícios, Simulação, Questionário, Diagrama, Figura, Gráfico, Índice, Tabela, Texto Narrativo, Exame, Experiência, Enunciado de um Problema e Auto Avaliação. Estes conceitos estão representados na figura 5.8. São eles:

- O relacionamento mat_temobjetos denota que os materiais de aprendizagem têm um ou mais objetos de aprendizagem. Esta relação tem cardinalidade $(1, n)$ determina o seguinte axioma: "Todo material de aprendizagem tem um ou mais objetos de aprendizagem".

- O relacionamento obj_eParteDeMaterial_Aprendizagem é um relacionamento inverso do relacionamento mat_temobjetos e indica que os 
objetos de aprendizagem podem pertencer aos materiais de aprendizagem. $\mathrm{O}$ relacionamento é-um indica que Exercício, Diagrama, Simulação e os demais objetos de aprendizagem são especializações de Objetos.

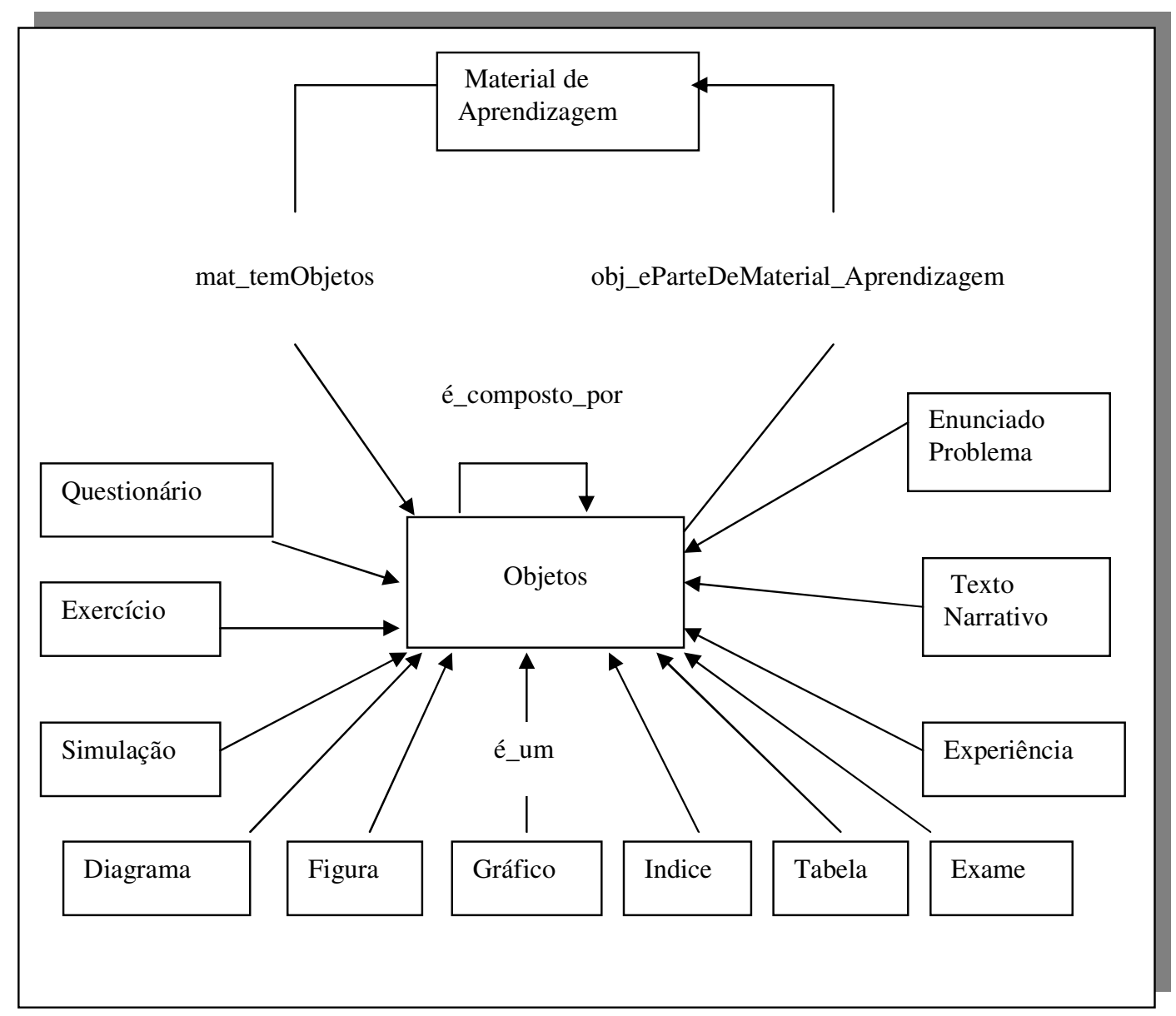

Fig. 5.8 - Relacionamento entre material de aprendizagem e tipos de componentes.

A questão de competência 8 refere-se aos formatos dos materiais de aprendizagem. Alguns formatos possíveis são Vídeo (avi, mpeg, mov etc.), Imagem (pic, pcx, jpeg etc.), Texto (html, Word etc.), Animação (Flash, avi etc.) e Áudio (wav etc.). Nesta ontologia, estes formatos estão representados como atributos do conceito Objeto de Aprendizagem. A tabela A.5, no anexo A, apresenta a lista completa de atributos modelados. 
A questão de competência 9 refere-se a algumas características dos objetos de aprendizagem e que são as seguintes: formato (questão 8), tamanho, localização, palavras-chave, dificuldade, interatividade, contexto, responsável, descrição, título, linguagem, restrição e data. Estas características são alguns metadados extraídos da especificação da Learning Technology Standards Committee of the IEEE (2002) e da especificação da IMS Global Learning Consortium (2001). Também foram representados na forma de atributos dos objetos de aprendizagem porque estas características podem ser consideradas como propriedades destes objetos de aprendizagem, o que facilita sua codificação na linguagem DAML+OIL.

A figura 5.9 mostra o modelo completo da ontologia - representada em UML - dos materiais de aprendizagem, aqui proposta. Na tabela 5.1 está representada uma parte do Glossário de Termos. Toda a documentação gerada nesta fase está incluída no anexo A desta tese.

Tabela 5.1 - Parte do Glossário de Termos

\begin{tabular}{|l|l|}
\hline Disciplina & Uma disciplina é pode ser composta por um ou mais módulos \\
\hline Módulo & $\begin{array}{l}\text { Um módulo é formado por uma ou mais páginas HTML ligadas e é } \\
\text { a unidade atômica que compõe a disciplina. }\end{array}$ \\
\hline Material de & $\begin{array}{l}\text { Um conjunto de documentos e/ou objetos indispensáveis ao } \\
\text { Aesempenho das atividades de aprendizagem. Portanto, um gráfico, } \\
\text { Fig., uma experiência, um jogo educacional, uma simulação, um } \\
\text { tutorial podem ser considerados materiais de aprendizagem. }\end{array}$ \\
\hline Objetos & $\begin{array}{l}\text { São os tipos de objetos de aprendizagem que compõem um material } \\
\text { de aprendizagem. Podem ser um, gráfico, tabela, fórmula, } \\
\text { animações, uma simulação, exercício, etc. }\end{array}$ \\
\hline Professor & \begin{tabular}{l} 
Responsável por disciplinas e módulos \\
\hline
\end{tabular}
\end{tabular}




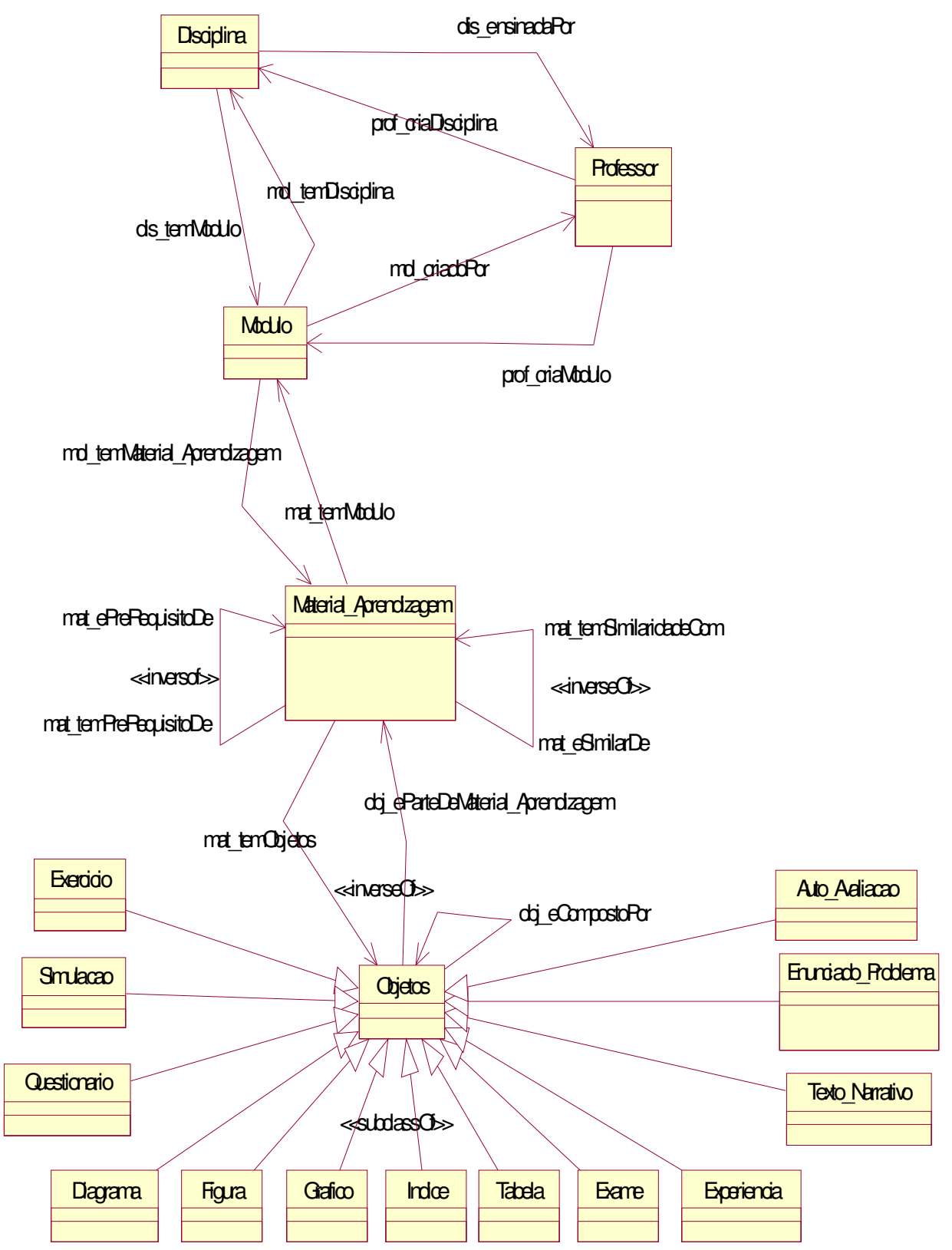

Fig. 5.9 - Ontologia dos Materiais de Aprendizagem 


\subsection{Proposta de um modelo baseada em ontologias para pesquisa de materiais de Aprendizagem}

A figura 5.10 representa a proposta de um modelo para pesquisa de materiais de aprendizagem, que são formados pelos objetos de aprendizagem, conforme o modelo proposto ao longo deste capítulo. Os pontos principais deste modelo são: Base de Conhecimento Ontológica, Anotação e Pesquisa.

\subsubsection{Base ontológica de conhecimento}

É o núcleo do modelo, pois contém uma ou mais ontologias, sobre as quais atuarão os mecanismos de inferência. Devido às restrições apontadas no item 3.4.9 do modelo RDF Schema (suas primitivas não são suficientes para desenvolver modelos ontológicos e de raciocínio) e as razões apontadas no item 3.5 deste trabalho, a linguagem utilizada é a DAML+OIL, que possibilita a representação de ontologias e metadados. Por exemplo, o conceito Material_Aprendizagem tem a codificação em DAML+OIL conforme representada na figura 5.11, que corresponde no modelo ao vocabulário, relacionamento e atributos.

Os relacionamentos descritos na figura 5.11 são os mostrados no Diagrama UML da figura 5.9 para Material_Aprendizagem.

Deve-se notar que as ontologias da Base Ontológica de Conhecimento ficam separadas em dois arquivos. Um arquivo contém a ontologia com os vocabulários, relacionamentos e atributos e o outro arquivo contém as instâncias geradas. Esta separação visa facilitar a manutenção das ontologias, pois é o arquivo de instâncias é alterado constantemente.

\subsubsection{Anotação}

É a técnica de anotar os documentos para que as informações possam ser compreendidas pelas máquinas, de modo que a pesquisa para recuperação de informações possa ser incrementada, tendo como base o modelo ontológico desenvolvido. Para isto, é necessário que a anotação esteja de acordo com os metadados que descrevem os materiais de aprendizagem e que estão definidos na 
ontologia do domínio em estudo. Entretanto, o processo de anotação pode tornar-se lento e pouco produtivo. Em Euzenat (2002) encontram-se os pontos a serem observados antes de iniciar um trabalho de anotação. A anotação pode ser realizada através de ferramentas específicas para este fim. Por exemplo, a ferramenta OntoAnnotate (Staab, 2001a) gera a anotação em RDF. A ferramenta Annotation Service (Bechhofer, 2001a) desenvolvida durante o projeto COHSE ${ }^{11}$ (Conceptual Open Hipermídia Service) é um protótipo para gerar anotação em DAML+OIL.

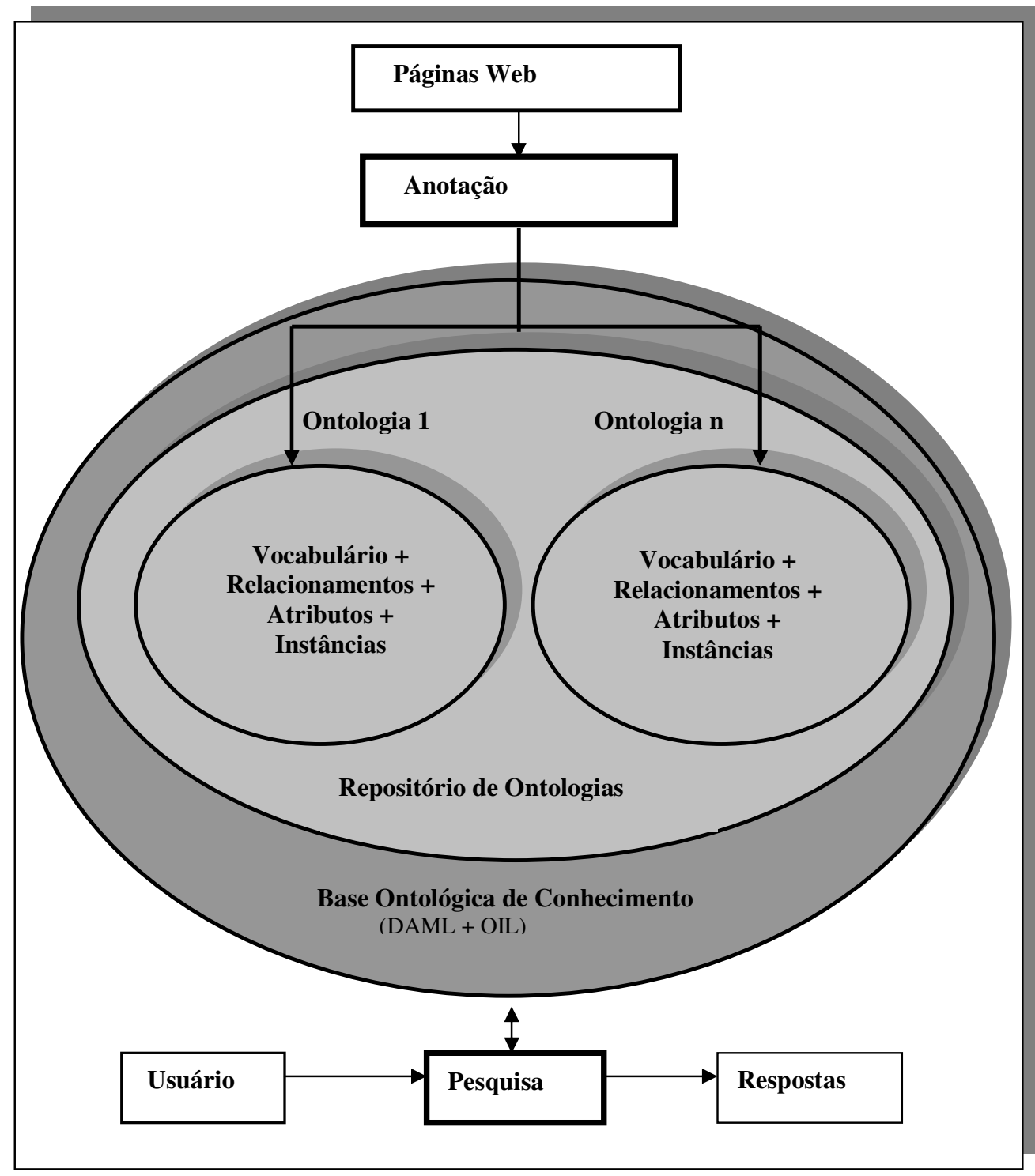

Fig. 5.10 - Proposta de modelo para pesquisa de materiais de aprendizagem

\footnotetext{
${ }^{11}$ http://cohse.semanticweb.org/
} 
$<$ daml:Class rdf:ID="Material_Aprendizagem" $>$

$</$ daml:Class $>$

$<$ daml:DatatypeProperty rdf:ID="codigo">

$<$ daml:domain rdf:resource="\#Material_Aprendizagem"/>

$<$ daml:range rdf:resource="http://www.w3.org/2000/10/XMLSchema\#string"/>

$</$ daml:DatatypeProperty $>$

<daml:DatatypeProperty rdf:ID="nome">

$<$ daml:domain rdf:resource="\#Material_Aprendizagem"/>

$<$ daml:range rdf:resource="http://www.w3.org/2000/10/XMLSchema\#string"/>

$</$ daml:DatatypeProperty $>$

<daml:ObjectProperty rdf:ID="mat_temModulo">

$<$ rdfs:domain rdf:resource="\#Material_Aprendizagem"/>

$<$ rdfs:range rdf:resource="\#Modulo"/>

$<$ daml:minCardinality $>1</$ daml:minCardinality $>$

$<$ daml:maxCardinality $>$ n $</$ daml:maxCardinality $>$

$</$ daml:ObjectProperty $>$

<daml:ObjectProperty rdf:ID="mat_temObjetos">

$<$ rdfs:comment $>$ Quais Objetos do material de aprendizagem $</$ rdfs:comment $>$

$<$ daml:domain rdf:resource="\#Material_Aprendizagem"/>

$<$ daml:range rdf:resource="\#Objetos"/>

$<$ daml:minCardinality $>1</$ daml:minCardinality $>$

$<$ daml:maxCardinality $>\mathrm{n}</$ daml:maxCardinality $>$

$</$ daml:ObjectProperty $>$

$<$ daml:ObjectProperty rdf:ID="mat_temPreRequisitoDe" $>$

$<$ daml:range rdf:resource="\#Material_Aprendizagem"/>

$<$ daml:domain rdf:resource="\#Material_Aprendizagem"/>

$</$ daml:ObjectProperty $>$

$<$ daml:ObjectProperty rdf:ID="mat_ePreRequisitoDe">

$<$ daml:range rdf:resource="\#Material_Aprendizagem"/>

$<$ daml:domain rdf:resource="\#Material_Aprendizagem"/>

$<$ daml:inverseOf rdf:resource="\#mat_temPreRequisitoDe"/>

$</$ daml:ObjectProperty $>$

<daml:ObjectProperty rdf:ID="mat_temSimilaridadeCom">

$<$ daml:range rdf:resource="\#Material_Aprendizagem"/>

$<$ daml:domain rdf:resource="\#Material_Aprendizagem"/>

$</$ daml:ObjectProperty $>$

<daml:ObjectProperty rdf:ID="mat_eSimilarA">

$<$ daml:range rdf:resource="\#Material_Aprendizagem"/>

$<$ daml:domain rdf:resource="\#Material_Aprendizagem"/>

$<$ daml:inverseOf rdf:resource="\#mat_temSemelhancaCom"/>

$</$ daml:ObjectProperty $>$

Fig. 5.11 - Codificação em DAML+OIL do conceito Material_Aprendizagem 
Normalmente, estas ferramentas capturam as páginas que devem ser anotadas. $\mathrm{O}$ usuário seleciona uma ontologia sobre o tema a ser anotado e as informações da página. Na medida que o usuário seleciona as informações na página, este vai preenchendo as informações correspondentes na ontologia. Por exemplo, se o usuário esta anotando uma página com informações sobre navios, a ontologia sobre navios deve ter conceitos do tipo: nome do navio, peso, tipo do navio, etc. À medida que o usuário vai selecionando os navios, vai preenchendo as informações conforme solicitado pela ontologia, gerando o arquivo das instâncias.

No caso da metodologia proposta, o usuário irá informar os dados sobre a disciplina, os módulos da disciplina, os materiais de aprendizagem e os objetos de aprendizagem que formam os materiais de aprendizagem, de acordo com a ontologia proposta. Neste trabalho não foi implementada uma ferramenta de anotação para a linguagem DAML+OIL. As instâncias foram geradas através de um editor de textos, pois as ferramentas de anotação existentes operam em conjunto com outros softwares que fazem parte de seu ambiente.

A figura 5.12 representa uma instância dos Materiais de Aprendizagem da disciplina XML - Conceitos Básicos, descrita no começo do capítulo.

\subsection{3 - Pesquisa}

Para realizar pesquisas neste modelo foi utilizado um sistema de pesquisa que verifica a ontologia que contém os relacionamentos e as instâncias codificadas em DAML+OIL. Este sistema, denominado AQ_Search, encontra-se disponível na página oficial da DAML (Darpa Agent Markup Language) ${ }^{2}$. Desenvolvida com as ferramentas do pacote Java, é composta por uma interface gráfica, que permite aos usuários realizar as pesquisas e retornar os resultados, e por um agente que processa as pesquisas com base nas ontologias disponíveis na Base Ontológica de Conhecimento. A figura 5.13 apresenta a interface gráfica, onde é possível selecionar as ontologias e elaborar as pesquisas e a figura 5.14 apresenta o resultado da pesquisa.

\footnotetext{
${ }^{2}$ http://www.daml.org/
} 


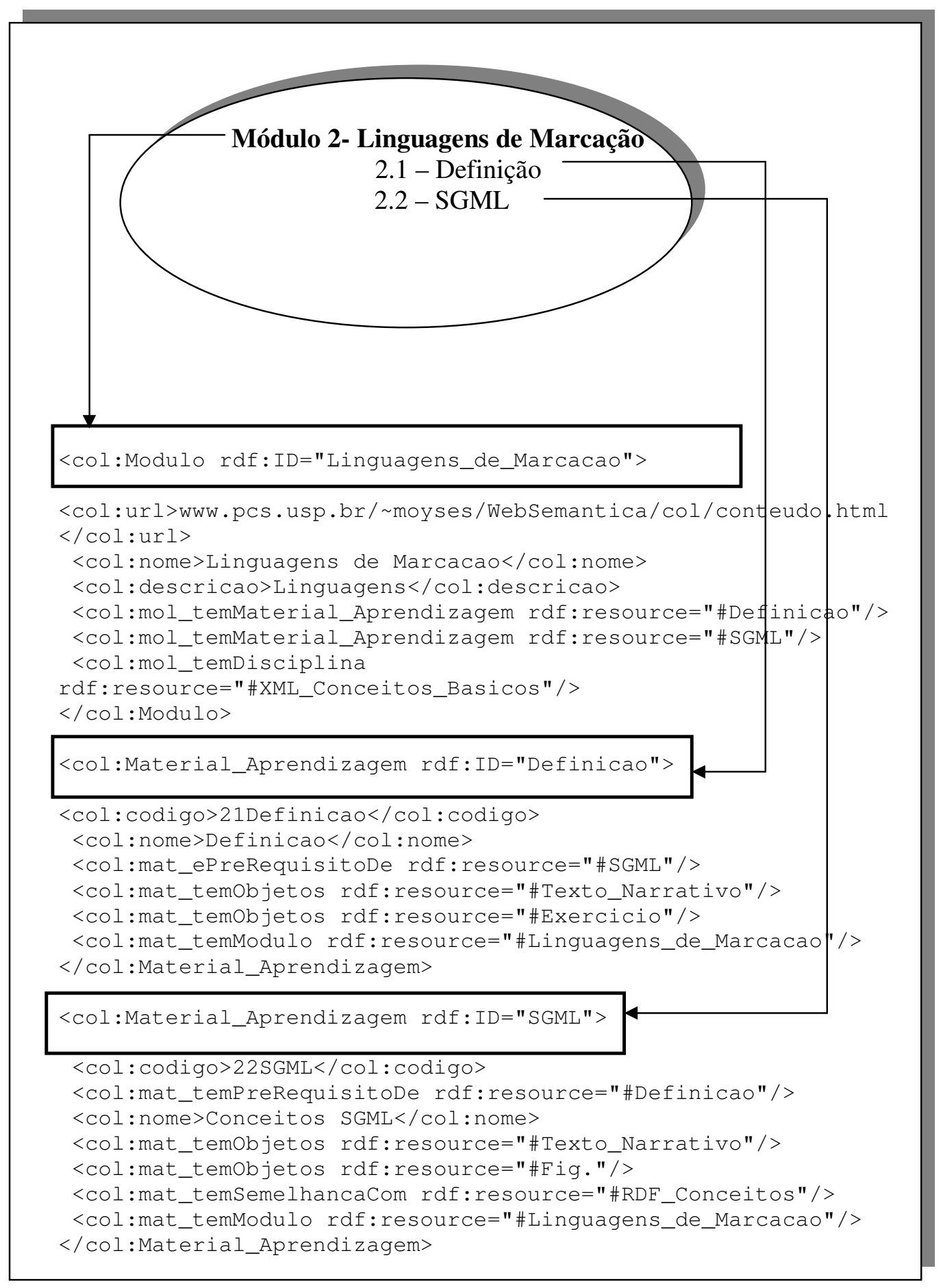

Fig. 5.12 - Instância do conceito Material de Aprendizagem 


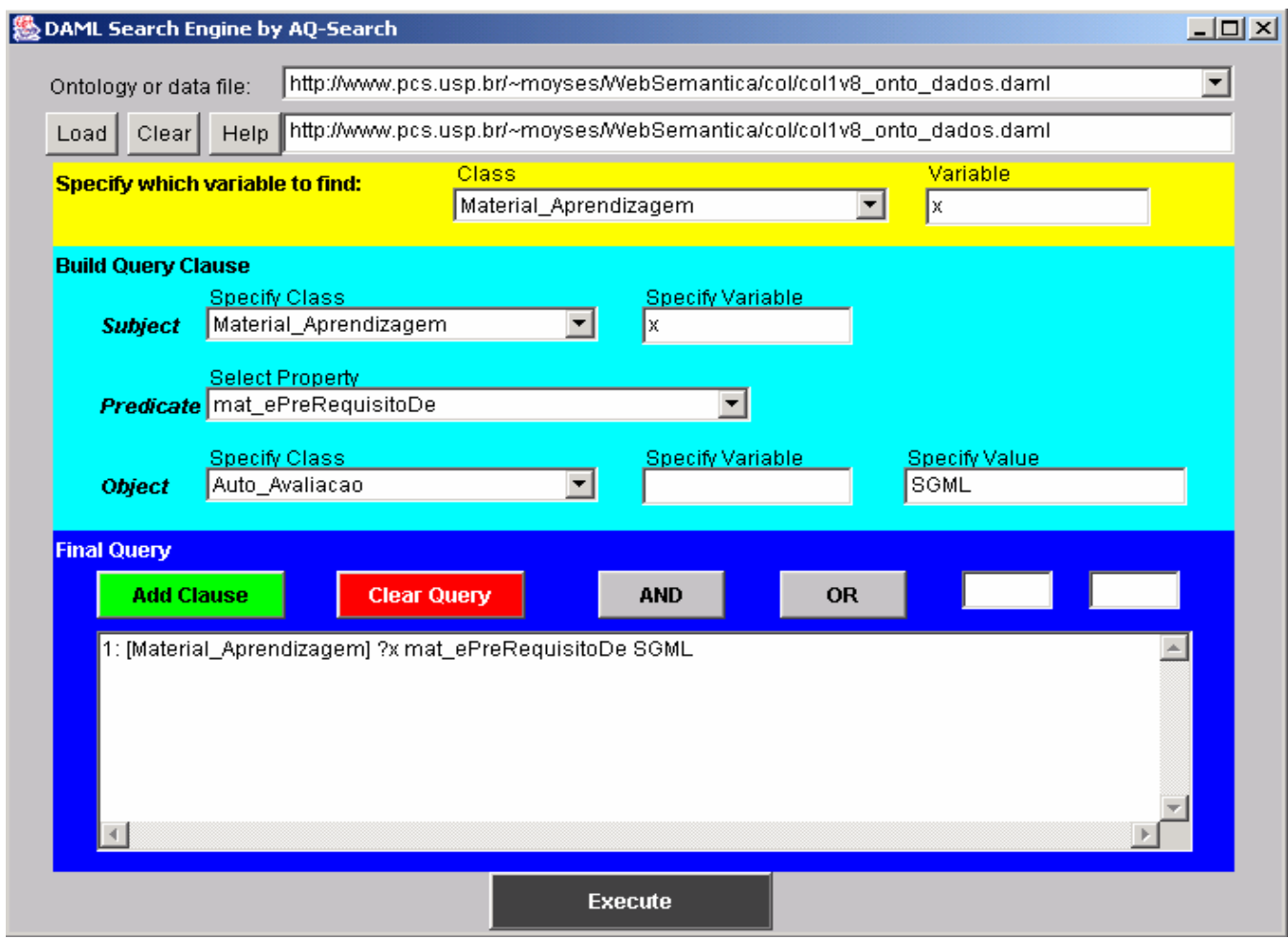

Fig.5.13 - Interface gráfica do sistema AQ-Search

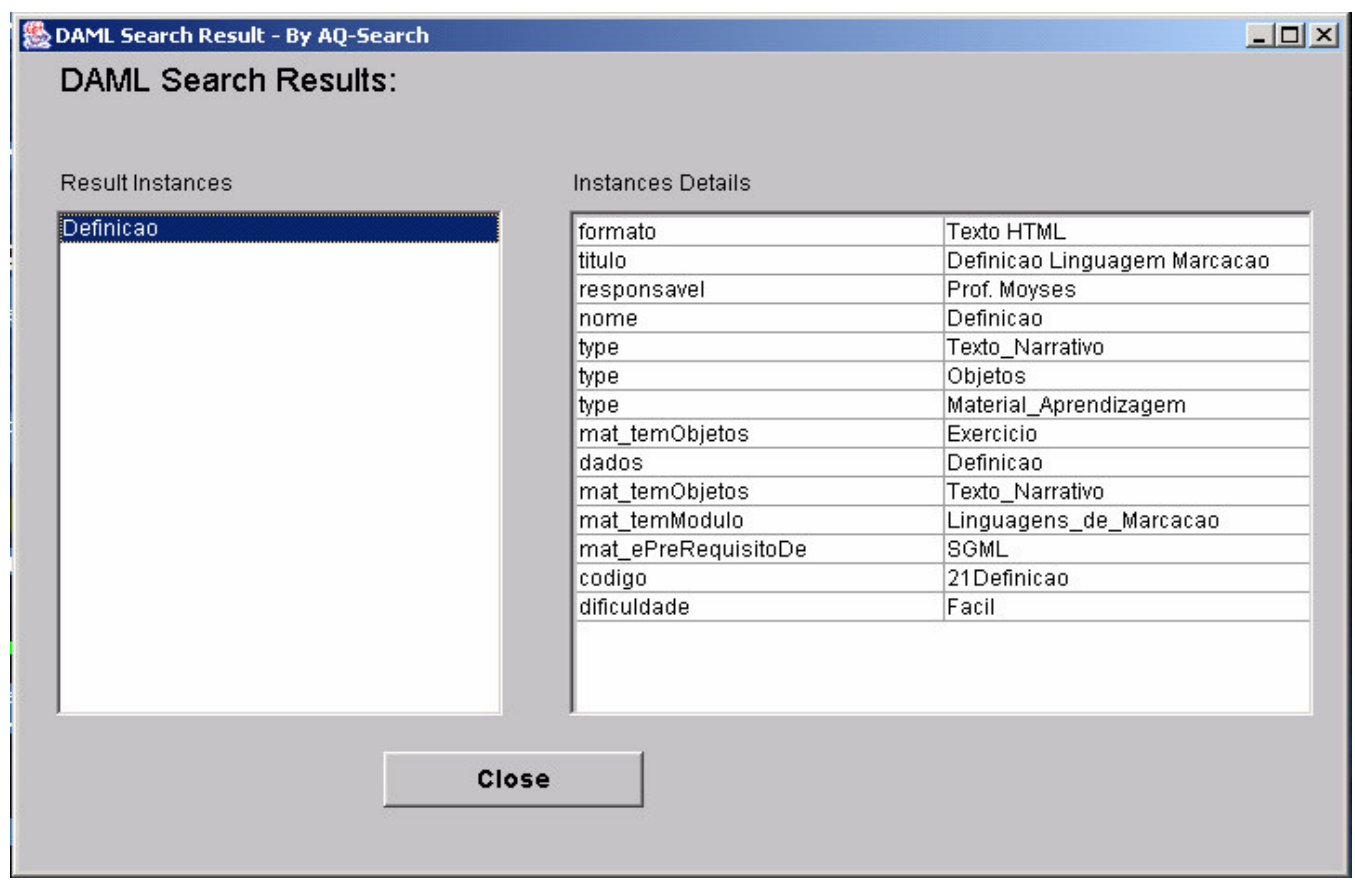

Fig. 5.14 - Interface gráfica com os resultados da pesquisa 
As figuras 5.13 e 5.14 representam a seguinte pesquisa: "Qual material de aprendizagem é pré-requisito do material de aprendizagem SGML?”. Nesta pesquisa é necessário identificar os seguintes termos apresentados e discutidos nos itens 3.3.2 e 3.4.2.

- Sujeito (Subject): representa o conceito ou a classe da qual solicitamos a informação - materiais de aprendizagem (Material_Aprendizagem), no exemplo.

- Predicado: que são as propriedades do sujeito - é pré-requisito de - no exemplo.

- Objeto: que são os valores do predicado - SGML - no exemplo.

Estes valores estão representados na figura 5.13. Clicando-se no botão Add Clause, se tem o formato da pesquisa que será gerada, no caso a seguinte frase:

1: [Material_Aprendizagem] ?x mat_ePreRequisitoDe SGML

Clicando-se no botão Execute, temos o resultado exibido na figura 5.14. Nesta figura, a máquina de busca apresenta no lado esquerdo, o resultado (Result Instances). No Anexo B encontram-se outras pesquisas que foram realizadas para testar o modelo, bem como as ontologias necessárias a esse fim.

\subsection{Conclusões}

Os trabalhos atuais da comunidade da Web Semântica está direcionado principalmente para a representação da informação na World Wide Web, de modo que estas informações possam ser usadas pelas máquinas, não só com propósitos de exibir informações, mas também para automação, integração, compartilhamento, pesquisas mais inteligentes e reutilização entre as aplicações. O modelo proposto é uma tentativa inicial para possibilitar estas pesquisas não somente dos materiais de aprendizagem, mas para recuperar informações dos seus componentes. A modelagem ontológica baseada na linguagem DAML+OIL, onde a ontologia que contém os relacionamentos e atributos está separada de suas instâncias, aliada com um agente de pesquisa possibilita a estudantes e professores acessar os materiais de aprendizagem e seus componentes de forma mais rápida e inteligente. 


\section{CONSIDERAÇÕES FINAIS}

Este trabalho apresentou um modelo baseado em ontologias para pesquisa e reutilização de materiais de aprendizagem tendo como abordagem principal os fundamentos propostos pela Web Semântica. Como ponto de partida para a elaboração do modelo final foram utilizados os conceitos da plataforma CoL e para os testes do modelo, um agente de pesquisa disponível na Web. A seguir apresenta-se uma síntese do trabalho, algumas considerações sobre o projeto e sugestões para trabalhos futuros.

\subsection{Síntese do trabalho}

A partir das pesquisas iniciais realizadas neste trabalho, percebeu-se que o tema proposto tem uma característica acentuadamente multidisciplinar, envolvendo Educação Baseada na Web (EBW), engenharia de software, inteligência artificial, ontologias, técnicas de orientação a objetos, ferramentas que dão suporte a Web Semântica e novas linguagens, que lhe dão suporte. Para determinar quais fundamentos eram necessários para realizar a modelagem proposta, foram realizadas inúmeras pesquisas, envolvendo:

- Plataformas que dão suporte a Educação Baseada na Web, para determinar quais são as principais características destas ferramentas, bem como a realização de um curso a distância sobre JavaScript, para experimentar a problemática da Educação a Distância, sob o ponto de vista do aluno;

- Desenvolvimento de sistemas baseados em ontologias, para determinar quais são as fases fundamentais e as características básicas que envolvem construir sistemas com base na Engenharia Ontológica (FERNÁNDEZ, 1997);

- Estudos detalhados da Web Semântica, para compreender a estrutura de camadas, que possibilita a estrutura e organização das informações na Web Semântica e as tecnologias que dão suporte a esta estrutura, tais como XML, RDF e, especialmente, a linguagem de ontologias DAML+OIL; 
- Ferramentas diversas para a Web Semântica, para determinar quais ferramentas são adequadas para implementar o modelo proposto, testando assim a sua viabilidade;

- Padrões de metadados existentes para a área educacional, para compreender as necessidades destes padrões e selecionar um vocabulário para ser utilizado no modelo ontológico proposto;

- Desenvolvimento de sistemas orientados a objetos e UML, para compreender as diferenças conceituais entre este paradigma e as tecnologias da Web Semântica, que também se apropriam de alguns conceitos da orientação a objeto, mas não seguem plenamente as suas regras.

A partir destas pesquisas e através da aplicação das fases da metodologia METHONTOLOGY definiu-se um modelo ontológico inicial, que após cada teste realizado, era modificado, conforme o ciclo de vida proposto pela metodologia. Nesta etapa do trabalho pôde-se avaliar o estado atual, efetivo, da tecnologia e ferramental utilizado na Web Semântica. Os seguintes comentários são pertinentes em relação às ferramentas e tecnologia:

- Linguagem DAML+OIL: é a principal linguagem para a Web Semântica e permite representar as informações da Web tanto no aspecto semântico quanto no sintático. Por ser uma linguagem nova, encontram-se poucas aplicações desenvolvidas e, por ser projetada para que máquinas entendam o significado das palavras, torna-se muito difícil o seu entendimento e aplicação plena. Algumas ferramentas procuram gerar automaticamente os códigos da ontologia que está sendo modelada, em DAML+OIL. A ferramenta Protégé-2000 possui um plug-in desenvolvido por terceiros para esta tarefa, mas seu funcionamento ainda é precário, pois freqüentemente, a ferramenta não consegue ler o código DAML+OIL gerado. A ferramenta WebODE, também gera o código DAML+OIL, mas em uma versão antiga, o que acabou inviabilizando o seu uso. Devido a estes problemas, a maior parte do código gerado neste trabalho foi editado utilizando-se editores de texto. Apesar destes problemas, atualmente 
DAML+OIL é a linguagem que permite desenvolver aplicações efetivas para a Web Semântica.

- Metodologia METHONTOLOGY: é uma metodologia muito poderosa para desenvolvimento de sistemas baseados em ontologias, tanto para sistemas simples, com uma única ontologia como para sistemas complexos, que envolvem várias delas. Na medida em que é empregada, e em que os conceitos principais vão sendo absorvidos, torna-se uma ferramenta clara e de fácil utilização. A ferramenta WebODE, que acompanha a metodologia, também é de fácil utilização e compreensão, sendo um suporte poderoso para a compreensão da metodologia. Seus pontos fracos residem na geração de código para a linguagem DAML+OIL e na sua parte gráfica, que é muito limitada, sendo necessário alguns "truques" para desenhar a ontologia. Tem-se a impressão que esta ferramenta não vem sendo atualizada, donde a geração de código que não acompanha a evolução da linguagem DAM+OIL. No desenvolvimento do modelo ontológico proposto neste trabalho, as fases de Integração, Implementação, Avaliação e Documentação não foram utilizados, por não serem necessários em um projeto experimental, de pequeno porte, como este.

- Protégé 2000: considerado um editor de ontologias é uma das ferramentas mais utilizadas pela comunidade acadêmica, e vem sendo constantemente aperfeiçoado. A ferramenta, que foi empregada nas etapas finais deste trabalho para a geração da codificação DAML+OIL, mostrou-se uma ferramenta fácil e simples de ser utilizada. Para gerar a codificação DAML+OIL, utiliza-se um plug-in desenvolvido por terceiros, não oferecendo suporte técnico nenhum. Devido aos problemas para gerar a codificação DAML+OIL, foi pouco utilizada, não sendo possível fazer comentários mais apurados sobre esta ferramenta em todo o seu potencial.

Durante o desenvolvimento do modelo ontológico, foi necessário estudar os padrões de metadados existentes para a área educacional, mais especificamente, os voltados para os objetos de aprendizagem. Estes padrões são extensos, confusos, sendo praticamente impossível implementá-los, plenamente. Por isto, foram selecionados 
os termos mais relevantes para a utilização no modelo, tendo em vista mostrar-se a viabilidade do modelo.

A partir dos testes realizados no protótipo implementado, pôde-se verificar a possibilidade de se realizar pesquisas mais estruturadas e específicas, que atenderam aos propósitos colocados no capítulo 1, chegando-se a uma proposta de modelo para os componentes dos materiais de aprendizagem, que facilita a recuperação e propicia a reutilização de materiais de aprendizagem. $\mathrm{O}$ anexo $\mathrm{B}$ apresenta algumas pesquisas realizadas com este protótipo. Como se pode observar nesse anexo, as interfaces das ferramentas não seguem o padrão amigável das interfaces às quais as pessoas estão acostumadas. Isto se deve ao fato de que tanto o estilo destas interfaces, quanto a linguagem nelas empregada, têm origem na própria dificuldade no desenvolvimento destes sistemas.

\subsection{Trabalhos futuros}

A Web Semântica ainda encontra-se nos estágios iniciais de seu desenvolvimento. Pesquisadores desta área acreditam que seus conceitos podem estar operacionais e integrados na vida diária somente daqui a dez anos ou mais. Por ser uma área multidisciplinar, há muitas pesquisas a serem desenvolvidas. Segundo a European Commission of US National Science Foundation (2001) recomendam-se pesquisas nas áreas de linguagens, infra-estrutura, ontologias e fatores humanos. Considerandose o modelo proposto, são identificados como trabalhos futuros:

- Implementação de uma ferramenta de anotação que atenda os requisitos do modelo proposto;

- Desenvolvimento de uma ferramenta que deverá ser acoplada à ferramenta de pesquisa AQSearch, para que as pesquisas e os resultados possam ser exibidos em uma interface gráfica mais amigável;

- Implementação do modelo proposto na plataforma CoL. O modelo proposto pode ser considerado uma extensão desta plataforma e poderia ser implementado de forma incremental. O modelo não afetaria a parte estrutural do CoL e poderia, mesmo, constituir um framework para ser adicionado a esta plataforma, pois as 
interfaces do modelo com o CoL são bem definidas. Basicamente o projeto proposto exige apenas o acesso aos bancos de dados (tabelas) Módulos, Professor e Disciplinas. O modelo proposto estende o conceito de módulo do CoL através de suas relações com os materiais e objetos de aprendizagem, e adiciona também relações aos conceitos de Disciplinas e Professor. No modelo, não se considerou os demais repositórios do CoL, como Apresentações, Turmas etc., pois o foco principal foi a recuperação e reutilização de materiais de aprendizagem e, nesta linha, pesquisou-se mais as propostas relativas a estruturação de dados, conforme descrito no capítulo 5. Entretanto, uma pesquisa mais aprofundada deste ambiente poderia trazer resultados muito interessantes quanto à extração de outros tipos de conhecimentos de todo o conjunto de bases de dados.

- Desenvolver para a plataforma CoL um modelo baseado em ontologias. Desta forma seria possível implementar uma arquitetura baseada em agentes, que poderiam realizar pesquisas mais automáticas e incrementar a interação entre os materiais de aprendizagem, professores e alunos; automatizar os serviços oferecidos pela plataforma CoL, com a utilização de serviços Web, através dos protocolos SOAP e WSDL.

- Desenvolvimento de repositórios de objetos de aprendizagem, modelados com ontologias.

- Realizar um estudo para a integração deste modelo com o ambiente PIAGET, proposto por Silveira (2003). PIAGET é uma plataforma baseada em uma arquitetura de objetos distribuídos, em Java. O objetivo principal de PIAGET é fornecer suporte à Educação a Distância, combinando várias formas de interação, que simulam grande parte das interações usuais entre professores, aprendizes e objetos de aprendizagem, num ambiente baseado em Realidade Virtual não imersiva - através de VRML. Os objetos de aprendizagem de PIAGET são de classes diferentes dos objetos aqui considerados, pois podem ser de qualquer tipo, criados pelos professores ou pelos alunos, através de autoria estática, dinâmica ou híbrida. Objetos de aprendizagem em PIAGET podem ser "um caderno" a ser emprestado a um colega durante a aula virtual, "uma molécula" modelada em uma aula de Química, uma imagem 2D, etc. Estes objetos são criados segundo 
um modelo próprio da plataforma PIAGET, que não visa a reutilização semântica. A incorporação de semântica a eles é um estudo interessante, a ser perseguido, e uma das propostas de Silveira em seu trabalho.

Considerando-se a fase em que se encontram as pesquisas na Web Semântica e na Educação Baseada na Web (EBW), muitas outras propostas poderiam ser aqui colocadas, entretanto, procurou-se listar aquelas mais importantes e imediatas.

Finalizando, pode-se dizer que a Web Semântica e a Educação Baseada na Web (EBW) são campos muito promissores para as pesquisas e ainda, muito inexplorados. 


\section{Anexo A - Relação dos documentos gerados pela ferramenta WEBODE da metodologia METHONTOLOGY}

\begin{tabular}{|c|c|c|c|c|}
\hline Name & Synonyms & Acronyms & Description & Type \\
\hline Disciplina : codigo & -- & -- & $\begin{array}{l}\text { Código alfanumérico que identifica a disciplina } \\
\text { dentro do sistema. }\end{array}$ & Class Attribute \\
\hline Disciplina : descricao & -- & -- & $\begin{array}{l}\text { Código alfanumérico que descreve as } \\
\text { informações sobre a disciplina. }\end{array}$ & Class Attribute \\
\hline Disciplina : id & -- & -- & Código que identifica a disciplina & Class Attribute \\
\hline Disciplina : link_bibliografia & -- & -- & $\begin{array}{l}\text { Referencia-se à página que contém a bibliografia } \\
\text { da disciplina. Esta informação é opcional. }\end{array}$ & Class Attribute \\
\hline Disciplina : link_glossario & -- & -- & $\begin{array}{l}\text { Referencia-se à página que contém o glossário } \\
\text { da disciplina. Esta informação é opcional. }\end{array}$ & Class Attribute \\
\hline Disciplina : link_sumario & -- & -- & $\begin{array}{l}\text { Referencia-se à página que contém o sumário, } \\
\text { ou o índice da disciplina. Esta informação é } \\
\text { opcional. }\end{array}$ & Class Attribute \\
\hline Disciplina : nome & -- & -- & Contém o nome da disciplina. & Class Attribute \\
\hline Disciplina : professor & -- & -- & $\begin{array}{l}\text { Identifica o professor responsável pela } \\
\text { disciplina. }\end{array}$ & Class Attribute \\
\hline Material_Aprendizagem :codigo & -- & -- & Código do material de aprendizagem. & Class Attribute \\
\hline Material_Aprendizagem : nome & -- & -- & Nome do material de aprendizagem & Class Attribute \\
\hline Modulo : descricao & -- & -- & Contém informações detalhadas sobre o módulo. & Class Attribute \\
\hline
\end{tabular}




\begin{tabular}{|c|c|c|c|c|}
\hline Name & Synonyms & Acronyms & Description & Type \\
\hline Modulo : id & -- & -- & $\begin{array}{l}\text { Código numérico que identifica o módulo dentro } \\
\text { do sistema }\end{array}$ & Class Attribute \\
\hline Modulo : nome & -- & -- & $\begin{array}{l}\text { Nome que será apresentado na lista de módulos } \\
\text { da disciplina. }\end{array}$ & Class Attribute \\
\hline Modulo : professor & -- & -- & Identifica o professor responsável pelo módulo. & Class Attribute \\
\hline Modulo : url & -- & -- & Referencia a página inicial do módulo. & Class Attribute \\
\hline Objetos : contexto & -- & -- & $\begin{array}{l}\text { Ambiente onde o material de aprendizagem pode } \\
\text { ser utilizado. Pode ser Educação Primária, } \\
\text { Secundária, Universitária etc. }\end{array}$ & Class Attribute \\
\hline Objetos : data & -- & -- & Data de criação do material de aprendizagem. & Class Attribute \\
\hline Objetos : descrícao & -- & -- & Descrição do material de aprendizagem. & Class Attribute \\
\hline Objetos : dificuldade & -- & -- & $\begin{array}{l}\text { Grau de dificuldade do material de } \\
\text { aprendizagem. Pode ser Muito fácil, Fácil, } \\
\text { Médio, Difícil e Muito Difícil. }\end{array}$ & Class Attribute \\
\hline Objetos : formato & -- & -- & $\begin{array}{l}\text { Formato do material de aprendizagem. Pode ser } \\
\text { um vídeo avi/mpeg, uma aplicação, um texto } \\
\text { html, uma animação Flash etc. }\end{array}$ & Class Attribute \\
\hline Objetos : interatividade & -- & -- & $\begin{array}{l}\text { Nível de interatividade entre o usuário e o } \\
\text { material do aprendiz. Pode ser Baixo, Muito } \\
\text { Baixo, Médio, Alto e Muito Alto. }\end{array}$ & Class Attribute \\
\hline Objetos : linguagem & -- & -- & $\begin{array}{l}\text { Linguagem (português, inglês,..) do material de } \\
\text { aprendizagem. }\end{array}$ & Class Attribute \\
\hline
\end{tabular}




\begin{tabular}{|c|c|c|c|c|}
\hline Name & Synonyms & Acronyms & Description & Type \\
\hline Objetos : localizacao & -- & -- & $\begin{array}{l}\text { Localização do material de aprendizagem, } \\
\text { normalmente um endereço URI. }\end{array}$ & Class Attribute \\
\hline Objetos : palavra_chave & -- & -- & Palavra chave do material de aprendizagem. & Class Attribute \\
\hline Objetos : responsavel & -- & -- & $\begin{array}{l}\text { Responsável e/ou criador do material de } \\
\text { aprendizagem. }\end{array}$ & Class Attribute \\
\hline Objetos : restricao & -- & -- & $\begin{array}{l}\text { Quais as restrições de uso do material de } \\
\text { aprendizagem. }\end{array}$ & Class Attribute \\
\hline Objetos : tamanho & -- & -- & Tamanho do material de aprendizagem. & Class Attribute \\
\hline Objetos : titulo & -- & -- & Título do material de aprendizagem. & Class Attribute \\
\hline Professor : email & -- & -- & Endereço eletrônico (email) do professor. & Class Attribute \\
\hline Professor : id & -- & -- & Código de identificação do professor. & Class Attribute \\
\hline Professor : nome & -- & -- & Nome do professor. & Class Attribute \\
\hline Auto_Avaliacao & -- & -- & $\begin{array}{l}\text { Tipo de objeto que contém testes de auto } \\
\text { avaliação. }\end{array}$ & Concept \\
\hline Diagrama & -- & -- & $\begin{array}{l}\text { Um tipo de objeto de aprendizagem que, por } \\
\text { meio de figuras geométricas (pontos, linhas, } \\
\text { áreas etc.), faz a representação de fatos, } \\
\text { fenômenos, grandezas, ou das relações entre } \\
\text { eles. }\end{array}$ & Concept \\
\hline Disciplina & -- & -- & $\begin{array}{l}\text { Uma disciplina é/pode ser composta por um ou } \\
\text { mais módulos. }\end{array}$ & Concept \\
\hline Enunciado_Problema & -- & -- & $\begin{array}{l}\text { Um tipo de objeto que representa um enunciado } \\
\text { de problema. }\end{array}$ & Concept \\
\hline
\end{tabular}




\begin{tabular}{|c|c|c|c|c|}
\hline Name & Synonyms & Acronyms & Description & Type \\
\hline Exame & -- & -- & $\begin{array}{l}\text { Um tipo de objeto de aprendizagem destinada a } \\
\text { avaliar a aptidão ou os conhecimentos de um } \\
\text { aluno. }\end{array}$ & Concept \\
\hline Exercicio & -- & -- & $\begin{array}{l}\text { Um tipo de objeto de aprendizagem com o } \\
\text { objetivo de treinar o estudante em determinada } \\
\text { disciplina. }\end{array}$ & Concept \\
\hline Experiencia & -- & -- & $\begin{array}{l}\text { Um tipo de objeto de aprendizagem que } \\
\text { representa um ato ou efeito de experimentar. }\end{array}$ & Concept \\
\hline Figura & -- & -- & $\begin{array}{l}\text { Um tipo de objeto de aprendizagem que através } \\
\text { de um conjunto de traços gráficos reproduz } \\
\text { alguém ou algo (real ou imaginário). }\end{array}$ & Concept \\
\hline Grafico & -- & -- & $\begin{array}{l}\text { Um tipo de objeto de aprendizagem destinado à } \\
\text { representação da linguagem por sinais visuais, } \\
\text { desenhados ou gravados. }\end{array}$ & Concept \\
\hline Indice & -- & -- & $\begin{array}{l}\text { Um tipo de objeto de aprendizagem que lista } \\
\text { todos, ou quase todos, os itens que se considera } \\
\text { de maior importância no texto de determinado } \\
\text { material de aprendizagem. }\end{array}$ & Concept \\
\hline Material_Aprendizagem & -- & -- & $\begin{array}{l}\text { Um conjunto de documentos e/ou objetos, } \\
\text { indispensáveis ao desempenho das atividades de } \\
\text { aprendizagem. Portanto, um gráfico, uma figura, } \\
\text { uma experiência, um jogo educacional, uma } \\
\text { simulação, um tutorial podem ser considerados } \\
\text { materiais de aprendizagem. }\end{array}$ & Concept \\
\hline
\end{tabular}




\begin{tabular}{|c|c|c|c|c|}
\hline Name & Synonyms & Acronyms & Description & Type \\
\hline Modulo & -- & -- & $\begin{array}{l}\text { Um módulo é formado por uma ou mais páginas } \\
\text { HTML unidas e é a unidade que compõe a } \\
\text { disciplina. }\end{array}$ & Concept \\
\hline Objetos & -- & -- & $\begin{array}{l}\text { São os tipos de objetos de aprendizagem que } \\
\text { compõem um material de aprendizagem. Pode } \\
\text { ser um gráfico, tabela, fórmula, animação, } \\
\text { simulação, exercício etc. }\end{array}$ & Concept \\
\hline Professor & -- & -- & $\begin{array}{l}\text { É aquele que é responsável por disciplinas, } \\
\text { módulos,elaboração de material de } \\
\text { aprendizagem e sua disponibilização às turmas. }\end{array}$ & Concept \\
\hline Questionario & -- & -- & $\begin{array}{l}\text { Um tipo de objeto de aprendizagem com uma } \\
\text { sequência de perguntas feitas para servir de guia } \\
\text { a uma investigação, entrevista, etc. }\end{array}$ & Concept \\
\hline Simulacao & -- & -- & $\begin{array}{l}\text { Um tipo de objeto de aprendizagem que imita o } \\
\text { funcionamento de um processo, por meio do } \\
\text { funcionamento de outro. }\end{array}$ & Concept \\
\hline Tabela & -- & -- & $\begin{array}{l}\text { Um tipo de objeto de aprendizagem que consta } \\
\text { de quadro sistemático de consulta de dados onde } \\
\text { se registram preços, relação de pessoas, etc. }\end{array}$ & Concept \\
\hline Texto_Narrativo & -- & -- & $\begin{array}{l}\text { Um tipo de objeto que contém um texto que } \\
\text { descreve um determinado assunto. }\end{array}$ & Concept \\
\hline $\begin{array}{l}\text { mol_temDisciplina(Modulo, } \\
\text { Disciplina) }\end{array}$ & -- & -- & -- & Relation \\
\hline
\end{tabular}




\begin{tabular}{|c|c|c|c|c|}
\hline Name & Synonyms & Acronyms & Description & Type \\
\hline mol_criadoPor(Modulo, Professor) & -- & -- & -- & Relation \\
\hline $\begin{array}{l}\text { mol_temMaterial_Aprendizagem( } \\
\text { Modulo, Material_Aprendizagem) }\end{array}$ & -- & -- & -- & Relation \\
\hline $\begin{array}{l}\text { mol_temMaterial_Aprendizagem( } \\
\text { Modulo, Material_Aprendizagem) }\end{array}$ & -- & -- & $\begin{array}{l}\text { Esta relação indica que os Módulos têm um ou } \\
\text { mais Materiais de aprendizagem }\end{array}$ & Relation \\
\hline $\begin{array}{l}\text { dis_ensinadaPor(Disciplina, } \\
\text { Professor) }\end{array}$ & -- & -- & -- & Relation \\
\hline $\begin{array}{l}\text { prof_criaModulo(Professor, } \\
\text { Modulo) }\end{array}$ & -- & -- & -- & Relation \\
\hline $\begin{array}{l}\text { prof_criaDisciplina(Professor, } \\
\text { Disciplina) }\end{array}$ & -- & -- & -- & Relation \\
\hline $\begin{array}{l}\text { mat_temModulo(Material_Aprendi } \\
\text { zagem, Modulo) }\end{array}$ & -- & -- & -- & Relation \\
\hline $\begin{array}{l}\text { mat_ePreRequisitoDe(Material_Ap } \\
\text { rendizagem, } \\
\text { Material_Aprendizagem) }\end{array}$ & -- & -- & -- & Relation \\
\hline $\begin{array}{l}\text { mat_eSemelhanteDe(Material_Apr } \\
\text { endizagem, } \\
\text { Material_Aprendizagem) }\end{array}$ & -- & -- & -- & Relation \\
\hline $\begin{array}{l}\text { mat_teSemelhancaCom(Material_A } \\
\text { prendizagem, } \\
\text { Material_Aprendizagem) }\end{array}$ & - & -- & -- & Relation \\
\hline $\begin{array}{l}\text { mat_temPreRequisitoDe(Material_ } \\
\text { Aprendizagem, } \\
\text { Material_Aprendizagem) }\end{array}$ & -- & -- & -- & Relation \\
\hline mat_temObjetos(Material_Aprendi & -- & -- & Indica que os Materiais de Aprendizagem têm & Relation \\
\hline
\end{tabular}


zagem, Objetos)

obj_eParteDeMaterial_Aprendizage

$\mathrm{m}$ (Objetos,

Material_Aprendizagem)

Materiais de Aprendizagem objetos de aprendizagem.

Relação inversa de mat_temObjetos; indica que os objetos são parte dos materiais de

Relation aprendizagem.

View 


\section{A2. Árvore de Classificação de Conceitos}

Subclass of

\begin{tabular}{|l|l|}
\hline Source (Specialization) & Target (Generalization) \\
\hline Exercicio & Objetos \\
\hline Simulacao & Objetos \\
\hline Questionario & Objetos \\
\hline Diagrama & Objetos \\
\hline Exame & Objetos \\
\hline Grafico & Objetos \\
\hline Indice & Objetos \\
\hline Tabela & Objetos \\
\hline Figura & Objetos \\
\hline Experiencia & Objetos \\
\hline Auto_Avaliacao & Objetos \\
\hline Enunciado_Problema & Objetos \\
\hline Texto_Narrativo & Objetos \\
\hline
\end{tabular}




\section{Disjoint partitions}

There are no disjoint partitions in the ontology

\section{Group Group components Target}

Exhaustive partitions

\section{Group Group components Target}

There are no exhaustive partitions in the ontology

Not Subclass of

\section{Source (Specialization) Target (Generalization)}

There are no not subclass of relations in the ontology 
A3. Dicionário de Conceitos

\begin{tabular}{|c|c|c|c|c|c|c|}
\hline Concept name & Synonyms & Acronyms & Instances & Class attributes & $\begin{array}{l}\text { Instance } \\
\text { attributes }\end{array}$ & Relations \\
\hline Auto_Avaliação & -- & -- & -- & -- & -- & -- \\
\hline Diagrama & -- & -- & -- & -- & -- & -- \\
\hline Disciplina & -- & -- & -- & $\begin{array}{l}\text { codigo } \\
\text { descricao } \\
\text { id } \\
\text { link_bibliografia } \\
\text { link_glossario } \\
\text { link_sumario } \\
\text { nome } \\
\text { professor }\end{array}$ & -- & dis_ensinadaPor \\
\hline Enunciado_Problema & -- & -- & -- & -- & -- & -- \\
\hline Exame & -- & -- & -- & -- & -- & -- \\
\hline Exercício & -- & -- & -- & -- & -- & -- \\
\hline Experiência & -- & -- & -- & -- & -- & -- \\
\hline Figura & -- & -- & -- & -- & -- & -- \\
\hline Gráfico & -- & -- & -- & -- & -- & -- \\
\hline Índice & -- & -- & -- & -- & -- & -- \\
\hline
\end{tabular}




\begin{tabular}{|c|c|c|c|c|c|c|}
\hline Concept name & Synonyms & Acronyms & Instances & Class attributes & $\begin{array}{l}\text { Instance } \\
\text { attributes }\end{array}$ & Relations \\
\hline Material_Aprendizagem & -- & -- & -- & $\begin{array}{l}\text { codigo } \\
\text { nome }\end{array}$ & -- & $\begin{array}{l}\text { mat_temModulo } \\
\text { mat_ePreRequisitoDe } \\
\text { mat_eSemelhanteDe } \\
\text { mat_teSemelhancaCom } \\
\text { mat_temPreRequisitoDe } \\
\text { mat_temObjetos }\end{array}$ \\
\hline Modulo & -- & -- & -- & $\begin{array}{l}\text { descricao } \\
\text { id } \\
\text { nome } \\
\text { professor } \\
\text { url }\end{array}$ & -- & $\begin{array}{l}\text { mol_temDisciplina } \\
\text { mol_criadoPor } \\
\text { mol_temMaterial_Apren } \\
\text { dizagem }\end{array}$ \\
\hline Objetos & -- & -- & -- & $\begin{array}{l}\text { contexto } \\
\text { data } \\
\text { descricao } \\
\text { dificuldade } \\
\text { formato } \\
\text { interatividade } \\
\text { linguagem } \\
\text { localizacao } \\
\text { palavra_chave } \\
\text { responsavel } \\
\text { restricao } \\
\text { tamanho } \\
\text { titulo }\end{array}$ & -- & $\begin{array}{l}\text { obj_eParteDeMaterial_ } \\
\text { Aprendizagem }\end{array}$ \\
\hline Professor & -- & -- & -- & $\begin{array}{l}\text { email } \\
\text { id } \\
\text { nome }\end{array}$ & -- & $\begin{array}{l}\text { prof_criaModulo } \\
\text { prof_criaDisciplina }\end{array}$ \\
\hline
\end{tabular}




\begin{tabular}{|c|c|c|c|c|c|c|}
\hline Concept name & Synonyms & Acronyms & Instances & Class attributes & $\begin{array}{l}\text { Instance } \\
\text { attributes }\end{array}$ & Relations \\
\hline Questionario & -- & -- & -- & -- & -- & -- \\
\hline Simulacao & -- & -- & -- & -- & -- & -- \\
\hline Tabela & -- & -- & -- & -- & -- & -- \\
\hline Texto_Narrativo & -- & -- & -- & -- & -- & -- \\
\hline
\end{tabular}

A4. Tabela de Relações Binárias

\begin{tabular}{|c|c|c|c|c|c|}
\hline Relation name & $\begin{array}{l}\text { Source } \\
\text { concept }\end{array}$ & $\begin{array}{l}\text { Source cardinality } \\
\text { (Max) }\end{array}$ & Target concept & $\begin{array}{l}\text { Mathematic } \\
\text { properties }\end{array}$ & Inverse relation \\
\hline Mol_temDisciplina & Modulo & $\mathbf{n}$ & Disciplina & -- & $\begin{array}{l}\text { To be } \\
\text { implemented }\end{array}$ \\
\hline mol_criadoPor & Modulo & $\mathbf{n}$ & Professor & -- & $\begin{array}{l}\text { To be } \\
\text { implemented }\end{array}$ \\
\hline mol_temMaterial_Aprendizagem & Modulo & $\mathbf{n}$ & Material_Aprendizagem & -- & $\begin{array}{l}\text { To be } \\
\text { implemented }\end{array}$ \\
\hline dis_ensinadaPor & Disciplina & $\mathbf{n}$ & Professor & -- & $\begin{array}{l}\text { To be } \\
\text { implemented }\end{array}$ \\
\hline prof_criaModulo & Professor & $\mathbf{n}$ & Modulo & -- & $\begin{array}{l}\text { To be } \\
\text { implemented }\end{array}$ \\
\hline
\end{tabular}




\begin{tabular}{|c|c|c|c|c|c|}
\hline Relation name & Source concept & $\begin{array}{l}\text { Source } \\
\text { cardinality } \\
\text { (Max) }\end{array}$ & Target concept & $\begin{array}{l}\text { Mathematic } \\
\text { properties }\end{array}$ & $\begin{array}{l}\text { Inverse } \\
\text { relation }\end{array}$ \\
\hline prof_criaDisciplina & Professor & $\mathbf{N}$ & Disciplina & -- & $\begin{array}{l}\text { To be } \\
\text { implemented }\end{array}$ \\
\hline mat_temModulo & Material_Aprendizagem & $\mathbf{N}$ & Modulo & -- & $\begin{array}{l}\text { To be } \\
\text { implemented }\end{array}$ \\
\hline mat_ePreRequisitoDe & Material_Aprendizagem & $\mathbf{N}$ & Material_Aprendizagem & $1--$ & $\begin{array}{l}\text { To be } \\
\text { implemented }\end{array}$ \\
\hline mat_eSemelhanteDe & Material_Aprendizagem & $\mathbf{N}$ & Material_Aprendizagem & -- & $\begin{array}{l}\text { To be } \\
\text { implemented }\end{array}$ \\
\hline mat_teSemelhancaCom & Material_Aprendizagem & $\mathbf{N}$ & Material_Aprendizagem & -- & $\begin{array}{l}\text { To be } \\
\text { implemented }\end{array}$ \\
\hline mat_temPreRequisitoDe & Material_Aprendizagem & $\mathbf{N}$ & Material_Aprendizagem & -- & $\begin{array}{l}\text { To be } \\
\text { implemented }\end{array}$ \\
\hline mat_temObjetos & Material_Aprendizagem & $\mathbf{N}$ & Objetos & -- & $\begin{array}{l}\text { To be } \\
\text { implemented }\end{array}$ \\
\hline obj_eParteDeMaterial_Aprendizagem & Objetos & $\mathbf{N}$ & Material_Aprendizagem & -- & $\begin{array}{l}\text { To be } \\
\text { implemented }\end{array}$ \\
\hline
\end{tabular}


A5. Tabela de Classe de Atributos

\begin{tabular}{|c|c|c|c|c|c|c|c|}
\hline Attribute name & Values & Concept name & Value type & Measurement unit & Precision & Cardinality & To deduce \\
\hline codigo & -- & Disciplina & String & -- & -- & $(1,1)$ & Not defined yet \\
\hline descricao & -- & Disciplina & String & -- & -- & $(1,1)$ & Not defined yet \\
\hline id & -- & Disciplina & String & -- & -- & $(1,1)$ & Not defined yet \\
\hline link_bibliografia & -- & Disciplina & String & -- & -- & $(1,1)$ & Not defined yet \\
\hline link_glossario & -- & Disciplina & String & -- & -- & $(1,1)$ & Not defined yet \\
\hline link_sumario & -- & Disciplina & String & -- & -- & $(1,1)$ & Not defined yet \\
\hline nome & -- & Disciplina & String & -- & -- & $(1,1)$ & Not defined yet \\
\hline professor & -- & Disciplina & String & -- & -- & $(1,1)$ & Not defined yet \\
\hline codigo & -- & Material_Aprendizagem & String & -- & -- & $(1,1)$ & Not defined yet \\
\hline nome & -- & Material_Aprendizagem & String & -- & -- & $(\mathbf{1}, \mathbf{1})$ & Not defined yet \\
\hline descricao & -- & Modulo & String & -- & -- & $(1,1)$ & Not defined yet \\
\hline id & -- & Modulo & Integer & -- & -- & $(1,1)$ & Not defined yet \\
\hline nome & -- & Modulo & String & -- & -- & $(1,1)$ & Not defined yet \\
\hline professor & -- & Modulo & String & -- & -- & $(1,1)$ & Not defined yet \\
\hline url & -- & Modulo & String & -- & -- & $(1,1)$ & Not defined yet \\
\hline contexto & -- & Objetos & String & -- & -- & $(1,1)$ & Not defined yet \\
\hline data & -- & Objetos & String & -- & -- & $(1,1)$ & Not defined yet \\
\hline descrícao & -- & Objetos & String & -- & -- & $(1,1)$ & Not defined yet \\
\hline dificuldade & -- & Objetos & String & -- & -- & $(1,1)$ & Not defined yet \\
\hline formato & -- & Objetos & String & -- & -- & $(1,1)$ & Not defined yet \\
\hline
\end{tabular}




\begin{tabular}{|l|l|l|l|l|l|l|l|}
\hline Attribute name & Values & Concept name & Value type & Measurement unit & Precision & \multicolumn{2}{l|}{ Cardinality To deduce } \\
\hline interatividade & -- & Objetos & String & -- & -- & $(1,1)$ & Not defined yet \\
\hline linguagem & -- & Objetos & String & -- & -- & $(1,1)$ & Not defined yet \\
\hline localizacao & -- & Objetos & String & -- & -- & $(1,1)$ & Not defined yet \\
\hline palavra_chave & -- & Objetos & String & -- & -- & $(1,1)$ & Not defined yet \\
\hline responsavel & -- & Objetos & String & -- & -- & $(1,1)$ & Not defined yet \\
\hline restricao & -- & Objetos & String & -- & -- & $(1,1)$ & Not defined yet \\
\hline tamanho & -- & Objetos & String & -- & -- & $(1,1)$ & Not defined yet \\
\hline titulo & -- & Objetos & String & -- & -- & $(1,1)$ & Not defined yet \\
\hline email & -- & Professor & String & -- & -- & $(1,1)$ & Not defined yet \\
\hline id & -- & Professor & String & -- & -- & $(1,1)$ & Not defined yet \\
\hline nome & -- & Professor & String & -- & -- & $(1,1)$ & Not defined yet
\end{tabular}




\section{Anexo B - Testes da proposta do Modelo Ontológico}

Para testar o modelo ontológico proposto, foram realizadas as seguintes tarefas:

\section{B.1 - Criar disciplinas na plataforma CoL}

Foram criadas as disciplinas: XML- Conceitos Básicos e RDF - Conceitos Básicos, com os seguintes conteúdos programáticos que se seguem:

\section{Disciplina: XML - Conceitos Básico}

Módulo 1 - Informações sobre a disciplina

1.1 - Objetivos

1.2 - Organização da Disciplina

Módulo 2- Linguagens de Marcação

2.1 - Definição

$2.2-\mathrm{SGML}$

Disciplina: RDF - Conceitos Básicos

Módulo 1 - RDF Básico

1.1 - Conceitos

1.2 - Modelo de Dados

Módulo 2- RDF Schema

2.1 - Conceitos

2.2 - Classes

B.2 - Criar os modelo ontológico que representa a estrutura das disciplinas e módulos na plataforma CoL e, a seguir, na linguagem DAML+OIL.

O modelo ontológico completo, na linguagem DAML+OIL, está inserido no item B.5. As disciplinas foram inseridas no ambiente $\mathrm{CoL}$, para a realização de testes.

\section{B. 3 - Criar as instâncias baseadas no modelo ontológico na linguagem} DAML+OIL.

O modelo ontológico completo, na linguagem DAML+OIL, está apresentado no item B.6. 


\section{B.4 - Testar o modelo através do sistema AQ-Search}

A interface da ferramenta AQ-Search tem sua interface gráfica representada na figura.

B1:

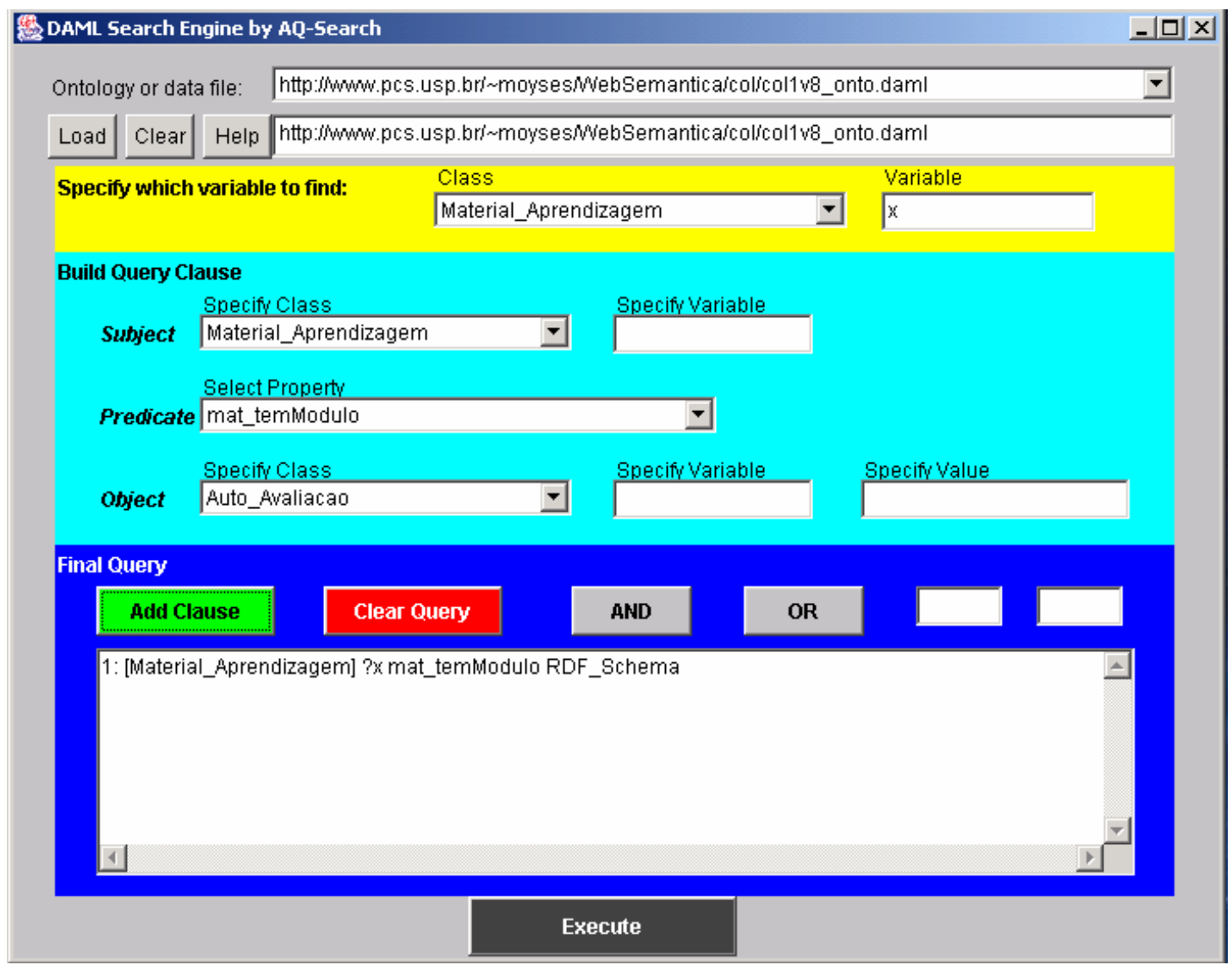

Fig. B.1 - Interface gráfica da ferramenta AQ-Search

Antes de iniciar as pesquisas é necessário carregar as ontologias que representam a estrutura das disciplinas e as instâncias. As seguintes etapas são necessárias:

Etapa 1: Carregar a ontologia que representam a estrutura das disciplinas.

Select "http://www.pcs.usp.br/ moyses/WebSemantica/col/col1v8_onto.daml” e clicar no botão Load. 
Etapa 2: Carregar a ontologia que representa as instâncias.

Select "http://www.pcs.usp.br/ moyses/WebSemantica/col/col1v8_onto_dados.daml" e clicar no botão Load.

As seguintes pesquisas podem ser realizadas:

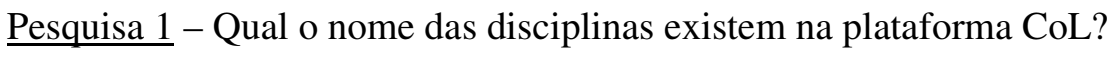

Etapa 1: Selecionar Disciplinas no campo Class e Specify Class. Digitar "x" no campo Variable e Specify Variable em Subject.

Etapa 2: Selecionar nome no campo Select Property.

Etapa 3: Digitar ** em Specify Value em Object.

Etapa 4: Clicar em Add Clause. Em Final Query a seguinte expressão é exibida: [Disciplina] ?x nome **

Etapa 5: Clicar no botão Execute. Em DAML Search Results, no campo Result Instances aparecerá o seguinte resultado:

\section{RDF_Conceitos_Básicos} XML_Conceitos_Básicos

Obs: Um clique duplo no resultado, mostrará os atributos da disciplina.

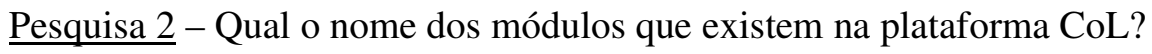

Etapa 1: Selecionar Modulo no campo Class e Specify Class. Digitar "x" no campo Variable e Specify Variable em Subject.

Etapa 2: Selecionar nome no campo Select Property.

Etapa 3: Digitar ** em Specify Value em Object.

Etapa 4: Clicar em Add Clause. Em Final Query a seguinte expressão é exibida: [Modulo] ?x nome **

Etapa 5: Clicar no botão Execute. Em DAML Search Results, no campo Result Instances aparecerá o seguinte resultado: 


\section{RDF_Básico \\ RDF_Schema}

Pesquisa 3 - Que disciplina tem módulo Linguagens de Marcação

Etapa 1: Selecionar Disciplinas no campo Class e Specify Class. Digitar "x" no campo Variable e Specify Variable em Subject.

Etapa 2: Selecionar dis_temModulo no campo Select Property.

Etapa 3: Digitar Linguagens_de_Marcação em Specify Value em Object.

Etapa 4: Clicar em Add Clause. Em Final Query a seguinte expressão é exibida:

[Disciplina] ?x dis_temModulo Linguagens_de_Marcacao

Etapa 5: Clicar no botão Execute. Em DAML Search Results, no campo Result Instances aparecerá o seguinte resultado:

XML_Conceitos_Básicos

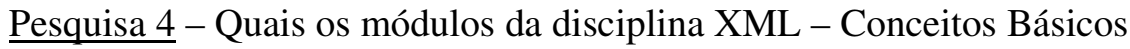

Etapa 1: Selecionar Modulo no campo Class e Specify Class. Digitar "x" no campo Variable e Specify Variable em Subject.

Etapa 2: Selecionar mol_temDisciplina no campo Select Property.

Etapa 3: Digitar XML_Conceitos_Basicos em Specify Value em Object.

Etapa 4: Clicar em Add Clause. Em Final Query a seguinte expressão é exibida:

[Modulo] ?x mol_temDisciplina XML_Conceitos_Basicos

Etapa 5: Clicar no botão Execute. Em DAML Search Results, no campo Result Instances aparecerá o seguinte resultado:

\section{Informações_sobre_Curso \\ Linguagens_de_Marcação}

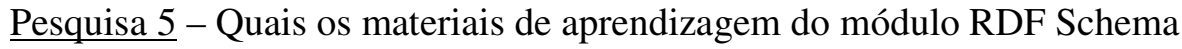

Etapa 1: Selecionar Material de Aprendizagem no campo Class e Specify Class. Digitar "x" no campo Variable e Specify Variable em Subject.

Etapa 2: Selecionar mat_temModulo no campo Select Property.

Etapa 3: Digitar RDF_Schema em Specify Value em Object. 
Etapa 4: Clicar em Add Clause. Em Final Query a seguinte expressão é exibida:

[Matéria_Aprendizagem] ?x mat_temModulo RDF_Schema

Etapa 5: Clicar no botão Execute. Em DAML Search Results, no campo Result Instances aparecerá o seguinte resultado:

\section{RDF_Schema_Classes \\ RDF_Schema_Conceitos}

Pesquisa 6 - Quais materiais de aprendizagem tem um tipo de objeto Tabela?

Etapa 1: Selecionar Material de Aprendizagem no campo Class e Specify Class. Digitar "x"

no campo Variable e Specify Variable em Subject.

Etapa 2: Selecionar mat_temObjetos no campo Select Property.

Etapa 3: Digitar Tabela em Specify Value em Object.

Etapa 4: Clicar em Add Clause. Em Final Query a seguinte expressão é exibida:

[Matéria_Aprendizagem] ?x mat_temObjetos Tabela

Etapa 5: Clicar no botão Execute. Em DAML Search Results, no campo Result Instances aparecerá o seguinte resultado:

\section{RDF_Modelo_Dados}

Pesquisa 7 - Quais materiais de aprendizagem têm um tipo de objeto Figura ou Diagrama?

Etapa 1: Selecionar Material de Aprendizagem no campo Class e Specify Class. Digitar "x" no campo Variable e Specify Variable em Subject.

Etapa 2: Selecionar mat_temObjetos no campo Select Property.

Etapa 3: Digitar Figura em Specify Value em Object.

Etapa 4: Clicar em Add Clause. Em Final Query a seguinte expressão é exibida:

1: [Matéria_Aprendizagem] ?x mat_temObjetos Figura

Etapa 5: Digitar Diagrama em Specify Value em Object.

Etapa 6: Clicar em Add Clause. Em Final Query a seguinte expressão é exibida:

2: [Matéria_Aprendizagem] ?x mat_temObjetos Diagrama

Etapa 7: Em Final Query, digita 1 e 2 nos campos em branco. 
Etapa 8: Clicar no botão OR. Em Final Query a seguinte expressão é exibida:

$3:=1$ OR 2

Etapa 9: Clicar no botão Execute. Em DAML Search Results, no campo Result Instances aparecerá o seguinte resultado:

\section{SGML \\ RDF_Conceitos}

Pesquisa 8 - Qual o nome do objetos com o formato Vídeo AVI?

Etapa 1: Selecionar Objetos no campo Class e Specify Class. Digitar " $x$ " no campo Variable e Specify Variable em Subject.

Etapa 2: Selecionar formato no campo Select Property.

Etapa 3: Digitar Vídeo AVI em Specify Value em Object.

Etapa 4: Clicar em Add Clause. Em Final Query a seguinte expressão é exibida:

[Objetos] ?x formato Vídeo AVI

Etapa 5: Clicar no botão Execute. Em DAML Search Results, no campo Result Instances aparecerá o seguinte resultado:

\section{Exe_Definição}

Pesquisa 9 - Quais tipos de objetos e parte do material de aprendizagem SGML?

Etapa 1: Selecionar Objetos no campo Class e Specify Class. Digitar "x" no campo Variable e Specify Variable em Subject.

Etapa 2: Selecionar obj_eParteDeMaterial_Aprendizagem no campo Select Property.

Etapa 3: Digitar SGML em Specify Value em Object.

Etapa 4: Clicar em Add Clause. Em Final Query a seguinte expressão é exibida:

1: [Objetos] ?x obj_eParteDeMaterial_Aprendizagem SGML

Etapa 5: Clicar no botão Execute. Em DAML Search Results, no campo Result Instances aparecerá o seguinte resultado:

Figura

Texto_Narrativo

$\underline{\text { Pesquisa } 10}$ - Qual disciplina tem a palavra chave Modelo

Etapa 1: Selecionar Objetos no campo Class e Specify Class. Digitar "x" no campo Variable e Specify Variable em Subject. 
Etapa 2: Selecionar palavra_chave no campo Select Property.

Etapa 3: Digitar Modelo em Specify Value em Object.

Etapa 4: Clicar em Add Clause. Em Final Query a seguinte expressão é exibida: 1: [Objetos] ?x palavra_chave Modelo

Etapa 5: Clicar no botão Execute. Em DAML Search Results, no campo Result Instances aparecerá o seguinte resultado:

\section{RDF_Conceitos_Básicos}

Estas são algumas pesquisas possíveis na modelagem baseada em ontologias. O modelo permite pesquisas nos objetos que compõem os materiais de aprendizagem. O sucesso destas pesquisas dependem de como o modelo ontológico é estruturado e da qualidade das anotações realizadas nos materiais de aprendizagem.

\section{B.5 - Modelo completo da ontologia, implementado na linguagem DAML+OIL}

\section{B.5.1 - Ontologia que representa a estrutura das disciplinas na plataforma CoL.}

$<$ !-- ****Ontology file: col1v8_onto.daml**** -->

$<!--? x m l$ version='1.0' encoding='ISO-8859-1'?-->

$<$ rdf:RDF

xmlns:rdf ='http://www.w3.org/1999/02/22-rdf-syntax-ns\#'

xmlns:rdfs='http://www.w3.org/2000/01/rdf-schema\#'

xmlns:xsd ='http://www.w3.org/2000/10/XMLSchema\#'

xmlns:daml='http://www.daml.org/2001/03/daml+oil\#'

xmlns:col='http://www.pcs.usp.br/ moyses/WebSemantica/col/col1v8_onto.daml\#'

$>$

$<$ daml:Ontology rdf:about="">

$<$ daml:versionInfo $>$ Ontologia para materiais de aprendizagem para o COL v.

$1.0</$ daml:versionInfo $>$

$<$ rdfs:comment $>$ Ontologia para o $\mathrm{COL}</$ rdfs:comment $>$

$<$ daml:imports rdf:resource="http://www.daml.org/2001/03/daml+oil"/>

$</$ daml:Ontology $>$

<daml:Class rdf:ID="Disciplina" $>$ 


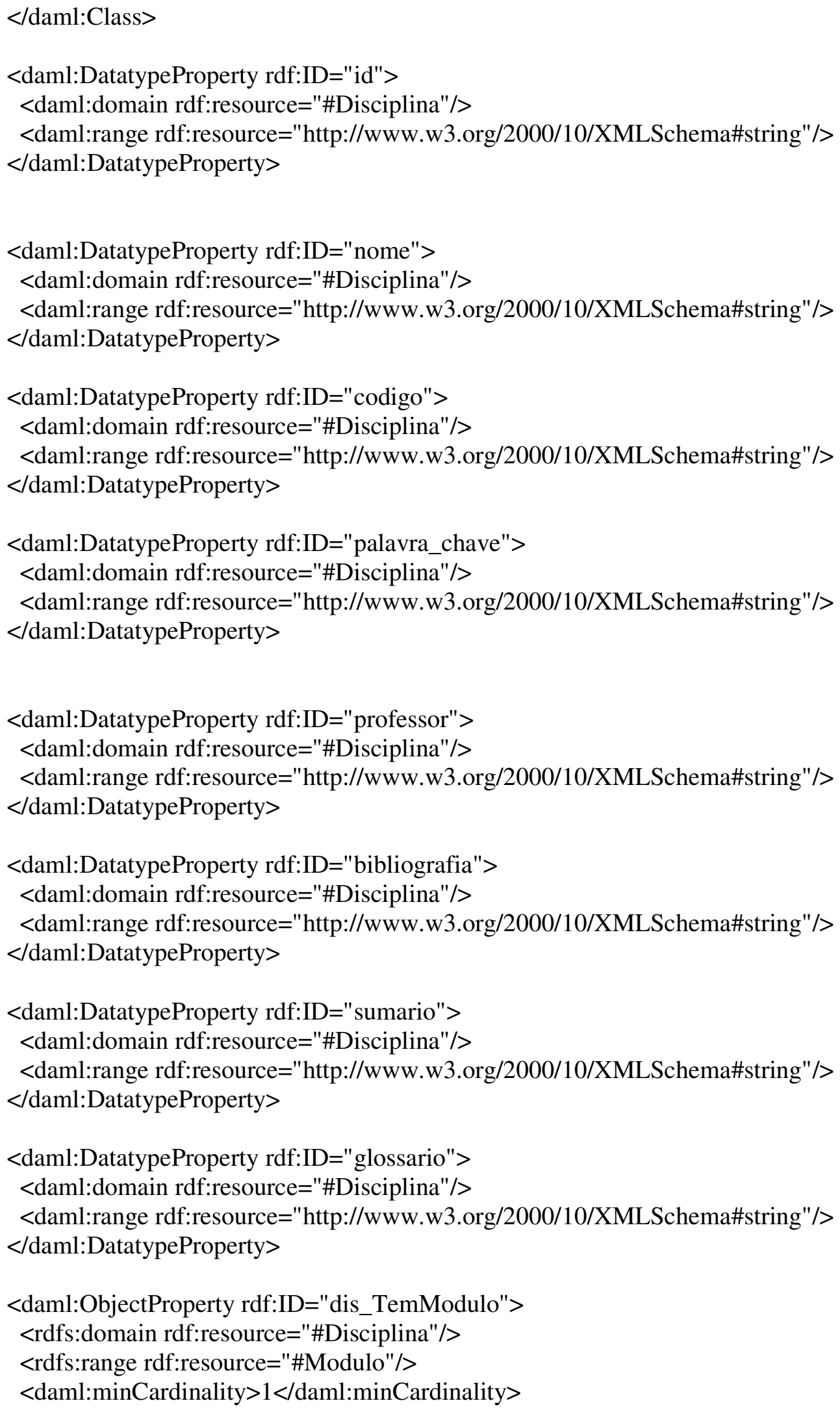


$<$ daml:maxCardinality $>$ n $</$ daml:maxCardinality $>$ $</$ daml:ObjectProperty $>$

$<$ daml:ObjectProperty rdf:ID="dis_ensinadaPor"> $<$ rdfs:domain rdf:resource="\#Disciplina"/> $<$ rdfs:range rdf:resource="\#Professor"/> $<$ daml:minCardinality $>1</$ daml:minCardinality $>$ $<$ daml:maxCardinality $>$ n $</$ daml:maxCardinality $>$ $</$ daml:ObjectProperty $>$

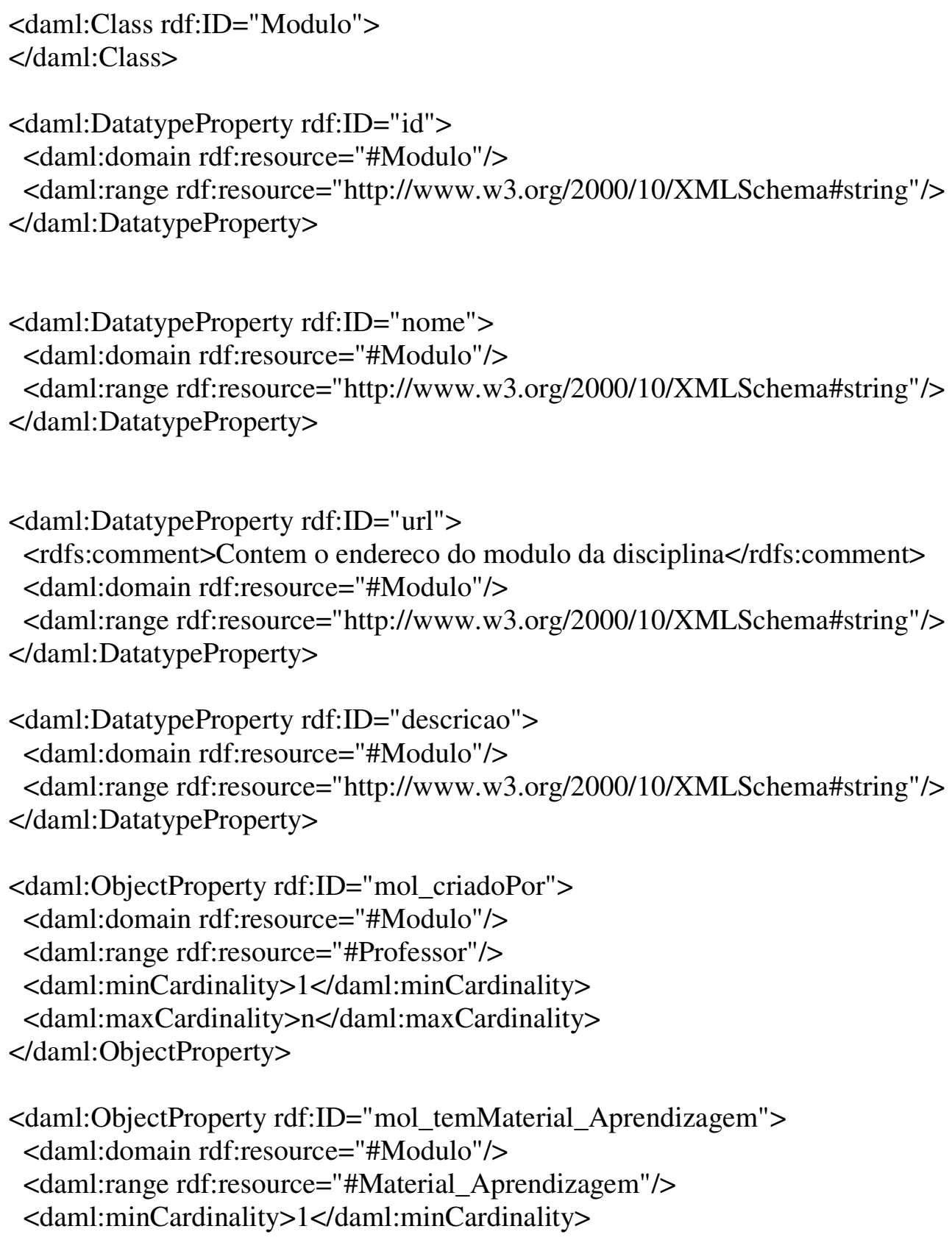




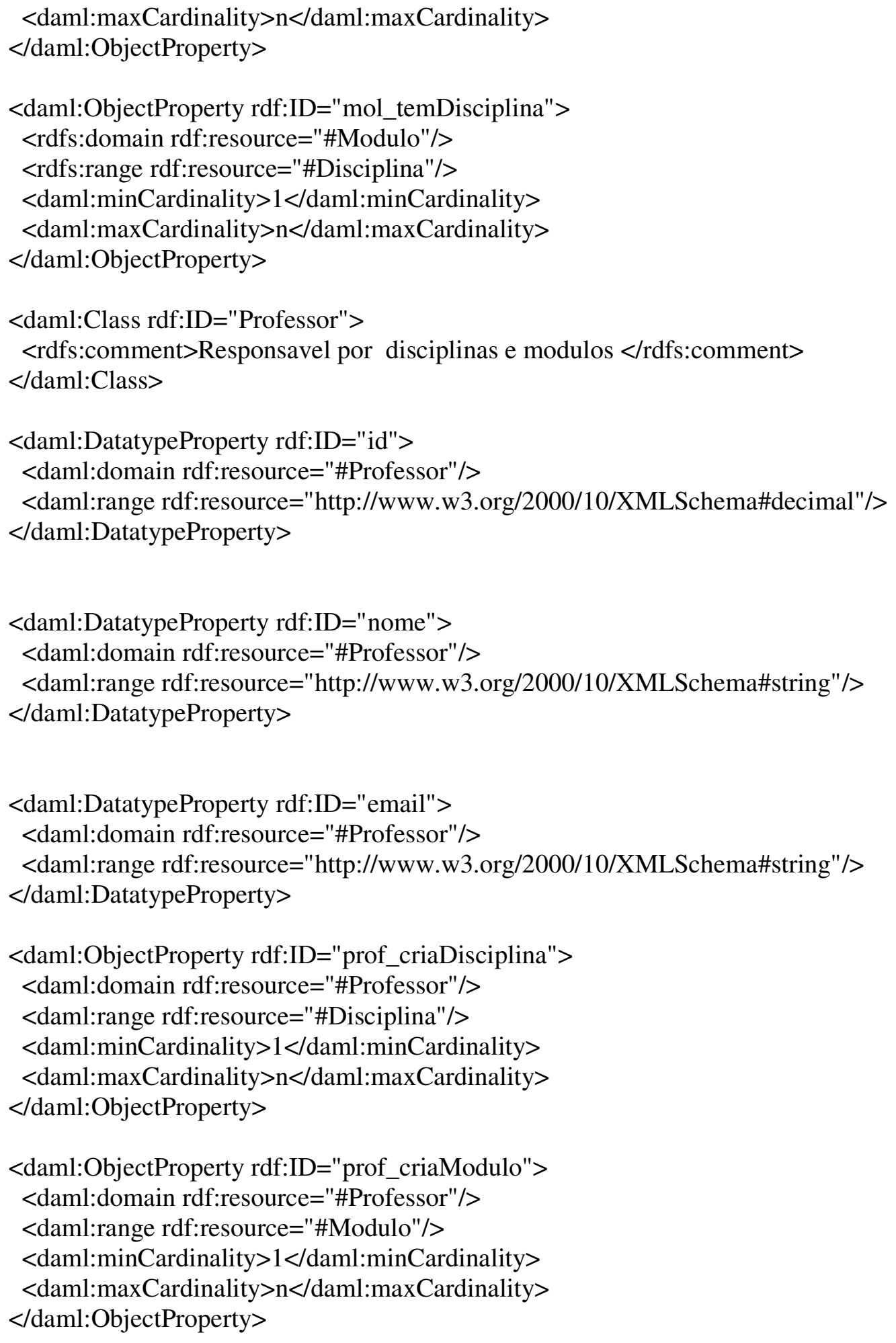




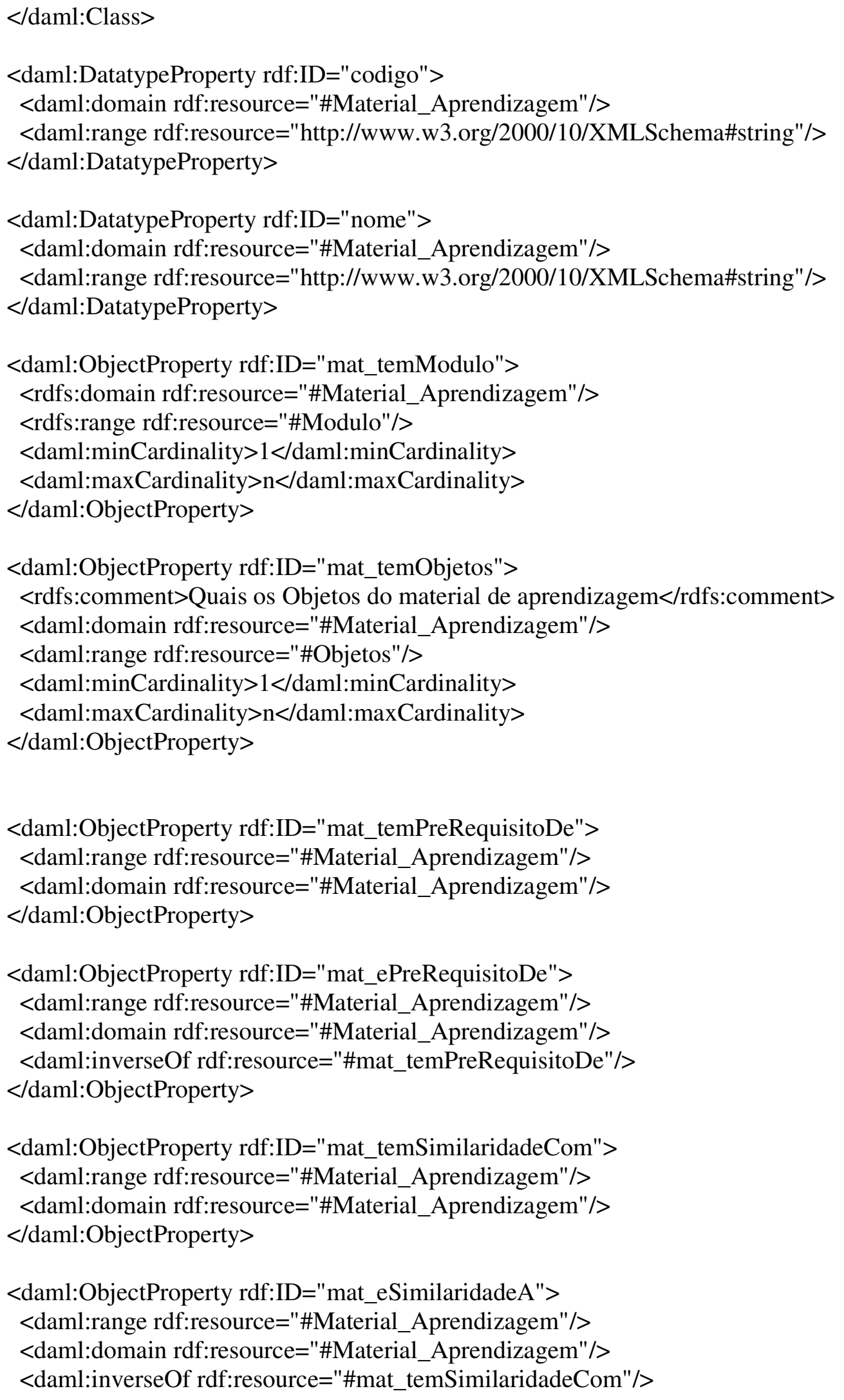




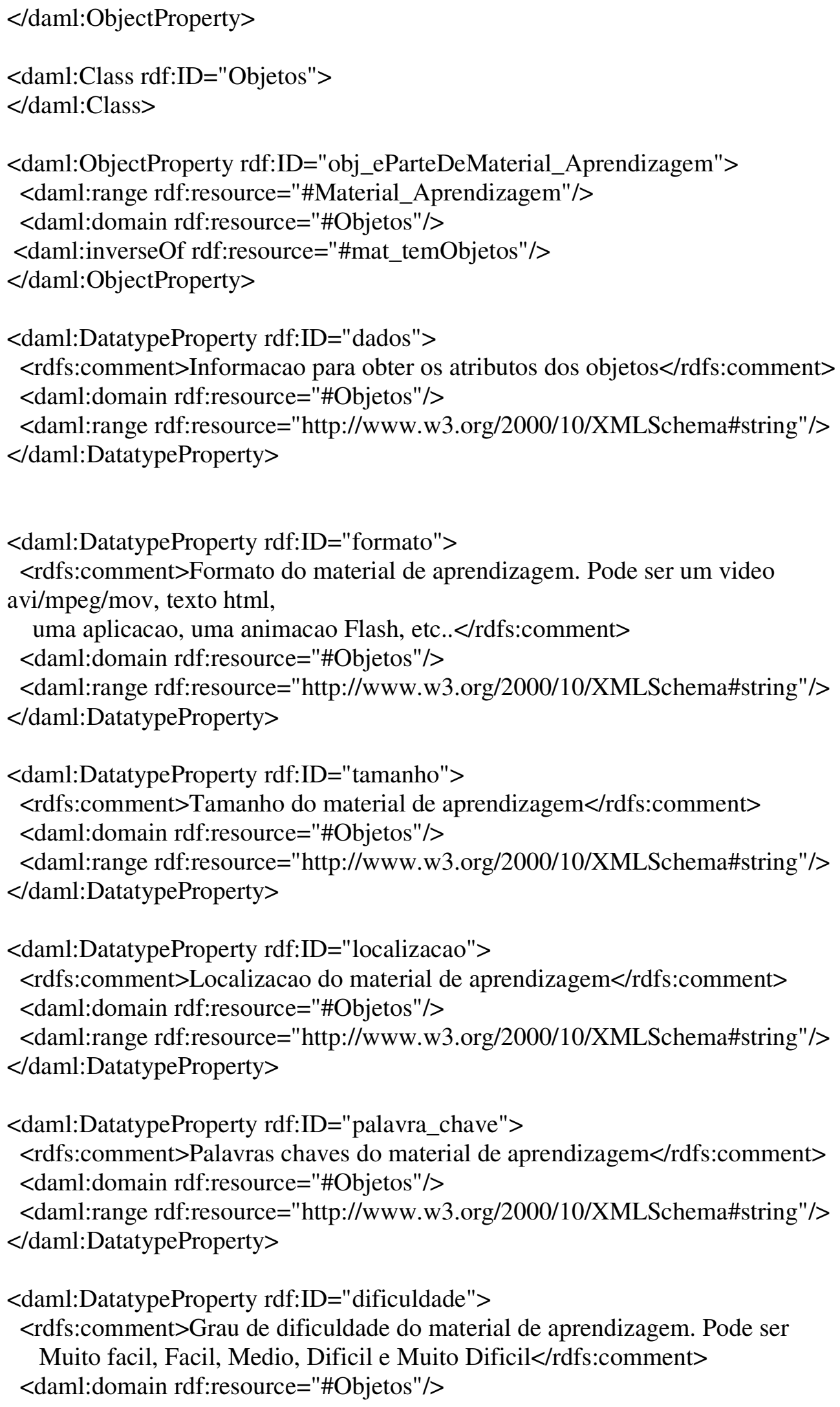


<daml:range rdf:resource="http://www.w3.org/2000/10/XMLSchema\#string"/> $</$ daml:DatatypeProperty $>$

$<$ daml:DatatypeProperty rdf:ID="interatividade" $>$ $<$ rdfs:comment $>$ Nivel de interatividade entre o usuario e o material de aprendizagem.

Pode ser Baixo, Muito Baixo, Medio, Alto e Muito Alto</rdfs:comment $>$ $<$ daml:domain rdf:resource="\#Objetos"/> $<$ daml:range rdf:resource="http://www.w3.org/2000/10/XMLSchema\#string"/> $</$ daml:DatatypeProperty $>$

$<$ daml:DatatypeProperty rdf:ID="contexto"> $<$ rdfs:comment $>$ Ambiente onde o material de aprendizagem pode ser utilizado Pode ser Educaçao Primaria, Secundaria, Universitaria, etc..</rdfs:comment $>$ $<$ daml:domain rdf:resource="\#Objetos"/>

$<$ daml:range rdf:resource="http://www.w3.org/2000/10/XMLSchema\#string"/> $</$ daml:DatatypeProperty $>$

$<$ daml:DatatypeProperty rdf:ID="responsavel"> $<$ rdfs:comment $>$ Responsavel e/ou criador do material de aprendizagem $</$ rdfs:comment $>$ $<$ daml:domain rdf:resource="\#Objetos"/> $<$ daml:range rdf:resource="http://www.w3.org/2000/10/XMLSchema\#string"/> $</$ daml:DatatypeProperty $>$

<daml:DatatypeProperty rdf:ID="descricao"> $<$ rdfs:comment $>$ Descricao do material de aprendizagem $</$ rdfs:comment $>$ $<$ daml:domain rdf:resource="\#Objetos"/>

$<$ daml:range rdf:resource="http://www.w3.org/2000/10/XMLSchema\#string"/> $</$ daml:DatatypeProperty $>$

$<$ daml:DatatypeProperty rdf:ID="titulo"> $<$ rdfs:comment $>$ Titulo do material de aprendizagem $</$ rdfs:comment $>$ $<$ daml:domain rdf:resource="\#Objetos"/> $<$ daml:range rdf:resource="http://www.w3.org/2000/10/XMLSchema\#string"/> $</$ daml:DatatypeProperty $>$

$<$ daml:DatatypeProperty rdf:ID="linguagem" $>$ $<$ rdfs:comment $>$ Linguagem (portuges, ingles,...) do material de aprendizagem $</$ rdfs:comment $>$ $<$ daml:domain rdf:resource="\#Objetos"/> $<$ daml:range rdf:resource="http://www.w3.org/2000/10/XMLSchema\#string"/> $</$ daml:DatatypeProperty $>$

<daml:DatatypeProperty rdf:ID="restricao"> $<$ rdfs:comment $>$ Quais as restricoes de uso do material de aprendizagem $</$ rdfs:comment $>$ $<$ daml:domain rdf:resource="\#Objetos"/> <daml:range rdf:resource="http://www.w3.org/2000/10/XMLSchema\#string"/> 


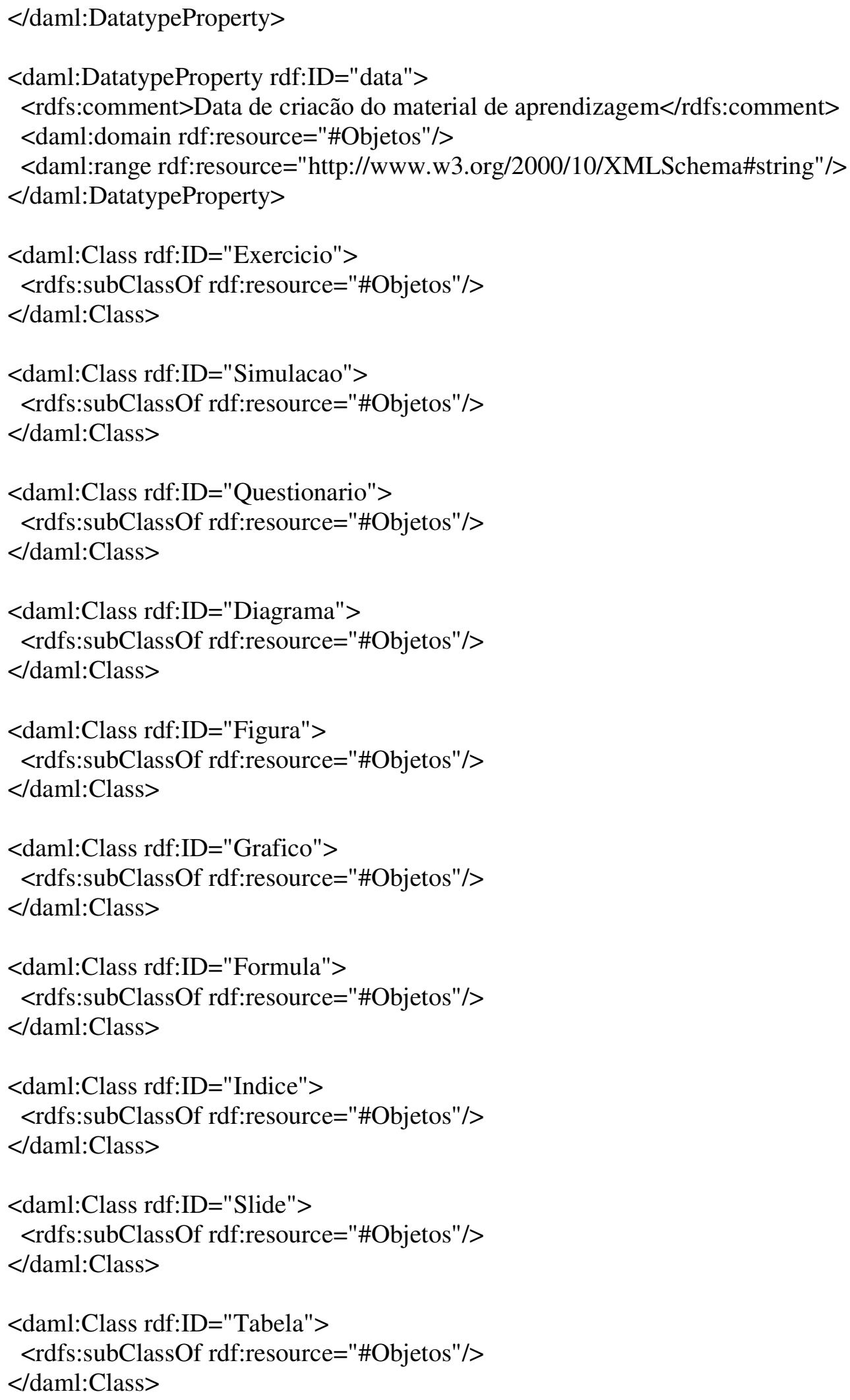




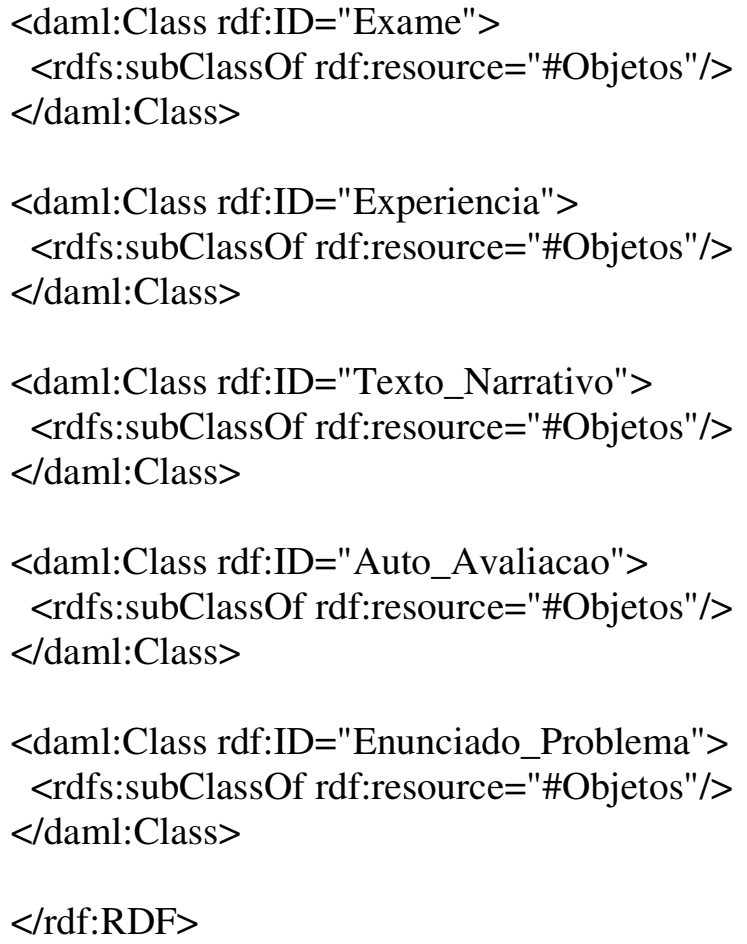

\section{B.5.2 - Arquivo de Instâncias}

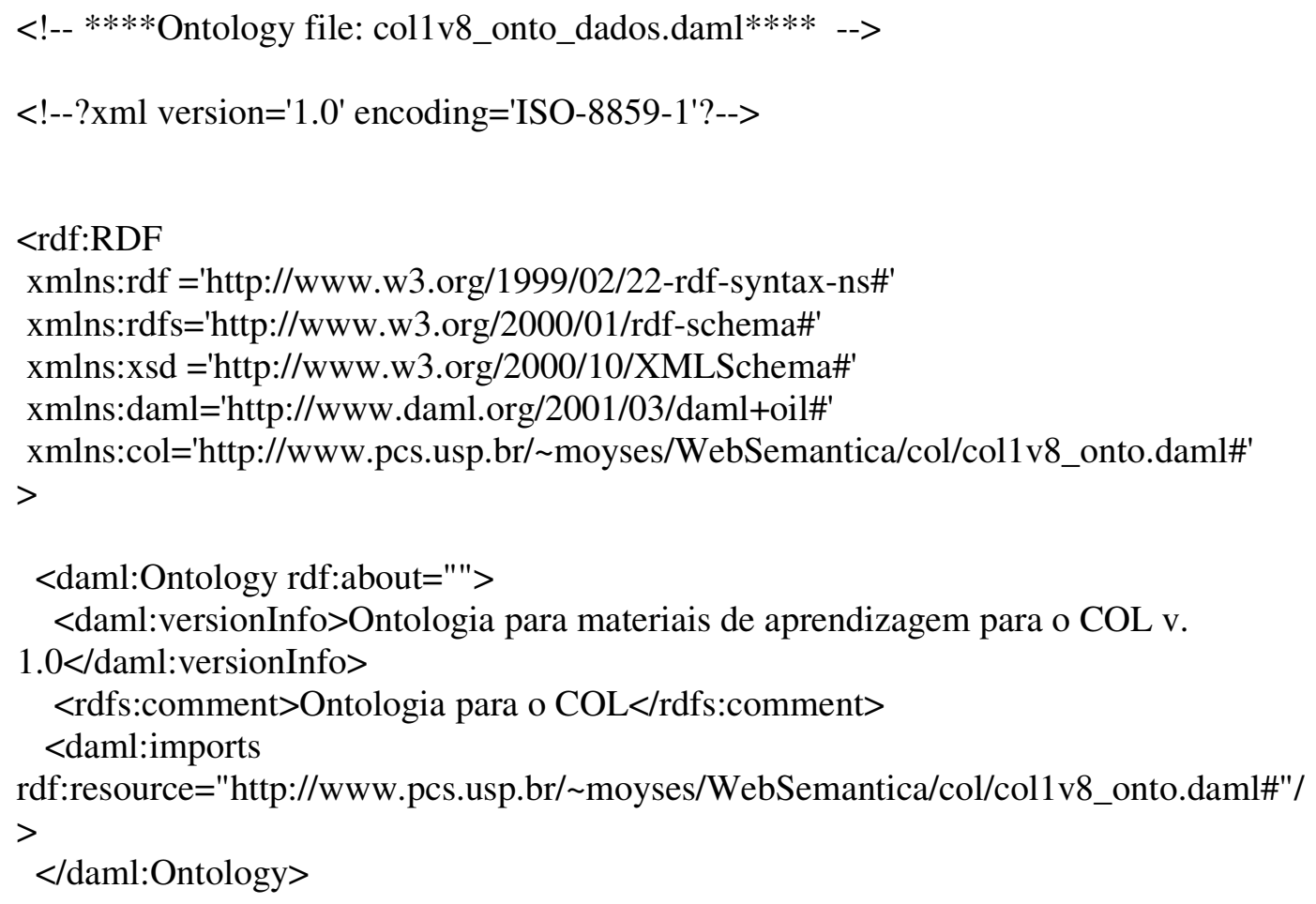




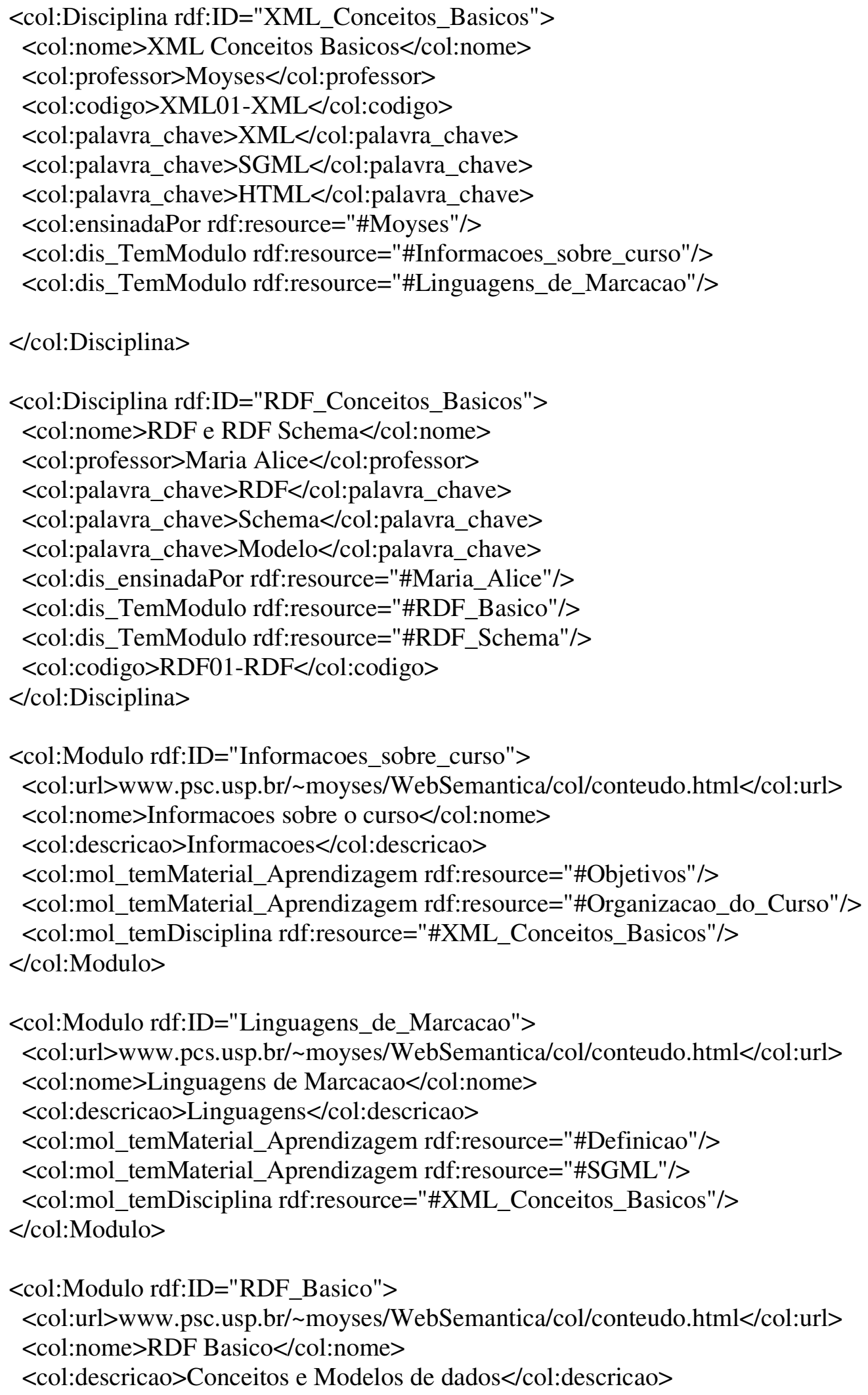




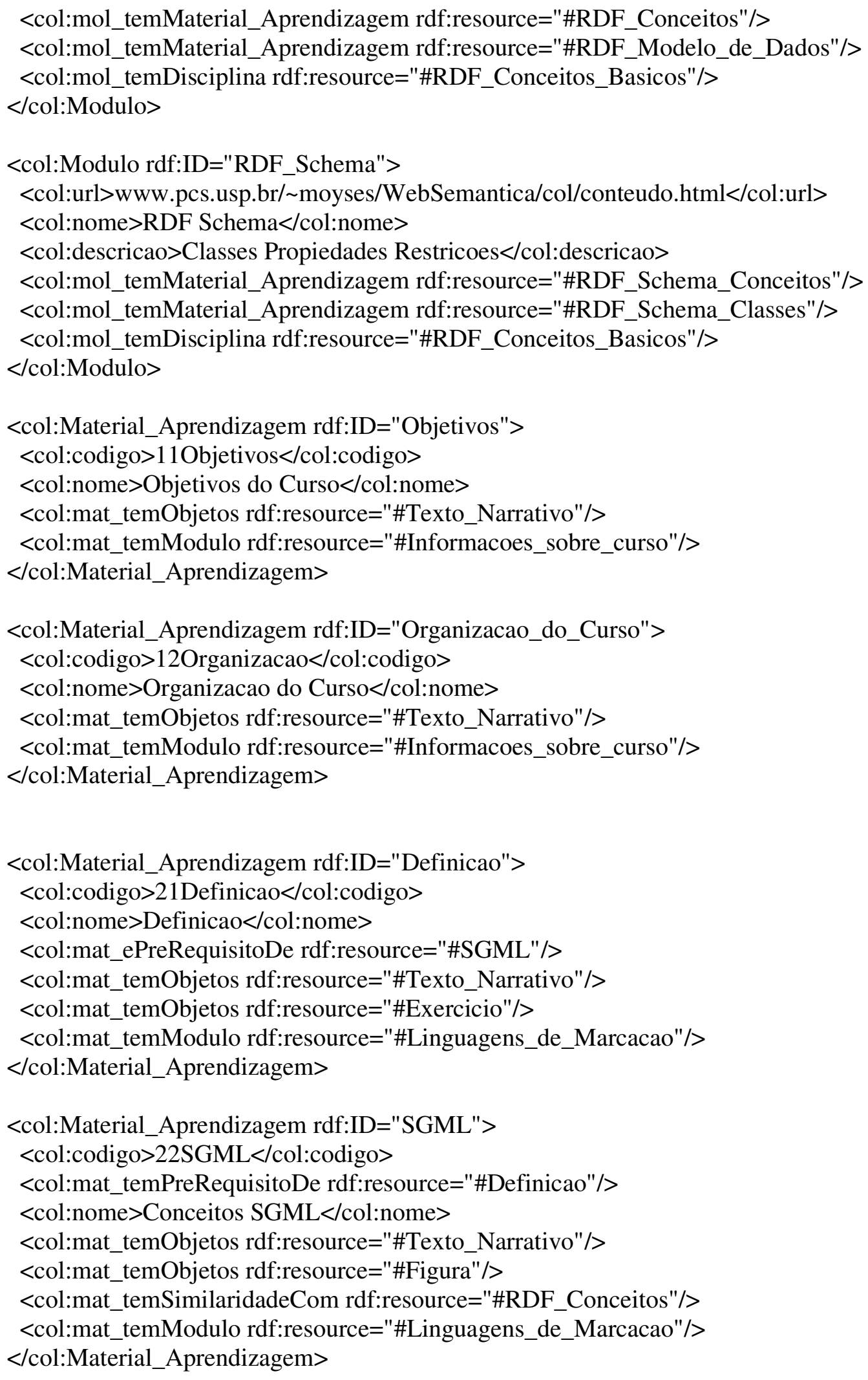




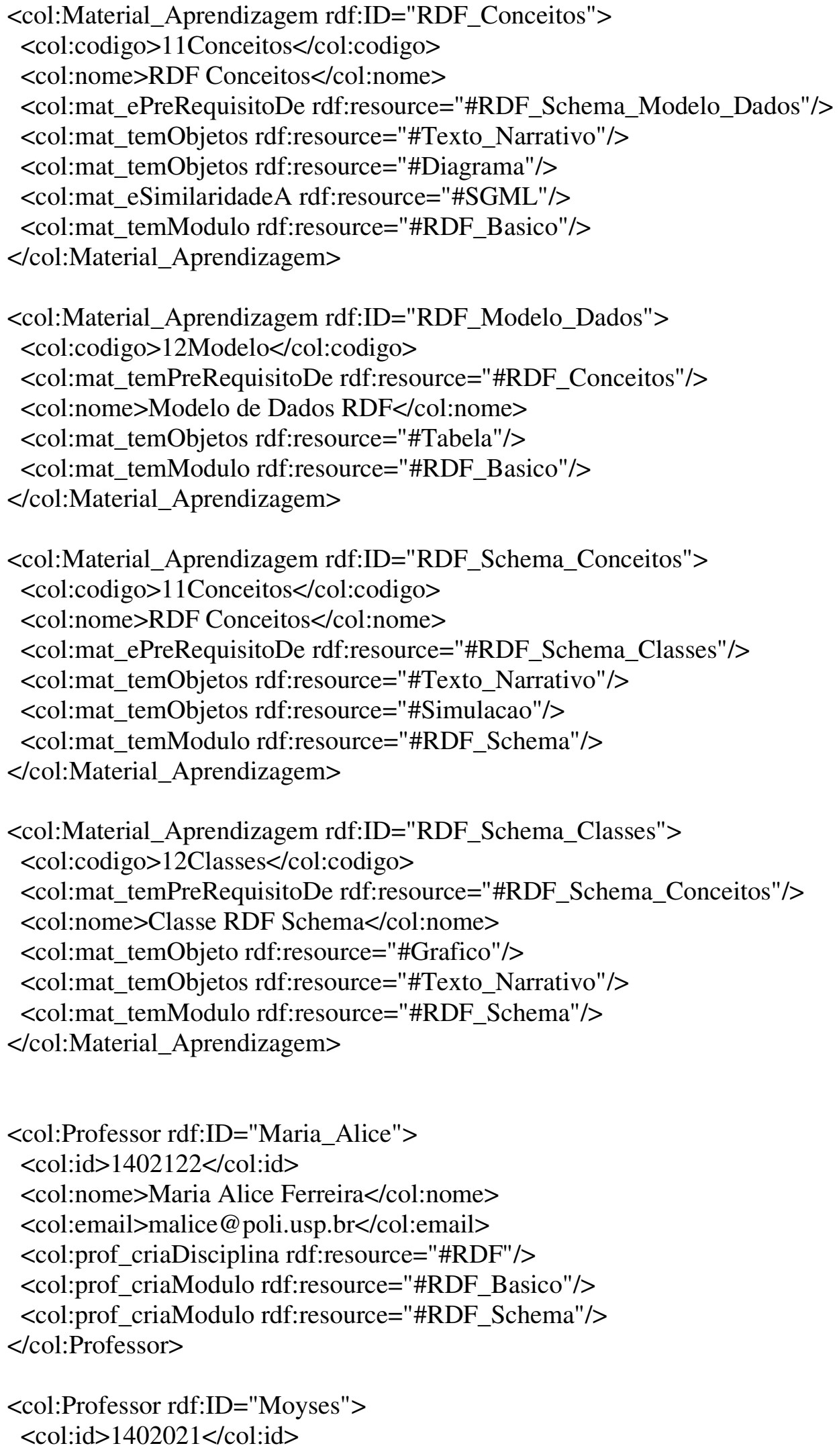


$<$ col:nome $>$ Moyses de Araujo $</$ col:nome $>$ $<$ col:email >moyses.araujo@poli.usp.br</col:email $>$ $<$ col:prof_criaModulo rdf:resource="\#Informacoes_sobre_curso"/> $<$ col:prof_criaModulo rdf:resource="\#Linguagens_de_Marcacao"/> $<$ col:prof_criaModulo rdf:resource="\#RDF_Basico"/> $<$ col:prof_criaDisciplina rdf:resource="\#XML_Conceitos_Basicos"/> $</$ col:Professor $>$

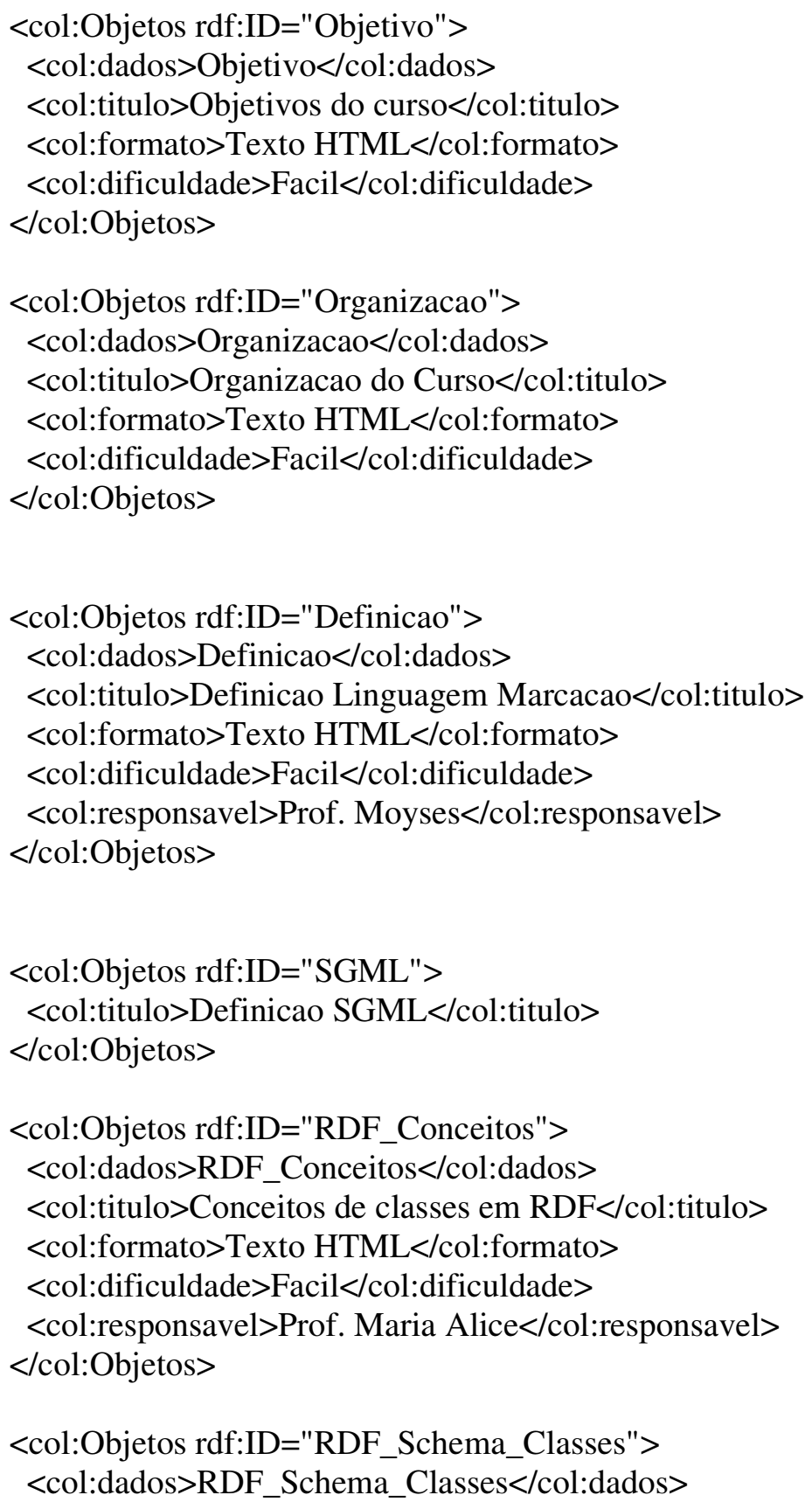


$<$ col:titulo $>$ Conceitos de classes em $\mathrm{RDF}</$ col:titulo $>$

$<$ col:formato $>$ Texto HTML $<$ col:formato $>$

$<$ col:formato $>$ Grafico em Word $<$ col:formato $>$

$<$ col:dificuldade $>$ Facil $</$ col:dificuldade $>$

$<$ col:responsavel $>$ Prof. Moyses $<$ /col:responsavel $>$

$</$ col:Objetos $>$

<col:Texto_Narrativo rdf:ID="Texto_Narrativo">

$<$ col:obj_eParteDeMaterial_Aprendizagem rdf:resource="\#Objetivos"/>

<col:obj_eParteDeMaterial_Aprendizagem rdf:resource="\#Organização_do_Curso"/>

$<$ col:obj_eParteDeMaterial_Aprendizagem rdf:resource="\#Definicao"/>

$<$ col:obj_eParteDeMaterial_Aprendizagem rdf:resource="\#SGML"/>

$<$ col:obj_eParteDeMaterial_Aprendizagem rdf:resource="\#RDF_Schema_Classes"/>

$<$ col:obj_eParteDeMaterial_Aprendizagem rdf:resource="\#RDF_Conceitos"/>

$</$ col:Texto_Narrativo $>$

<col:Texto_Narrativo rdf:ID="Objetivo">

$<$ col:dados $>$ Objetivo $</$ col:dados $>$

$<$ col:titulo $>$ Objetivos do curso $<$ col:titulo $>$

$<$ col:formato $>$ Texto HTML $<$ col:formato $>$

$<$ col:dificuldade $>$ Facil $</$ col:dificuldade $>$

$</$ col:Texto_Narrativo $>$

<col:Texto_Narrativo rdf:ID="Organizacao">

$<$ col:dados $>$ Organizacao $<$ col:dados $>$

$<$ col:titulo $>$ Organizacao do Curso $</$ col:titulo $>$

$<$ col:formato $>$ Texto HTML </col:formato $>$

$<$ col:dificuldade $>$ Facil $</$ col:dificuldade $>$

$</$ col:Texto_Narrativo $>$

$<$ col:Texto_Narrativo rdf:ID="Definicao">

$<$ col:dados $>$ Definicao $</$ col:dados $>$

$<$ col:titulo $>$ Definicao Linguagem Marcacao $</$ col:titulo $>$

$<$ col:formato $>$ Texto HTML </col:formato $>$

$<$ col:dificuldade $>$ Facil $</$ col:dificuldade $>$

$<$ col:responsavel $>$ Prof. Moyses $</$ col:responsavel $>$

$</$ col:Texto_Narrativo $>$

$<$ col:Texto_Narrativo rdf:ID="SGML">

$<$ col:titulo $>$ Definicao SGML </col:titulo $>$

$</$ col:Texto_Narrativo $>$

$<$ col:Texto_Narrativo rdf:ID="RDF_Conceitos">

$<$ col:dados $>$ RDF_Conceitos $</$ col:dados $>$

$<$ col:titulo $>$ Conceitos de classes em $\mathrm{RDF}</$ col:titulo $>$

$<$ col:formato $>$ Texto HTML $</$ col:formato $>$ 
$<$ col:dificuldade $>$ Facil $</$ col:dificuldade $>$

$<$ col:responsavel $>$ Prof. Maria Alice $<$ col:responsavel $>$

$</$ col:Texto_Narrativo $>$

<col:Texto_Narrativo rdf:ID="RDF_Schema_Classes">

$<$ col:dados $>$ RDF_Schema_Classes $</$ col:dados $>$

$<$ col:titulo $>$ Conceitos de classes em $\mathrm{RDF}</$ col:titulo $>$

$<$ col:formato $>$ Texto HTML $<$ /col:formato $>$

$<$ col:dificuldade $>$ Facil $</$ col:dificuldade $>$

$<$ col:responsavel $>$ Prof. Moyses $</$ col:responsavel $>$

$</$ col:Texto_Narrativo $>$

<col:Exercicio rdf:ID="Exercicio">

$<$ col:obj_eParteDeMaterial_Aprendizagem rdf:resource="\#Definicao"/>

$</$ col:Exercicio $>$

$<$ col:Figura rdf:ID="Figura" $>$

$<$ col:obj_eParteDeMaterial_Aprendizagem rdf:resource="\#SGML"/>

$</$ col:Figura $>$

<col:Diagrama rdf:ID="Diagrama">

$<$ col:obj_eParteDeMaterial_Aprendizagem rdf:resource="\#RDF_Conceitos"/>

$</$ col:Diagrama $>$

<col:Tabela rdf:ID="Tabela">

$<$ col:obj_eParteDeMaterial_Aprendizagem

rdf:resource="\#RDF_Modelo_de_Dados"/>

$</$ col:Tabela $>$

$<$ col:Simulacao rdf:ID="Simulacao">

$<$ col:obj_eParteDeMaterial_Aprendizagem

rdf:resource="\#RDF_Schema_Conceitos"/>

$</$ col:Simulacao $>$

<col:Grafico rdf:ID="Grafico">

$<$ col:obj_eParteDeMaterial_Aprendizagem rdf:resource="\#RDF_Schema_Classes"/>

$</$ col:Grafico $>$

$<$ col:Figura rdf:ID="fig_SGML">

$<$ col:dados $>$ SGML $</$ col:dados $>$

$<$ col:formato $>$ JPEG $</$ col:formato $>$

$<$ col:descricao $>$ Figura com SGML e HTML </col:descricao $>$

$</$ col:Figura $>$

<col:Tabela rdf:ID="tab_RDF_ModeloDados">

$<$ col:dados $>$ RDF_Modelos_Dados $</$ col:dados $>$ 
$<$ col:formato $>$ Tabela Excel $<$ col:formato $>$

$<$ col:descricao $>$ Tabela com Modelo de Dados</col:descricao $>$

$</$ col:Tabela $>$

<col:Diagrama rdf:ID="dia_RDF_Conceitos">

$<$ col:dados $>$ RDF_Conceitos $</$ col:dados $>$

$<$ col:formato $>$ texto HTML $<$ /col:formato $>$

$<$ col:descricao $>$ Narracao dos conceitos de $\mathrm{RDF}</$ col:descricao $>$

$<$ col:obj_eParteDeMaterial_Aprendizagem rdf:resource="\#RDF_Conceitos"/>

$</$ col:Diagrama $>$

$<$ col:Exercicio rdf:ID="exe_Definicao">

$<$ col:dados $>$ Definicao $</$ col:dados $>$

$<$ col:titulo $>$ Definicao Linguagem Marcacao $</$ col:titulo $>$

$<$ col:formato $>$ Video AVI $</$ col:formato $>$

$<$ col:dificuldade $>$ Facil $</$ col:dificuldade $>$

$<$ col:responsavel $>$ Prof. Moyses $<$ /col:responsavel $>$

$<$ col:descricao $>$ Video explicando linguagens de maracao $</$ col:descricao $>$

$<$ col:obj_eParteDeMaterial_Aprendizagem rdf:resource="\#Definicao"/>

$</$ col:Exercicio $>$

<col:Simulacao rdf:ID="sim_RDF_Conceitos">

$<$ col:dados $>$ RDF_Conceitos $</$ col:dados $>$

$<$ col:titulo $>$ RDF Conceitos $</$ col:titulo $>$

$<$ col:formato $>$ Flash $</$ col:formato $>$

$<$ col:dificuldade $>$ Facil $</$ col:dificuldade $>$

$<$ col:responsavel $>$ Prof. Moyses $</$ col:responsavel $>$

$<$ col:descricao $>$ Animacao sobre conceitos de $\mathrm{RDF}</$ col:descricao $>$

$</$ col:Simulacao $>$

$</$ rdf:RDF $>$ 


\section{LISTA DE REFERÊNCIAS}

ABBEY, B. Instructional and Cognitive Impacts of Web-Based Educaction. London: Idea Group, 2000. 270p.

AGGARWAL, A. Web-based Learning and Teaching Technologies: Opportunities and Challenges. London: Idea Group, 2000. 372p.

ANDERSON, T. An Updated and Theoretical Rationale for Interaction. May 2002. Disponível em: <http://it.coe.uga.edu/itforum/paper63/paper63.htm>. Acesso em 07 Nov. 2002.

ARAUJO, M. et al. Em Direção a uma Metodologia para Construção de Ontologias. In: Simpósio Brasileiro de Informática na Educação,13, São Leopoldo, 2002. SBIE2002: Workshop de Ontologias para a construção de metodologias de busca na web por conteúdos educacionais, São Leopoldo: Editora Unisinos, 2002. p. 579-582

ARPÍREZ, J. C. et. al. WebODE: a Workbench for Ontological Engineering. In: International Conference on Knowledge Capture, 1, Victoria. 2001. Proceedings. Victoria:ACM, 2001. Disponível em: $<$ http://delicias.dia.fi.upm.es/WebODE/Documents/arpirezEtAl01_submission.pdf $>$. Acesso em 18 Out. 2002.

BECHHOFER, S.; GOBLE, C.; HORROCKS, I. DAML+OIL is not Enough. In: Proceeding of First Semantic Web Working Symposium, 1, Stanford, 2001. Proceeding, p. 151-159.

BECHHOFER, S.; GOBLE, C. Towards Annotation using DAML+OIL. Workshop on Knowledge Markup and Semantic Annotation. 2001a. Disponível em $<$ http://cohse.semanticweb.org/papers/index.html > . Acesso em 20 Mar. 2002.

BENJAMIN, V. R. et al. (KA) ${ }^{2}$ : Building Ontologies for the Internet: A Mid Term Report. International Journal of Human Computer Studies (IJHCS), v. 1, n.3, p. 687-719, 1999.

BERNERS-LEE, T. What the Semantic Web can represent. 2000. Disponível em <http://www.w3.org/DesignIssues/RDFnot.html $>$. Acesso em 20 Abr. 2002.

BERNERS-LEE, T.; HENDLER, J.; LASSILA, O. The Semantic Web. Scientific American. v. 284, n. 5, p. 28-37, 2001.

BIRON, P. V.; MALHOTRA, A. (ed). XML Schema Part 2: Datatypes. W3C Recommendation, 2001. Disponível em <http://www.w3.org/TR/xmlschema2/>.Acesso em 12 Out.2002.

BOSAK, J. XML, Java, and the future of the Web. 1997. Disponível em: $<$ http://www.ibiblio.org/pub/sun-info/standards/xml/why/xmlapps.htm $>$.Acesso em: 7 Out. 2002. 
BRAGANHOLO, V. P. XML Schema, RDF(S) e UML: uma Comparação. Quarta Jornada Iberoamericana de Ingenieria de Requisitos y Ambiente de Software. San José, 2001, p. 78-90.

BRAY, T.; PAOLI, J. McQUEEN; C.M.S., Extensible Markup Language(XML) 1.0. W3C Recommendation, Feb. 1998. Disponível em: <http://www.w3.org/TR/1998/REC-xml-19980210>. Acesso em 07/10/2002.

BRAY, T., HOLLANDER, D.; LAYMAN, A. Namespaces in XML. Jan. 1999. Disponível em: <http://www.w3.org/TR/1999/REC-xml-names-19990104/>. Acesso em 11/10/2002.

BRICKLEY, D.; GUHA, R.V. Resource Description Framework (RDF) Schema Specification 1.0. Mar. 2000. Disponível em: <http://www.w3.org/TR/2000/CR-rdfschema-20000327>. Acesso em 04/04/2002.

BROEKSTA, J. et al. Enabling Knowledge Representation on the Web by Extending RDF Schema. In: The Tenth International World Wide Web Conference on World Wide Web, Hong Kong, 2001, p. 467-477.

CAMPOS, F. C. A .; SANTOS, N.; BRAGA, R.M. M. Ontologia para o Domínio da Educação Mediada pela Web. In: XIII Simpósio Brasileiro de Informática na Educação, São Leopoldo, 2002. Workshop 4: Ontologias para a construção de metodologias de busca por conteúdos educacionais. 2002.

CASTELlS, M. A Sociedade em Rede. São Paulo: Paz e Terra, 1999. 617p.

CHAMPIN, P. A. RDF Tutorial. Abr. 2001. Disponível em $<\underline{\mathrm{http}: / / \mathrm{www} 710 . u n i v-}$ lyon1.fr/ champin/rdf-tutorial>. Acesso em 20 Abr. 2002.

CHANDRASEKARAN, B.; JOSEPHSON, R.; BENJAMINS, V. R. What Are Ontologies, and Why Do We Need Them? IEEE Inteligent Systems. v. 14, n. 1, p. 20 25, Jan. 1999.

CONNOLLY, D. et al., Annotated DAML Ontology Markup, World Wide Web Consortium, Note 18, Dez. 2001. Disponível em <http://www.w3.org/TR/daml+oilwalkthru>. Acesso em 01 Set. 2001.

CONNOLLY, D. et al., DAML+OIL(March 2001) Reference Description, World Wide Web Consortium, Note 18, Dez. 2001a. Disponível em $<$ http://www.w3.org/TR/daml+oil-reference>. Acesso em 01 Set. 2001.

COST, R. S. et al. ITtalks: A Case Study in the Semantic Web and DAML+OIL. IEEE Inteligent Systems. v. 17, n. 1, p. 40-47, Jan. 2002.

DAHLGREN, K. A linguistic ontology. International Journal of Human-Computer Studies. v. 43, n. 5-6, p. 809-818, 1995

DAUM, B.; UDO, M. Arquitetura de Sistemas com XML. Rio de Janeiro: Editora Campos, 2002, 441p. 
DECKER, S.; MITRA, P.; MELNIK, S. Framework for the Semantic Web: An RDF tutorial. IEEE Internet Computing, v.4, n. 6, p.68-73, Nov. 2000.

DECKER, S. et al. Ontobroker: Ontology based Acess to Distributed and Semi-Structu red Information. In: Semantic Issues in Multimedia Systems. Proceeding of DS-8. Boston:Academic Publisher, 1999. p. 351-369.

DERTOUZOS, M. A Revolução Inacabada. São Paulo: Futura, 2002. 253p.

DEVEDZIC, V. What does current web-based educaction lack. Proceeding of the IASTED International Conference APPLIED INFORMATICS. Innsbruck, Austria, Feb 2002.

DING, Y. Ontology: The enabler for the Semantic Web. Journal of Information Science. v. 27, n.6, p. 377-384, 2001.

DOWNES, S. Learning Objects. University of Alberta, May, 2000. Disponível em: $<$ http://www.atl.ualberta.ca/downes/naweb/Learning_Objects.htm $>$. Acesso em 19 Set. 2002.

DUBlin CORE METADATA INITIATIVE. Dublin Core Metadata Element Set, version 1.1. 1999. Disponível em <http://dublincore.org/documents $>$. Acesso em 18 Out. 2002.

ERDMANN, M.; STUDER, R. How to structure and access XML documents with ontologies. Data \& Knowledge Engineering. 2000, v. 36, p. 317-335.

EUROPEAN COMMISSION - US NATIONAL SCIENCE FOUNDATION, Research Challenges and Perspectives of the Semantic Web. Sophia-Antipolis:EU-NSF, 2001 (Final Report)

EUZENAT, J. Eight Questions about Semantic Web Annotations. IEEE Inteligent Systems. v. 22, n. 2, p. 55-62, Mar. 2002.

FALLSIDE, D. C. (ed) XML Schema Part 0: Primer. W3C Recommendation, 2001. Disponível em <http://www.w3.org/TR/xmlschema-0/>. Acesso em 12 Out.2002.

FENSEL, D. et al. OIL: An Ontology Infrastructure for the Semantic Web. IEEE Inteligent Systems. v. 16, n. 2, p. 38-45, Mar. 2001.

FENSEL, D. Ontologies: Silver Bullets for Knowledge Management and Electronic Comerce. Berlin: Springer-Velag, 2001a

FERNÁNDEZ, M.; PERÉZ, A. G.; JURINO, N. Methontology: From ontological art towards ontological engineering. In: Spring Symposium Series, Stanford, p. 33-40, 1997.

FERREIRA, A. B. de H. Novo Aurélio - O Dicionário da Língua Portuguesa.

Disponível em <http://www.uol.com.br/aurelio/. Acesso em 01 Jun. 2003. 
FREIRE, P. Pedagogia do oprimido. Rio de Janeiro: Terra e Paz. 1978.

FRIESEN, N. Waht are Educational Objects? Interactive Learning Environments, v. 9, n. 3, Dez. 2001.

FURGERI, S. Ensino didático da linguagem XML. 1 ed. São Paulo: Editora Érica, 2001. 278p.

GENNARI, J. H. et al. The Evolution of Protégé: An Environment for KnowledgeBased Systems Development. Technical Report SMI-2002-0943. 2002. Disponível em: $<$ http://smi-web.stanford.edu/pubs/SMI_Reports/SMI-2002.0943.pdf $>$. Acesso em 02 Nov. 2002.

GIL, Y.; RATNAKAR, V. A comparison of (Semantic) Markup Languages. 2000.

Disponível em <http://trellis.semanticweb.org/expect/web/semanticweb/paper.pdf>. Acesso em 01 Out. 2002.

GONI, J. L.; FERNANDES, M. C. P.; LUCENA, C. J. P. Geração de Ontologias usando Protege-2000 para reuso de conteúdos educacionais numa arquitetura multiagente. In: XIII Simpósio Brasileiro de Informática na Educação, São Leopoldo, 2002. Workshop 4: Ontologias para a construção de metodologias de busca por conteúdos educacionais. 2002.

GONZÁlEZ, L. A. G. Educação pela Web: Metodologia e Ferramenta de Elaboração de Cursos com Navegação Dinâmica. São Paulo, 2000. 137p. Dissertação(Mestrado) - Escola Politécnica, Universidade de São Paulo.

GRUBER, T.R. A Translation Approach to Portable Ontology Specifications. Knowledge Acquisition. v. 5, n.2, p. 199-221, 1993.

GRUBER, T.R. Toward Principles for the Design of Ontologies Used for Knowledge Sharing. In: Nicola Guarino and Roberto Poli, editors, Formal Ontology in Conceptual Analysis and Knowledge Representation. Kluwer Academic Plubishers, $1993 \mathrm{a}$

GRUNINGER, N. Formal ontology, conceptual analysis and knowledge representation. International Journal of Human-Computer Studies, v. 43, 1995.

GUARINO, N. Formal Ontology and Information Systems. In: Proceedings of the first International Conference on Formal Ontology in Information Systems. FOIS'98. Trento. Jun. 1998.

GULBRANSEN, D. Using XML Schema. Indiana: QUE, 2002, 480p.

HARMELEN, F. V. D. et al., A Model-Theoric Semantics for DAML+OIL (March 2001), World Wide Web Consortium, Note 18, Dez. 2001. Disponível em <http://www.w3.org/TR/NOTE-daml+oil-model-20011218>. Acesso em 01 Set. 2001. 
HAVELIWALA, T. Efficient Computation of PageRank. 1999. Technical Report

Stanford University, Digital Library Project. Disponível em $<$ http://dbpubs.stanford.edu/pub/1999-31>. Acesso em 23 Set. 2002.

HEFLIN, J. D. Towards the Semantic Web: Knowledge Representation in a Dynamic, Distributed Environment. Maryland, 2001a. 137p. Tese (Doutorado) University of Maryland.

HEFLIN, J. A Portrait of the Semantic Web in Action. IEEE Inteligent Systems. v. 16, n. 2, p. 54-69, Mar. 2001b.

HENDER, J. Agents and the Semantic Web. IEEE Inteligent Systems. v. 16, n. 2, p. 30-37, Mar. 2001.

HOLZINGER, A. Multimedia Learning Systems based on IEEE Learning Object Metadata (LOM). In: World Conference on Educational Multimedia, Hypermedia \& Telecommunications. ED-MEDIA 2001. Tampere, Finland. p. 772-777. 1 CD-ROM.

HORROCKS, I. et al. The Ontology Inference Layer OIL. Technical Report. University of Amsterda. 2000. Disponível em $<$ http://www.ontoknowledge.org/oil/TR/oil.long.html>. Acesso em 05 Aug 2002.

HOUAISS, A. Dicionário Eletrônico da Língua Portuguesa. São Paulo: Objetiva, 2002. 1 CD-ROM.

IANNELLA, R. An Idiot's Guide to the Resource Description Framework. Disponível em <http://archive.dstc.edu.au/RDU/reports/RDF-Idiot $>$. Acesso em $04 \mathrm{Abr}$ 2002.

IMS GLOBAL LEARNING CONSORTIUM, IMS Learning Resource Meta-Data XML Binding, Version 1.2.1 Final Specification, 28 Set. 2001. Disponível em <http://www.imsglobal.org>. Acesso em 20 Fev 2003.

KARP, R.; CHAUDHRI, V.; THOMERE, J. XOL: An XML-Based Ontology Exchange Language. Aug. 1999. Disponível em <http://www.ai.sri.com/ pkarp/xol $>$. Acesso em 29 Out. 2002.

KENT, R. Conceptual Knowledge Markup Language. Disponível em <http://www.ontologos.org/CKML/CKML\%200.2.html>. Acesso em 29 Out. 2002. 1998.

KLEIN, M. XML, RDF, and Relatives. IEEE Inteligent Systems. v. 16, n. 2, p. 26-28, Mar. 2001.

KRÄMER. B. J. Web-Based Learning Environments: Tools and Enginnering Issues. Handbook of Software Engineering \& Knowledge Engineering - Fundamentals Vol 1. Pittsburg:World Scientific Publishing. 2002. 915p 
LAKE, D. The Web: Growing by 2 Million Pages a Day. Fev. 2000. Disponível em <http://www.thestandard.com/article/0,1902,12329,00.html > . Acesso em 15 Set. 2002.

LASSILA, O.; SWICK, R. R. Resource Description Framework (RDF) Model and Syntax Specification. W3C Recommendation, Feb. 1999, Disponível em <http://www.w3.org/TR/1999/REC-rdf-syntax-19990222/>. Acesso em 14 Out.2002.

LEARNING TECHNOLOGY STANDARDS COMMITTEE of the IEEE, New York, 15/07/2002. Draft Standard for Learning Object Metadata. Disponível em:http://ltsc.ieee.org/wg12/index.html. Acesso em 9 Abr. 2003.

LIGHT, R. Iniciando em XML. São Paulo: Makron Books, 1999. 404p.

LIMA, F. O. A Sociedade Digital. Rio de Janeiro: Qualitymark, 2000. 152p.

LOGMIRE, W. A primer on learning objects. 2001. Disponível em <http://www.learningcircuits.org/mar2000/primer.html>. Acesso em 19 Set. 2002.

MARIETTO, M. B. et al. Requeriments analysis of multi-agent-based simulation platforms. Technical report. São Paulo University, 2002

McCORMACK, C.; JONES, D. Web-Based Education System. Boston: John Wiley \& Sons, 1997, 446p.

McGRATH, S. XML Aplicações práticas. Rio de Janeiro: Editora Campus Ltda, 1999, $367 p$.

McGUINNESS, D. et al. DAML+OIL: An Ontology Language for the Semantic Web. IEEE Inteligent Systems. v. 17, n. 5, p. 72-80, Set. 2002.

MILLER, E. An Introduction to the Resource Description Framework. D-Lib Magazine, May $1998 . \quad$ Disponível em: <http://www.dlib.org/dlib/may98/miller/05miller.html>. Acesso em 04 Mar. 2002.

MOORE, M.G. Three types of interaction. The American Journal of Distance Education. v. 3, n.2, Fev.1989.

MOULTIS, N. P.; KIRK, C. XML Black Book. São Paulo: Makron Books, 2000. 627p.

MURRAY, B. H.; MOORE, A. Sizing the Internet. Jul. 2000. Disponível em: $<$ http://www.cyveillance.com/web/us/downloads/Sizing_the_Internet.pdf. $>$. Acesso em 15 Set. 2002.

NOY, N. F. et al. Creating Semantic Web Contents with Protégé-2000. IEEE Inteligent Systems. v. 16, n. 2, p. 60-71, Mar. 2001. 
OGBUJI, U.; OUELlET, R. DAML Reference. May 2002. Disponível em: <http://www.xml.com/lpt/a/2002/05/01/damlref.html >. Acesso em 20 Jun. 2002.

PERÉZ, A. G.; BENJAMINS, V. R. Overview of knowledge sharing and reuse components: Ontologies and problem-solving methods. In: Proceedings of the IJCAI99 Workshop on Ontologies and Problem-Solving Methods, 1999

PERÉZ, A G.; CORCHO, O . Ontology Languages for the Semantic Web. IEEE Intelligent Systems. v. 13, n. 1, p. 54-60. Jan. 2002.

PHILLIPS, L. A. Using XML. Indianapolis: QUE, 2000. 879p.

QIN, J.; FINNERAN, C. Ontological Representation for Learning Objects. Proceedings of the Workshop on Document Search Interface Design and Intelligent Access in Large-Scale Collections, Portland, OR. Jul. 2001.

QUINTON, S. R. Toward Adaptive Online Learning. Proceeding of the $5^{\text {th }}$ IASTED International Conference COMPUTERS AND AVANCED TECHNOLOGY IN EDUCATION. Cancun, Mexico, p. 469-474, May 2002.

RABARIJAONA, A. et al. Building and Searching an XML-Based Corporate Memory. IEEE Inteligent Systems. v. 15, n. 3, p. 56-63, May 2000.

REINHARDT, A. New ways to learn. Byte. Mar 1995. Disponível em: <http://www.byte.com/art/9503/sec7/art1.htm>. Acesso em: 05 Nov. 2002.

ROMANI, L. AA. S. InterMap: Ferramenta para Visualização da Interação em Ambientes de Educação a Distância. Campinas, 2000. 120 p. Dissertação (Mestrado) - Unicamp

ROY, J.; RAMANUJAN, A. XML Schema Language: Taking XML to the Next Level. It Professional. v. 3, n. 2, p. 37-40, Mar 2001.

SILVEIRA, R. M. et al. COL - Ferramenta de Apoio ao Ensino. LARC Laboratório de Arquitetura e Redes de Computadores. PCS - Departamento de Engenharia de Computação e Sistemas Digitais. EPUSP - Escola Politécnica da USP. 2002.

SILVEIRA, I. F. Um ambiente de realidade virtual distribuída aplicado à aprendizagem colaborativa. São Paulo, 2003, 150p. Tese (Doutorado) - Escola Politécnica, Universidade de São Paulo.

SIMONSON M. et al. Teaching and Learning at a Distance: Fundations of Distance Education. New Jersey: Prentice-Hall, 2000. 240p.

STAAB, S. et. al. Knowledge process and ontologies. IEEE Intelligent Systems. v. 16, n. 1, p. 26-34. Jan. 2001. 
STAAB, S; MAEDCHE, A.; HANDSCHUH, S. An Annotation Framework for the Semantic Web. Proceeding of the International Workshop on Multimedia Annotation. Tokyo, Japan, p. 30-41, Jan 2001a.

SOSTERIC, M.; HESEMEIER, S. When is a Learning Object not an Object: A firts step towards a theory of learning objects. In: International Review of Research in Open and Distance Learning. 2002. Disponivel em <http://www.irrodl.org/content/v3.2/soc-hes.html>. Acesso em: 17 Mai 2003.

STEINACKER, A.; GHAVAN, A.; STEINMETZ, R. Metadata Standards for WebBased Resources. IEEE Multimedia. v. 6, n. 1, p. 70-76, Jan. 2001.

STOJANOVIC, L.; STAAB, S.; STUDER, R. eLearning based on the Semantic Web. In: World Conference on the WWW and Internet, Orlando, Oct. 2001. WebNet 2001. Disponível em: <http://www.aifb.unikarlsruhe.de/WBS/Publ/2001/WebNet_lstsstrst_2001.pdf >. Acesso em: 10 Mai. 2002.

STUDER, R.; BENJAMINS, V.; FENSEL, D. Knowledge Engineering: Principles ans Methods. IEEE Transaction on Data and Knowledge Engineering. v. 25, n. 1-2, p. 161-197, 1998.

SUlIVAN. D. Search Engines Sizes. The Search Engine Report. Dec. 2001. Disponível em: <http://www.searchenginewatch.com/reports/sizes.html >. Acesso em 18 Nov. 2002.

SWARTOUT, W. Ontologies. IEEE Inteligent Systems. v. 14, n. 1, p. 18-19, Jan. 1999.

SWICK, R.R. RDF: Weaving the Web of Discovery, Putting it Together. NetWorker, v.3, n.2, p. 21-25, Jun. 1999.

TABOADA, M. et al. An use case for DAML+OIL: a knowledge base I a clinical domain. In: The First International Workshop on the Rule Markup Language for Business on the Semantic Web (RuleML-2002). Sardinia, Jun. 2002. Disponível em: $<$ http://www.soi.city.ac.uk/ msch/ruleml/chus.pdf> . Acesso em: 01 Ago. 2002.

TAYLOR, J. C. Automating E-Learning: The future of Higher Education. In: International Conference on Emerging Telecommunications Applications (ICETA). Kosice. Oct 2001. Disponível em: <http://www.usq.edu.au/dec/staff/taylorj/index.htm>. Acesso em: 15 Set. 2002.

TeSsarollo, M. R. M. Ambiente de Autoria de Cursos a Distância. Campinas, 2000. 97 p. Dissertação (Mestrado) - Unicamp.

THOMPSON, H. S. et al (ed) XML Schema Part 1: Structures. W3C Recommendation, 2001. Disponível em <http://www.w3.org/TR/xmlschema-1/>. Acesso em 12 Out.2002. 
TOSCARO, A. A. M. et al. Preparação de Conteúdo para Web. 2003. Disponível em <http://www.ead.unicamp.br/ensinoaberto/preparacao.pdf. $>$ Acesso em: 30 Abr 2003.

USCHOLD, M.; KING, M.; Towards a Methodology for Building Ontologies. In: Workshop on Basic Ontological Issues in Knowledge Sharing. IJCAI-95. Jul. 1995.

USCHOLD, M. et al. The Enterprise Ontology. 1996. Disponível em $<$ http://citeseer.nj.nec.com/255311.html>. Acesso em 20 Jul. 2002.

USCHOLD, M.; GRUNINGER, M. Ontologies: Principles, Methods and Applications. The Knowledge Engineering Review. v. 11, n. 2, Jun 1996a.

VEGA, J.C.A. WebODE 1.0 User's Manual. Laboratory of Artificial Intelligence, School of Computer Science. Techical University of Madri. Dec. 2000. Disponível em: $<$ http://delicias.dia.upm.es/webODE/Documents/usermanual.pdf $>$. Acesso em 18 Out. 2002.

WILEY, D. A. Connecting learning objects to instructional design theory: A definition, a metaphor, and a taxonomy. In D. A. Wiley (Ed.) The instructional use of learning objects. 2001. Disponivel em <http://reusability.org/read/chapters/wiley.doc $>$. Acesso em 25 Mai 2003.

WOOD, L. Programming the Web: The W3C DOM Specification. IEEE Internet Computing. v. 3, n. 1, p. 48-54, Jan.1999. 


\section{Apêndice A}

\section{Descrição das Ferramentas SHOE e ONTOBROKER}

\section{A.1 - SHOE (Simple HTML Ontology Extension)}

A ferramenta SHOE (HEFLIN, 2001a), (HEFLIN, 2001b) combina características de linguagens de marcação, representação de conhecimento e ontologias que tratam de problemas de semântica na Web. Suporta aquisição de conhecimento na Web, com marcas que dispõem de significado semântico. Sua estrutura básica consiste de ontologias, que definem regras, que guiam quais tipos de asserções podem ser feitas e que tipos de conclusões podem ser tiradas destas asserções. Como representação de linguagem de conhecimento, SHOE utiliza lógica de predicados e de sistemas baseados em frames. As primitivas do SHOE permitem a definição de:

- Ontologias: podem ser derivadas de outras ontologias e podem conter qualquer número de classes, relações, constantes e regras de inferências;

- Classes (chamadas de Categorias): uma subclasse pré-definida permite a definição de hierarquias;

- Relações e o tipo de argumentos;

- Renomeações: ajudam a relacionar classes em ontologias diferentes;

- Regras de inferência: são cláusula Horn, simples (sem negação);

- Definição de constantes: são úteis em ontologias; por exemplo, podemos declarar vermelho como uma instância de cor;

- Definição de tipo de dados: além dos tipos básicos de dados NUMBER, STRING, DATE e TRUTH, tipos arbitrários de dados podem ser definidos. Entretanto, estes tipos de dados existem apenas como nomes, sem nenhuma semântica adicional; 
- Asserção de instâncias: não pertencem a uma ontologia, mas podem comprometerse com uma ou mais ontologias. Instâncias possuem relações, definição de tipos e subinstâncias.

A arquitetura do SHOE é representada na figura A.1. O primeiro passo para usar SHOE é adicionar marcas nas páginas Web, através de um editor de texto, um processo chamado de anotação. Para fazê-la, o usuário seleciona uma ontologia apropriada e a utiliza para descrever os conceitos na página. Este esquema faz com que as anotações estejam separadas do conteúdo do documento anotado.

Para facilitar a anotação, a ferramenta Anotador de Conhecimento permite selecionar os conhecimentos disponíveis do SHOE, tais como ontologias e instâncias, através do preenchimento de formulários. Quando as páginas estiverem anotadas e colocadas na Web, elas podem ser indexadas e consultadas. A ferramente Exposé pesquisa estas páginas anotadas e gera a base de conhecimento do SHOE. Esta base é consultada pela ferramenta de pesquisa do $\mathrm{SHOE}^{12}$.

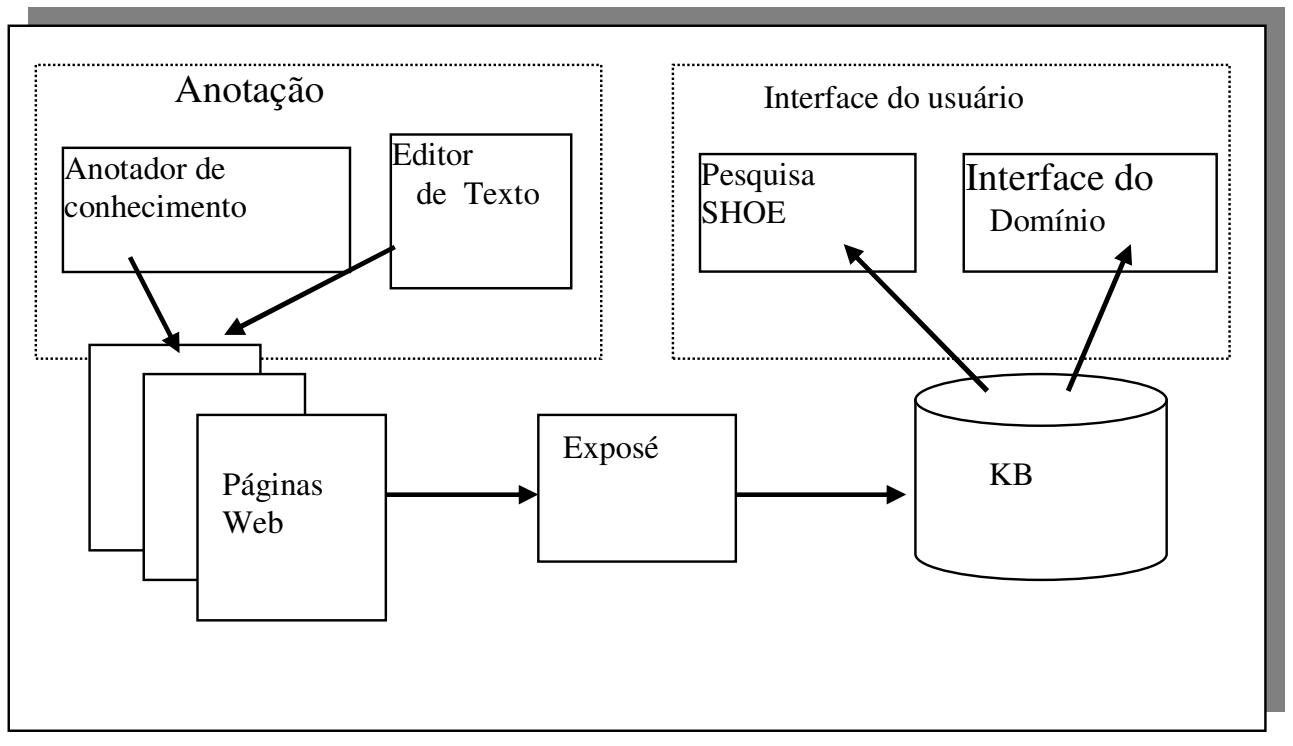

Fig A.1 - Arquitetura do sistema SHOE (HEFLIN, 2001B)

\footnotetext{
${ }^{12}$ Disponível em http://www.cs.umd.edu/projects/plus/SHOE/search/.
} 


\section{A.2 - ONTOBROKER ${ }^{13}$}

O projeto Ontobroker (DECKER et al., 1999) usa ontologias para anotar e pesquisar documentos Web e provê um serviço de respostas baseadas em ontologias. Para isto combina técnicas de lógica de programação, bancos de dados orientados a objetos, dados semi-estruturados, sistemas de informação em hipertexto, inteligência artificial e visualização de informação, para aperfeiçoar o acesso a fontes de informações distribuídas e heterogêneas, como é na Web. A idéia central é tornar disponível uma ontologia como maneira de organizar a criação de dados e prover uma interface de pesquisa que usa a ontologia como guia para formular consultas a respeito dos dados.

A figura A.2 mostra a arquitetura do Ontobroker. A parte central do sistema são as ontologias, que influenciam a criação dos dados, bem como os mecanismos de pesquisa, que são usados para estabelecer o raciocínio a respeito dos dados, e as interfaces de consulta. As fontes de dados do Ontobroker são:

Documentos XML e HTML anotados, que são enriquecidos com anotações baseadas em ontologias. As anotações são feitas pelo editor HTML chamado OntoPad;

Metadados, no formato RDF;

Dados baseados em wrappers, que conectam sistemas legados ao Ontobroker.

O mecanismo de inferência é capaz de realizar raciocínio através das ontologias e os metadados. A interface de consulta possibilita a composição de consultas guiadas pela ontologia.

\footnotetext{
${ }^{13}$ Disponível em http://ontobroker.semanticweb.org
} 


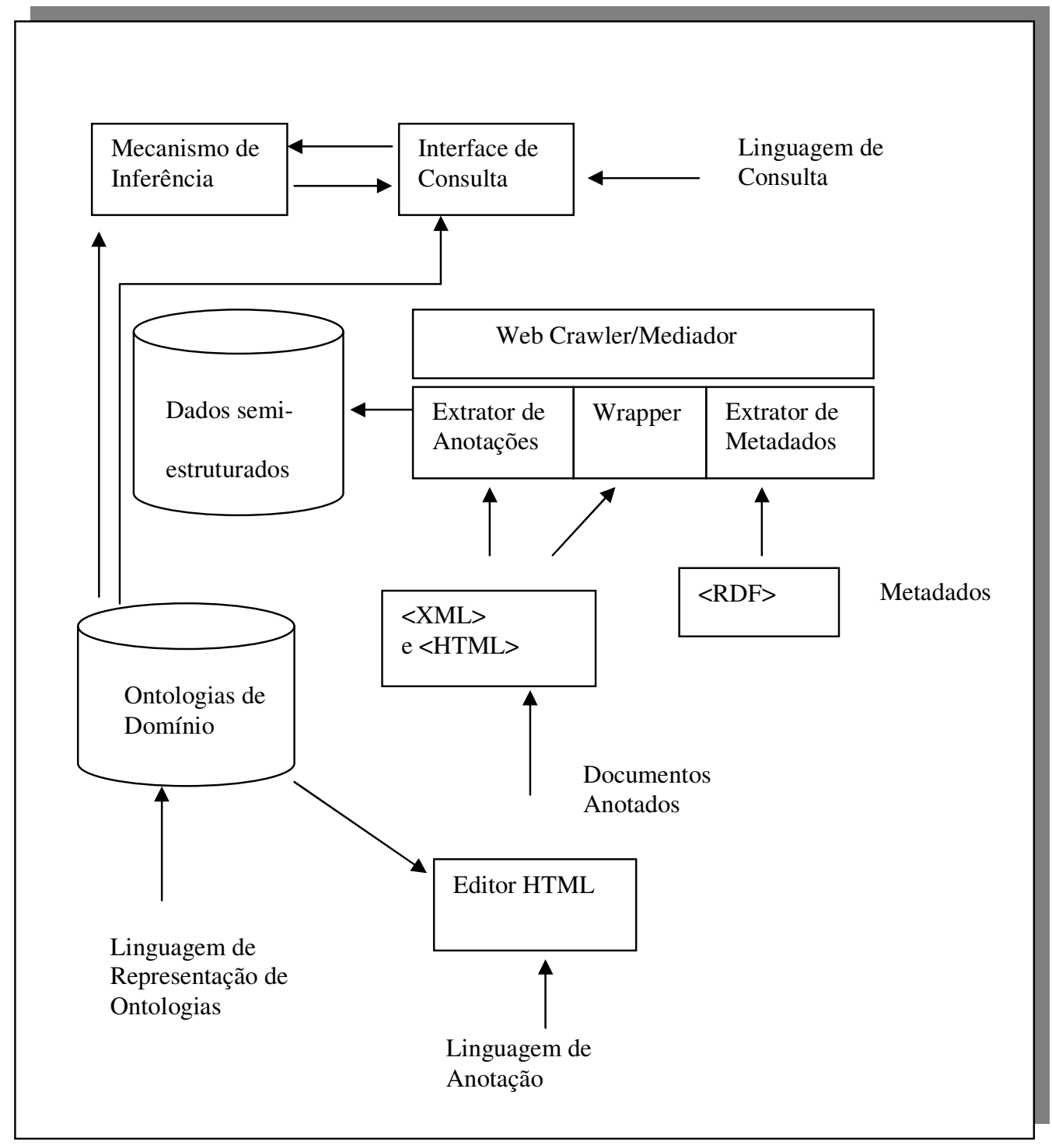

Fig. A.2 - Arquitetura do Ontobroker (DECKER et al., 1999) 